\title{
Faktoren des Kerntransports von Core-Histonproteinen: Strukturelle und funktionelle Analyse
}

\author{
Dissertation \\ zur Erlangung des Doktorgrades \\ der Mathematisch-Naturwissenschaftlichen Fakultäten \\ der Georg-August-Universität zu Göttingen
}

\author{
vorgelegt von \\ Matthias Baake \\ aus Rehren
}

Göttingen 2001 
D7

Referent:

Prof. Dr. A. Zeeck

Korreferent:

Prof. Dr. L.F. Tietze

Tag der mündlichen Prüfung: $\quad$ 03. Mai 2001 
Die vorliegende Arbeit wurde in der Zeit von Oktober 1997 bis März 2001 in der Abteilung Molekularbiologie am Zentrum für Biochemie und Molekulare Zellbiologie der Universität Göttingen durchgeführt.

Herrn Prof. Dr. D. Doenecke und Herrn PD Dr. W. Albig danke ich für die interessante Themenstellung sowie für ihr stetes Interesse am Fortgang dieser Arbeit. 


\section{INHALTSVERZEICHNIS}

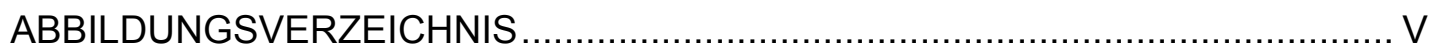

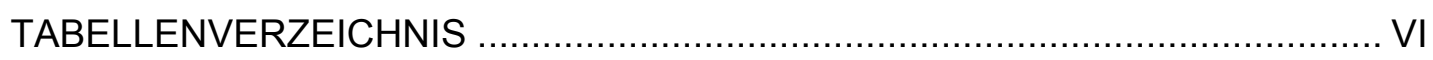

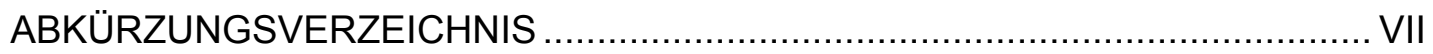

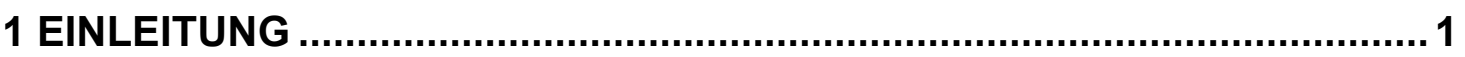

1.1 Der Weg durch die Kernpore ................................................................

1.2 Kernlokalisationssignale und Transportfaktoren ..........................................

1.3 Das Ran-System bestimmt die Richtung des Kerntransports.......................... 7

1.4 Der Transportzyklus des Kernimports ............................................................ 9

1.5 Kerntransport unabhängig von Importinß̧-ähnlichen Importfaktoren.................11

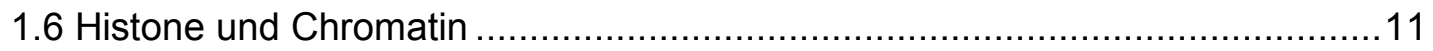

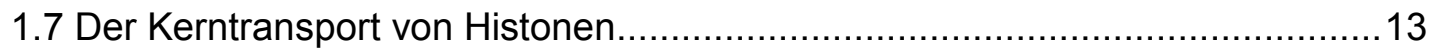

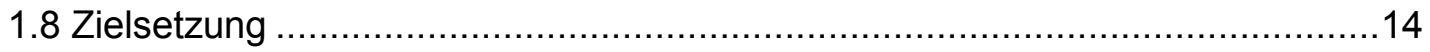

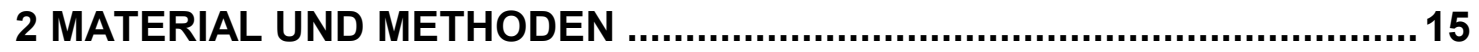

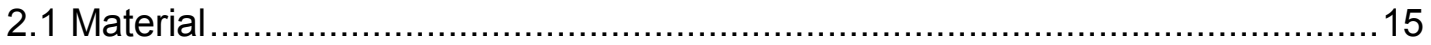

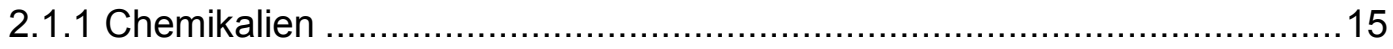

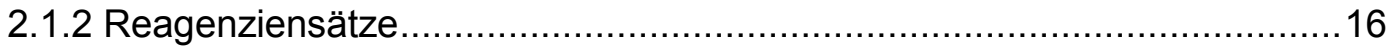

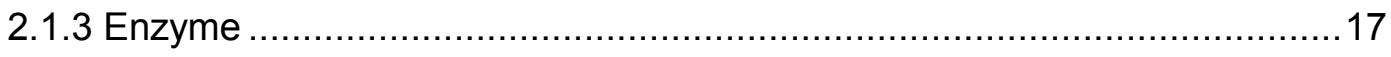

2.1.3.1 Restriktionsenzyme.......................................................... 17

2.1.3.2 DNA-modifizierende Enzyme ................................................ 17

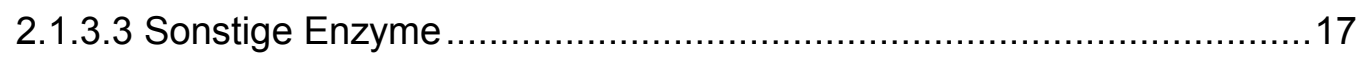

2.1.4 Proteaseinhibitoren ........................................................................ 17

2.1.5 Oligonukleotide (siehe Anhang) ..........................................................17

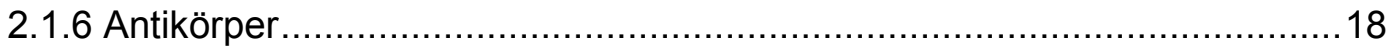

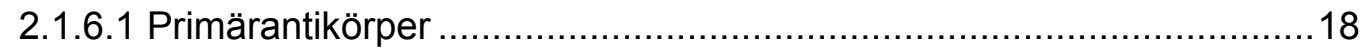

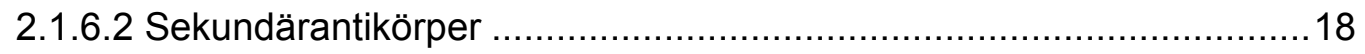

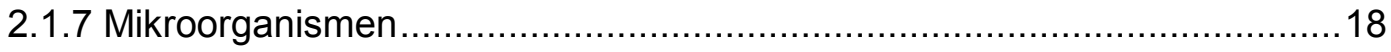

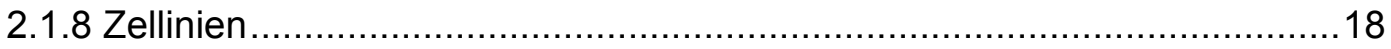

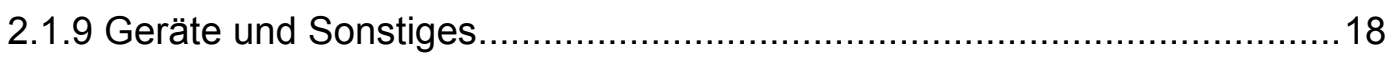

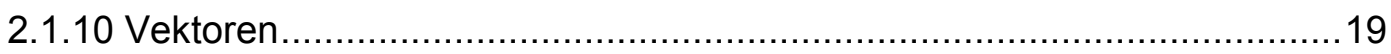

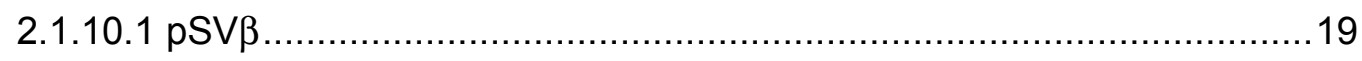




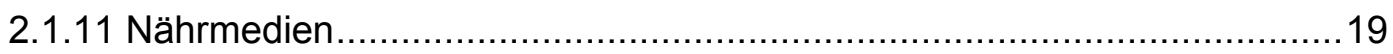

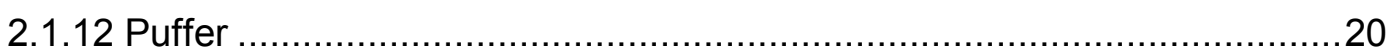

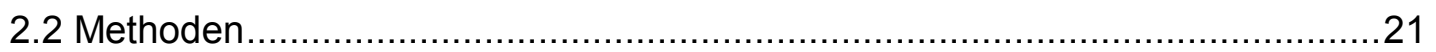

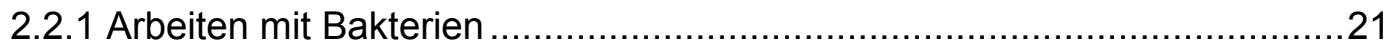

2.2.1.1 Anlegen von Bakteriendauerkulturen ..........................................21

2.2.1.2 Herstellung kompetenter Bakterien (Mandel und Higa, 1970) .............22

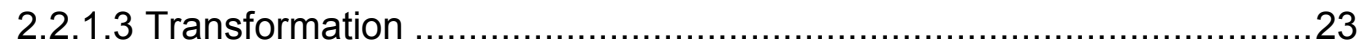

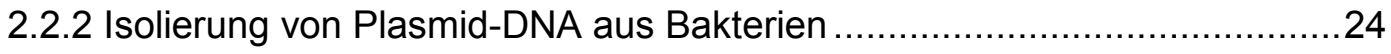

2.2.2.1 Plasmid-Präparation mit Tris-EDTA-LiCl-Triton (TELT) ....................24

2.2.2.2 Plasmid-Maxi-Präparation über QIAGEN-Säulen ..............................25

2.2.2.3 Plasmidpräparation mit dem E.Z.N.A. Plasmid-Miniprep Kit II.............26

2.2.3 Spaltung von DNA mit Restriktionsendonukleasen...............................27

2.2.4 Dephosphorylierung eines linearisierten Vektors .....................................28

2.2.5 Agarose-Gelelektrophorese zur Auftrennung von DNA ..........................28

2.2.6 Extraktion von DNA aus Agarosegelen .............................................29

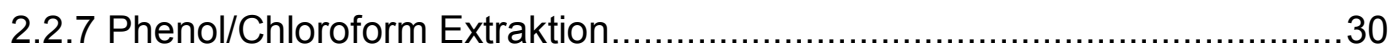

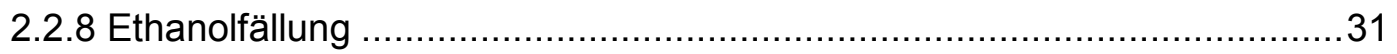

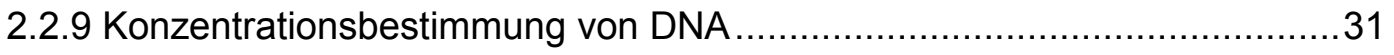

2.2.9.1 Konzentrationsbestimmung von DNA durch Gelelektrophorese..........32

2.2.9.2 Konzentrationsbestimmung von DNA nach UV-Spektroskopie ............32

2.2.10 "Annealen" von einzelsträngigen Oligonukleotiden................................32

2.2.11 Polymerase-Kettenreaktion (PCR) (Mullis und Faloona, 1987)................33

2.2.12 Mutagenese von doppelsträngiger DNA ............................................ 34

2.2.13 Aufreinigung von PCR-DNA mit dem E.Z.N.A Cycle-Pure-Kit..................36

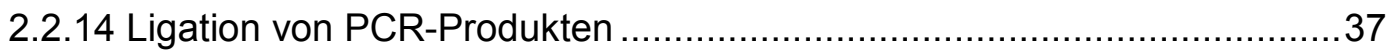

2.2.15 Nicht-radioaktive Sequenzierung von Plasmid-DNA (Sanger et al., 1977)37

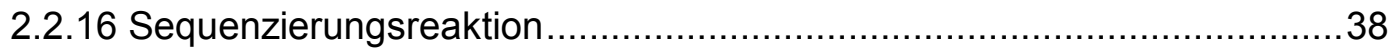

2.2.17 Denaturierende Protein-SDS-Polyacrylamid-Gelelektrophorese (SDS-

PAGE; Laemmli, 1970) ......................................................... 39

2.2.18 Kultivierung humaner Tumorzellinien.................................................4 41

2.2.19 Gefrierkonservierung .................................................................. 42

2.2.20 Anlegen einer adhärent wachsenden Zellinie ....................................42

2.2.21 Transiente Transfektion von Zellen ..................................................43

2.2.21.1 Transfektion durch Elektroporation (Showe et al., 1992) .................43

2.2.22 Immunfluoreszenz-Detektion ............................................................ 44

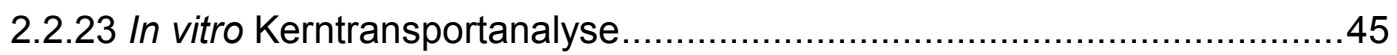


2.2.24 Herstellung der Transportliganden und Kompetitoren ..........................46

2.2.24.1 Peptidsynthese ...................................................................... 47

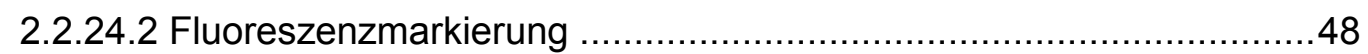

2.2.24.2.1 TRITC- bzw. FITC-Markierung von HSA und H1 .........................48

2.2.24.2.2 Fluoreszenzmarkierung von $\mathrm{H} 2 \mathrm{~B}$ mit Alexa ${ }^{\mathrm{TM}}$ Protein Labeling-Kit 49

2.2.24.3 Peptidkopplung von HSA-TRITC mit dem SV40-wt-NLS-Peptid über

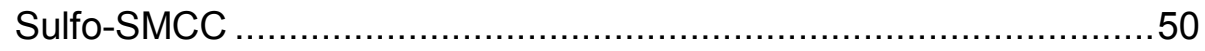

2.2.25 Expression und Aufreinigung der Transportfaktoren ...........................51

2.2.26 Expression und Aufreinigung von M9-GST......................................53

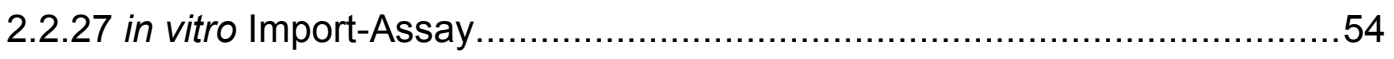

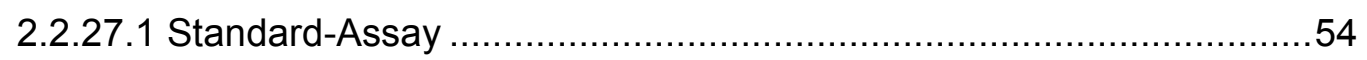

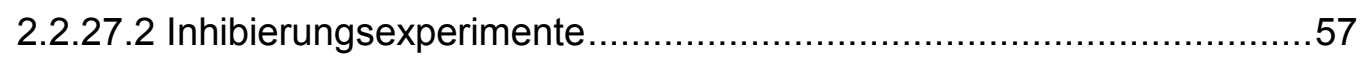

2.2.27.3 Kompetitionsexperimente....................................................... 58

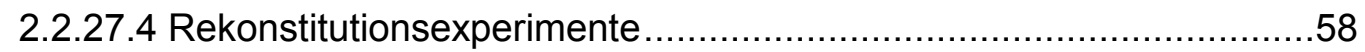

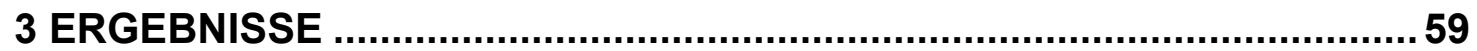

3.1 Charakterisierung des Importweges für Core-Histone ..................................59

3.2 In vitro Importassay: Zytosolische Komponenten sind am Transport der Core-

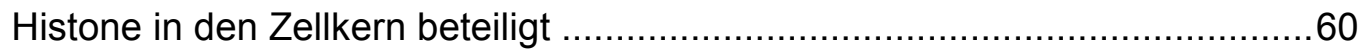

3.2.1. Präparation der Importsubstrate .......................................................60

3.2.2 Fluoreszenmarkierte Core-Histone als Transportsubstrate im in vitro

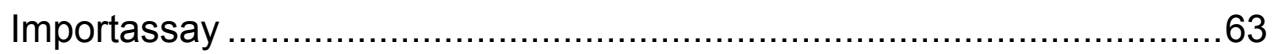

3.3 Inbierungsexperimente: Der Kerntransport der Core-Histone ist ein aktiver, rezeptorvermittelter Prozeß ..................................................................6 66

3.4 Identifizierung von Kernlokalisationssignalen (NLS)...................................68

3.4.1 Klonierung der $\beta$-Galaktosidase-Fusionskonstrukte ..............................70

3.4.2 Transfektion der $\beta$-Galaktosidase Konstrukte in HeLa-Zellen durch Elektroporation. .71

3.4.3 Core-Histone und Core-Histon-Fragmente als Vermittler des Kerntransports in Fusionskonstrukten ..................................................................... 72

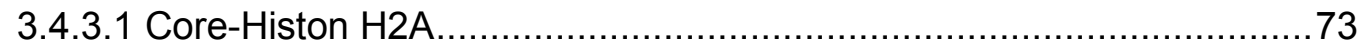

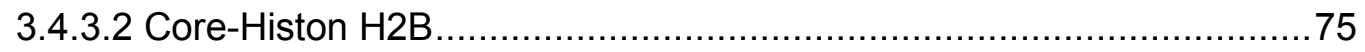

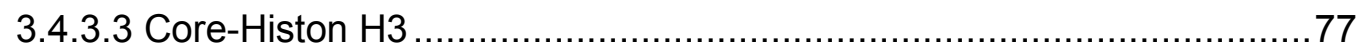

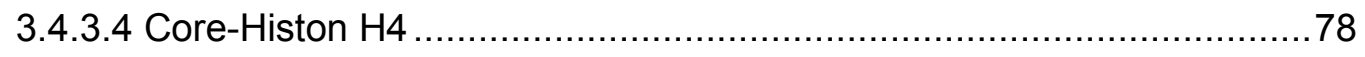

3.4.3.5 Jedes Core-Histon enthält zwei strukturell unterschiedliche NLS-Typen 
3.4.4 Untersuchung des Imports von $\mathrm{H} 2 \mathrm{~A}$ und $\mathrm{H} 2 \mathrm{~B}$ als Heterodimere. .81

3.4.5 NLS-Studien von nicht-Histon-Proteinen, die das "Histone-Fold-Motif" enthalten.....

3.5 Identifizierung beteiligter Faktoren beim Kernimport der Core-Histone

3.5.1 Kompetitionsexperimente: Import der Core-Histone wird nicht durch klassische NLS oder Linker-Histone kompetiert....

3.5.2 Rekonstitutionsexperimente: Importin $\beta$, Importin7, Importin5 und Transportin sind funktionelle Importrezeptoren für Core-Histone .93

3.5.2.1 Präparation der Transportrezeptoren und Kontrollsubstrate .93

3.5.2.2 In vitro Import der Core-Histone mit aufgereinigten Importfaktoren ....95

3.5.2.2 H2B enthält ein klassisches NLS, das im Kontext des gesamten Proteins nicht funktionell ist 100

\section{DISKUSSION}

4.1 Kerntransport von Histonen 103

4.2. In vitro Kernimportstudien von Core-Histonen. 104

4.3 Identifizierung von Kernlokalisationssignalen (NLS). 108

4.4 Untersuchung des "Histone-Fold-Motifs" als NLS in nicht-Histonproteinen ....115

4.5 Identifizierung des Importwegs der Core-Histone 116

4.5.1 Der Kernimport der Core-Histone kann alternativ durch Importin $\beta$, Importin5, Importin7 und Transportin rekonstituiert werden 117

4.6 Ausblick 124 


\section{ABBILDUNGSVERZEICHNIS}

Abb. 1 Schematische Darstellung des Kernimportzyklus 9

Abb. 2 Schematische Garstellung der Core-Histonstrukturen 12

$\begin{array}{lll}\text { Abb. } 3 & \text { Plasmidkarte von pSV } \beta & 19\end{array}$

Abb. 4 Schematische Darstellung der Mutagenese-Reaktion nach der 35 Methode von Ho et al. (1989)

$\begin{array}{lll}\text { Abb. } 5 & \text { Analyse der NLS-HSA-Konjugate } & 61\end{array}$

Abb. 6 Analyse der fluoreszenzmarkierten Core-Histone 63

Abb. $7 \quad$ In vitro Importassay mit fluoreszenzmarkierten Substraten 64

$\begin{array}{lll}\text { Abb. } 8 & \text { Zusammenfassung der Inhibierungsexperimente } & 67\end{array}$

Abb. 9 Herstellung der $\beta$-Galaktosidase Fusionskonstrukte $\quad 71$

Abb. 10 Intrazelluläre Lokalisation transfizierter $\beta$-Galaktosidase - $\quad 72$ Fusionskonstrukte in HeLa-Zellen

Abb. 11 Schematische Zusammenfassung der Transfektionsexperimente für $\quad 74$ $\mathrm{H} 2 \mathrm{~A}$

Abb. 12 Schematische Zusammenfassung der Transfektionsexperimente für $\mathrm{H} 2 \mathrm{~B}$

Abb. 13 Mutationsanalyse des aminoterminalen NLS von H2B

Abb. 14 Schematische Zusammenfassung der Transfektionsexperimente für $\mathrm{H} 3$

Abb. 15 Schematische Zusammenfassung der Transfektionsexperimente für $\mathrm{H} 4$

Abb. 16 Intrazelluläre Verteilung von Fragmenten der globulären Domäne von $\mathrm{H} 4$

Abb. 17 Fluoreszenzdetektion einiger $\beta$-Galaktosidase-Konstrukte mit NF-YB

Abb. 18 Zusammenfassung der NLS-Studien an NF-YB 85

Abb. 19 Fluoreszenzdetektion einiger $\beta$-Galaktosidase-Konstrukte mit NF-YC 86

Abb. 20 Zusammenfassung der NLS-Studien an NF-YC 86

Abb. 21 Kontrollexperimente für Kompetitionsversuche 88 
Abb. 22 Core-Histone als Kompetitoren des klassischen Importinwegs und des H1-Imports

Abb. 23 Der Kerntransport der Core-Histone wird weder durch Substrate des klassischen Importinwegs noch durch $\mathrm{H} 1$-Histone kompetiert

Abb. 24 Der Kerntransport jedes Core-Histons ist mit einem anderen kompetierbar

Abb. 25 Analyse der affinitätschromatographisch aufgereinigten Importfaktoren

Abb. 26 In vitro Rekonstitutionsexperimente mit Kontrollsubstraten und aufgereinigten Importfaktoren

Abb. 27 In vitro Rekonstitutionsexperimente mit fluoreszenzmarkierten CoreHistonen und aufgereinigten Importfaktoren

Abb. 28 Gelelektrophoretische Analyse des H2B-NLS-HSA-FITC-Konjugats

Abb. 29 Rekonstitutionsexperimente zur Identifizierung des Importrezeptors des H2B-NLS1

Abb. 30 Modell für den Kernimport der Core-Histone im Vergleich mit dem klassischen Importinweg und dem Importweg der H1-Histone

\section{TABELLENVERZEICHNIS}

Tab. 1 Zusammenstellung einiger etablierter Importrezeptoren, ihrer Substrate sowie deren Kernlokalisationssignale (NLS)

Tab. 2 Zusammensetzung der Polyacrylamidlösungen für Trenn- und Sammelgel (jew. für $10 \mathrm{ml}$ )

Tab. 3 Verwendete Importsubstrate für den in vitro Importassay, Herkunft bzw. Präparation und Nachweismethode und gekoppelter Farbstoff

Tab. 4 Übersicht über verwendete Impoertfaktoren

Tab. 5 Zusammenstellung basischer Motive im N-Terminus von H2B aus unterschiedlichen Spezies im Vergleich mit etablierten klassischen NLS. 


\section{ABKÜRZUNGSVERZEICHNIS}

\begin{tabular}{|c|c|}
\hline Abb. & Abbildung \\
\hline Ac & Acetat \\
\hline Amp & Ampicillin \\
\hline APS & Ammoniumpersulfat \\
\hline AS & Aminosäure \\
\hline ATP & Adenosintriphosphat \\
\hline $\mathbf{B p}$ & Basenpaare \\
\hline BSA & Bovines Serum Albumin (Rinderserumalbumin) \\
\hline CAS & Cellular Apoptosis Suscebility gene \\
\hline ct & Kalbs-Thymus \\
\hline $\mathrm{Da}$ & Dalton \\
\hline DAPI & Diamido-2-Phenylindol \\
\hline DMF & Dimethylformamid \\
\hline DMSO & Dimethylsulfoxid \\
\hline DNA & Desoxyribonukleinsäure \\
\hline ddNTP & Didesoxynukleosidtriphosphat (ddATP, ddCTP, ddGTP, ddTTP) \\
\hline dNTP & Desoxyribonukleosidtriphosphat (dATP, dCTP, dGTP, dTTP) \\
\hline ds & doppelsträngig \\
\hline DTT & Dithiothreitol \\
\hline E. coli & Escherichia coli \\
\hline EDTA & Ethylendiaminotetraessigsäure \\
\hline EGTA & [Ethylenbis(oxyethylennitrilo)]-tetraessigsäure \\
\hline $\mathrm{EtOH}$ & Ethanol \\
\hline FCS & Fetal Calf Serum (Fötales Kälberserum) \\
\hline FITC & Fluoreszeinisothiocyanat \\
\hline g & Erdbeschleunigung \\
\hline GTP & Guanosintriphosphat \\
\hline
\end{tabular}


GAP

GMP-PNP

Hepes

HSA

$\lg G$

IBB

$\mathrm{kDa}$

KAc

L

LB

Lsg.

M

$\mathrm{MDa}$

MCS

MOPS

$\min$

mRNA

mut

$\mathrm{NaAc}$

NLS

NPC

NTF2

$O D_{x}$

p

p.A.

PAGE

$\mathrm{pH}$
GTPase aktivierendes Protein

Guanylyl-imidodiphosphat

4-(2-Hydroxyethyl)-1 Piperazinethansulfonsäure

humanes Serum-Albumin

Immunglobulin G

Importin $\beta$-Bindungsdomäne

Kilodalton $=1000$ Dalton

Kaliumacetat

Liter

Luria-Bertani

Lösung

Molar

Megadalton $=1$ Million Dalton

Multiple Klonierungs-Stelle

3-N-Morpholinopropansulfonsäure

Minute

messenger RNA

mutiert

Natriumacetat

Kernlokalisationssignal (Nuclear Localization Signal)

Kernporenkomplex (Nuclear pore complex)

Nuclear Transport Factor 2

Optische Dichte bei einer Wellenlänge von $\mathrm{x} \mathrm{nm}$

Plasmid

zur Analyse

Polyacrylamidgelelektrophorese

potentia hydrogenii (negativer dekadischer Logarythmus der $\mathrm{H}^{+}$-

Konzentration 
PBS

Phosphat gepufferte Kochsalzlösung (Phosphate buffered saline)

PCR

Polymerase Chain Reaction

$\begin{array}{ll}\text { QBT-Puffer } & \text { Äquilibrierungspuffer } \\ \text { QC-Puffer } & \text { Waschpuffer } \\ \text { QF-Puffer } & \text { Elutionspuffer }\end{array}$

Ran

Ras related nuclear protein

RanBP

Ran Binding Protein

RanGAP

Ran GTPase activated Protein

RCC1

Regulator of Chromosome Condensation 1

RNA

Ribonukleinsäure

RNP

Ribonukleoprotein

RNase

Ribonuklease

rRNA

ribosomale RNA

RT

Raumtemperatur

SDS

Sodium dodecyl sulfate (Natriumlaurylsulfat)

$\mathrm{sec}$

Sekunde

snRNP

small nuclear RNP

SV40

Simian Virus 40

SV40mut

mutiertes SV40-T-Antigen-NLS

SV40-HSA

SV40-NLS-Peptid gekoppelt an HSA

SV40mut-HSA

mutiertes SV40-T-Antigen-NLS-Peptid gekoppelt an HSA

TAE

Tris-Acetat-EDTA-Puffer

Tab.

Tabelle

TBS

Tris buffered saline (Tris gepufferte Salzlösung)

TE

Tris-EDTA-Puffer

TEMED

$\mathrm{N}, \mathrm{N}, \mathrm{N}$ ',N'-Tetramethylethylendiamin

TELT

Tris-EDTA-LiCl-Triton

TRIS

Tris-(Hydroxymethyl)-Aminomethan

TRITC

Tetramethylrhodaminisothiocyanat

tRNA

transfer RNA

TTP

Thymidintriphosphat 
Tween-20

Polyoxyethylensorbitan-Monolaurat

$\mathbf{U}$

Unit

ü.N.

über Nacht

UV

Ultraviolett

V

Volt

vgl.

vergleiche

$\mathrm{v} / \mathrm{v}$

Volumen pro Volumen

WGA

Weizenkeimagglutinin (wheat germ agglutinin)

wt

Wildtyp

$w / v$

Gewicht pro Volumen

X-Gal

5-Chlor-4-Brom-3-Indolyl-b-D-Galaktosepyranosid 


\section{EINLEITUNG}

Die Zelle ist die kleinste Einheit, die die Grundfunktionen des Lebens erfüllt und ist Bestandteil aller irdischer Lebensformen. Fehlerfrei funktionierende Zellen sind für alle Lebewesen Grundvoraussetzung, andernfalls leiden diese an Krankheiten oder sind nicht überlebensfähig. Die Erforschung von funktionellen Zusammenhängen der Zellen ist daher nicht allein durch rein wissenschaftliches Interesse, sondern auch durch die Erwartung motiviert, mit besserem Verständnis Ansatzpunkte zur Behebung von Zellfunktionsstörungen und damit zur Heilung von Krankheiten zu erhalten. Da die Ursachen vieler Krankheiten sehr komplex sind und häufig in fehlerhaften Erbanlagen liegen, müssen zur Entwicklung von erfolgversprechenden Therapiekonzepten genaue Kenntnisse über zelluläre Vorgänge vorhanden sein. Diese Arbeit soll einen Beitrag dazu leisten, das Verständnis von intrazellulären Transportprozessen zu erweitern.

Die Erbinformation ist bei allen Lebewesen in Form von DNA auf dieselbe Art gespeichert, im Gegensatz zu Prokaryonten ist aber bei Eukaryonten die DNA in einem gesonderten Zellkompartiment, dem Zellkern lokalisiert. Dort ist die DNA mit Histonen und anderen Proteinen zu kondensierten Strukturen verpackt und durch die Kernhülle, eine Lipiddoppelmembran, die den Zellkern umgibt, von Zytoplasma, dem Ort der Proteinsynthese getrennt. Diese räumliche Separierung von genetischer Information und Synthese der Genprodukte ermöglicht einerseits zusätzliche Regulationsmöglichkeiten und Kontrollen einiger zellulärer Schlüsselschritte wie der Genexpression, erfordert aber andererseits einen Austausch von Molekülen zwischen diesen beiden Kompartimenten. So müssen z.B. mRNA und ribosomale Untereinheiten aus dem Zellkern exportiert, DNA-Polymerasen und in einer großen Zahl Histone in den Kern importiert werden, um die Funktion des Zellekerns aufrecht erhalten zu können. Man schätzt, daß etwa 100-200 unterschiedliche Proteine und pro Minute etwa 1 Million Moleküle aktiv zwischen Zellkern und Zytoplasma ausgetauscht werden. Der Transport zwischen Zellkern und Zytoplasma stellt damit einen integralen Bestandteil zellulärer Prozesse in Eukaryonten dar. Um den hohen organisatorischen Aufwand dieser Austauschvorgänge bewältigen zu können, sind eukaryotische Zellen mit einem effektiven Transportsystem ausgestattet, an dem spezielle Transportrezeptoren sowie Signale zu ihrer Erkennung beteiligt sind. 
Transportrezeptoren vermitteln dabei die Translokation durch die Kernpore, den einzigen Weg für Makromoleküle durch die Kernhülle.

\subsection{Der Weg durch die Kernpore}

Der Transportprozeß von Proteinen durch die Kernporen in den Zellkern kann entweder durch passive Diffusion und anschließende Akkumulation durch Bindung an nukleäre Komponenten wie DNA, oder durch einen aktiven Prozeß erfolgen, der über die spezifische Erkennung des Proteins durch einen Transportrezeptor und Interaktionen mit einzelnen Komponenten der Kernpore verläuft.

Die Kernpore stellt einen wäßrigen Kanal bereit, durch den der Austausch zwischen Kern und Zytoplasma geschieht. Dieser erlaubt einerseits die Diffusion von kleinen Molekülen wie lonen und andererseits einen aktiven Transport von größeren Molekülen wie Proteinen oder Nukleinsäuren. Der Durchmesser des Diffusionskanals wird auf etwa $9 \mathrm{~nm}$ geschätzt, wodurch Proteinen bis zu einer Masse von etwa 40-60 kDa (Feldherr et al., 1984) eine Diffusion prinzipiell möglich ist. Von Proteinen mit wesentlich kleinerem Durchmesser wird angenommen, daß sie leicht in den Zellkern diffundieren können.

Proteine, die größer als das Ausschlußvolumen sind, können durch einen aktiven, rezeptorvermittelten Transportprozeß in den Kern importiert werden. Dies erfordert das Vorhandensein eines spezifischen Transportsystems, bestehend aus Kernlokalisationssignalen, Transportrezeptoren, gegebenenfalls Adapter, und dem RanGTPase-System. Es wird angenommen, daß sich die Kernpore bis zu $25 \mathrm{~nm}$ öffnen kann, um große Proteine oder Proteinkomplexe hindurchzulassen.

Für einige kleine Moleküle wie ribosomale Proteine (Rout et al., 1997, Jäkel und Görlich, 1998) und für tRNA (Arts et al., 1998, Kutay et al., 1998) wurde gezeigt, daß sie den NPC nicht durch Diffusion passieren, obwohl sie es aufgrund ihre Größe könnten, sondern wie die größeren Proteine aktiv und rezeptorvermittelt in den Zellkern importiert werden.

Die Kernporen stellen die einzige Verbindungsstelle für Makromoleküle zwischen Zytoplasma und Zellkern dar. Sie bestehen aus einem makromolekularen Proteinkomplex, dem Kernporenkomplex (NPC), der in die Doppelmembran der Kernhülle eingebettet ist. Die Anzahl von NPC pro Zellkern variiert unter verschiedenen Spezies. So enthält der Kern der Hefe Saccharomyces cerevisiae etwa 
200 NPC, während die Kernmembran eines menschlichen Zellkerns von 3000-5000 dieser Proteinkomplexe durchdrungen wird. Die NPC in menschlichen Zellen haben jeweils eine molekulare Masse von etwa 125 MDa (Reichelt et al., 1990) und man schätzt, daß sie aus etwa 50-100 unterschiedlichen Proteinen, sog. Nucleoporine, zusammengesetzt sind.

Die Struktur des NPC ist trotz unterschiedlicher Größe unter verschiedenen Spezies stark konserviert. Sie läßt sich charakterisieren durch eine oktagonale Symmetrie um eine zylindrische Zentralstruktur, die die Doppelmembran der Kernhülle durchdringt und den Zentralen Kanal umgibt, durch den der Stoffaustausch stattfindet. Sowohl in zytoplasmatischer als auch in nukleoplasmatischer Richtung befinden sich Fibrillen, die auf der Kernseite eine korbartige Struktur bilden (Akey und Radermacher, 1993; Panté und Aebi, 1994; Goldberg und Allen, 1996).

In der Hefe Saccharomyces cerevisiae sind kürzlich alle 30 Nukleoporine identifiziert und charakterisiert worden (Rout et al., 2000), in Säugern sind bisher 16 bekannt. Viele Nukleoporine enthalten charakteristische Motive aus Phenylalanin und Glycin (FG-Repeats) und man vermutet, daß diese Motive bei der Translokation durch den NPC entscheidend sind, indem sie Transportrezeptoren durch spezifische Interaktionen durch den NPC dirigieren (lovine et al., 1995, Radu et al., 1995, Rout et al., 2000). Die Nukleoporine stellen damit keine reinen Strukturproteine dar, sondern sind aktiv am Transportvorgang durch den NPC beteiligt (Ohno et al., 1998).

\subsection{Kernlokalisationssignale und Transportfaktoren}

Aktive Transportprozesse von Proteinen zwischen verschiedenen zellulären Kompartimenten werden durch spezifische Signale, sog. topogene Signale vermittelt (Blobel, 1980). Diese werden durch die Aminosäuresequenz des Proteins bestimmt und determinieren seine intrazelluläre Lokalisation.

Im Gegensatz zu Transportprozessen in andere Zellkompartimente, wie das endoplasmatische Retikulum oder Mitochondrien, werden die Signalsequenzen für den Kerntransport nach dem Translokationsvorgang nicht entfernt, sondern stellen einen integralen Teil des Proteins dar. Transportprozesse durch den NPC können in beide Richtungen stattfinden. Signale, die den Transport vom Zytoplasma in den Zellkern vermitteln, werden Kernlokalisationssignale (NLS) genannt. Für den Transport aus dem Kern ins Zytoplasma sind Kernexportsignale (NES) verantwortlich. Während NES meist Leucin-reiche Motive enthalten, bestehen die NLS häufig aus wenigen basischen 
Aminosäuren, Lysinen und Argininen, die in Clustern angeordnet sind. Der Prototyp hierfür ist das NLS des T-Antigens des Simian Virus 40 (SV40), das zugleich das erste identifizierte Kernlokalisationssignal überhaupt darstellt. Es besteht aus einem Heptapeptid mit der Sequenz PKKKRKV (Kalderon et al., 1984a). In manchen Fällen ist das Signal zweigeteilt. Dies gilt für das NLS in Nucleoplasmin, das das erste gefundene NLS dieser Art darstellt, es enthält die Sequenz KRPAATKKAGQAKKKK, in dem zwei basische Cluster durch eine variable Region von etwa 10 Aminosäuren getrennt sind (Dingwall et al., 1982; Robbins et al., 1991). Die NLS für SV40-T-Antigen und Nukleoplasmin werden im allgemeinen als klassische NLS bezeichnet.

Durch Sequenzvergleiche und Datenbankrecherchen sind ähnliche Motive in einer großn Zahl von Kernproteinen, vor allem in Transkriptionsfaktoren, gefunden worden, die potentielle NLS darstellten (Boulikas, 1994). Zwar ist erst für relativ wenige von innen eine funktionelle Bedeutung nachgewiesen worden, diese stellen aber den weitus größten Anteil an bisher identifizierten funktionellen NLS dar (Jans, 2000).

Der Transport durch den NPC erfolgt durch Transportrezeptoren, die direkt oder indirekt über ein Adaptermolekül an das NLS des Substrats binden und durch Interaktionen mit der Kernpore das Substrat auf die nukleäre Seite der Kernhülle transportieren. An der Entdeckung der Transportfaktoren, die an vielen Kerntransportreaktion beteiligt sind, hatte die Entwicklung des in vitro Importassays (Adam et al., 1990) maßgeblichen Anteil. Dieses Testsystem beruht auf der selektiven Permeabilisierung der Plasmamembran von Säugerzellen mit der entscheidenden Konsequenz, daß die Zellen von ihren endogenen zytosolischen Komponenten durch Auswaschen befreit werden können und daß ein detektierbares Substrat in die Zellen eingeführt werden kann. Die Beobachtung, daß der Kernimport eines Substrats durch Zugabe von exogenem Zytosol, zytosolischen Fraktionen oder aufgereinigten Importfaktoren rekonstituiert werden kann (Adam et al., 1991), machte diesen Assay zu einem effektiven Instrument für die Suche nach essentiellen Transportfaktoren und führte zu detaillierten Charakterisierungen der Transportmaschinerie durch die Kernpore (zusammengefaßt von Görlich und Kutay, 1999). Der erste charakterisierte, als klassischer Importinweg bezeichneter Transportweg, wird durch die klassischen NLS, wie SV40-T-Antigen- oder Nukleoplasmin-NLS vermittelt. Die beteiligten Importfaktoren wurden als Importin $\alpha$ und Importin $\beta$ bezeichnet (Görlich et al., 1994; Görlich et al, 1995).

Importin $\alpha$ ist dabei für die Erkennung des NLS verantwortlich und vermittelt als Adapter die Bindung zwischen Substrat und Importin $\beta$. Importin $\beta$ ist der eigentliche 
Transportrezeptor, der die Interaktionen mit dem NPC herstellt und das Substrat in den Kern dirigiert. Zusätzliche Komponenten sind Ran und NTF2, die eine entscheidende Rolle bei der Freisetzung des Substrats im Kern, des Recyclings der Importrezeptoren und der Festlegung der Richtung des Translokationsprozesses.

Für einige Substrate mit basischem NLS-Motiv konnte gezeigt werden, daß sie über den klassischen Importinweg in den Kern transportiert werden (Jans, 2000). Zu diesen gehören das Protooncogen c-Myc (Markkerh et al., 1996) und der Transkriptionsfaktor NF-кB (Nuclear Factor-кB, Nadler et al., 1997).

Entgegen der Vorstellung, daß sich alle NLS aus kurzen basischen Motiven zusammensetzen, wurden in der Zwischenzeit auch NLS beschrieben, die sich vom klassischen Typ eindeutig unterscheiden. Das bekannteste Beispiel hierfür ist die M9Domäne des Ribonukleoproteins hnRNP A1 (heterogenous nuclear ribonucleoprotein A1, Michael et al., 1995, Pollard et al., 1996). Sie besteht aus 38 Aminosäuren, die eine geringe Anzahl an basischen Resten enthalten, ist aber glycinreich. Interssanterweise konnte für diese Domäne sowohl eine NLS- als auch eine NES-Funktion beobchtet werden (Bogerd et al., 1999). Für ribosomale Proteine sind NLS beschrieen worden, die zwar auch basisch sind, sich aber über weite Proteinbereiche erstrecken und wesentlich komplexer zusammengesetzt sind als der klassische NLS-Typ (Rout et al., 1997, Claussen et al., 1998, Jäkel und Görlich, 1998).

Proteine, die solche nicht-klassischen NLS enthalten, werden über Importwege in den Kern importiert, die unabhängig von Importin $\alpha$ und in vielen Fällen auch unabhängig von Importin $\beta$ verlaufen.

Transportrezeptoren binden ihr Substrat auf der einen Seite der Kernmembran, wandern zusammen mit inm durch den NPC, setzen es auf der anderen Seite frei und kehren schließlich ohne Substrat in ihr ursprüngliches Kompartiment zurück.

Dabei ist eine Gruppe von Importrezeptoren beteiligt, die entsprechend der Richtung des Transportprozesses, den sie vermitteln, Importine oder Exportine genannt werden. Sie gehören zu einer gemeinsamen Familie, den Importin $\beta$-ähnlichen Transportrezeptoren, die in höheren Eukaryonten inzwischen bis zu 21 Mitglieder umfaßt, von denen aber erst für 8 eine Funktion als Transportrezeptor nachgewiesen 


\begin{tabular}{|c|c|c|c|}
\hline $\begin{array}{l}\text { Import- } \\
\text { rezeptor }\end{array}$ & Substrat & NLS & Ref. \\
\hline Importin $\beta$ & $\begin{array}{l}\text { rpL23a (BIB-Domäne) } \\
\text { HIV Rev }\end{array}$ & $\begin{array}{l}41 \text { Aminosäuren } \\
\text { mit hohem } \\
\text { basischen Anteil } \\
\text { RQARRNRRRW }\end{array}$ & $\begin{array}{l}\text { Jäkel, Görlich, } \\
1998 \\
\\
\text { Truant et al., } \\
1999 \\
\end{array}$ \\
\hline $\begin{array}{l}\text { Importin } \beta / \\
\text { Importin } \alpha\end{array}$ & $\begin{array}{l}\text { SV40-T-Antigen } \\
\text { Nukleoplasmin } \\
\text { c-myc }\end{array}$ & $\begin{array}{l}\text { „klassische NLS“: } \\
\text { PKKKRKV } \\
\text { KRPAATKKAGQA } \\
\text { KKKKLD } \\
\text { PAAKRVKLD }\end{array}$ & $\begin{array}{l}\text { Görlich et al., } \\
1995 \\
\text { Robbins et al., } \\
1991 \\
\text { Nadler et al., } \\
1997\end{array}$ \\
\hline $\begin{array}{l}\text { Importin } \beta / \\
\text { Importin7 }\end{array}$ & $\begin{array}{l}\text { H1-Histone: } \\
\text { - glob. Domäne } \\
\text { - C-term.Domäne }\end{array}$ & $\begin{array}{l}75 \text { Aminosäuren, } \\
\text { relativ hydrophob; } \\
\text { mehrere basische } \\
\text { NLS }\end{array}$ & $\begin{array}{l}\text { Jäkel et el., 1999; } \\
\text { Schwamborn et } \\
\text { al., } 1998\end{array}$ \\
\hline Importin5 & rpL23a (BIB-Domäne) & S.o. & $\begin{array}{l}\text { Jäkel, Görlich, } \\
1998\end{array}$ \\
\hline Importin7 & rpL23a (BIB-Domäne) & s.o. & $\begin{array}{l}\text { Jäkel, Görlich, } \\
1998\end{array}$ \\
\hline Transportin & $\begin{array}{l}\text { hnRNPA1 } \\
\text { (M9Domäne) } \\
\text { rpL23a (BIB-Domäne) }\end{array}$ & $\begin{array}{l}38 \text { Aminosäuren, } \\
\text { glycinreich } \\
\text { s.o. }\end{array}$ & $\begin{array}{l}\text { Pollard et al., } \\
1996 \\
\text { Jäkel und } \\
\text { Görlich, } 1998 \\
\end{array}$ \\
\hline
\end{tabular}

Tabelle 1: Zusammenstellung einiger etablierter Importrezeptoren, ihrer Substrate sowie deren Kernlokalisationssignale (NLS). Importin $\beta / I m p o r t i n \alpha$, Importin $\beta / I m p o r t i n 7$ : Ein Komplex beider Faktoren ist für den Kerntransport essentiell. Abkürzungen: rp: ribosomales Protein; BIBDomäne: beta-ähnliche Importrezeptor Bindungsdomäne; SV40: Simian Virus; HIV: Human immunodefiency vius. glob. Domäne: globuläre Domäne; C-term. Domäne: C.terminale Domäne.

werden konnte (Görlich und Kutay, 1999). Eine Auswahl ist in Tabelle 1 dargestellt. Zu diesen Transportrezeptoren zählt Transportin, das den Kernimport der M9-Domäne vermittelt. Importin5 und Importin7 sind ebenfalls dieser Proteinfamilie zugehörig. Sie stellen Importrezeptoren für ribosomale Proteine dar (Jäkel und Görlich, 1998). In Tab.1 sind Importrezeptoren sowie ihre vermittelnden NLS zusammengestellt.

Importin $\beta$ selbst fungiert als Importrezeptor für das Rev-Protein des HIV (Human immunodefiency virus, Nadler et al., 1997, Truant und Cullen, 1999), oder für das HTLV Rex Protein (Palmeri et al., 1999). 
Importin $\beta$ ist nur in wenigen bisher bekannten Fällen in der Lage, direkt an das Substrat zu binden, sondern benötigt meist ein Adaptermolekül. Der bestuntersuchte Adapter ist Importin $\alpha$, das die Erkennung von Proteinen mit klassischem NLS durch Importin $\beta$ vermittelt. Dabei bindet das NLS an Importin $\alpha$, das seinerseits über die IBBDomäne (Importin-beta-binding-domain) mit Importin $\beta$ interagiert. Weitere Adapter, die die Bindung an Importin $\beta$ vermitteln, sind Snurportin und XRIP $\alpha$, die am Import von UsnRNPs (Huber et al., 1998) bzw. XRPA (Jullien et al., 1999) beteiligt sind. Darüber hinaus kann Importin $\beta$ auch als Komplex mit anderen Importin $\beta$-ähnlichen Importrezeptoren wie RanBP8 (Ran binding Protein 8), Snurprotin oder Importin7 auftreten. Letzteres bildet mit Importin $\beta$ den funktionellen Rezeptor für den Kernimport der H1-Histone (Jäkel et al., 199).

Verschiedene Exportrezeptoren gehören ebenfalls zur Proteinfamilie der Importin $\beta$ ähnlichen Transportrezeptoren. So ist CRM1 für den Export der Proteine mit Leucinreichem NES (Hood et al., 1999), CAS (Cellular Apoptosis Susceptibility gene) für Export des Importina (Kutay et al., 1997) und Exportin t für den tRNA-Transport ins Zytoplasma (Kutay et al., 1998; Arts et al., 1998) zuständig.

Transportrezeptoren binden zwar spezifisch das Kernlokalisationssignal eines Substrats, können aber durchaus verschiedene NLS erkennen. Andererseits kann auch ein NLS von unterschiedlichen Rezeptoren erkannt werden. Dieses Phänomen ist eindruckvoll am Beispiel des ribosomalen Proteins L23a beschrieben: Über ein einziges NLS kann es in vitro sowohl durch Transportin als auch durch Importin $\beta$, Importin5 oder Importin7 in den Kern importiert werden (Jäkel und Görlich, 1998).

Den Vertretern der Importin $\beta$-ähnlichen Transportrezeptoren ist neben der Verwandtschaft zu Importin $\beta$ und einer Substrat-bindenden Domäne die Fähigkeit gemeinsam, an Komponenten des NPC zu binden. Darüber hinaus besitzen sie ein RanGTP-bindendes Motiv. Die RanGTP-Bindung ist entscheidend für die Regulation der Interaktion des Transportrezeptors mit ihrem Substrat oder einem Adaptermolekül.

\subsection{Das Ran-System bestimmt die Richtung des Kerntransports}

Das RanGTPase-System nimmt eine zentrale Rolle im Transportprozeß zwischen Zytoplasma und Zellkern ein. Es ist entscheidend für die Freisetzung des Substrats im Zielkompartiment, für das Recycling des Transportrezeptors und für die Festlegung der Richtung des Transportprozesses. Es besteht aus Ran, dem Guanin-Nukleotid- 
Austasuchfaktor RCC1 (Regulator of Chromatin Condensation 1), dem GTPaseaktivierenden Protein RanGAP (Ran GTPase Activating Protein), NTF2 (Nuclear Transport-Factor 2, Paschal und Gerace, 1995) sowie dem Ran-bindenden Protein RanBP1 (Bischoff und Görlich, 1997).

Die kleine GTPase Ran kann zwischen zwei Nukleotid-gebundenen Zuständen wechseln, dem GTP- und dem GDP-gebundenen Zustand. Der Übergang vom GDP in den GTP-Zustand entspricht einem Nukleotid-Austausch, der durch RCC1 hergestellt wird (Bischoff und Ponstingl, 1991). Die Hydrolyse von GTP zu GDP wird von RanGAP (Bischoff et al., 1994) und dem Koaktivator RanBP1 katalysiert, die die geringe GTPase-Aktivität von Ran signifikant steigern (Melchior et al., 1998, Moore et al., 1998).

Die Regulatoren des Nukleotid-Bindungszustands von Ran sind in unterschiedlichen Zellkompartimenten lokalisiert. Da RCC1 ausschließlich im Zellkern vorkommt (Ohtsubo et al., 1989), erfolgt dort die Bildung von RanGTP, während das rein zytoplasmatisch lokalisierte RanGAP RanGTP in RanGDP umwandelt. Weiterhin importiert NTF2 permanent zytoplasmatisches RanGDP in den Kern. Man nimmt daher an, daß dadurch ein Konzentrationsgradient von RanGTP entlang der Kernmembran erzeugt wird, der durch eine hohe Konzentration an RanGTP im Zellkern und einer niedrigen im Zytoplasma gekennzeichnet ist.

Transportrezeptoren können durch ihre RanGTP-bindende Domäne Ran ausschließlich in der GTP-Form binden, so daß eine GTP-Hydrolyse zu einer Dissoziation von Ran und Importrezeptor führt.

Die Festlegung der Richtung von Transportprozessen durch den NPC ist durch die unterschiedliche Affinität der RanGTP-gebundenen und der Ran-freien Konformation des Transportrezeptors für sein Substrat bestimmt: Transportrezeptoren binden das Substrat ausschließlich in der Ran-freien Form im Zytoplasma, während im Zellkern eine Bindung an RanGTP zu seiner Freisetzung des Substrats führt. Für Exportrezeptoren gestaltet sich diese Situation gerade umgekehrt, sie binden ihr Substrat im Kern in der RanGTP-gebundenen Form, GTP-Hydrolyse im Zytoplasma resultiert dort in einer Dissoziation des Ran/Rezeptor/Substrat-Komplexes Moore, 1999). 


\subsection{Der Transportzyklus des Kernimports}

Aus den Eigenschaften des NPC, der NLS, der Importrezeptoren und des RanSystems ergibt sich ein Zyklus für den Kernimport von Proteinen aus dem Zytoplasma in den Zellkern. In Abb. 1 ist ein Modell dieses Importzyklus graphisch dargestellt. Im Zytoplasma bindet das Kernprotein durch sein NLS an die Ran-freie Konformation des Importrezeptors (1). Kann es nicht direkt binden, benötigt es einen Adapter (hier nicht gezeigt). Der resultierende Substrat/Rezeptor-Komplex bindet an die zytoplasmatischen Filamente des NPC (2). Anschließend wird der Komplex durch noch nicht genauer identifizierte Vorgänge auf die Kernseite des NPC transportiert (3). Dort liegt Ran in hoher Konzentration in der GTP-gebundenen Form vor. RanGTP bindet an den Importrezeptor und setzt das Substrat im Kern frei (4), da die RanGTP-gebundene Konformation des Rezeptors keine Bindung eines Substrats zuläßt. Der RanGTPgebundene Importrezeptor wird anschließend ohne das Substrat ins Zytoplasma zurückbefördert (5). Dort findet durch RanGAP und RanBP1 (Bischoff und Görlich, 1997) die Hydrolyse von RanGTP zu RanGDP statt, die zu einer Dissoziation des Rezeptor/Ran-Komplexes führt (6) und ein Rezeptormonomer zurückläßt, das für einen erneuten Import eines NLS-tragenden Substrates in den Zellkern zur Verfügung steht.

Da bei jedem Transportprozeß RanGTP aus dem Kern exportiert wird, muß ständig Ran reimportiert werden, damit der Kern nicht an RanGTP verarmt. Dafür ist NTF2 zuständig, das RanGDP aus den Zytoplasma in den Zellkern transportiert (7), das dort zu RanGTP umgewandelt wird (8) (Moore und Blobel, 1994, Ribbeck et al., 1998).

Für viele Kernproteine ist der in einer lebenden Zelle ablaufende Transportprozeß möglicherweise weitaus komplizierter. Der Transport in und aus dem Zellkern wird für viele Proteine z.B. durch Phosphorylierung subtil reguliert. Je nach relativer Lage zum NLS kann eine Phosphorylierung einen stimulierenden oder einen hemmenden Einfluß auf den Kernimport eines Substrats haben. Diese Regulierung kann z.B. durch zellzyklusabhängige Kinasen geschehen (Jans, 1995). Darüber hinaus gibt es Hinweise, daß einige Faktoren wie die Hitzeschockproteine (z.B. HSP70) in Kerntransportprozesse involviert sind, indem sie durch ihre Interaktion mit einem Substrat möglicherweise zu einer Freilegung von maskierten NLS führen (Jeoung et al., 1991, Imamoto et al., 1992). 


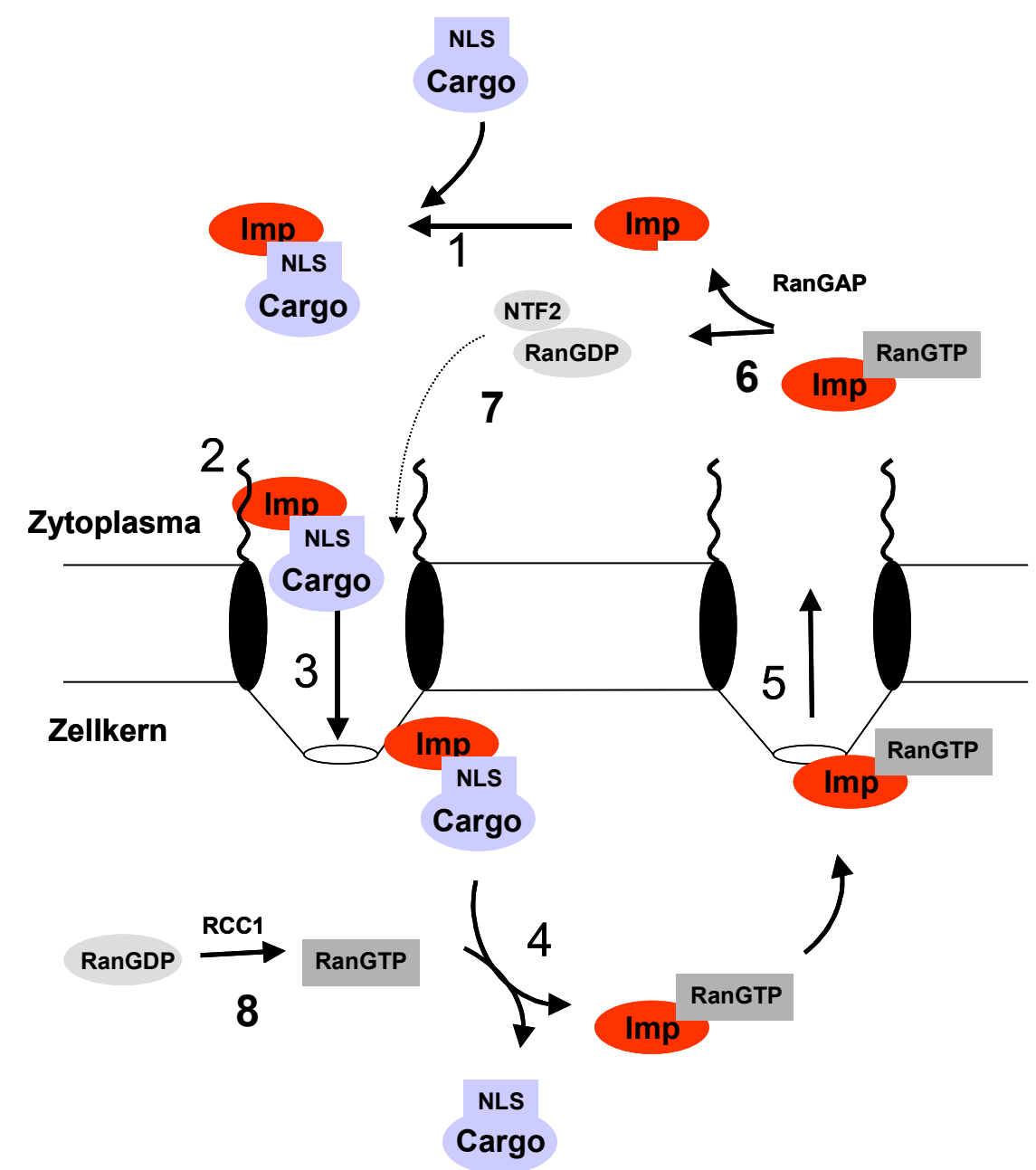

Abb. 1: Schematische Darstellung des Kernimportzyklus. Gezeigt ist ein Modell des Kernimports von Kernproteinen (Cargo) aus dem Zytoplasma durch den Kernporenkomplex in den Zellkern (modifiziert nach Görlich und Kutay, 1999). Abkürzungen: Imp: Importin $\beta$-ähnlicher Importrezeptor; NLS: Kernlokalisationssignal; RCC1: Regulator of Chromatin Condensation 1, RanGAP: Ran GTPase Activating Protein , NTF2: Nuclear Transport-Factor 2.

Für Moleküle, die kein eigenes NLS besitzen, aber dennoch im Zellkern funktionell sind, wird vermutet, daß sie durch Interaktion mit einem anderen NLS-haltigen Protein, sozusagen „Huckepack“ in den Kern befördert werden (Kambach und Mattaj, 1994). 


\subsection{Kerntransport unabhängig von Importin $\beta$-ähnlichen Importfaktoren}

In letzter Zeit ist bei verschiedenen Proteinen beobachtet worden, daß die Importrezeptoren der Importin $\beta$-ähnlichen Importfaktoren nicht für den Transport aller Proteine vom Zytoplasma in den Zellkern verantwortlich sind. Für einige Transportsubstrate konnte beobachtet werden, daß sie unabhängig von einem Importrezeptor dieser Proteinfamilie direkt mit dem NPC interagieren und in den Kern gelangen. Ein Beispiel hierfür ist das bereits erwähnte NTF2, das den Import von RanGDP in den Zellkern vermittelt (Ribbeck et al., 1998, Katahira et al., 1999). Ein weiteres Beispiel stellt $\beta$-Catenin dar, dessen Import in den Kern ebenfalls unabhängig von Importrezeptoren ist und vermutlich auch über direkte Interaktion mit dem NPC verläuft (Fagotto et al., 1998, Yokoya et al., 1999). Das hnRNP K Protein enthält neben einem klassischen NLS die KNS-Domäne (K nuclear shuttling domain), die vermutlich sowohl den Kernimport als auch den Export auch über direkte Bindung an den NPC vermittelt (Michael et al., 1997).

\subsection{Histone und Chromatin}

Die DNA eines haploiden Genoms des Menschen besteht aus $3 \times 10^{9}$ Basenpaaren, die einer Länge von ungefähr 1-2 m entsprechen. Sie ist im Zellkern eukaryontischer Zellen lokalisiert, der mit einem Durchmesser von $10 \mu \mathrm{m}$ so klein ist, daß die DNA nur in einer stark kondensierten Form hineinpaßt. Dies wird durch die Assoziation mit verschiedenen Proteinen erreicht, die zusammen mit der DNA eine kompakte Struktur bilden, die als Chromatin bezeichnet wird. Zu den beteiligten Proteinen gehören vor allem die Histone, die mengenmäßig den größten Anteil haben.

Histone sind sehr basische Proteine, die zu etwa einem Viertel aus basischen Aminosäuren (Lysin und Arginin) bestehen und einen Isoelektrischen Punkt besitzen, der mit durchschnittlich 10,8 weit im basischen Bereich liegt.

Histone werden in fünf Proteinklassen eingeteilt: die argininreichen H3- und H4-, die lysinreichen $\mathrm{H} 2 \mathrm{~A}$ - und H2B- sowie die sehr lysinreichen $\mathrm{H} 1-\mathrm{Histone}$. Funktionell ergeben sich zwei Gruppen von Histonen: die Core-Histone H2A, H2B, H3 und H4 und die Linker-Histone $\mathrm{H} 1$. 
Die Core-Histone neigen zu Interaktionen untereinander, die in Heterodimeren aus $\mathrm{H} 2 \mathrm{~A}$ und $\mathrm{H} 2 \mathrm{~B}$ bzw. in Heterotetrameren aus $\mathrm{H} 3$ und $\mathrm{H} 4$ resultieren (Abb. 2). Diese Eigenschaft ist für die Bildung des Chromatins von großer Bedeutung: Zwei H2A/H2BDimere und ein $(\mathrm{H} 3 / \mathrm{H} 4)_{2}$-Tetramer bilden zusammen ein Histonoktamer. Diesen
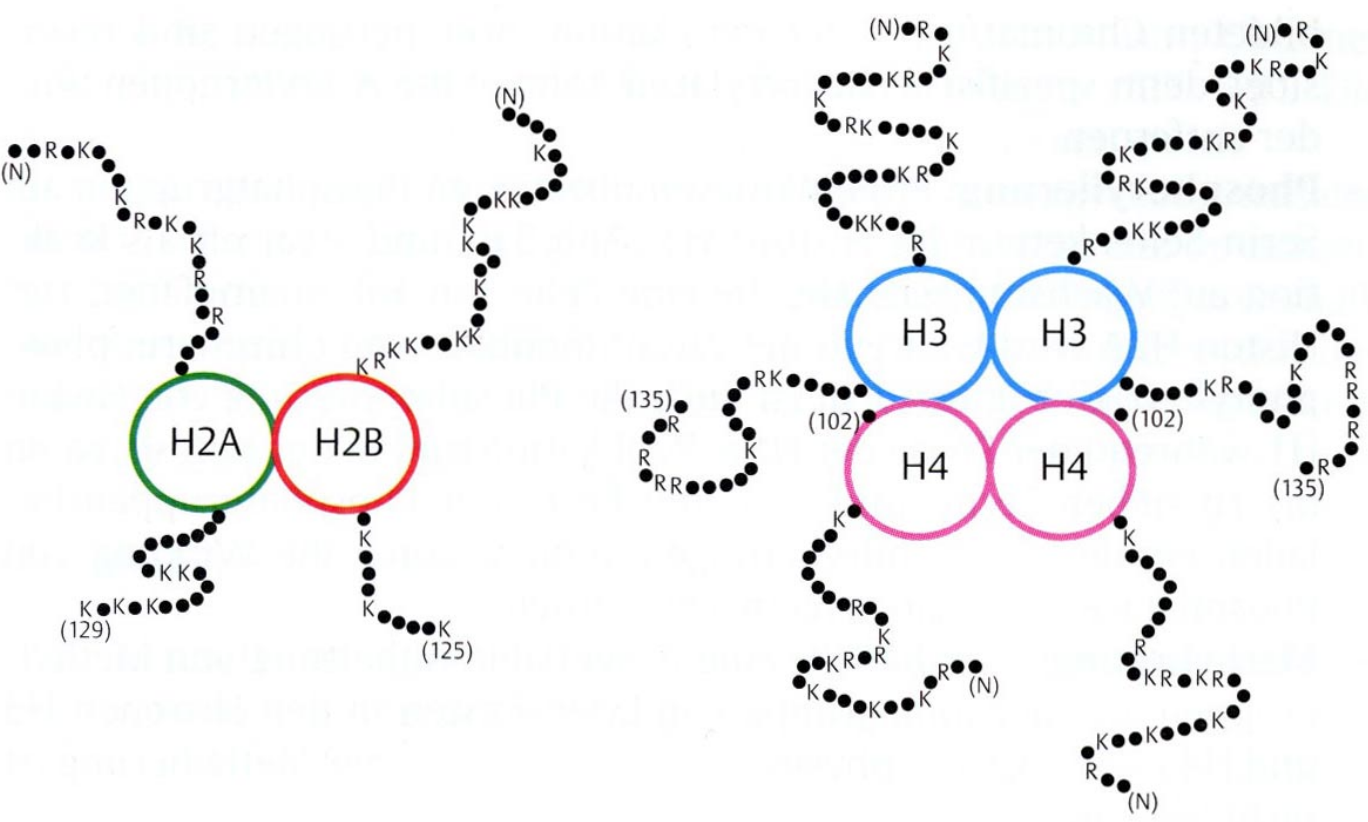

Abb.16: Intrazelluläre Verteilung der Untereinheiten der globulären Domäne von H4: Dargestellt sind die Immunfluoreszenzfärbungen der $\beta$-Galaktosidase-Fusionen der globulären Domäne von $\mathrm{H} 4$ sowie eines Teilbereiches und ihre jeweiligen mutierten Analoga. Die globuläre Domäne (pMB11), wie auch das N-terminale Fragment (pMB20) führen zu einer nukleären Lokalisation des Fusionskonstrukts. Die mutierte Variante des $\mathrm{N}$-terminalen Abschnitts (pMB32) verliert durch den Aminosäureaustausch an Transportkompetenz, während die Mutationen in der gesamten globulären Domäne keinen Einfluß auf den

umgibt die DNA im Zellkern mit 146 Basenpaaren in 1,75 Windungen, woraus das Nukleosom-Core entsteht. Die Linker-DNA verbindet einzelne Nukleosomen-Cores miteinander, wobei das Linker-Histone $(\mathrm{H} 1)$ an der Ein- und Austrittsstelle der DNA am Core-Partikel mit der Linker-DNA verbunden ist. Die so gebildete Struktureinheit aus Nukleosom-Core, Linker-Histon und Linker-DNA wird als Nukleosom bezeichnet und bildet die Wiederholungseinheit des Chromatins. Das $\mathrm{H} 1$-Histon hat dabei eine wichtige Funktion bei der Chromatinkondensierung und der Ausbildung einer Struktur höherer Ordnung (Wolffe, 1998).

Histone sind unter verschiedenen Spezies sehr konserviert. So unterscheidet sich z.B. H4 aus einer tierischen Zelle von dem H4 aus einer Pflanzenzelle in nur zwei von 102 Aminosäuren. 
Core-Histone besitzen eine Domänenstruktur, die sich durch eine aminoterminale Domäne mit hoher Basizität und eine hydrophobe globuläre Domäne und ein Cterminales Endstück beschreiben läßt. Die globuläre Domäne ist für die Interaktion der Core-Histone untereinander verantwortlich (Abb. 2).

Die N-Termini der Histone $\mathrm{H} 3$ und $\mathrm{H} 4$ stellen Zielstrukturen für Modifikationen, vor allem für Acetylierungen, dar. Von diesen wird angenommen, daß sie entscheidende Bedeutung für reversible Veränderungen in der Chromatinstruktur haben, die eng mit Prozessen der Genexpression verknüpft sind (Kornberg und Lorch, 1999).

Im Gegensatz zu den unstrukturierten N-terminalen Domänen, zeigt die globuläre Domäne eine definierte Tertiärstruktur, die das sogenannte "Histone-Fold-Motif" enthält (Arents et al., 1991). Dieses sich wiederholende Helix-Schleifenmotiv ist an der Interaktion der Core-Histone untereinander sowie an der Histon-DNA-Interaktion und daher an der Bildung der Nukleosomen verantwortlich. Dieser Proteinbereich der Core-Histone ist der am stärksten konservierte Teil und zeigt darüber hinaus eine bemerkenswerte Strukturhomologie einerseits unter den verschiedenen CoreHistonen. H1-Histone enthalten dieses Motiv nicht. Erstaunlicherweise ist diese Homologie aber zu anderen DNA-bindenden Proteinen (Baxevanis et al., 1995), die dieses Motiv zur Ausbildung von heterooligomeren Proteinstrukturen verwenden, erkennbar (Xie et al., 1996). Zu diesen Proteinen gehört NF-Y, ein Transkriptionsfaktor, der an spezifische DNA-Motive eukaryontischer Promotoren bindet (Mantovani, 1999).

\subsection{Der Kerntransport von Histonen}

In der S-Phase des Zellzyklus findet die DNA-Synthese statt, die eine große Zahl an Histonen im Zellkern erforderlich macht, um die neusynthetisierte DNA in Chromatin zu verpacken.

Die großen Mengen an benötigten Histonen und die erforderliche präzise Stöchiometrie lassen vermuten, daß es für sie einen spezifischen Transportmechanismus gibt.

Bisher veröffentliche Forschungsergebnisse zum Kerntransport von Histonen beziehen sich vorwiegend auf die Linker H1-Histone: Durch verschiedene Experimente konnte 
gezeigt werden, daß die H1-Histone durch einen aktiven Prozeß in den Kern transportiert werden (Breeuwer und Goldfarb 1990; Imamoto et al., 1995; Kurz et al., 1997; Schwamborn et al., 1998), der durch ein Heterodimer aus Importin $\beta$ und Importin7 als funktionellen Importrezeptor vermittelt wird (Jäkel et al., 1999). Darüber hinaus wurden für $\mathrm{H}^{\circ}$ die Kernlokalisationssignale identifiziert, wobei gezeigt werden konnte, daß die globuläre Domäne ein nicht klassisches NLS darstellt, während die Cterminale Domäne drei basische NLS enthält (Schwamborn et al., 1998). Für die CoreHistone wurde im Fall von H2B in der Hefe ein funktionelles NLS identifiziert, was einen Hinweis auf einen rezeptorvermittelten Transportprozeß gibt (Moreland et al., 1987). In Interaktionsstudien mit verschiedenen DNA-bindenden Proteinen ergaben sich Hinweise, daß die Core-Histone unabhängig von Importin $\alpha$ mit Importin $\beta$ interagieren (Johnson-Saliba et al., 2000).

\subsection{Zielsetzung}

Gegenstand dieser Arbeit war es, den Proteintransport der Core-Histone aus dem Zytoplasma in den Zellkern zu untersuchen.

Dazu sollte durch Verwendung des in vitro Importassays mit fluoreszenzmarkierten Substraten zunächst geprüft werden, ob die Core-Histone durch einen rezeptorvermittelten Prozeß in den Kern gelangen. Gegebenenfalls war die Beteiligung verschiedener Rezeptoren durch Kompetitionsstudien und Rekonstitutionsexperimente mit aufgereinigten rekombinanten Importrezeptoren zu identifizieren.

Weiterhin galt es, die Kernlokalisationssignale (NLS) der vier Core-Histone durch Transfektionsexperimente mit $\beta$-Galaktosidase-Fusionsproteinen zu charakterisieren. 


\section{MATERIAL UND METHODEN}

\subsection{Material}

\subsubsection{Chemikalien}

ROCHE Molecular Biochemicals (Mannheim)

dNTPs, GMP-PNP, GTP $\gamma \mathrm{S}, \mathrm{H} 2 \mathrm{~A}, \mathrm{H} 2 \mathrm{~B}, \mathrm{H} 3, \mathrm{H} 4$, ctH1

BIOCHROM (Berlin)

FCS, Trypsin-EDTA-Lösung

BIOMOL (Hamburg)

DTT, Phenol, Gelfiltrationssäulen

BIORAD (München)

Bromphenolblau, Proteinmarker

CALBIOCHEM (Bad Soden/Ts.)

Digitonin, SulfoSMCC, HSA, WGA

DIFCO (Detroit, USA)

Bacto-Agar, Bacto-Yeast-Extract, Bacto-Trypton

FLUKA (Neu-UIm)

Triton X-100, DMSO

GIBCO/BRL (Karlsruhe)

MEM-Medium

\section{MERCK (Darmstadt)}

Ammoniumchlorid, Ammoniumsulfat, Dimethylformamid, Formaldehyd, Coomassie Brilliantblau R-250, Borsäure, Chloroform, Ethanol, Glukose, Kaliumacetat, Triethanolamin, Formamid, EDTA, $\mathrm{HCl}, \mathrm{NaOH}, \mathrm{NaHCO}_{3}, \mathrm{MgSO}_{4}, \mathrm{MgCl}_{2}, \mathrm{KH}_{2} \mathrm{PO}_{4}$, $\mathrm{NaHCO}_{3}, \mathrm{NaAc}, \mathrm{KCl}, \mathrm{Na}_{2} \mathrm{HPO}_{4}$ 
MOLECULAR PROBES (Eugene, USA)

Alexa $^{\mathrm{TM}} 546$, Alexa $^{\mathrm{TM}} 488$

PHARMACIA (Freiburg)

Sephadex-G25

PROMEGA (Mannheim)

Retikulozytenlysat

SMCC (Sulfosuccinimidyl 4-(N-maleimidomethyl)cyclohexan-1-carboxylat)

QIAGEN (Hilden)

Ni-NTA-Agarose

RATIOPHARM (UIm)

Ampicillin

ROTH (Karlsruhe)

Aceton, $30 \%$ Acrylamid-Stammlösung mit 0,8 \% Bisacrylamid, Isoamylalkohol, $\mathrm{NaCl}$, TRIS

SERVA (Heidelberg)

Ammoniumpersulfat, $\beta$-Mercaptoethanol, Ethidiumbromid, Glycerin, Hepes, Maltose, SDS

SIGMA (München)

Harnstoff, Kreatinkinase, Phosphokreatin, Apyrase, Essigsäure, Phenylendiamin, DAPI, TRITC, EGTA, ATP, BSA

\subsubsection{Reagenziensätze}

QIAGEN (Düsseldorf)

Plasmid-DNA-Isolierungskit, QiaexII-DNA-Extraktionskit

PEQLAB

E.Z.N.A. Plasmid-Miniprep-Kit II

E.Z.N.A Cycle-Pure-Kit (PeqLab) 


\subsubsection{Enzyme}

\subsubsection{Restriktionsenzyme}

Restriktionsenzyme wurden von folgenden Firmen verwendet:

BIOLABS (Schwalbach), GIBCO/BRL (Karlsruhe), MBI FERMENTAS (Vilnius, Litauen), TAKARA Biomedicals (Otsu, Japan)

\subsubsection{DNA-modifizierende Enzyme}

ROCHE Molecular Biochemicals (Mannheim)

Taq-DNA-Polymerase

Alkalische Phosphatase

BIOLABS (Schwalbach)

Pfu-Polymerase

GIBCO/BRL (Karlsruhe)

T4-DNA-Ligase

\subsubsection{Sonstige Enzyme}

SIGMA

Lysozym

\subsubsection{Proteaseinhibitoren}

ROCHE Molecular Biochemicals (Mannheim)

Aprotinin

Leupeptin

Pepstatin

PMSF

\subsubsection{Oligonukleotide (siehe Anhang)}

INTERACTIVA, MWG-Biotech 


\subsubsection{Antikörper}

\subsubsection{Primärantikörper}

Maus-IgG gegen $\beta$-Galaktosidase (SIGMA, München), polyklonal

Maus-IgG gegen GST (SANTA CRUZ, BIOTECHNOLOGY), monoklonal

\subsubsection{Sekundärantikörper}

Ziege-Anti-Maus-IgG mit Rhodamin (TRITC) gekoppelt (DIANOVA, Hamburg) Ziege-Anti-Maus-IgG mit Cy3 gekoppelt (AMERSHAM PHARMACIA BIOTECH, Uppsala, Schweden)

\subsubsection{Mikroorganismen}

CLONTECH (Palo Alto, USA)

Echerichia coli K12 Stamm: $\mathrm{DH} 5 \alpha$

XL1-blue

BL21

\subsubsection{Zellinien}

HeLa (humane Portiokarzinom-Zellen); (DSMZ, Braunschweig) kultiviert in MEMMedium

\subsubsection{Geräte und Sonstiges}

Zell-Zählgerät: CASY 1 (SCHÄRFE SYSTEM, Reutlingen)

Elektroporationsgeräte:

für Bakterien: MicroPulser ${ }^{T M}$ der Firma BIORAD

für HeLa-Zellen: Easyject II der Firma EUROGENTEC

Thermocycler: GeneAmp PCR System 2400 (PERKIN ELMER)

Sequenzierer: 373 DNA-Sequencer (APPLIED BIOSYSTEMS)

Inkubator: Cytoperm2, Firma HERAERUS

Ultraschallgerät: Digital Sonifier (BRANSON SONIFIER) 


\subsubsection{Vektoren}

\subsubsection{1 pSV $\beta$}

Dieser Vektor dient als Reporter-Plasmid zur Expression des bakteriellen $\beta$ Galaktosidasegens in Säugerzellen. Das Gen für $\beta$-Galaktosidase steht hier unter der Kontrolle des frühen SV40-Promotors. Zur Selektion des Plasmids in Bakterien enthält der Vektor ein Ampicillin-Resistenzgen.

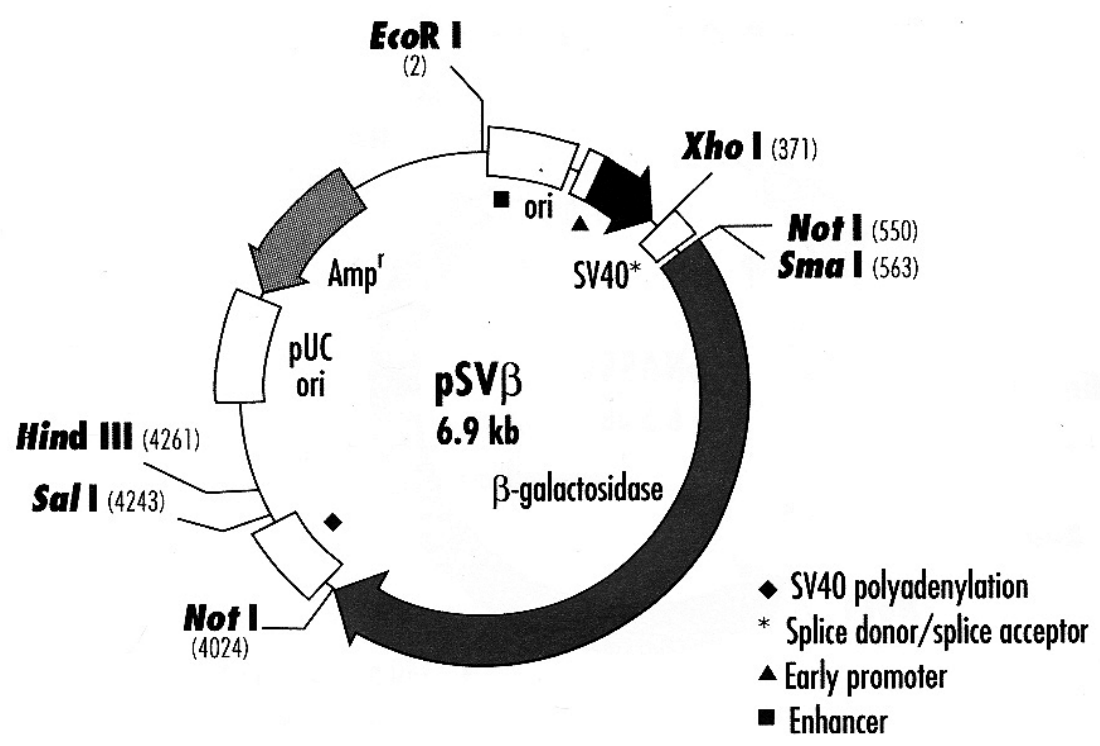

Abb. 3 Plasmidkarte von pSVß. (Abbildung aus Clontech Katalog 96/97) Abkürzungen: ori: SV40 Replikationsursprung; Amp ${ }^{R}$ : Ampicillin-Resistenzgen; die fettgedruckten Buchstaben mit Zahlen in den Klammern geben die Schnittstellen mit entsprechender Position im Plasmid an. Die Symbole: $\bullet$ : SV40 Polyadenylierungssignal; $\mathbf{\Delta}$ : SV40 Promotor; *: SV40 Spleiß-DonorAkzeptorsequenz; $\mathbf{\square}$ : Enhancer. Die Pfeile geben die funktionelle Orientierung der Gene an.

\subsubsection{Nährmedien}

LB-Medium:

$1 \%(w / v)$ Bacto-Trypton

$1 \%(w / v) \mathrm{NaCl}$

$0,5 \%(w / v)$ Hefe-Extrakt

$0,2 \%(w / v)$ Maltose

auf $\mathrm{pH}$ 7,0 mit $\mathrm{NaOH}$ 
$\mathrm{LB}_{\text {Amp }}$-Medium: LB-Medium wurde direkt vor der Anwendung mit $50 \mu \mathrm{g} / \mathrm{ml}$ Ampicillin (Endkonzentration) versetzt.

LB-Agarplatten: Dem LB-Medium wurde vor dem Autoklavieren 15\% (w/v) Agar zugegeben. Nach der Sterilisierung wurde auf $60^{\circ} \mathrm{C}$ abgekühlt und in Petrischalen gegossen.

LB-Amp-Agarplatten: Vor dem Gießen in Petrischalen wurde Ampicillin in $50 \mu \mathrm{g} / \mathrm{ml}$ Endkonzentration gegeben.

Komplettes MEM-Medium:

$2 \mathrm{mM}$ L-Glutamin

$15 \mathrm{mM}$ Hepes

$24 \mathrm{mM} \mathrm{NaHCO}_{3}, \mathrm{pH} 7,4$

$1 \%(w / v)$ NEAA

$10 \%(v / v)$ FCS

\subsubsection{Puffer}

PBS-Puffer:

$140 \mathrm{mM} \mathrm{NaCl}$

$2,5 \mathrm{mM} \mathrm{KCl}$

$8,0 \mathrm{mM} \mathrm{Na}_{2} \mathrm{HPO}_{4}$

$1,5 \mathrm{mM} \mathrm{KH}_{2} \mathrm{PO}_{4}$

Transportpuffer:

$20 \mathrm{mM}$ Hepes

$110 \mathrm{mM} \mathrm{KAc}$

$2 \mathrm{mM} \mathrm{Mg}(\mathrm{Ac})_{2}$

$1 \mathrm{mM}$ EGTA

2 mM DTT

$1 \mu \mathrm{g} / \mathrm{ml}$ jew. Aprotinin, Leupeptin,

Pepstatin

Einbettungsmedium:

$10 \%(v / v)$ PBS

$90 \%(v / v)$ Glycerin

$1 \mathrm{mg} / \mathrm{ml}$ Phenylendiamin

$1 \mu \mathrm{g} / \mathrm{ml}$ 4,6-Diamino-2-Phenylindol (DAPI) 


\subsection{Methoden}

\subsubsection{Arbeiten mit Bakterien}

Reagenzien:

LB- Medium (vgl. 2.1.11)

LB-Agarplatten (vgl. 2.1.11)

Antibiotika (jeweils angegeben): $\quad$ Ampicillin, Chloramphenicol oder Tetracyclin

\section{Durchführung:}

Für die Arbeiten mit Bakterien wurden alle Glasgeräte und Medien autoklaviert $\left(121^{\circ} \mathrm{C}\right.$, 20 min). Zur Präparation von DNA und Proteinen wurden E.coli-Bakterien verwendet, die als Bakteriendauerkulturen bei $-70^{\circ} \mathrm{C}$ gelagert waren. Als Medium für die Bakterienkulturen wurde in der Regel LB-Medium verwendet. Zur Anzucht der Bakterien wurden von einer Bakteriendauerkultur ca. $10 \mu \mathrm{l}$ auf eine LB-Agarplatte ausgestrichen und über Nacht bei $37^{\circ} \mathrm{C}$ inkubiert. Je nach Weiterverwendung wurde ein best. Volumen Medium mit einem einzelnen Klon beimpft und unter Schütteln bei 180-250 rpm und $37^{\circ} \mathrm{C}$ inkubiert. Das Wachstum der Zellen wurde durch Messung der optischen Dichte bei einer Wellenlänge von $600 \mathrm{~nm}\left(\mathrm{OD}_{600}\right)$ beobachtet.

\subsubsection{Anlegen von Bakteriendauerkulturen}

Reagenzien:

Glycerinlösung

$60 \%(v / v)$

Durchführung:

Zwei Volumenanteile einer Übernacht-Bakterienkultur wurden mit einem Volumenanteil Glycerinlösung gemischt. Die Bakterien können so durch eine Lagerung bei $-70^{\circ} \mathrm{C}$ über mehrere Jahre konserviert werden. 


\subsubsection{Herstellung kompetenter Bakterien (Mandel und Higa, 1970)}

Damit Bakterien DNA aufnehmen können, müssen sie transformationskompetent sein. Dazu ist eine Vorbehandlung der Bakterien notwendig, wobei zwischen chemisch und elektrisch induzierbarer Kompetenz unterschieden wird.

In dieser Arbeit wurden die E.coli Stämme DH5a, BL21 und XL1-blue eingesetzt. Dem Medium wurde ein Antibiotikum zugesetzt, für das der jeweilige Bakterienstamm eine Resistenz besaß: Für BL21-Kulturen wurde Chloramphenicol in einer Endkonzentration von $170 \mu \mathrm{g} / \mathrm{ml}$ und für XL1-blue Tetracyclin in einer Endkonzentration von $50 \mu \mathrm{g} / \mathrm{ml}$ eingesetzt.

\section{Durchführung:}

Zunächst wurde eine Vorkultur von $5 \mathrm{ml}$ LB $_{\text {Amp-Medium mit etwa }} 1 \mu \mathrm{l}$ Glycerindauerkultur des Bakterienstamms angeimpft und über Nacht bei $37^{\circ} \mathrm{C}$ geschüttelt. $1 \mathrm{ml}$ dieser Vorkultur diente als Impfmaterial für eine $100 \mathrm{ml}$ Kultur, die anschließend bei $37^{\circ} \mathrm{C}$ inkubiert wurde, bis die $\mathrm{OD}_{600}$ einen Wert von 0,6 bis 0,9 erreichte. Diese Kultur wurde für chemische bzw. Elektrokompetenz entsprechend weiterbehandelt.

a) chemisch kompetente Bakterien

Reagenzien:

$\mathrm{CaCl}_{2}$

$50 \mathrm{mM}$

Die Kultur wurde zunächst für 30 min auf Eis stehengelassen. Die Bakterien wurden für 5 min bei $4.000 \times$ g sedimentiert, mit $25 \mathrm{ml}$ eiskalter $\mathrm{CaCl}_{2}$-Lösung resuspendiert und nochmals für weitere $30 \mathrm{~min}$ auf Eis belassen. Die Suspension wurde erneut zentrifugiert, das Zellsediment in $5 \mathrm{ml}$ eiskalter $\mathrm{CaCl}_{2}$-Lösung aufgenommen und für 2 Stunden auf Eis gestellt. Nach Zugabe von Glycerin (15\% Endkonzentration) wurden die kompetenten Bakterien aliquotiert und in flüssigem Stickstoff schockgefroren. Bei $-70^{\circ} \mathrm{C}$ konnten die Bakterien für mehrere Monate gelagert werden. 
b) elektrokompetente Bakterien

Die Kultur wurde nach 30 min Inkubation auf Eis für 5 min bei $4.000 \times$ g zentrifugiert. Das Bakteriensediment wurde anschließend mit $5 \mathrm{ml}$ kaltem $\mathrm{H}_{2} \mathrm{O}$, dann mit $5 \mathrm{ml}$ kaltem 10\% Glycerin gewaschen. Nach Sedimentieren ( 5 min bei $4.000 \times$ g) wurde das Pellet in $2 \mathrm{ml} 10 \%$ Glycerin aufgenommen, aliquotiert, in flüssigem Stickstoff schockgefroren und anschließend bei $-70{ }^{\circ} \mathrm{C}$ gelagert.

\subsubsection{Transformation}

Das Einschleusen von Plasmid-DNA in kompetente Zellen bezeichnet man als Transformation.

Reagenzien:

LB-Medium (vgl. 2.1.11)

$\mathrm{LB}_{\text {Amp }}$-Agarplatten vgl. (2.1.11.)

Transformationskompetente Zellen (vgl. 2.2.1.2.)

Plasmid-DNA ca. $100 \mathrm{ng}$ (z.B. aus Ligationsansatz (vgl. 2.2.14))

$0,2 \mathrm{~cm}$ Elektroporationsküvetten

Durchführung:

a) chemische Transformation

$100 \mu$ einer Suspension kompetenter Bakterien wurden mit ca. 10 ng Plasmid-DNA oder $20 \mu$ Ligationsansatz zunächst für 30 min auf Eis belassen. Nach 2 minütigem Hitzeschock bei $42^{\circ} \mathrm{C}$ und anschließender 5 minütiger Inkubation auf Eis wurden $500 \mu \mathrm{l}$ LB-Medium hinzugefügt. Nach Inkubation von $1 \mathrm{~h}$ bei $37^{\circ} \mathrm{C}$ wurde $5 \mathrm{~min}$ bei $2.000 \times \mathrm{g}$ abzentrifugiert. Das Bakteriensediment wurde in etwa $100 \mu \mathrm{l}$ Medium resuspendiert, auf $\mathrm{LB}_{\mathrm{Amp}}$ Agarplatten ausgestrichen und über Nacht bei $37^{\circ} \mathrm{C}$ inkubiert.

b) Elektrotransformation

Um in Bakterien Plasmid-DNA durch Elektrotransformation einzuschleusen wurden $50 \mu \mathrm{l}$ einer kompetenten Bakteriensuspension (2.2.1.2.) mit $1 \mu \mathrm{l}$ DNA-Lösung in einer 
$0,2 \mathrm{~cm}$ Küvette mit einem Elektroporationsgerät (2.2.1.3.) transformiert (1,8 kV, Puls: 5 ms). Der Transformationansatz wurde anschließend mit $500 \mu$ LB-Medium versetzt und $1 \mathrm{~h}$ bei $37^{\circ} \mathrm{C}$ inkubiert. Etwa $100 \mu \mathrm{l}$ des Ansatzes wurden auf $\mathrm{LB}_{\mathrm{Amp}}$-Agarplatten ausgestrichen und über Nacht bei $37^{\circ} \mathrm{C}$ inkubiert.

Die verwendeten Vektoren enthielten ein $\beta$-Lactamase-Gen enthalten, welches denjenigen Bakterienkolonien eine Ampicillinresistenz verlieh, die durch die Transformation ein Plasmid ausgenommen hatten. Durch Verwendung von Amicillinhaltigen Agarplatten konnten transformierte Bakterienkolonien selektioniert werden.

\subsubsection{Isolierung von Plasmid-DNA aus Bakterien}

Es gibt verschiedene Methoden, um Plasmid-DNA zu präparieren. Sie weisen in Bezug auf die DNA-Qualität, die Ausbeute und den Arbeitsaufwand bzw. Kosten erhebliche Unterschiede auf.

Für das Screenen von Klonen nach korrekten Plasmiden wurde die TELT-Mini-ScreenMethode verwendet. Diese liefert zwar verhältnismäßig geringe und unreine Ausbeuten an Plasmid-DNA, ermöglicht aber einen hohen Probendurchsatz (vgl. 2.2.2.1).

Zur Sequenzierung von Plasmid-DNA wurde in der Regel das E.Z.N.A. PlasmidMiniprep-Kit von PeqLab eingesetzt (vgl. 2.2.2.3).

Für die Präparation von größeren Mengen an Plasmid-DNA mit hohem Reinheitsgrad verwendete man das Qiagen-Säulenelutions-Kit (vgl. 2.2.2.2).

\subsubsection{Plasmid-Präparation mit Tris-EDTA-LiCl-Triton (TELT)}

Reagenzien:

TELT-Puffer:

$50 \quad \mathrm{mM} \quad$ Tris/HCl, $\mathrm{pH} 7,5$

$62,5 \mathrm{mM} \quad$ EDTA

$2,5 \mathrm{M} \quad \mathrm{LiCl}$

$4 \%(\mathrm{v} / \mathrm{v})$ Triton $\mathrm{X}-100$

Lysozymlösung: $\quad 10 \mathrm{mg} / \mathrm{ml}$ Lysozym in $\mathrm{H}_{2} \mathrm{O}$

Isopropanol

$\mathrm{EtOH} \quad 70 \%(\mathrm{v} / \mathrm{v})$ 


\section{Durchführung:}

Das Zellsediment aus 1,5 ml einer Bakterien-Übernachtkultur wurde mit $150 \mu \mathrm{l} \mathrm{TELT-}$ Puffer resuspendiert und mit $15 \mu \mathrm{l}$ Lysozym-Lösung versetzt. Anschließend wurde $1 \mathrm{~min}$ bei $95^{\circ} \mathrm{C}$ erhitzt, danach $5 \mathrm{~min}$ auf Eis gekühlt und $15 \mathrm{~min}$ bei $10.000 \times \mathrm{g}$ zentrifugiert. Das Sediment wurde verworfen und der DNA-haltige Überstand mit $150 \mu \mathrm{l}$ Isopropanol versetzt. Anschließend wurde für $20 \mathrm{~min}$ bei $10.000 \times \mathrm{g}$ zentrifugiert, das DNA-Sediment mit $70 \%$ Ethanol gewaschen und nach Vakuumtrocknung in $25 \mu \mathrm{l} \mathrm{H}_{2} \mathrm{O}$ gelöst.

Um zu überprüfen, ob das richtige DNA-Fragment in das Plasmid eingebaut worden war, wurden $10 \mu \mathrm{l}$ in eine Restriktionsverdauung (vgl. 2.2.3) eingesetzt und dieser anschließend durch Agarose-Gelelektrophorese (vgl. 2.2.5) analysiert.

\subsubsection{Plasmid-Maxi-Präparation über QIAGEN-Säulen}

\section{Reagenzien:}

vom Hersteller mitgeliefert:

$\begin{array}{lrll}\text { Lösung P1 } & 50 \mathrm{mM} & \text { Tris/HCl, pH 8,0 } \\ & 10 \mathrm{mM} & \text { EDTA } \\ 1 & \mu \mathrm{g} / \mathrm{ml} & \text { RNase A } \\ \text { Lösung P2 } & 200 \mathrm{mM} & \mathrm{NaOH} \\ & 1 \%(\mathrm{w} / \mathrm{v}) & \mathrm{SDS} \\ \text { Lösung P3 } & 2,55 \mathrm{M} & \mathrm{KAc}, \mathrm{pH} 4,8 \\ \text { Lösung QBT } & 750 \mathrm{mM} & \mathrm{NaCl} \\ & 50 \mathrm{mM} & \mathrm{MOPS}, \mathrm{pH} 7,0 \\ & 15 \%(\mathrm{v} / \mathrm{v}) & \text { Ethanol } \\ & 1 \mathrm{M} & \mathrm{NaCl} \\ \text { Lösung QC } & 50 \mathrm{mM} & \mathrm{MOPS}, \mathrm{pH} 7,0 \text { Ethanol } \\ & 15 \%(\mathrm{v} / \mathrm{v}) & \\ & 1,2 \mathrm{M} & \mathrm{NaCl} \\ \text { Lösung QF } & 50 \mathrm{mM} & \mathrm{MOPS}, \mathrm{pH} \mathrm{8,0} \\ & 15 \%(\mathrm{v} / \mathrm{v}) & \text { Ethanol } \\ \text { Qiagen-Tip } 500 \text { Säule } & & \\ \text { zusätzlich benötigt: } & & \\ \text { Isopropanol } & 70 \%(\mathrm{v} / \mathrm{v}) & \\ \text { EtOH } & \end{array}$




\section{Durchführung:}

$400 \mathrm{ml}$ einer Bakterien-Übernachtkultur mit einer $\mathrm{OD}_{600}$ von 0,9 wurden für 10 min bei 4.000 x g zentrifugiert. Das Sediment wurde mit $10 \mathrm{ml}$ Lösung P1 resuspendiert, mit $10 \mathrm{ml}$ Lösung P2 versetzt und genau $5 \mathrm{~min}$ bei RT inkubiert. Anschließend wurden weitere $10 \mathrm{ml}$ von Lösung P3 zugegeben und für 20 min auf Eis inkubiert. Nach einer Zentrifugation für $30 \mathrm{~min}$ bei $4^{\circ} \mathrm{C}$ und $10.000 \times \mathrm{g}$ wurde der klare Überstand durch einen Papierfilter in eine zuvor mit $10 \mathrm{ml}$ Lösung QBT äquilibrierte Tip-500 Säule überführt. Die Säule wurde zweimal mit $30 \mathrm{ml}$ Lösung QC gewaschen und gebundene DNA mit $15 \mathrm{ml}$ Lösung QF eluiert. Die DNA wurde mit 10,5 ml Isopropanol gefällt und für $30 \mathrm{~min}$ bei $4^{\circ} \mathrm{C}$ und $10.000 \times \mathrm{g}$ abzentrifugiert. Das Sediment wurde mit $15 \mathrm{ml} 70 \%$ EtOH gewaschen, luftgetrocknet und in $200 \mu \mathrm{H} \mathrm{H}_{2} \mathrm{O}$ aufgenommen. Die Qualität und Konzentration der so präparierten DNA wurde anschließend photometrisch (vgl. 2.2.9.2) und durch Agarose-Gelelektrophorese (vgl. 2.2.5) bestimmt.

\subsubsection{Plasmidpräparation mit dem E.Z.N.A. Plasmid-Miniprep Kit II}

\section{Reagenzien:}

von Hersteller mitgeliefert:

HiBind-Säulen

$2 \mathrm{ml}$ Sammelgefäße

Lösung I

Lösung II

Lösung III

HB-Puffer

DNA-Waschpuffer

Elutionspuffer:

10mM Tris/HCl, $\mathrm{pH} 8,5$

RNaseA

$1 \mathrm{mg} / \mathrm{ml}$

\section{Durchführung:}

Das Bakteriensediment einer $15 \mathrm{ml}$ Übernachtkultur wurde mit $500 \mu \mathrm{l}$ Lösung I resuspendiert, die zuvor mit RNaseA (1 $\mathrm{gg} / \mathrm{ml}$ Endkonzentration) komplettiert worden war. Die Suspension wurde in einem $2 \mathrm{ml}$ Zentrifugenröhrchen mit $500 \mu \mathrm{l}$ Lösung II versetzt und nach sechsmaligem Invertieren 5 min bei RT Inkubiert. Anschließend wurden $700 \mu$ lösung III zugegeben, durch mehrmaliges Invertieren gemischt, für 
10 min auf Eis inkubiert und 10 min bei $10.000 x \mathrm{~g}$ zentrifugiert. Der klare Überstand wurde in eine HiBind-Säule gegeben, die zuvor in ein $2 \mathrm{ml}$ Sammelgefäß gesteckt worden war, und erneut zentrifugiert (1 min bei $10.000 \times \mathrm{g}$ ). Der Durchlauf wurde verworfen und die Säule zunächst mit $500 \mu \mathrm{lHB}-P$ uffer, und dann zweimal mit $750 \mu \mathrm{l}$ DNA-Waschpuffer gewaschen. Zur Trocknung wurde noch einmal mit geleertem Sammelgefäß zentrifugiert. Die DNA wurde durch Zugabe von $50 \mu \mathrm{l}$ Elutionspuffer direkt auf die Membran der HiBind-Säule und anschließende Zentrifugation eluiert.

\subsubsection{Spaltung von DNA mit Restriktionsendonukleasen}

Restriktionsendonukleasen sind Enzyme, die spezifische DNA-Sequenzen erkennen und die DNA dort doppelsträngig schneiden (verdauen). Die Erkennungssequenzen sind in der Regel palindromisch aufgebaut und bestehen aus 4-8 Basenpaaren. Man unterscheidet zwei Arten von Restriktionsenzymen, die entweder zu glatten Enden (blunt-ends) oder kohäsiven Enden (sticky-ends) führen. Die Aktivität vonRestriktionsendonukleasen ist abhängig von der Temperatur und der Salzkonzentration, so daß vom Hersteller zu den käuflichen Restriktionsendonukleasen optimierte Puffer mitgeliefert werden.

\section{Reagenzien:}

Restriktionsenzyme

10× Reaktionspuffer

$4 \times$ DNA-Auftragspuffer
$40 \%(w / v) \quad$ Saccharose
$0,1 \%(w / v) \quad$ Bromphenolblau
$0,1 \mathrm{M} \quad$ EDTA $(\mathrm{pH} 7,5)$

\section{Durchführung:}

Die Restriktionsverdauung fand in einem 1,5 ml Reaktionsgefäß statt und der Ansatz setzte sich aus $10 \mathrm{Vol} \%$ 10x Puffer, Restriktionsenzym und DNA zusammen. Die Menge des eingesetzten Enzyms richtete sich nach der verwendeten DNA-Menge: Die Aktivität eines Enzyms ist dabei durch die Enzymeinheit (U, Unit) definiert: $1 U$ eines Enzyms schneidet $1 \mu \mathrm{g}$ Lambda-DNA in einer Stunde vollständig. Für analytische Zwecke wurde in der Regel 1-3 $\mu$ g, für präparative Zwecke bis zu $10 \mu \mathrm{g}$ DNA geschnitten. Die Restriktionsverdauung wurde nach einer Inkubationszeit von 1-2 $\mathrm{h}$ bei 
$37^{\circ} \mathrm{C}$ durch Zugabe von 1/4 Volumen Auftragspuffer gestoppt. Anschließend wurde der Ansatz durch Agarose-Gelelektrophorese (vgl. 2.2.5) untersucht.

\subsubsection{Dephosphorylierung eines linearisierten Vektors}

Um zu verhindern, daß ein geschnittener (linearisierter) Vektor bei der Ligation rezirkularisiert, ohne ein DNA-Insert eingebaut zu haben, wurden die 5'-Phosphatgruppen des Vektors mit Alkalischer Phosphatase entfernt.

\section{Reagenzien:}

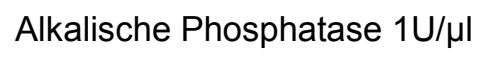

Plasmid

$10 \times$ Phosphatasepuffer

$$
0,5 \mathrm{M} \text { Tris } / \mathrm{HCl}, \mathrm{pH} 8,5
$$

$0,001 \mathrm{M}$ EDTA

EDTA-Lösung

$0,5 \mathrm{M} \quad \mathrm{pH} 8,0$

Durchführung:

Linearisierte Vektor-DNA wurde in einem Gesamtvolumen von $40 \mu \mathrm{l}$ mit Phosphatasepuffer und $1 \mu \mathrm{l}$ alkalischer Phosphatase für $30 \mathrm{~min}$ bei $37^{\circ} \mathrm{C}$ inkubiert. Anschließend wurde $1 \mu \mathrm{l}$ EDTA-Lösung hinzugefügt und der Ansatz auf $75^{\circ} \mathrm{C}$ für 15 min erhitzt. Die DNA wurde durch Agarose-Gelelektrophorese (vgl. 2.2.5) gereinigt und für Klonierungsexperimente eingesetzt.

\subsubsection{Agarose-Gelelektrophorese zur Auftrennung von DNA}

Die Agarose-Gelelektrophorese ermöglicht es, DNA-Moleküle entsprechend ihrer Größe aufzutrennen. Ihre Laufstrecke im Gel ist dabei umgekehrt proportional zum Logarithmus ihrer Größe (Helling et al., 1974). So kann eine Größenbestimmung mit Hilfe von DNA-Fragmenten bekannter Größe (DNA-Marker) erfolgen. Darüber hinaus ist diese Methode geeignet, die Konzentration von DNA abzuschätzen (vgl. 2.2.9.1). 
Reagenzien:

Agarose

TAE-Puffer

$\begin{array}{rll}50 \mathrm{mM} & \text { Tris/HAc, } \mathrm{pH} 7,8 \\ 20 \mathrm{mM} & \text { NaAc } \\ 2,5 \mathrm{mM} & \text { EDTA }\end{array}$

TBE-Puffer

$90 \mathrm{mM} \quad$ Tris $\mathrm{pH} 8,3$

$80 \mathrm{mM} \quad$ Borsäure

4× DNA-Auftragspuffer

2,5 mM EDTA

$\begin{array}{lll}0,1 \%(\mathrm{w} / \mathrm{v}) & \text { Bromphenolblau } \\ 0,1 \mathrm{M} & \operatorname{EDTA}(\mathrm{pH} \mathrm{7,5})\end{array}$

Ethidiumbromid-Lösung

$2 \mathrm{mg}$

in $600 \mathrm{ml} \mathrm{H}_{2} \mathrm{O}$

\section{Durchführung:}

In der Regel wurden 0,8-2,0 \%(w/v) Agarosegele hergestellt. Dazu wurde in TBE-oder TAE-Puffer (TBE-Puffer und hohe Agaroseanteile wurden vorwiegend für die Auftrennung kleiner DNA-Fragmente verwendet) die entsprechende Menge Agarose unter Aufkochen im Mikrowellengerät gelöst. Nach Abkühlung auf ca. $60^{\circ} \mathrm{C}$, wurde die Agaroselösung in einen Gelträger gegossen, der mit einem Kamm für die Geltaschen zum späteren Probenauftrag versehen war. Das erstarrte Gel wurde anschließend in einer Horizontalelektrophorese-Kammer mit Puffer überschichtet. Die DNA-Proben $(0,1-2 \mu \mathrm{g}, 20-30 \mu \mathrm{l})$ wurden mit DNA-Auftragspuffer versetzt und in die Geltaschen pipettiert. Als Längenstandard diente eine Marker-DNA, die in DNA-Fragmente bekannter Größe geschnitten war. Die Elektrophorese wurde bei konstanter Spannung von ca. $100 \mathrm{~V}$ durchgeführt, bis der Farbstoff am Ende des Gels angelangt war. Das Gel wurde in einer Ethidiumbromid-Lösung 10 min gefärbt und anschließend unter UVLicht analysiert. Mit den Nukleinsäuren bildet Ethidiumbromid einen stabilen Komplex, der unter UV-Licht fluoresziert.

\subsubsection{Extraktion von DNA aus Agarosegelen}

Zur Extraktion von DNA aus Agarosegelen nach erfolgter Auftrennung durch AgaroseGelelektrophorese wurde der QiaEx II Agarose Gel Extraktions-Kit (Qiagen) benutzt, dessen Prinzip auf der Bindung von DNA an einer Matrix beruht. 
Reagenzien:

vom Hersteller mitgeliefert:

Glasmilchsupension

Lösung QX1

Lösung P1

zusätzlich benötigt:

Elutionspuffer

$10 \mathrm{mM}$ Tris/ $\mathrm{HCl}, \mathrm{pH} 8,0$

\section{Durchführung:}

Die gewünschte DNA-Bande wurde nach Färbung des Agarosegels mit Ethidiumbromid unter UV-Licht (vgl. 2.2.5) aus dem Agarosegel ausgeschnitten und mit dem ca. 5-fachen Volumen von Lösung QX1 versetzt. Anschließend wurden $10 \mu \mathrm{l}$ Glasmilch zugegeben und bei $50{ }^{\circ} \mathrm{C}$ erhitzt, bis die Agarose gelöst war. Die Glasmilchsuspension wurde dann $60 \mathrm{sec}$ bei $10.000 \times \mathrm{g}$ sedimentiert. Das Sediment wurde nacheinander einmal mit $500 \mu$ l Lösung QX1 und zweimal mit $500 \mu$ l Lösung P1 gewaschen und anschließend 15 min bei RT getrocknet. Zur DNA-Elution wurde das trockene Sediment in $15 \mu$ l Elutionspuffer aufgenommen und bei RT 10 min inkubiert. Die Glasmilch wurde $60 \mathrm{sec}$ bei $10.000 \times \mathrm{g}$ sedimentiert und der DNA-haltige Überstand abgenommen.

\subsubsection{Phenol/Chloroform Extraktion}

Reagenzien:

Phenol (TE-gepuffert)

Phenol/ Chloroform/Isoamylalkohol

$25: 24: 1 \quad(v / v / v)$

Chloroform/lsoamylalkohol

$24: 1 \quad(v / v)$

\section{Durchführung:}

Die DNA-Lösung wurde mit gleichem Volumen Phenol versetzt, durchmischt und 5 min bei $13.000 \times g$ zentrifugiert. Die DNA enthaltende, wäßrige, obere Phase wurde abgenommen, mit einem äquivalenten Volumen Phenol/Chloroform/lsoamylalkoholLösung ein zweites Mal extrahiert und wie oben zentrifugiert. Die wäßrige Phase wurde erneut abgenommen und durch Ausschütteln mit dem äquivalenten Volumen 
Chloroform/lsoamylalkohol von Phenolresten befreit. Nach einem weiteren Zentrifugationsschritt wurde die wäßrige Phase abgenommen und die DNA mit Ethanol gefällt (vgl. 2.2.8).

\subsubsection{Ethanolfällung}

Reagenzien:

NaAc-Lösung

$3 \mathrm{M}, \mathrm{pH} 4,8$

Ethanol

Ethanol

$70 \%(\mathrm{v} / \mathrm{v})$

\section{Durchführung:}

Man versetzte eine DNA-Lösung mit 1/10 Volumen NaAc-Lösung und 2,5 Volumenanteilen absolutem Ethanol und ließ sie ca. $1 \mathrm{~h}$ bei $-70^{\circ} \mathrm{C}$ stehen. Anschließend wurde $15 \mathrm{~min}$ bei $10.000 \times \mathrm{g}$ und $4^{\circ} \mathrm{C}$ zentrifugiert, der Überstand abgenommen und das Pellet mit $70 \%$ Ethanol gewaschen. Nach einem weiteren Zentrifugationsschritt $\left(10.000 \times \mathrm{g}, 10 \mathrm{~min}, 4^{\circ} \mathrm{C}\right)$ wurde der Überstand abgenommen und restliches Ethanol durch Vakuumtrocknung entfernt. Schließlich wurde das DNASediment in einem gewünschten Volumen $\mathrm{H}_{2} \mathrm{O}$. aufgenommen.

\subsubsection{Konzentrationsbestimmung von DNA}

Die Konzentration von DNA läßt sich grob durch Ethidiumbromid-Fluoreszenz nach erfolgter Agarose-Gelelektrophorese (2.2.5) abschätzen oder genauer durch photometrische Analyse bestimmen. 


\subsubsection{Konzentrationsbestimmung von DNA durch Gelelektrophorese}

Zur Ethidiumbromid-Fluoreszenzabschätzung wurden geringe Mengen DNA-Lösung neben Standardlösungen bekannter Konzentrationen im Agarosegel aufgetrennt. Durch einen Vergleich der Fluoreszenzintensitäten konnte die DNA-Konzentration abgeschätzt werden.

\subsubsection{Konzentrationsbestimmung von DNA nach UV-Spektroskopie}

Die photometrische Analyse erfolgte durch ein Spektralphotometer bei einer Wellenlänge von $260 \mathrm{~nm}$ (Absorptionsmaxima von AMP und TMP) und bei $280 \mathrm{~nm}$ (Absorptionsmaximum der Aminosäure Tryptophan). Der Quotient aus beiden Extinktionen ( $260 \mathrm{~nm} / 280 \mathrm{~nm}$ ) gab Auskunft über den Grad der Verunreinigung der DNA-Lösung durch Proteine. Im optimalen Fall sollte der Quotient zwischen 1,8 und 2,0 liegen (Maniatis et al., 1989).

\subsubsection{0 "Annealen" von einzelsträngigen Oligonukleotiden}

Synthetische einzelsträngige Oligonukleotide müssen in doppelsträngige überführt werden (Annealing), damit sie in einen Vektor ligiert werden können.

Reagenzien:

$\begin{array}{lll}2 \mathrm{x} \text { Annealing- } & 0,04 \mathrm{M} & \mathrm{Tris} / \mathrm{HCl}, \mathrm{pH} \mathrm{7,6} \\ \text { Puffer: } & 0,06 \mathrm{M} & \mathrm{NaCl}\end{array}$

komplementäre $\quad$ in $\mathrm{H}_{2} \mathrm{O}$

Oligonukleotide: $\quad 1 \mu \mathrm{g} / \mu \mathrm{l}$

Durchführung:

Je $20 \mu \mathrm{l}$ der komplementären Oligonukleotide und $40 \mu \mathrm{l} 2$ x Annealing-Puffer wurden zusammengegeben, auf $85^{\circ} \mathrm{C}$ im Wasserbad erhitzt und über Nacht abgekühlt. 


\subsubsection{Polymerase-Kettenreaktion (PCR) (Mullis und Faloona, 1987)}

Die PCR dient zur Vervielfältigung definierter DNA-Bereiche. Benötigt werden die zu vervielfältigende doppelsträngige DNA, zwei einzelsträngige Oligonukleotid-Primer (sense und antisense), die den zu vervielfältigenden Abschnitt flankieren, Desoxyribonukleosid-Triphosphate (dNTPs) sowie eine thermostabile DNA-Polymerase zur DNASynthese (in dieser Arbeit wurde standardmäßig die Taq-DNA-Polymerase verwendet). Der Vervielfältigungsprozeß läuft in drei aufeinanderfolgenden Schritten $a b$ :

1. Denaturierung der doppelsträngigen DNA.

2. Anlagerung der Primer an die DNA-Einzelstränge

3. Elongation des neuen DNA-Strangs.

Im ersten Schritt wird die doppelsträngige DNA durch Hitzedenaturierung in Einzelstränge überführt. Die Primer lagern sich im zweiten Schritt an die komplementären Bereiche der erzeugten einzelsträngigen DNA an (Annealing). Im dritten Reaktionsschritt wird ausgehend von den Primern entlang der Matritzen-DNA der neue DNA-Strang synthetisiert. Bei jedem Durchlauf dieser Reaktionsabfolge erreicht man eine theoretische Verdopplung des DNA-Bereichs, so daß eine mehrfache Wiederholung zu einer exponentiellen Vervielfältigung des gewünschten DNA-Bereichs führt.

\section{Reagenzien:}

Oligonukleotidprimer

dNTP-Lösung

$\begin{array}{cll}100 \mathrm{pmol} / \mu \mathrm{l} & \text { in } \mathrm{H}_{2} \mathrm{O} \\ 2 \mathrm{mM} & \text { dATP } \\ 2 \mathrm{mM} & \text { dGTP } \\ 2 \mathrm{mM} & \text { dCTP } \\ 2 \mathrm{mM} & \text { dTTP }\end{array}$

10× Reaktionspuffer

$0,1 \mathrm{M} \quad$ Tris/ $\mathrm{HCl}(\mathrm{pH} \mathrm{8,3)}$

Taq-DNA-Polymerase

$\begin{array}{rll}0,5 \mathrm{M} & \mathrm{KCl} \\ 15 \mathrm{mM} & \mathrm{MgCl}_{2} \\ 1 \mathrm{mg} / \mathrm{ml} & \text { Gelatine } \\ 5 \mathrm{U} / \mathrm{\mu l} & \end{array}$




\section{Durchführung:}

Der Reaktionsansatz bestand aus etwa $10 \mathrm{ng}$ Plasmid-DNA, jeweils $1 \mu \mathrm{l}$ Primer, $10 \mu \mathrm{l}$ Puffer, $10 \mu \mathrm{l}$ dNTP-Lösung und $1 \mu \mathrm{l}$ Taq-Polymerase. Anschließend wurde mit $\mathrm{H}_{2} \mathrm{O}$ auf $100 \mu$ l aufgefüllt.

Durchgeführt wurde die Reaktion in einem Thermocycler (2.1.9.), dem die einzelnen Reaktionsschritte einprogrammiert werden konnten. Ein typisches PCR-Programm sah folgendermaßen aus:

0. Schritt: $96^{\circ} \mathrm{C}, 1 \mathrm{~min}$

1. Schritt: $96^{\circ} \mathrm{C}, 1 \mathrm{~min}$

2. Schritt: $55^{\circ} \mathrm{C}, 1 \mathrm{~min}$

3. Schritt: $72^{\circ} \mathrm{C}, 2 \mathrm{~min}$

4. Schritt: $72^{\circ} \mathrm{C}, 7 \mathrm{~min}$

Die Schritte 1-3 wurden dabei bis zu 30× wiederholt, Schritt 0 diente zur vollständigen Denaturierung, der Schritt 4 zur Vervollständigung der Synthese der DNA-Stränge. Nach dem letzten Schritt wurde der Reaktionsansatz auf $4^{\circ} \mathrm{C}$ gekühlt. Die Temperatur für die Anlagerung der Primer richtete sich nach dem GC-Gehalt der Primer. Die Annealing-Temperatur, Zyklenzahl und Dauer der einzelnen Schritte mußte in einigen Fällen optimiert werden.

Die vervielfältigte DNA wurde anschließend durch Agarose-Gelelektrophorese (2.2.5) analysiert, mit dem E.Z.N.A. Cycle-Pure-Kit gereinigt (vgl. 2.2.13) und in Klonierungsexperimente eingesetzt.

Die Primer waren so konstruiert worden, daß sie über die Originalsequenz des Plasmids am 5'-Ende eine zusätzliche Restriktionsschnittstelle besaßen, die eine effiziente Subklonierung mit kohäsiven Enden ermöglichte.

\subsubsection{Mutagenese von doppelsträngiger DNA}

In dieser Arbeit wurde für die Mutagenese die Methode von Ho et al. (1989) verwendet. Diese beruht auf dem Prinzip, daß zunächst in zwei unabhängigen PCRReaktionen DNA-Stränge erzeugt werden, die die gewünschte Mutation in einem überlappenden komplementären Bereich tragen. In einer dritten PCR-Reaktion hybridisieren jeweils die DNA-Einzelstränge in 5'-3'-Richtung in der überlappenden mutierten Region und werden zu einem mutierten doppelsträngen DNA-Amplifakat 
synthetisiert, das in derselben Reaktion als Matrize für die Vervielfältigung dient. Dazu benötigt man neben der Template-DNA vier Oligonukleotide, von denen zwei den zu mutierenden Bereich flankieren (FM, RM). Zwei weitere Primer enthalten neben der gewünschte Mutation jeweils die komplementäre Sequenz zu einem der beiden DNAStränge des Templates und sind zueinander komplementär (FM, RM).

In der ersten PCR-Reaktion (1) wird unter Verwendung von F2 und RM ein Teilbereich

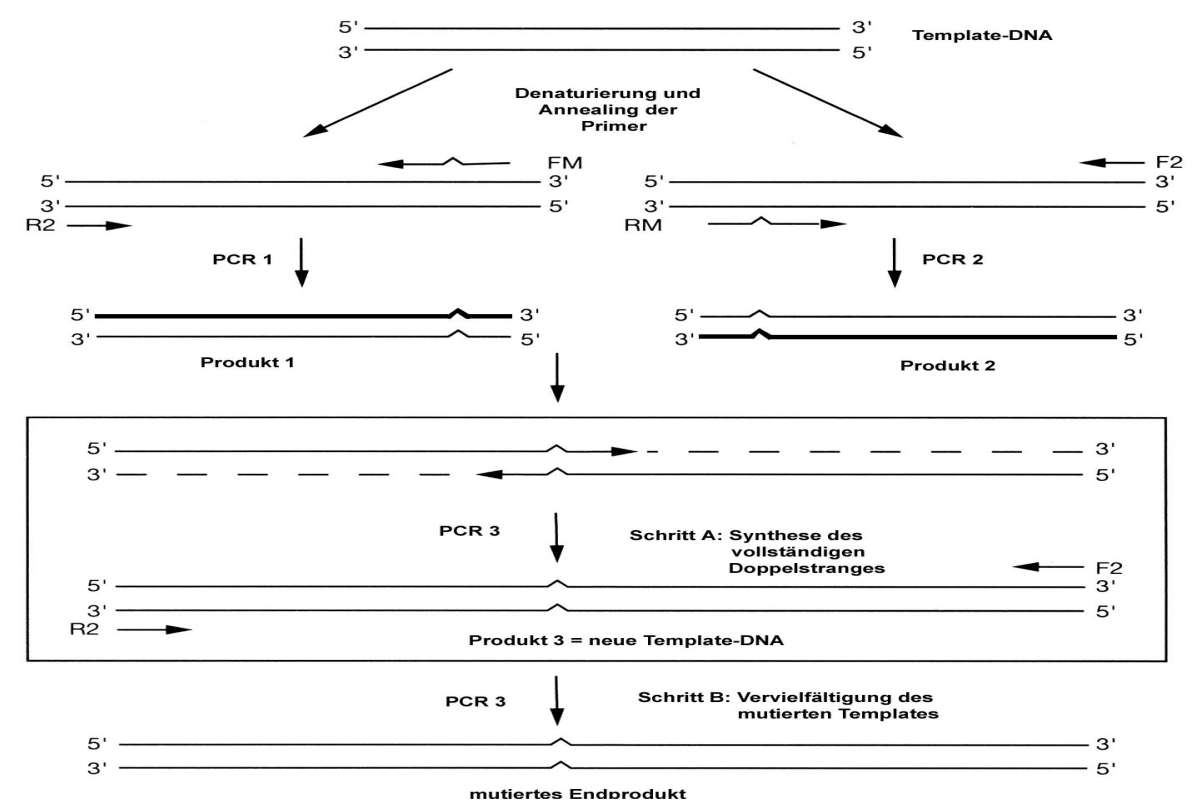

Abb.4 Schematische Darstellung der Mutagenese-Reaktion nach der Methode von Ho et al. (1989). In zwei unabhängigen PCR-Reaktionen (PCR1 und PCR2) werden unter Verwendung jeweils eines Primers mit der gewünschten Mutation FM bzw. RM (komplementär!) und des entsprechenden entgegengesetzten-Primers sowie der eingesetzten Template-DNA zwei unterschiedliche mutierte Produkte erhalten. Der 5'-3'-Strang der Reaktion1 und der 3'-5'Strang der Reaktion2 sind in dem überlappenden Bereich komplementär, der die Mutation enthält. In einer Dritten PCR-Reaktion können diese Amplifikate zusammen annealen und ihre Synthese kann jeweils in 3'-Richtung vervollständigt werden. Durch Verwendung der Primer F2 und R2 können in derselben Reaktion die vervollständigten Amplifikate als Matrize für eine Vervielfältigungsreaktion dienen, die zum Endprodukt führt.

amplifiziert, der am 3'-Ende die Mutation trägt. In der zweiten Reaktion (2) werden Primer R2 und FM eingesetzt, das Produkt enthält die Mutation genau an der entgegen gesetzten Stelle.

In einer dritten Reaktion werden diese Amplifikate als Matrizen eingesetzt, die sich nach Denaturierung in der Annealingphase an ihre überlappenden Sequenzen anlagern und gegenseitig als Primer dienen. Zunächst werden die Fragmente zur 
vollen Länge verlängert und dann mit den zugesetzten flankierenden Primern amplifiziert (Abb. 4.)

Für die zwei ersten PCR-Reaktionen darf keine Taq-Polymerase verwendet werden, da diese unabhängig vom Template ein Adenosin an das 3'-Ende anhängt, das in der dritten PCR-Reaktion zu einem falschen Leserahmen des Produktes führen würde. Daher wurde für diese Reaktionsschritte die Pfu-Polymerase verwendet. Bevor die Amplifikate der ersten und zweiten PCR-Reaktion für die dritte Reaktion eingesetzt wurden, wurden sie durch Agarose-Gelelektrophorese gereinigt.

\subsubsection{Aufreinigung von PCR-DNA mit dem E.Z.N.A Cycle-Pure-Kit}

Bei dieser Methode wird die DNA an eine Membran gebunden und durch mehrere Waschschritte von Proteinen und freien Nukleotiden befreit.

Reagenzien:

vom Hersteller mitgeliefert:

HiBind-DNA-Säulen

$2 \mathrm{ml}$ Sammelgefäße

CP-Puffer

DNA-Waschpuffer

weiterhin benötigt:

$100 \%$ Ethanol

Elutionspuffer $\quad 10 \mathrm{mM} \mathrm{Tris/HCl} \mathrm{pH} \mathrm{8,0}$

Durchführung:

Der PCR-Ansatz wurde mit 4-5-fachem Volumen CP-Puffer versetzt und in eine HiBind-Säule gegeben, die zuvor auf ein Sammelgefäß gesteckt war. Nach Zentrifugation bei 10.000 x g für 1 min wurde der Durchfluß verworfen und die Säule zweimal mit jeweils $750 \mu \mathrm{l}$ Waschpuffer gewaschen. Anschließend wurde zur Trocknung noch einmal zentrifugiert und anschließend die DNA mit etwa $30 \mu \mathrm{l}$ Elutionspuffer eluiert. Dazu wurde der Puffer direkt auf die Säulenmembran gegeben und erneut zentrifugiert. Der Durchfluß enthielt die gewünschte DNA. 


\subsubsection{Ligation von PCR-Produkten}

Mit Hilfe der T4-DNA Ligase können DNA-Fragmente in einen Vektor eingebaut werden. Diese bildet in Gegenwart von ATP Phosphodiesterbindungen zwischen 3'Hydroxyl-Enden und 5'-Phosphatgruppen und verknüpft so Vektor mit der Fremd-DNA. Ein typischer Ligationsansatz hatte ein Gesamtvolumen von $20 \mu$ l. Dieser beinhaltete neben dem Ligasepuffer, der T4-Ligase und 50-100 ng Vektor-DNA einen etwa 3-5fachen molaren Überschuß an Insert-DNA. Der Reaktionsansatz wurde für 12-16 h bei $12^{\circ} \mathrm{C}$ inkubiert und konnte anschließend direkt in die Transformation (siehe 3.2.1.4) eingesetzt werden.

\section{Reagenzien:}

$10 \times$ Ligationspuffer

$\begin{array}{rll}300 \mathrm{mM} & \text { Tris } / \mathrm{HCl}(\mathrm{pH} 7,8) \\ 100 \mathrm{mM} & \mathrm{MgCl}_{2} \\ 100 \mathrm{mM} & \text { DTT } \\ 10 \mathrm{mM} & \text { ATP }\end{array}$

T4 DNA Ligase

$3 \mathrm{U} / \mu \mathrm{l}$

Vektor-DNA

DNA-Fragment

\subsubsection{Nicht-radioaktive Sequenzierung von Plasmid-DNA (Sanger et al., 1977)}

Bei dieser Methode werden neben nicht markierten Desoxynukleosidtriphosphaten auch fluoreszenzmarkierte Didesoxynukleosidtriphosphate, sogenannte Terminatoren (ddATP, ddTTP, ddCTP, ddGTP, Dye Desoxy ${ }^{\text {TM }}$ Terminatoren) verwendet, die für jede Base mit unterschiedlichen Fluoreszenz-Farbstoffen gekoppelt sind und wegen der fehlenden 3'-OH-Gruppe nicht zur Ausbildung einer Phosphodiesterbindung fähig sind. Ihr Einbau durch eine DNA-Polymerase führt daher zum Kettenabbruch. Die DNAMatrize wird ausgehend von einem einzigen Oligonukleotid-Primer durch PCR (2.2.11.) vervielfältigt. Durch Einbau der Terminatoren bricht die Synthese ab, und es entstehen einzelsträngige DNA-Fragmente, die sich einerseits jeweils in ihrer Länge um eine Base unterscheiden und andererseits endständig basenspezifisch fluoreszenzmarkiert sind. Diese DNA-Fragmente werden elektrophoretisch aufgetrennt 
und durch ihre Fluoreszenz im Gel nachgewiesen. Die Abfolge der Farbbanden im Gel entspricht dabei der Basensequenz des analysierten DNA-Bereichs.

In dieser Arbeit wurde die „Taq-DyeDeoxy ${ }^{\mathrm{TM}}$ Terminator-Cycle-Sequencing“-Methode von $\mathrm{ABI}$ entsprechend der Herstellervorschrift angewendet.

\subsubsection{Sequenzierungsreaktion}

\section{Reagenzien:}

vom Hersteller mitgeliefert:

Tris/HCl

$5 \times$ Terminator Ammonium Cycle

$\mathrm{MgCl}_{2}$

Sequencing Puffer

$\left(\mathrm{NH}_{4}\right)_{2} \mathrm{SO}_{4}$

(TACS-Puffer)

dATP, dCTP, dGTP, dTTP

fluoreszenzmarkierte Dye Deoxy ${ }^{\mathrm{TM}}$ Terminatoren:

ddATP

ddCTP

ddGTP

ddTTP

Ampli-Taq-Polymerase

zusätzlich erforderlich:

Auftragspuffer:

$3 \mathrm{M} \mathrm{NaAc}, \mathrm{pH} 4,8$

$70 \%(v / v)$ Ethanol

$100 \%(v / v)$ Ethanol

$83 \%(v / v)$ Formamid

4,2 mM EDTA, pH 8,0 in 1x TE

Puffer

Oligonukleotidprimer

$10 \mathrm{pmol}$

\section{Durchführung:}

0,5-1,0 $\mu \mathrm{g}$ DNA-Matrize (Plasmid-Doppelstrang) wurden mit 10 pmol Primer und 6,0 $\mu \mathrm{l}$ TACS-Sequenzier-Puffer mit $\mathrm{H}_{2} \mathrm{O}$. auf ein Endvolumen von $20 \mu$ l eingestellt. Dieser Ansatz wurde mit folgendem Programm in einem Thermocycler inkubiert:

Denaturierung: $\quad 30 \mathrm{sec}$ bei $96^{\circ} \mathrm{C}$

Anlagerung der Primer: $\quad 15 \mathrm{sec}$ bei $50^{\circ} \mathrm{C}$

Kettenverlängerung: $\quad 4 \min$ bei $60^{\circ} \mathrm{C}$.

Anzahl der Zyklen $\quad 25$ 
Nach Abschluß der PCR wurde der Reaktionsansatz auf $4^{\circ} \mathrm{C}$ gekühlt, mit $2 \mu \mathrm{NaAc}-$ Lösung und $50 \mu \mathrm{l}$ absolutem Ethanol versetzt, 10 min bei RT inkubiert und bei $13.000 \times g$ zentrifugiert. Das DNA-Sediment wurde mit $250 \mu \mathrm{l} 70 \%$ Ethanol gewaschen, getrocknet und anschließend in $3 \mu \mathrm{l}$ Formamid/EDTA-Lösung aufgenommen. Die DNA wurde 2 min bei $90^{\circ} \mathrm{C}$ denaturiert und anschließend durch Polyacrylamid-Gelelektrophorese der Größe entsprechend aufgetrennt. Die Fluoreszenzsignale wurden durch ein Detektorsystem des DNA-Sequenzierungsgeräts analysiert und EDV-unterstützt in die Basensequenz übersetzt. Die Gelelektrophorese und Bestimmung der Sequenz wurde von den Mitarbeitern des Service-Labors am Institut für Biochemie und Molekulare Zellbiologie (Universität Göttingen) durchgeführt.

\subsubsection{Denaturierende Protein-SDS-Polyacrylamid-Gelelektrophorese (SDS- PAGE; Laemmli, 1970)}

Die denaturierende Protein-Gelelektrophorese wird verwendet, um Proteine entsprechend ihrer Größe aufzutrennen, ihre Größe und ihre Reinheit zu bestimmen, oder ihre Menge abzuschätzen. Die Proteinprobe wird dazu mit SDS und einem reduzierenden Agens ( $\beta$-Mercaptoethanol) versetzt und hitzedenaturiert. Das SDS lagert sich dabei an die Proteine an und bildet so einen Komplex, dessen negative Ladung dem Molekulargewicht der Proteins proportional ist. Im elektrischen Feld können die Proteine daher durch ein Polyacrylamid-Matrix abhängig von ihrer Molekülmasse aufgetrennt werden.

\section{Reagenzien:}

Glasplatten für Minigele

$10 \times 10 \mathrm{~cm}$

Puffer A

$1,5 \mathrm{M}$

Tris/ $\mathrm{HCl} \mathrm{pH} \mathrm{8,8}$

Puffer B

$0,5 \mathrm{M}$

Tris/HCl pH6,8

SDS-Lösung

$10 \%(w / v)$

APS

$10 \%(w / v)$

TEMED

gebrauchsfertige wäßrige

$30 \%$ Acrylamidlösung

Acrylamid-/Bisacrylamidlösung

$0,8 \%$ Bisacrylamidlösung

im Verhältnis 37,5:1 
$2 \times$ Probenpuffer

$$
\begin{array}{rll}
200 & \mathrm{mM} & \text { Tris/HCl pH 6,7 } \\
6 & \%(\mathrm{w} / \mathrm{v}) & \text { SDS } \\
15 & \%(\mathrm{v} / \mathrm{v}) & \text { Glycerin } \\
0,005 & \%(\mathrm{w} / \mathrm{v}) & \text { Bromphenolblau }
\end{array}
$$

Probenpuffer-Gebrauchs-

lösung

$0,9 \mathrm{ml}$

Probenpuffer $(2 \times)$

$5 \times$ Laemmli-Laufpuffer

$0,1 \mathrm{ml}$ $\beta$-Mercaptoethanol

$0,25 \mathrm{M}$

Tris/ $\mathrm{HCl}(\mathrm{pH} 8,7)$

$10 \mathrm{mM}$

EDTA

$1,9 \mathrm{M}$

Glycin

$0,5 \%(w / v)$

SDS

Coomassie-Färbelösung

$0,15 \%(w / v) \quad$ Coomassie Brilliant Blue R 250

$50 \%(v / v) \quad$ Methanol

$10 \%(\mathrm{v} / \mathrm{v}) \quad$ Essigsäure

Entfärberlösung I

$50 \%(\mathrm{v} / \mathrm{v}) \quad$ Methanol

$10 \%(\mathrm{v} / \mathrm{v}) \quad$ Essigsäure

Entfärberlösung II

$10 \%(\mathrm{v} / \mathrm{v}) \quad$ Methanol

$5 \%(v / v) \quad$ Essigsäure

\begin{tabular}{|l|c|c|c|c|}
\hline & $\begin{array}{c}\text { Trenngel } \\
10 \%\end{array}$ & $\begin{array}{c}\text { Trenngel } \\
12 \%\end{array}$ & $\begin{array}{c}\text { Trenngel } \\
15 \%\end{array}$ & $\begin{array}{c}\text { Sammel- } \\
\text { gel }\end{array}$ \\
\hline Lösung A $(\mathrm{ml})$ & 2,5 & 2,5 & 2,5 & - \\
\hline Lösung B $(\mathrm{ml})$ & - & - & - & 2,5 \\
\hline SDS-Lösung $(\mu \mathrm{l})$ & 100 & 100 & 100 & 100 \\
\hline TEMED $(\mu \mathrm{l})$ & 10 & 10 & 10 & 10 \\
\hline $\begin{array}{l}\text { Acrylamid-l } \\
\text { Bisacrylamidlösung }(\mathrm{ml})\end{array}$ & 3,3 & 4,3 & 4,9 & 1,3 \\
\hline $\mathrm{H}_{2} \mathrm{O} .(\mathrm{ml})$ & 4,3 & 3,3 & 2,6 & 6,1 \\
\hline APS $(\mu \mathrm{l})$ & 100 & 100 & 100 & 100 \\
\hline
\end{tabular}

Tab. 2: Zusammensetzung der Polyacrylamidlösungen für Trenn- und Sammelgel (jew. für $10 \mathrm{ml}$ ). 
Durchführung:

Zwei Glasplatten $(10 \times 10 \mathrm{~cm})$ wurden mit Abstandhalter zusammengebaut und mit einer Gummidichtung abgedichtet. In den Raum zwischen den beiden Glasplatten wurde zunächst die entsprechend Tab. 2 vorbereitete Trenngel-Lösung bis ca. $2 \mathrm{~cm}$ unter den Rand gegossen, mit Isopropanol überschichtet und $30 \mathrm{~min}$ zur Polymerisierung des Polyacrylamids bei RT stehen gelassen. Anschließend wurde das Isopropanol entfernt, die Sammelgel-Lösung hineingegossen und ein Probenkamm eingesteckt, um die nötigen Aussparungen für den Probenauftrag zu schaffen. Nach der Polymerisierung wurde das Gel in eine Laufkammer gespannt, die mit Laufpuffer gefüllt wurde. Die Proben wurden mit Probenpuffer versetzt, bei $95^{\circ} \mathrm{C} 5$ min denaturiert und in die Geltaschen pipettiert. Die Elektrophorese erfolgte bei 14-20 mA für ca. 90150 min bis der Farbstoff den unteren Rand des Gels erreicht hatte. Das Gel wurde nach der Elektrophorese für ca. 30 min bei RT mit Coomassie-Färbelösung gefärbt. Um die Proteinbanden sichtbar zu machen, wurden das Gel danach zunächst mit Entfärberlösung I 15 min und anschließend mit Entfärberlösung II 30 min entfärbt.

\subsubsection{Kultivierung humaner Tumorzellinien}

In der vorliegenden Arbeit wurden adhärent wachsende HeLa-Zellen verwendet, die in $650 \mathrm{ml}$ Zellkulturflaschen und mit $50 \mathrm{ml}$ MEM-Medium kultiviert wurden. Die Inkubation erfolgte in einem Brutschrank bei $37^{\circ} \mathrm{C}$ und $5 \%(\mathrm{v} / \mathrm{v}) \mathrm{CO}_{2}$.

\section{Reagenzien:}

MEM-Medium (2.1.11)

PBS-Puffer (2.2.12)

Trypsin-EDTA-Lösung:

$0,05 \%(w / v)$ Trypsin

$0,02 \%(w / v)$ EDTA in PBS

Penicillin/Streptomycin-Lösung

DMSO

\section{Durchführung:}

Adhärent wachsenden HeLa-Zellen wurden bis zur einer maximalen Zelldichte von $1,25 \times 10^{5}$ Zellen $/ \mathrm{cm}^{2}$ kultiviert. Anschließend wurde das Medium abgesaugt, die 
Zellen mit PBS gewaschen und mit 2,5 ml Trypsin-EDTA-Lösung 5 min bei $37^{\circ} \mathrm{C}$ inkubiert. Die vom Boden der Kulturflasche abgelösten Zellen wurden in $10 \mathrm{ml}$ frischem Kulturmedium resuspendiert. Diese Zellsuspension wurde dann in der gewünschten Dichte weiterkultiviert. ur Bestimmung der Zelldichten wurde ein automatisches Zell-Zählgerät verwendet (2.1.9).

\subsubsection{Gefrierkonservierung}

Reagenzien:

Konservierungsmedium

Komplettes-MEM-Medium mit

$20 \%(\mathrm{v} / \mathrm{v}) \mathrm{FCS}$

$10 \%(\mathrm{v} / \mathrm{v}) \mathrm{DMSO}$

Nunc-Cryo-Röhrchen

Durchführung:

Etwa $1 \times 10^{7}$ konfluent gewachsene Zellen wurden trypsiniert, zweimal mit PBS gewaschen und zentrifugiert. Das Zellsediment wurde mit $1 \mathrm{ml}$ Konservierungsmedium resuspendiert, in ein Nunc-Cryo-Röhrchen gefüllt und bei $-70^{\circ} \mathrm{C}$ über Nacht eingefroren. Anschließend wurden die Zellen in flüssigen Stickstoff gelagert.

\subsubsection{Anlegen einer adhärent wachsenden Zellinie}

Eine in flüssigem Stickstoff konservierte Zellprobe wurde bei $37^{\circ} \mathrm{C}$ in einem Wasserbad schnell aufgetaut und danach sofort in $10 \mathrm{ml}$ frisches Kulturmedium überführt. Die Zellen wurden bei $2.000 \times \mathrm{g}$ für 5 min sedimentiert, der Überstand abgenommen und das Zellsediment in $1 \mathrm{ml}$ frischem Medium resuspendiert. Die Zellsuspension wurde in eine Kulturflasche überführt, mit $50 \mathrm{ml}$ Medium aufgefüllt und bei $37^{\circ} \mathrm{C}$ und $5 \%(\mathrm{v} / \mathrm{v}) \mathrm{CO}_{2}$ inkubiert. 


\subsubsection{Transiente Transfektion von Zellen}

Als Transfektion bezeichnet man die Einführung von Makromolekülen in lebende, höhere eukaryontische Zellen. Bei der transienten Transfektion mit Plasmid-DNA kann diese in Zellen exprimiert und das Genprodukt enzymatisch oder immunologisch nach 2 Tagen nachgewiesen werden. In dieser Arbeit wurden HeLa-Zellen mit Plasmid-DNA transfiziert.

\subsubsection{Transfektion durch Elektroporation (Showe et al., 1992)}

Reagenzien:

PBS (2.1.12.)

Paraformaldehyd-Lösung $\quad 3 \%(w / v)$ in PBS

Farbreagenz:

$\begin{array}{ll}\text { X-Gal: } & 20 \mathrm{mg} / \mathrm{ml} \\ \text { Na-Ferricyanid: } & 5 \mathrm{mM} \\ \text { Na-Ferrocyanid: } & 5 \mathrm{mM} \\ \mathrm{MgCl}_{2}: & 2 \mathrm{mM}\end{array}$

Gewebekulturschale mit 6 Vertiefungen (pro Vertiefung $4 \mathrm{~cm}^{2}$ Wachstumsfläche)

Glasplättchen (10mm Durchmesser)

Küvette:

$0,4 \mathrm{~cm}$ Elektrodenabstand

Bei der Elektroporation wird die Aufnahme von Fremd-DNA in Zellen durch eine kurzzeitige reversible Permeabilisierung der Zellmembran mittels einer angelegten Hochspannung ermöglicht. Folgende Elektroporationsbedingungen für HeLa-Zellen wurden angewendet:

$\begin{array}{ll}\text { Elektroporationsgerät: } & \text { EASYJECT II ( Eurogentec) } \\ \text { Kapazität: } & 1350 \mu \mathrm{F} \\ \text { Spannung: } & 240 \mathrm{~V} \\ \text { Ableitungswiderstand: } & 156 \mathrm{Ohm} \\ \text { Widerstand vor Impuls: } & 20-40 \Omega \\ \text { Effektive Pulsdauer: } & 10-40 \mathrm{msec} \\ \text { DNA-Menge: } & 25 \mu \mathrm{g} \text { in } 50 \mu \mathrm{H} \mathrm{H}_{2} \mathrm{O} \\ \text { Zell-Anzahl: } & 5 \times 10^{5} \text { in } 500 \mu \mathrm{l} \text { MEM-Medium }\end{array}$


In die Vertiefungen einer 6er-Gewebekulturschale wurden jeweils 4-5 Glasplättchen gelegt, für 15 min unter UV-Bestrahlung sterilisiert und anschließend mit $5 \mathrm{ml}$ MEMMedium gefüllt. Die Zellen wurden trypsiniert, für $5 \mathrm{~min}$ bei $1.500 \times \mathrm{g}$ abzentrifugiert und mit $10 \mathrm{ml}$ PBS gewaschen. Anschließend wurde erneut abzentrifugiert und in einer Zelldichte von $1 \times 10^{6}$ Zellen $/ \mathrm{ml}$ mit MEM-Medium resuspendiert. $500 \mu \mathrm{l}$ dieser Zellsuspension wurden in eine Elektroporationsküvette überführt, mit einer Lösung von $20 \mu \mathrm{g}$ Plasmid-DNA in $50 \mu \mathrm{l} \mathrm{H}_{2} \mathrm{O}$ versetzt und elektroporiert. Anschließend wurde der Küvetteninhalt in die Vertiefungen der Gewebekulturschale überführt und diese bei $37^{\circ} \mathrm{C}$ und $5 \%(\mathrm{v} / \mathrm{v})$ im Brutschrank inkubiert. Nach 24 Stunden wurde das Medium abgesaugt und $5 \mathrm{ml}$ frisches Medium hinzugefügt. Nach weiteren 24 Stunden wurde die Detektion des Genprodukts durchgeführt (vgl. 2.2.22).

Zur Kontrolle und Ermittlung der Transfektionseffizienz wurde $\beta$-Galaktosidase aus pSV $\beta$ (2.1.10.1) durch in situ Färbung mit X-Gal nachgewiesen, wodurch die transfizierten Zellen eine blaue Farbe erhalten: Dazu wurden die Zellen mit PBS gewaschen, 15 min mit 3 \% Paraformaldehyd in PBS fixiert, und nach einem weiteren Waschschritt mit PBS mit dem Farbreagenz bei $37^{\circ} \mathrm{C}$ für $2-4$ Stunden inkubiert. Die Transfektionseffizienz wurde durch Auszählen der blau gefärbten Zellen ermittelt.

\subsubsection{Immunfluoreszenz-Detektion}

Diese Methode wurde zur Detektion der $\beta$-Galaktosidase-Fusionsproteine im Transfektionsassay sowie zum Nachweis von M9-GST im in vitro Importassay (vgl. 2.2.27) verwendet. Dabei wurden die entsprechenden Primärantikörper verwendet (vgl. 2.1.6.1); die Sekundärantikörper waren in beiden Fällen identisch (gegen Maus aus Ziege, vgl. 2.1.6.2)

Reagenzien:

PBS (vgl. 2.1.12)

Paraformaldehyd

$3 \%(w / v)$ in PBS

Triton

$0,5 \%(v / v)$ in PBS

Block-Lösung

$3 \%(w / v)$ BSA in PBS

Primärantikörper:

- für $\beta$-Galaktosidase

polyklonaler Antikörper gegen $\beta$-Galaktosidase

aus Maus (1:1000 Verdünnung in BlockLösung) 
- für GST

Sekundärantikörper

Objektträger

DAPI-Einbettungsmedium monoklonaler Antikörper gegen GST aus Maus (Verdünnung: 1:1000 in Blocklösung) Cy3 markierter Antikörper gegen Maus aus Ziege (1:1000 Verdünnung in Block-Lösung)

$10 \%(v / v)$ PBS

$90 \%(\mathrm{v} / \mathrm{v})$ Glycerin

$1 \mathrm{mg} / \mathrm{ml}$ Phenylendiamin

$1 \mu \mathrm{g} / \mathrm{ml}$ 4,6-Diamidino-2-Phenylindol (DAPI)

Nagellack

Die Detektion des $\beta$-Galaktosidase enthaltenden Genprodukts erfolgte etwa $48 \mathrm{~h}$ nach der Elektroporation. Das Medium wurde abgesaugt und die Zellen zweimal mit PBS gewaschen. Anschließend wurde für 15 min bei RT mit Paraformaldehyd fixiert und nach zweimaligem Waschen mit PBS für 10 min mit Triton inkubiert. Nach zwei weiteren Waschschritten mit PBS wurde mit der Block-Lösung für 15 min inkubiert. Die Primärantikörperinkubation erfolgte danach für eine Stunde bei $37^{\circ} \mathrm{C}$ in einer feuchten Kammer. Nach erneutem Waschen mit PBS, wurde mit dem Zweitantikörper unter den gleichen Bedingungen inkubiert. Die Zellen wurden zweimal mit PBS gewaschen, im DAPI-Einbettungsmedium auf einem Objektträger eingebettet und mit Nagellack versiegelt. Die Visualisierung wurde wie unten (vgl. 2.2.22) vorgenommen.

\subsubsection{In vitro Kerntransportanalyse}

Einige wesentliche Charakteristika des Kerntransportes der Core-Histone wurden mit Hilfe des in vitro Importassays (auch Permeabilisierungsassay, Adam et al., 1990) untersucht. Dieser basiert auf der Verwendung von semiintakten Zellen, die durch Permeabilisierung lebender HeLa-Zellen mit dem nichtionischen Detergens Digitonin präpariert werden. Durch die Inkubation mit Digitonin in niedriger Konzentration wird die cholesterinhaltige Plasmamembran perforiert und durchlässig für Zytoplasma und von außen zugegebene Flüssigkeiten sowie darin enthaltene Makromoleküle. Lösliche Komponenten des Zytoplasmas werden so freigesetzt, wobei intrazelluläre Strukturen, insbesondere die Kernmembran intakt bleiben.

Diese semiintakten Zellen werden mit dem zu untersuchenden fluoreszenzmarkierten Substrat sowie mit einem ATP-regenerierenden System, exogenem Zytosol bzw. 
definierten, am Transport beteiligten Komponenten inkubiert. Ist das Substrat im Zellkern detektierbar, so hat ein Kerntransport stattgefunden, andernfalls verbleibt das Substrat im Zytoplasma oder wird ausgewaschen. Diese in vitro Methode ermöglicht es, je nach Fragestellung, den Einfluß verschiedener Bedingungen sowie die Beteiligung bestimmter Faktoren auf die Transportreaktion des Substrats zu untersuchen.

\subsubsection{Herstellung der Transportliganden und Kompetitoren}

Damit die zu untersuchenden Substrate detektierbar waren, wurden sie chemisch an Fluoreszenzfarbstoffe gekoppelt (M9-GST wurde durch Immunfluoreszenz nachgewiesen (vgl. 2.2.22). Diese besitzen die Eigenschaft, bei einer bestimmten Anregung Licht einer spezifischen Wellenlänge zu emittieren, das dann mit einem geeigneten Mikroskop detektiert werden kann. Dies ermöglicht eine Zuordnung des Transportsubstrats zu einem bestimmten intrazellulären Bereich z.B. dem Zellkern.

\begin{tabular}{|c|c|c|c|}
\hline Substrat & Herkunft & $\begin{array}{l}\text { Fluoreszenzdete } \\
\text { ktionsmethode }\end{array}$ & Farbstoff \\
\hline $\begin{array}{l}\mathrm{H} 2 \mathrm{~A}, \mathrm{H} 2 \mathrm{~B}, \mathrm{H} 3, \\
\mathrm{H} 4\end{array}$ & aus Kalbsthymus & direkt & Alexa $^{\mathrm{TM}}$ Farbstoff \\
\hline $\begin{array}{l}\text { H2B-NLS-(As } \\
\text { 26-35)-HSA }\end{array}$ & $\begin{array}{l}\text { synthetisches Peptid an } \\
\text { HSA gekoppelt }\end{array}$ & direkt & FITC \\
\hline $\begin{array}{l}\text { SV40-T-Antigen- } \\
\text { wtNLS-HSA }\end{array}$ & $\begin{array}{l}\text { synthetisches Peptid an } \\
\text { HSA gekoppelt }\end{array}$ & direkt & TRITC \\
\hline $\mathrm{H} 1$ & aus Kalbsthymus & direkt & TRITC \\
\hline M9-Domäne & $\begin{array}{l}\text { in E.coli überexprimiert } \\
\text { und aufgereinigt (vgl. } \\
2.2 .26 \text { ) }\end{array}$ & $\begin{array}{l}\text { Immunfluoreszenz } \\
\text { gegen GST (vgl. } \\
2.1 .6 .1)\end{array}$ & $\begin{array}{l}\text { Cy3 (markierter } \\
\text { Sekundäranti- } \\
\text { körper) }\end{array}$ \\
\hline IBB-Domäne & $\begin{array}{l}\text { in E.coli überexprimiert } \\
\text { und aufgereinigt }\end{array}$ & direkt & $\begin{array}{l}\text { Fluoreszein- } \\
\text { maleimid }\end{array}$ \\
\hline L23a & $\begin{array}{l}\text { in E.coli überexprimiert } \\
\text { und aufgereinigt }\end{array}$ & direkt & \begin{tabular}{|l} 
Fluoreszein- \\
maleimid
\end{tabular} \\
\hline
\end{tabular}

Tab. 3: Verwendete Importsubstrate für den in vitro Importassay, Herkunft bzw. Präparation und Nachweismethode und gekoppelter Farbstoff. 
Die in dieser Arbeit verwendeten Transportsubstrate sind in Tab. 3 aufgeführt. Die Histone $\mathrm{H} 1, \mathrm{H} 2 \mathrm{~A}, \mathrm{H} 2 \mathrm{~B}, \mathrm{H} 3$ und $\mathrm{H} 4$ wurden als käufliche Proteine aus Kalbsthymus (vgl. 2.1.1) erhalten und fluoreszenzmarkiert (vgl. 2.2.24.2). M9-GST wurde in Bakterien exprimiert und aufgereinigt, aber nicht weiter modifiziert (vgl. 2.2.26). L23a wurde von der Arbeitsgruppe zur Verfügung gestellt, (Marc Bäuerle, Institut für Biochemie, Göttingen, Dissertation in Arbeit), IBB wurde von Dr. Görlich (Heidelberg) erhalten. Weitere verwendete Substrate waren SV40-T-Antigen-NLS-HSA und H2BNLS1-HSA. Diese enthielten fluoreszenzmarkiertes HSA (Humanes Serumalbumin ), das mit den entsprechenden synthetischen Peptiden (vgl. 2.2.24.3) versehen war. Die Peptide enthielten die Aminosäuresequenzen des SV40-T-Antigen-NLS oder des klassischen NLS von humanem H2B (siehe Ergebnisteil 3.5.2.2). HSA wurde als Trägerprotein verwendet, das eine Diffusion des Peptids in den Zellkern verhindert. Fluoreszenzmarkiert und mit einem NLS-Peptid als funktionelles Kern-LokalisationsSignal gekoppelt, wurde es in dem in vitro Importassay eingesetzt.

Als Kompetitoren dienten nicht markierte Histone $\mathrm{H} 1, \mathrm{H} 2 \mathrm{~A}, \mathrm{H} 2 \mathrm{~B}, \mathrm{H} 3$ und $\mathrm{H} 4$ sowie SV40-T-Antigen-NLS mit der wildtyp- bzw. mutierten Sequenz als synthetische Peptide, gekoppelt an nicht-markiertes HSA.

\subsubsection{Peptidsynthese}

Die synthetischen Peptide SV40-T-antigen-wtNLS (Cys-Tyr-Thr-Pro-Pro-Lys-Lys-LysArg-Lys-Val) SV40-T-antigen-mutNLS (Cys-Tyr-Thr-Pro-Pro-Lys-Thr-Lys-Arg-Lys-Val) wurden durch Festphase-FMOC-Synthese hergestellt und mit RP-HPLC (Säule: C18RP; Detektor: UV 210 nm; Gradient: linearer Gradient von 0-83 \% Trifluoressigsäure in $90 \%$ Acetonitril in 37,5 min; Flußrate $1 \mathrm{ml} / \mathrm{min}$ ) aufgereinigt, anschließend lyophilisiert und bei $-20^{\circ} \mathrm{C}$ gelagert. Die Präparation der Peptide wurde vom Service-Labor der Abt. Biochemie II (Universität Göttingen) durchgeführt.

Das Peptid mit der Aminosäuresequenz (Cys-Thr-Thr-Pro-Pro-Lys-Lys-Arg-Lys-ArgSer-Arg-Lys-Val) für das klassische NLS von H2B (siehe Ergebnisteil, 3.5.2.2) wurde von der Firma Jerini Biotools (Berlin) hergestellt. 


\subsubsection{Fluoreszenzmarkierung}

Als Fluoreszenzreagenzien wurden TRITC (Tetramethylrhodaminisothiocyanat), FITC (Fluoreszeinisothiocyanat), Alexa ${ }^{\mathrm{TM}} 488$ oder Alexa ${ }^{\mathrm{TM}} 546$ verwendet. Die Fluoreszenzfarbstoffe TRITC und FITC binden kovalent über die reaktiven Thiocyanatgruppen, die Alexa-Reagenzien über Succinimidylgruppen an die primären Aminogruppen des Proteins. Durch UV-Anregung emittiert dieser Farbstoff eine rote Fluoreszenz im Falle von TRITC und Alexa $^{{ }^{\mathrm{M} M}} 546$ oder eine grüne Fluoreszenz im Falle von FITC und Alexa ${ }^{\mathrm{TM}} 488$. HSA wurde vor der Kopplung des SV40-wt-NLS-Peptids zuerst fluoreszenzmarkiert, um eine Maskierung des NLS mit dem Farbstoff zu verhindern.

Fluoreszenzfarbstoffe und fluoreszenzmarkierte Proteine wurden stets vor Lichteinwirkung geschützt, um eine Ausbleichung zu verhindern.

\subsection{TRITC- bzw. FITC-Markierung von HSA und H1}

Reagenzien:

TRITC bzw. FITC-Stammlösung:

$1 \mathrm{mg} / \mathrm{ml}$ in DMSO

(vor Gebrauch frisch angesetzt)

Konjugationspuffer:

$0,1 \mathrm{M} \mathrm{Na} \mathrm{CO}_{3}$

$0,1 \mathrm{M} \mathrm{NaHCO} 3, \mathrm{pH} 9,0$

$50 \mathrm{mM} \mathrm{NaCl}$

Sephadex-G50 in PBS

Na-Borat-Puffer:

$50 \mathrm{mM}, \mathrm{pH} 7,6$

Ammoniumchlorid:

$1 \mathrm{M}$

HSA

H1 (aus Kalbsthymus

Centricon C30

Gelfiltrationssäulen

PBS (vgl.2.2.12)

Eine Lösung von $2 \mathrm{mg} \mathrm{HSA}$ in $2 \mathrm{ml}$ Konjugationspuffer wurde mit $50 \mu \mathrm{l}$ der TRITCStammlösung versetzt und für 3 Stunden bei RT langsam rotiert. Anschließend wurden $200 \mu \mathrm{l}$ Ammoniumchlorid-Lösung hinzugegeben und für weitere $20 \mathrm{~min}$ inkubiert. Danach wurde freies TRITC durch Gelfiltration über eine Sephadex-G50 Säule 
abgetrennt. Dazu wurde Sephadex-G50 in Na-Borat-Puffer gequollen, bis eine gelartige Masse entstand. Diese wurde in eine Gelfiltrationsäule gefüllt, bis sie ein Volumen von $5 \mathrm{ml}$ eingenommen hatte. Die Säule wurde mit $20 \mathrm{ml}$ Na-Borat-Puffer äquilibriert. Anschließend wurde der Reaktionsansatz langsam auf die Säule gegeben. Nachdem die Probe in die Matrix eingeflossen war, wurde mit dem Borat-Puffer nachgewaschen. Da die Protein-TRITC-Konjugate die Matrix schneller passieren als freies TRITC, konnte so überschüssiger Farbstoff abgetrennt werden. Die Probe wurde in 0,5 ml Fraktionen gesammelt und durch SDS-PAGE analysiert. Proteinhaltige Fraktionen wurden vereinigt und mit Centricon C30 bis auf ein Volumen von $200 \mu \mathrm{l}$ eingeengt. Der Grad der Markierung, d.h. das Verhältnis von Fluoreszenzfarbstoff zu Protein, wurde durch Bestimmung der Absorption bei $575 \mathrm{~nm}$ (Rhodamin) und $280 \mathrm{~nm}$ (Protein) abgeschätzt. Das Absorptionsverhätnis sollte zwischen 0,3 und 0,7 liegen. Die Probe wurde über Nacht gegen $\mathrm{H}_{2} \mathrm{O}$ dialysiert und anschließend für die Peptidkopplung (vgl. 2.2.24.3) eingesetzt.

Für die Kopplung mit dem H2B-NLS-Peptid wurde HSA mit FITC markiert. Die Durchführung verlief analog zur TRITC-Markierung.

Die Markierung von H1 mit TRITC wurde entsprechend verfahren, jedoch wurden nur $500 \mu g$ Protein eingesetzt. Die Menge der verwendeten Reagenzien wurde entsprechend verringert.

\subsection{Fluoreszenzmarkierung von H2B mit Alexa ${ }^{\mathrm{TM}}$ Protein Labeling-Kit}

Die Alexa ${ }^{T M}$-Farbstoffe sind Rhodaminderivate, die sich von diesem durch ihre erhöhte Hydrophilie unterscheiden. Sie werden wie TRITC an primäre Aminogruppen des Proteins gebunden; die Kopplung erfolgt allerdings über ein Succinimidyl-Ester. Verwendet wurden Alexa $^{\mathrm{TM}} 488$ und Alexa ${ }^{\mathrm{TM}} 546$.

Reagenzien:

vom Hersteller mitgeliefert:

$\mathrm{NaHCO}_{3}$-Lösung

Hydroxylamin-Lösung

Alexa $^{\mathrm{TM}}$-Fluoreszenzfarbstoff

Reaktionsgefäß mit Rührkern

$\mathrm{H} 2 \mathrm{~A}, \mathrm{H} 2 \mathrm{~B}, \mathrm{H} 3$ und $\mathrm{H} 4$

(aus Kalbsthymus) $\quad 500 \mu \mathrm{g} / \mathrm{ml}$ in $\mathrm{H}_{2} \mathrm{O}$ 
Durchführung:

Zur Fluoreszenzmarkierung wurde eine Lösung von $500 \mu \mathrm{g} \mathrm{H} 2 \mathrm{~B}$ in $500 \mu \mathrm{H}_{2} \mathrm{O}$ mit $50 \mu \mathrm{l} 1 \mathrm{M}$ Bicarbonatlösung versetzt und anschließend in das Reaktionsgefäß gegeben. Nach 1 h Rühren bei Raumtemperatur wurde die Reaktion durch Zugabe von $15 \mu$ Hydroxylamin-Lösung gestoppt. Das fluoreszenzmarkierte Produkt wurde anschließend durch Gelfiltration gereinigt.

\subsubsection{Peptidkopplung von HSA-TRITC mit dem SV40-wt-NLS-Peptid über Sulfo-SMCC}

Nachdem HSA mit TRITC markiert war, konnte dieses Konjugat mit dem SV40-NLSwtPeptid gekoppelt werden. Die Kopplung wurde mit dem heterobifunktionellen Crosslinker Sulfo-SMCC (Sulfosuccinimidyl-4-N-maleimidomethylcyclohexan-1carboxylat) durchgeführt. Seine reaktiven Sulfosuccinimidylestergruppen reagieren bei pH 7 mit den primären Aminen des Proteins unter Ausbildung einer Peptidbindung. Das entstehende maleimidaktivierte Protein reagiert schnell mit Thiolgruppen des reduzierten Peptids, aber nur sehr langsam mit anderen funktionellen Gruppen.

Reagenzien:

TRITC- bzw. FITC-markiertes HSA:

ca. $4 \mathrm{mg}$

Sulfo-SMCC

Gelfiltrationssäule

Na-Phosphatpuffer:

$0,1 \mathrm{M}, \mathrm{pH} 7.0$

Sephadex-G25

$\beta$-Mercaptoethanol:

$0,1 \mathrm{M}$

Transportpuffer (vgl. 2.1.12)

Tris $/ \mathrm{HCl}$

$50 \mathrm{mM}, \mathrm{pH} 7,0$

Centricon C30

$1 \mathrm{mg}$ Crosslinker Sulfo-SMCC wurden in $200 \mu \mathrm{H} \mathrm{H}_{2} \mathrm{O}$ gelöst und mit $4 \mathrm{mg}$ HSA-TRITC für $45 \mathrm{~min}$ bei $37^{\circ} \mathrm{C}$ unter Rotieren inkubiert. Überschüssiges Crosslinking-Reagenz wurde durch Gelfiltration abgetrennt (Säule: $5 \mathrm{ml}$ Sephadex-G25 in NaPhosphatpuffer). Die Fraktionen wurden zu $500 \mu \mathrm{l}$ gesammelt. Fluoreszierende Fraktionen wurden vereinigt. Zur Peptidkopplung wurde eine Lösung von 2 mg Peptid in $200 \mu$ l Tris-Puffer hinzupipettiert und über Nacht bei $4^{\circ} \mathrm{C}$ rotiert. Anschließend wurden $5 \mu \mathrm{l} \beta$ - 
Mercaptoethanol hinzugegeben und für weitere $20 \mathrm{~min}$ bei RT inkubiert. Das Reaktionsgemisch wurde mit Centricon C30 auf ein Volumen von $200 \mu$ in der Zentrifuge eingeengt und gegen Transportpuffer dialysiert. Das Reaktionsprodukt wurde durch SDS-PAGE analysiert.

\subsubsection{Expression und Aufreinigung der Transportfaktoren}

Die Plasmid-DNA für die Transportfaktoren Importin $\alpha$, Importin $\beta$, Importin5, Importin7 und Transportin waren freundlicher Weise von Dr. Görlich (Heidelberg) zur Verfügung gestellt worden und wurden in die entsprechenden en $E$. coli-Stämme transformiert (vgl. 2.2.1.3):

Reagenzien:

Puffer A:

Puffer B:

Waschpuffer

Elutionspuffer1:

Elutionspuffer2:

GT-Elutionspuffer

IPTG-Lösung

$2 \mathrm{YT}_{\mathrm{AMP}}-$ Medium

$2 \mathrm{YT}_{\mathrm{AMP}}$-Medium $+2 \%$ Glukose

LB $_{\text {AMP }}$-Medium (vgl. 2.1.11)

Ni-NTA-Agarose
$50 \mathrm{mM} \mathrm{Tris/HCl} \mathrm{pH} \mathrm{7,5}$

$500 \mathrm{mM} \mathrm{NaCl}$

$5 \%(v / v)$ Glycerin

$2 \mathrm{mM} \beta$-Mercaptoethanol

$2 \mathrm{mM}$ PMSF

$50 \mathrm{mM}$ Tris/ $\mathrm{HCl} \mathrm{pH} \mathrm{7,5}$

$200 \mathrm{mM} \mathrm{NaCl}$

$5 \%(\mathrm{v} / \mathrm{v})$ Glycerin

2 mM DTT

$2 \mathrm{mM} \mathrm{MgCl}_{2}$

Puffer A + 20 mM Imidazol

Puffer $A+100$ mM Imidazol

Puffer A + 150 mM Imidazol

$50 \mathrm{mM} \mathrm{Tris} / \mathrm{HCl} \mathrm{pH} \mathrm{8,0}$

$10 \mathrm{mM}$ Glutathion (reduzierte Form)

$1 \mathrm{M}$ 
Importino:

Expression des Proteins:

$400 \mathrm{ml} 2 \mathrm{YT}_{\mathrm{Amp}}$ wurden mit einer $15 \mathrm{ml}$ Übernachtkultur von Importin $\alpha$ angeimpft und bei $37^{\circ} \mathrm{C}$ bis zu einer $\mathrm{OD}_{600}$ von 0,6 inkubiert. Anschließend wurden $800 \mu \mathrm{l}$ IPTGLösung zugegeben und weitere $3 \mathrm{~h}$ bei $30^{\circ} \mathrm{C}$ inkubiert. Die Zellen wurden sedimentiert $(15 \mathrm{~min} 4000 \times \mathrm{g})$, in Puffer A resuspendiert und in flüssigem Stickstoff eingefroren.

\section{Aufreinigung des Proteins:}

Die Bakteriensuspension wurde aufgetaut und nach Sonifizieren (4 x $10 \mathrm{sec}$, Amplitude: $46 \%$ ) 30 min bei $10.000 \times$ g zentrifugiert. Der Überstand wurde mit $500 \mu \mathrm{l}$ Ni-NTA-Agarosesuspension versetzt, die zuvor mit Puffer A äquilibriert worden war, und $2 \mathrm{~h}$ bei $4^{\circ} \mathrm{C}$ unter Rotieren inkubiert. Anschließend wurde bei $400 \mathrm{x}$ g sedimentiert, der Überstand verworfen und das Sediment zweimal mit Puffer A gewaschen. Nach einem weiteren Zentrifugationsschritt bei $400 \times \mathrm{g}$ wurde das proteinhaltige Ni-NTAAgarose-Sediment mit $500 \mu \mathrm{l}$ Waschpuffer resuspendiert und $10 \mathrm{~min}$ bei $4^{\circ} \mathrm{C}$ rotiert. Zur Elution des gebundenen Proteins wurde mit Elutionpuffer1 resuspendiert und 30 min bei $4^{\circ} \mathrm{C}$ inkubiert. Anschließend wurde bei $10.000 \times \mathrm{g}$ zentrifugiert, der proteinhaltige Überstand abgenommen und der Elutionsvorgang mit Elutionspuffer2 wiederholt. Die Überstände wurden $3 \mathrm{~h}$ gegen Puffer B dialysiert und in Aliquots von $50 \mu \mathrm{l}$ in flüssigem Stickstoff schockgefroren. Analyse erfolgte durch SDS-PAGE (vgl. 2.2.17). Man erhielt so etwa $200 \mu \mathrm{g}$ Importin $\alpha$.

Importin $\beta$ :

Eine $200 \mathrm{ml} 2 \mathrm{YT}_{\mathrm{Amp}}+2 \%$ Glukose Kultur von Importin $\beta$ wurde über Nacht bei $37^{\circ} \mathrm{C}$ bis zu einer $\mathrm{OD}_{600}$ von 1,2 wachsen gelassen. Anschließend gab man $600 \mathrm{ml} 2 \mathrm{YT}_{\mathrm{Amp}}$ ohne Glukose hinzu und inkubierte bei $37^{\circ} \mathrm{C}$, bis die Kultur eine $\mathrm{OD}_{600}$ von 0,9 erreichte. Durch Zugabe von $800 \mathrm{ml}$ eiskaltem LB $_{\text {Amp }}$ und $800 \mu \mathrm{l}$ IPTG-Lösung wurde die Proteinsynthese induziert und man ließ bei $21^{\circ} \mathrm{C}$ für weitere $4 \mathrm{~h}$ wachsen. Nach Zentrifugation bei $4.000 \times \mathrm{g}$ für $15 \mathrm{~min}$ wurde das Bakterienpellet in $40 \mathrm{ml}$ Puffer $\mathrm{A}$ resuspendiert und in flüssigem Stickstoff schockgefroren.

Die Aufreinigung des Proteins wurde analog zu Importin $\alpha$ durchgeführt. Man erhielt aus einer 1,6 I-Kultur etwa $350 \mu \mathrm{g}$ Importin $\beta$. 
Importin5 und Importin7:

Hier wurde die Expression und Aufreinigung analog Importin $\beta$ durchgeführt mit den beiden Unterschieden, daß die Expression bei $17^{\circ} \mathrm{C}$ und für höchstens $3 \mathrm{~h}$ erfolgte. Man erhielt aus einer 1,6 I-Bakterienkultur etwa $500 \mu \mathrm{g}$ Importin5 bzw. $200 \mu \mathrm{g}$ Importin7.

Transportin:

Expression und Aufreinigung erfolgten analog zu Importin $\alpha$. Man erhielt aus einer 400 ml-Kultur etwa $200 \mu \mathrm{g}$ Transportin.

\subsubsection{Expression und Aufreinigung von M9-GST}

Die Plasmid-DNA mit dem Gen für das Fusionsprotein aus GST und der M9-Domäne von hnRNPA1 wurde von Dr. Dreyfuss (Philadelphia, USA) zur Verfügung gestellt (Michael et al., 1995).

Die Expression in Echerichia coli erfolgte analog zur Methode, die für Importin $\alpha$ angewendet wurde (vgl. 2.2.25). Die gefrorene Bakteriensuspension wurde nach Auftauen sonifiziert (4 × $10 \mathrm{sec}$, Amplitude: 46\%) und anschließend mit $100 \mu \mathrm{l}$ Gluthathion-Agarose-Matrix versetzt, die zuvor mit Puffer A äquilibriert worden war. Man ließ $2 \mathrm{~h}$ bei $4^{\circ} \mathrm{C}$ rotieren, sedimentierte bei $2000 \times \mathrm{g}$ und verwarf den Überstand. Das Pellet wurde dreimal mit Puffer A gewaschen und zur Elution des Proteins von der Matrix anschließend mit $250 \mu \mathrm{l}$ GT-Elutionspuffer versetzt und $20 \mathrm{~min}$ bei $4^{\circ} \mathrm{C}$ unter Rotieren inkubiert. Nach erneutem Sedimentieren $(2000 \times \mathrm{g})$ wurde der proteinhaltige Überstand abgenommen und gegen Puffer B dialysiert. Anschließend wurde die Probe durch SDS-PAGE (vgl. 2.2.17) analysiert und in $50 \mu$ l-Aliquots in flüssigem Stickstoff schockgefroren. Man erhielt aus einer $400 \mathrm{ml}-K u l t u r$ etwa 0,8 mg Protein.

M9-GST wurde nicht fluoreszenzmarkiert. Die Detektion erfolgte durch Immunfluoreszenz (vgl. 2.2.22). 


\subsubsection{7 in vitro Import-Assay}

Der in vitro Importassay wurde für die verschiedene Experimente unter folgenden Bedingungen durchgeführt:

Standard-Assay: Die mit Digitonin behandelten Zellen wurden zusammen mit den Transportsubstrat, einem ATP-regenerierenden System und exogenem Zytosol inkubiert.

Inhibierungsexperiment: Durch Veränderung der Standardbedingungen, z.B. durch Zugabe bestimmter Substanzen, wurden Teile des Transportsystems inhibiert. Kompetitionsexperiment: Ein weiteres Kernprotein (nicht fluoszenzmarkiert!) wurde als Kompetitor im Überschuß hinzugegeben.

Rekonstitutionsexperiment: Exogenes Zytosol wurde ersetzt durch aufgereinigte Transportfaktoren.

\subsubsection{Standard-Assay}

Reagenzien:

Transportpuffer (vgl.2.1.12)

Digitonin:

Stammlösung: $20 \mathrm{mg} / \mathrm{ml}$ in DMSO

Permeabilisierungspuffer:

$40 \mathrm{mg} / \mathrm{ml}$ Digitonin in Transportpuffer

Einbettungsmedium (vgl. 2.1.12)

BSA-Lösung

$20 \mathrm{mg} / \mathrm{ml}$ in PBS

ATP regenerierendes System: (Energiemix)

ATP

GTP

Phosphokreatin

Kreatinkinase

Retikulozytenlysat als exogenes Zytosol:

Transportsubstrate (vgl. 2.2.24):
$20 \mathrm{mM}$

$20 \mathrm{mM}$

$100 \mathrm{mM}$

$400 \mathrm{U} / \mathrm{ml}$

$50 \mathrm{mg} / \mathrm{ml}$

$200 \mathrm{nM}-500 \mathrm{nM}$ (Endkonzentration)

SV40-T-Antigen-wt-NLS-HSA-TRITC

H2A-Alexa ${ }^{\mathrm{TM}} 546$

H2B-Alexa ${ }^{T M} 546$, H2B- Alexa $^{T M} 488$

H3-Alexa ${ }^{\mathrm{TM}} 546$, H3-Alexa ${ }^{\mathrm{TM}} 488$

H4-Alexa ${ }^{\mathrm{TM}} 488$

ctH1-TRITC (vgl. 2.2.24.2.1) 


\section{L23a-FLUOS (wurde in der Arbeitsgruppe präpariert, Marc Bäuerle, Diss. in Präp.) \\ M9-GST (vgl. 2.2.26) \\ IBB-FLUOS (wurde freundlicherweise von Dr. Görlich. Heidelberg zur Verfügung gestellt; Jäkel, Görlich, 1998)}

HeLa-Zellen (auf Glasplättchen gewachsen)

Gewebekulturschale mit 6 Vertiefungen

Glasplättchen (10mm Durchmesser)

Paraformaldehyd-Lösung

$3 \%(w / v)$ in PBS

Nagellack

Objektträger

Parafilm

Durchführung:

\section{Präparation der semiintakten Zellen und Zytosoldepletierung}

In einer mit sterilen Glasplättchen versehenden Vertiefung einer Ger Gewebekulturschale wurden $4 \times 10^{5}$ Zellen in $5 \mathrm{ml}$ MEM-Medium ausgesät. Nach einer Inkubationsdauer $\left(37^{\circ} \mathrm{C}, 5 \%(\mathrm{v} / \mathrm{v}) \mathrm{CO}_{2}\right)$ von etwa 48 Stunden wurde das KulturMedium abgesaugt und die Zellen zweimal mit $5 \mathrm{ml}$ kaltem Transportpuffer gewaschen. Danach wurden die Zellen mit $5 \mathrm{ml}$ kaltem Permeabilisierungspuffer für 5 min auf Eis inkubiert. Anschließend wurde dreimal mit kaltem Transportpuffer gewaschen. Für die Zytosoldepletierung wurden die Zellen für $10 \mathrm{~min}$ in Transportpuffer inkubiert, wobei nach 5 min erneut mit Transportpuffer gewaschen wurde. Nach einem abschließenden Waschschritt mit Transportpuffer waren die permeabilisierten Zellen bereit für die Transportreaktion.

\section{Zusammenpipettieren der Reaktionsansätze und Kerntransportinkubation}

Standard-Reaktionsansatz:

$1 \mu \mathrm{l}$ Transportsubstrat

$4 \mu \mathrm{l}$ Energiemix

$1 \mu \mathrm{l}$ BSA-Lösung

$10 \mu$ Retikulozytenlysat

$4 \mu \mathrm{l}$ Transportpuffer

Gesamtvolumen: $20 \mu \mathrm{l}$

Die mit permeabilisierten Zellen bedeckten Glasplättchen wurden auf Parafilm gelegt und vorsichtig von überschüssiger Flüssigkeit befreit. Der Reaktionsansatz wurde auf 
die Glasplättchen pipettiert und in einer feuchten Kammmer für 30 min bei $37^{\circ} \mathrm{C}$ inkubiert.

\section{Fixierung der Zellen}

Der Transportansatz wurde abgesaugt und die Zellen dreimal mit Transportpuffer gewaschen. Anschließend erfolgte die Fixierung der Zellen durch Zugabe von Paraformaldehyd-Lösung und einer Inkubation für 15 min bei RT. Nach 3 weiteren Waschvorgängen mit Transportpuffer wurden die Glasplättchen mit der bedeckten Seite auf jeweils etwa $20 \mu \mathrm{l}$ Einbettungsmedium gelegt, das zuvor auf einen Objektträger gegeben war. Überschüssiges Einbettungsmedium wurde abgesaugt und die Glasplättchen mit Nagellack versiegelt. Anschließend konnte die Detektion vorgenommen werden.

\section{Fluoreszenzdetektion}

Die verwendeten Importsubstrate waren mit einem Fluoreszenzfarbstoff versehen, der eine direkte Fluoreszenzdetektion ermöglichte. Die Detektion von M9-GST wurde allerdings durch Immunfluoreszenz durchgeführt (vgl. 2.2.22). Hierfür wurde ein monoklonaler Primärantikörper gegen GST (vgl. 2.1.6.1) sowie ein fluoreszenzmarkierter Sekundärantikörper verwendet.

Fluoreszenzfarbstoffe emittieren Licht einer spezifischen Wellenlänge, wenn sie in ihrem Anregungswellenlängenbereich bestrahlt werden. Für jeden Farbstoff gelten dabei spezifische Anregungs- und Emissionsmaxima ( $\lambda_{\mathrm{Abs}}$ bzW. $\left.\lambda_{\mathrm{Em}}\right)$. Diese sind:

$\lambda_{\mathrm{Abs}}=543 \mathrm{~nm} ; \lambda_{\mathrm{Em}}=575 \mathrm{~nm}$ für TRITC

$\lambda_{\text {Abs }}=494 \mathrm{~nm} ; \lambda_{\mathrm{Em}}=526 \mathrm{~nm}$ für FITC und FLUOS

$\lambda_{\text {Abs }}=494 \mathrm{~nm} ; \lambda_{\mathrm{Em}}=.519 \mathrm{~nm}$ für Alexa ${ }^{\mathrm{TM}} 488$

$\lambda_{\text {Abs }}=558 \mathrm{~nm} ; \lambda_{\mathrm{Em}}=.573 \mathrm{~nm}$ für Alexa ${ }^{\mathrm{TM}} 546$

$\lambda_{\mathrm{Abs}}=344 \mathrm{~nm} ; \lambda_{\mathrm{Em}}=450 \mathrm{~nm}$ für DAPI

Fluoreszenzmikroskope sind mit Filtern ausgestattet, die eine UV-Anregung sowie die Detektion im Bereich dieser Maxima ermöglichen. Auf diese Weise konnte die intrazelluläre Lokalisation der fluoreszenzmarkierten Transportsubstrate analysiert werden. DAPI ist ein Farbstoff, der spezifisch an DNA bindet und so den Zellkern in Zellen sichtbarmacht. Dies erleichterte bei der Detektion die Beurteilung der intrazellulären Lokalisation des Transportsubstrats. 


\subsubsection{Inhibierungsexperimente}

Für diese Experimente wurden die Komponenten für den Standard-Assay wie oben beschrieben zusammenpipettiert, die Zellen entweder entsprechend behandelt oder der jeweilige Hemmstoff hinzugefügt.

\section{Inkubation bei $4^{\circ} \mathrm{C}$}

Die Transportreaktion wurde wie beim Standard-Assay durchgeführt mit der Ausnahme, daß die Inkubation bei $4{ }^{\circ} \mathrm{C}$ durchgeführt wurde.

\section{WGA-Behandlung der Zellen}

Das Lektin Weizenkeimagglutin (WGA) bindet an die O-verknüpften NAcetylglucosaminreste von Nukleoporinen und hemmt so den Kerntransport, wenn dieser über eine Interaktion mit der Kernpore stattfindet.

Reagenzien:

WGA-Lösung

$50 \mu \mathrm{g} / \mathrm{ml}$ in Transportpuffer

Die semiintakten Zellen wurden vor der Transportreaktion mit einer WGA-Lösung für 15 min bei RT inkubiert. Danach wurden die Zellen dreimal mit Transportpuffer gewaschen, mit dem Transportansatz inkubiert und wie beim Standard-Assay weiterverfahren.

\section{ATP-Depletierung}

Reagenzien:

Apyrase

$2000 \mathrm{U} / \mathrm{ml}$

Der Energiemix im Transportansatz wurde durch $1 \mu$ Apyrase und $3 \mu$ Transportpuffer ersetzt und vor der Transportreaktion für $15 \mathrm{~min}$ auf Eis vorinkubiert. Die Zellen wurden mit diesem vorbehandelten Transportansatz wie unter 2. (s.o.) behandelt. 


\section{Zugabe der GTP-Analoga GMP-PNP bzw. GTPyS}

GMP-PNP und GTPyS können zwar von der GTPase Ran gebunden, aber nicht hydrolysiert werden.

Reagenzien:

Guanyl-imidodiphosphat (GMP-PNP): $\quad 20 \mathrm{mM}$

GTP $\gamma S \quad 20 \mathrm{mM}$

$1 \mu \mathrm{l}$ eines Nukleotidanalogons wurde zu dem $20 \mu \mathrm{l}$ Reaktionsansatz hinzugegeben.

\subsubsection{Kompetitionsexperimente}

Die entsprechenden Kompetitoren wurden in den angegebenen Konzentrationen zu dem Reaktionsansatz hinzugegeben. Dieser wurde 15 min auf Eis vorinkubiert und auf die Zellen pipettiert. Anschließend wurde standardmäßig weiterverfahren.

\subsubsection{Rekonstitutionsexperimente}

Bei diesen Experimenten wurde exogenes Zytosol als Transportsubstrat durch eine Kombination aus definierten Transportfaktoren wie angegeben ersetzt.

Der Transportansatz bestand aus folgenden Komponenten:

Transportsubstrat

Energiemix

Ran

NTF2

Transportfaktoren:

Transportpuffer ad $20 \mu \mathrm{l}$
200-500 nM (vgl. 2.2.24)

(vgl. 2.2.27.1)

$3 \mu \mathrm{M}$

$0,4 \mu \mathrm{M}$

Importino: $3 \mu \mathrm{M}$

Importin $\beta$ : $2 \mu \mathrm{M}$

Importin5 $3 \mu \mathrm{M}$

Importin7: $3 \mu \mathrm{M}$

Transportin: $2 \mu \mathrm{M}$ 


\section{ERGEBNISSE}

Karyophile Proteine üben ihre Funktion im Zellkern eukaryontischer Zellen aus, werden aber wie alle Proteine im Zytoplasma synthetisiert. Daher müssen sie zunächst vom Zytoplasma in den Zellkern gelangen und dabei die Kernmembran passieren, die den Kern umgibt und inn vom Zytoplasma abgrenzt. Der Austausch zwischen diesen beiden Kompartimenten findet ausschließlich durch die Kernporenkomplexe (NPC) statt, die in die Doppelmembran der Kernhülle eingebettet sind. Diese makromolekularen Proteinkomplexe ermöglichen einen Durchtritt kleiner Moleküle (bis 40-60 kDa) durch passive Diffusion; größere aber können auf diese Weise nur sehr langsam oder gar nicht in den Kern gelangen. Ihr Kerntransport erfordert Kernlokalisationsignale (NLS) zur Erkennung durch Transportrezeptoren, die den Übergang vom nukleären ins zytoplasmatische Kompartiment durch Interaktion mit dem Kernporenkomplex vermitteln.

\subsection{Charakterisierung des Importweges für Core-Histone}

Da Core-Histone mit molekularen Massen von $11 \mathrm{kDa}(\mathrm{H} 4)$ bis $15 \mathrm{kDa}(\mathrm{H} 3)$ wesentlich kleiner als das Ausschlußvolumen der Kernporenkomplexe von ca. 40-60 kDa sind, ist es theoretisch möglich, daß inr Transport in den Zellkern durch freie Diffusion und anschließender Bindung an nukleäre DNA zustande kommt (Paine, 1993). Für die etwas größeren $\mathrm{H} 1$-Histone (21 kDa) war aber bereits durch Mikroinjektionsuntersuchungen (Breeuwer und Goldfarb, 1990) und im in vitro Importassay (Kurz et al., 1997, Schwamborn et al., 1998, Jäkel et al., 1999) gezeigt worden, daß diese nicht in den Zellkern diffundieren, sondern energieabhängig und rezeptorvermittelt importiert werden. In $\mathrm{H} 2 \mathrm{~B}$ aus der Hefe Saccharomyces cerevisiae war durch in vivo Experimente mit Fusionskonstrukten aus Histon und $\beta$-Galaktosidase ein funktionelles NLS identifiziert worden (Moreland et al., 1987), was vermuten ließ, daß ein rezeptorvermittelter Prozeß auch am Kerntransport der Core-Histone beteiligt ist. Zunächst galt es herauszufinden, ob die Core-Histone tatsächlich rezeptorvermittelt oder durch freie Diffusion in den Kern gelangen. Die Experimente zur Untersuchung dieser Fragestellung wurden mit Hilfe des in vitro Importassays durchgeführt. 


\subsection{In vitro Importassay: Zytosolische Komponenten sind am Transport der Core-Histone in den Zellkern beteiligt}

Das Prinzip des in vitro Importassays besteht darin, daß durch eine selektive Permeabilisierung der Plasmamembran das Zytosol aus den Zellen ausgewaschen wird und semiintakte, zytosolfreie Zellen zurückbleiben. Die Permeabilisierung erfolgt durch Digitonin, ein nichtionisches Detergens, das die cholesterinreiche Plasmamembran perforiert, während die Kernmembran intakt bleibt. Auf diese Weise können Zellen selektiv von endogenem Zytosol befreit und exogene Komponenten zugeführt werden.

Diese semiintakten permeabilisierten Zellen stellen in zweierlei Hinsicht ein gutes Testsystem für Kerntransportstudien dar: Einerseits können sie mit fluoreszierenden Substraten beschickt werden, deren intrazelluläre Lokalisation anschließend durch Fluoreszenzmikroskopie untersucht werden kann (Adam et al., 1990). Andererseits erlauben sie die Untersuchung des Kerntransports von Substraten in Abhängigkeit von zytosolischen Komponenten oder aufgereinigten Transportfaktoren. Außerdem ist es möglich, die Auswirkung von Variationen der äußeren Bedingungen und von Zugaben verschiedener Substanzen (z.B. Kompetitoren) auf den Kerntransport zu untersuchen. Für den Transport eines Proteins in den Kern permeabilisierter Zellen sind verschiedene Voraussetzungen erforderlich: 1. ein detektierbares Protein, dessen Kerntransport untersucht werden soll (Substrat) 2. ein ATP-regenerierenden System, 3. Faktoren, die den Transport in den Kern vermitteln. Letztere können in Form von exogenem Zytosol (z.B. Zellextrakt, Retikulozytenlysat) als Quelle von Transportfaktoren eingesetzt werden. Alternativ kann der Transport durch Zugabe aufgereinigter Transportfaktoren rekonstituiert werden.

\subsubsection{Präparation der Importsubstrate}

Als Substrate für den in vitro Importassay dienen in der Regel Proteine, die entweder direkt fluoreszenzmarkiert oder aber indirekt durch Immunfluoreszenz nachweisbar sind. Als Kontrollsubstrat wurde zunächst ein synthetisches Substrat verwendet, das sich aus fluoreszenzmarkiertem humanem Serumalbumin (HSA) und einem chemisch daran gekoppelten Peptid zusammensetzte. Das Peptid enthielt das Kernlokalisationssignal (NLS) des T-Antigens des SV40-Virus mit der Aminosäuresequenz PKKKRKV. HSA wurde dabei als Trägerprotein verwendet, um 
unspezifische Diffusion des Peptids durch die Kernpore zu verhindern. Wegen seiner molekularen Masse von ca. 66 kDa und einem fehlenden NLS wird es vom Kern ausgeschlossen. Die Kernimportkompetenz erhält HSA durch die Kopplung an das NLS-Peptid. Das bereits gut untersuchte NLS (z.B. Moore und Blobel, 1992) wird vom Transportsystem erkannt und dirigiert das gesamte Hybridprotein in den Zellkern. Als Kompetitoren für Kompetitionsexperimente (vgl. 3.5.1) wurden das SV40-wt-NLS sowie eine importdefiziente mutierte Variante (SV40-mut-NLS, Moore und Blobel, 1992) an nicht markiertes HSA gekoppelt. Das mutierte NLS bestand aus der Sequenz PKTKRKV, es enthielt an Position 3 statt des Lysins ein Threonin.

Die Peptide wurden von Mitarbeitern des Instituts durch automatisierte Festphasensynthese hergestellt. Dabei wurde für eine gerichtete Kopplung des Peptids an das Trägerprotein zusätzlich ein Cystein angehängt, das mit seiner Mercaptogruppe die Ausbildung einer kovalenten Bindung über einen Crosslinker ermöglicht (vgl. 2.2.24.3). Außerdem waren zwischen Signalsequenz und Cystein noch weitere Aminosäuren enthalten, die als Spacer den Zugang zum NLS und damit seine Effizienz erhöhen sollten. Die Gesamtpeptide bestanden aus folgenden Aminosäuresequenzen:

SV40-wt-NLS: CYTPPKKKRKV; importkompetent

SV40-mut-NLS: CYTPPKTKRKV; importdefizient

HSA wurde wie unter 2.2.24.2 beschrieben mit dem Fluoreszenzfarbstoff TRITC umgesetzt. Dieser Farbstoff verfügt über die reaktive Isothiocyanatgruppe, die selektiv mit Aminogruppen des Proteins reagiert.

Das HSA-TRITC-Konjugat wurde durch Gelfiltration mit Sephadex-G25 von nicht umgesetzten Farbstoff befreit und anschließend in die nachfolgende Peptidkopplung mit SMCC eingesetzt.

Für die Kopplung des Peptids an HSA wurde Sulfo-SMCC, ein wasserlösliches heterobifunktionelles Crosslink-Reagenz, verwendet. Dieses enthält als reaktive Bestandteile einen Succinimidylester sowie ein Maleimid, die beide über einen Cyclohexanring miteinander verbunden sind. Der Crosslinker wurde zunächst mit HSA umgesetzt, wobei der Succinimidylester des Crosslinkers mit den primären Aminogruppen des Proteins unter Ausbildung einer Amidbindung reagiert. Das so modifizierte Protein wurde durch Gelfiltration vom überschüssigen Crosslinker befreit und im nächsten Schritt mit dem NLS-Peptid umgesetzt. Dieses reagierte über die Mercaptogruppe des in der Aminosäuresequenz des Peptids enthaltenen Cysteins mit 
dem Maleimid des eingeführten Crosslinkers zum gewünschten Produkt Kopplungsprodukt aus HSA und Peptid. Überschüssiges Peptid wurde erneut durch Gelfiltration entfernt. Die so erhaltenen SV40-NLS-HSA-TRITC-Konjugate wurden anschließend auf einem SDS-Gel analysiert. Wie in Abb. 5 zu erkennen, war das

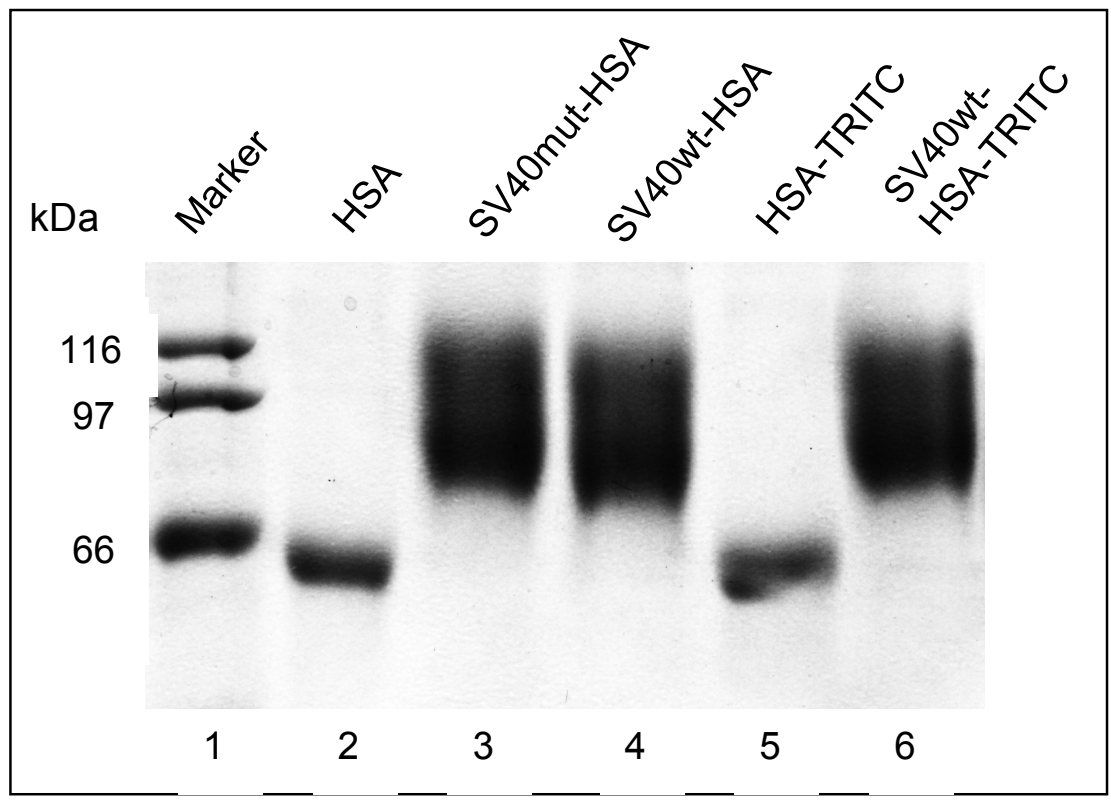

Abb. 5: Analyse der NLS-HSA-Konjugate. Dargestellt ist die Coomassie-Färbung eines SDSPolyacrylamid-Gels (10\%). Je Spur sind ca. 2 bzw. $10 \mu \mathrm{g}$ Protein aufgetragen. Spur 1: Proteinmarker; 2: HSA (nicht modifiziert); 3: SV40-wt-NLS-HSA; 4: SV40-mut-NLS-HSA; 5: HSA-TRITC; 6: SV40-wt-NLS-HSA-TRITC.

Laufverhalten des mit Peptiden modifizierten HSA stark verändert: Während HSA und HSA-TRITC relativ scharfe Banden zeigten, bildeten die HSA-PeptidKopplungsprodukte jeweils ein diffuses, stark verbreitertes Signal. Aus der Laufstrecke und der Bandenbreite ließ sich entnehmen, daß eine variable Anzahl von etwa 10-40 Peptiden pro HSA-Molekül gebunden hatte.

Die HSA-Konjugate stellten rein synthetische Moleküle, ohne physiologische Bedeutung, dar. Ihre Funktionalität und Spezifität bei der Untersuchung von Kerntransportprozessen in vitro und in vivo war aber in verschiedenen Arbeiten gezeigt worden (Goldfarb et al., 1986, Moore und Blobel, 1992).

Die Core-Histone $\mathrm{H} 2 \mathrm{~A}, \mathrm{H} 2 \mathrm{~B}, \mathrm{H} 3$ und $\mathrm{H} 4$ wurden mit Alexa ${ }^{\mathrm{TM}}$-Farbstoffen fluoreszenzmarkiert, die sich von Rhodamin ableiten, aber durch zusätzliche polare Gruppen hydrophiler sind. Über ein Succinimid können die Alexa ${ }^{{ }^{T M}}$-Farbstoffe an die Aminogruppen des Proteins gekoppelt werden. 


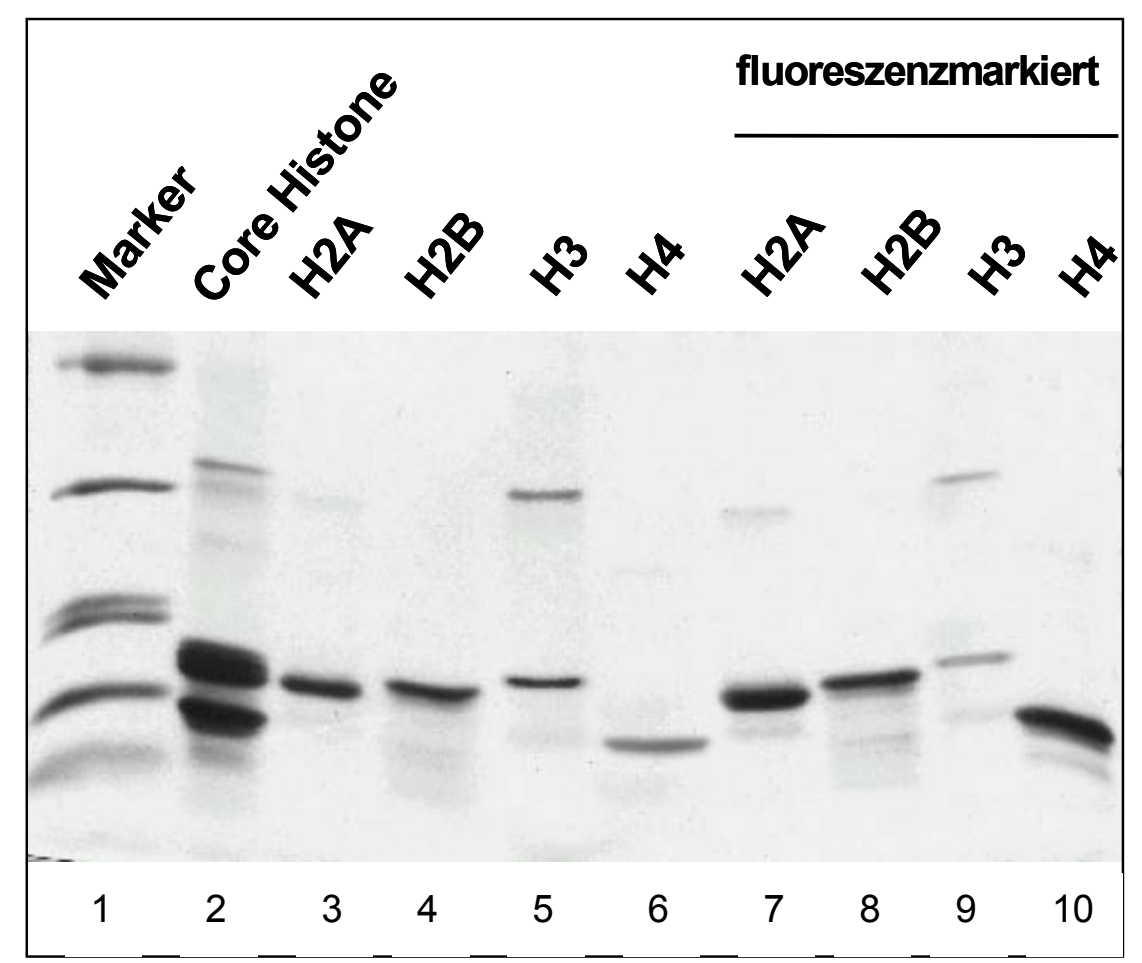

Abb. 6: Analyse der fluoreszenzmarkierten Core-Histone. Fluoreszenzmarkierte und nicht modifizierte Core-Histone wurden auf einem SDS-Polyacrylamid-Gel (15\%) analysiert. Zu erkennen ist die Coomassie-Färbung der Proteine. Pro Spur wurden ca. $2 \mu \mathrm{g}$ Protein aufgetragen. Spur1: Proteinmarker; 2: Core-Histone H2A, H2B, H3, H4; 3: H2A; 4: H2B; 5: H3; 6: H4; 7: H2A-TRITC; 8: H2B-TRITC; 9: H3-TRITC; 10: H4-TRITC

Die Reaktion wurde wie unter 2.2.24.2.2 durchgeführt. Abb. 6 zeigt die gelelektrophoretische Analyse der Markierungsprodukte.

\subsubsection{Fluoreszenmarkierte Core-Histone als Transportsubstrate im in vitro Importassay}

Die fluoreszenzmarkierten Substrate wurden im in vitro Importassay eingesetzt. Für die Transportreaktion unter Standardbedingungen wurden permeabilisierte HeLaZellen mit etwa $500 \mathrm{nM}$ Transportsubstrat, Retikulozytenlysat als exogene Zytosolquelle und einem ATP-regenerierenden System 30 min bei $37^{\circ} \mathrm{C}$ inkubiert. 
In Abb. 7 sind Fluoreszenzbilder der Experimente im in vitro Importassay mit den Substraten dargestellt. Wie zu erkennen, akkumulierte das SV40-NLS-HSA-TRITC-

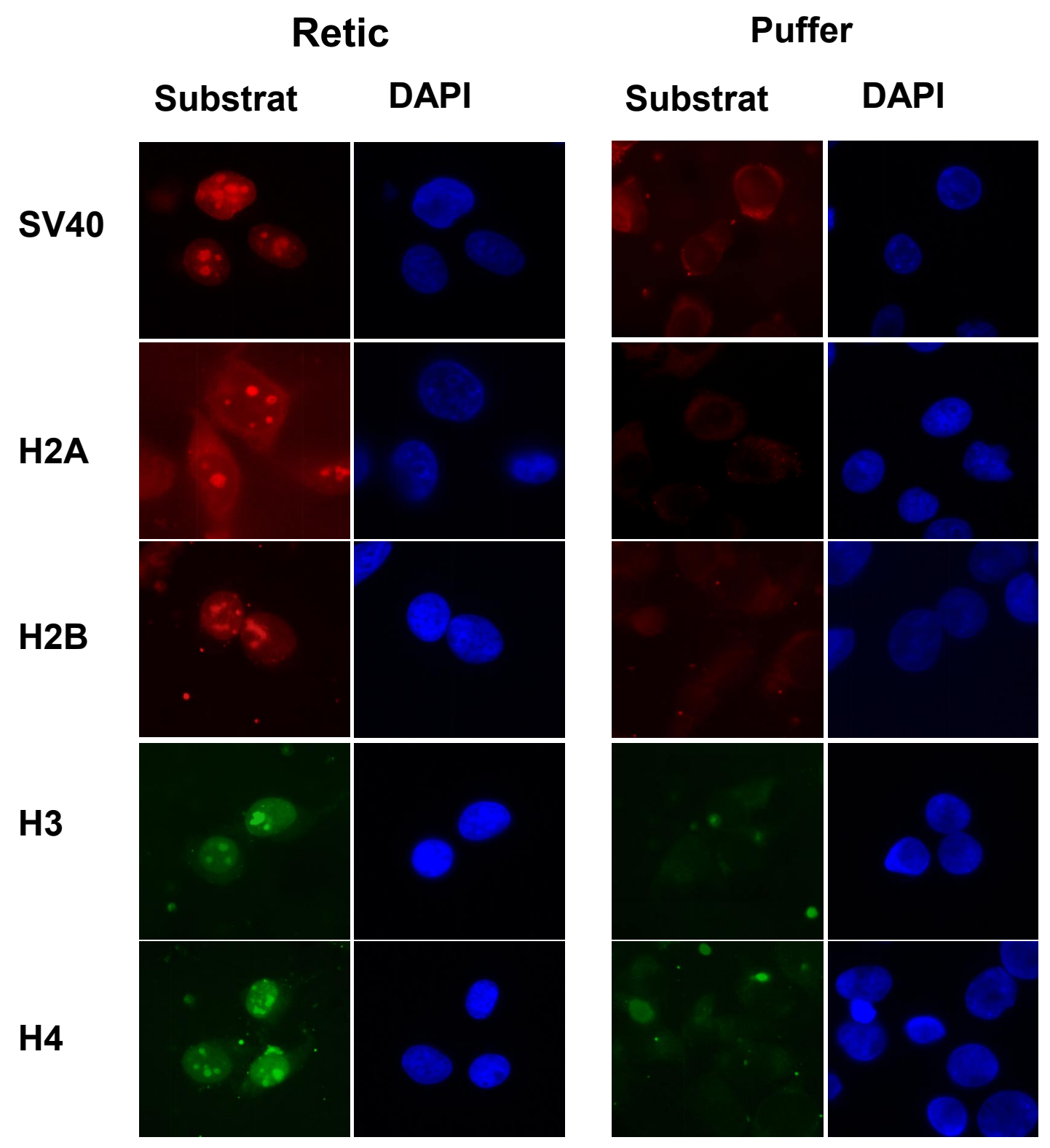

Abb. 7: In vitro Importassay mit fluoreszenzmarkierten Substraten: Dargestellt sind die Fluoreszenzen der Substrate (wie angegeben) sowie jeweils die DAPI-Färbung der nukleären DNA der permeabilisierten HeLa-Zellen. Diginonin-permeabilisierte HeLa-Zellen wurden mit fluoreszenzmarkierten Core-Histonen bzw. Kontrollsubstrat, und einem Energieregenerierenden System für $30 \mathrm{~min}$ bei $37^{\circ} \mathrm{C}$ inkubiert. Die Transportreaktion wurde mit Retikulozytenlysat als exogenes Zytosol (Retic) oder ohne Zytosol (Puffer) durchgeführt.

Konjugat unter Standardbedingungen vollständig in den Zellkernen der permeabilisierten Zellen. Die Position der Zellkerne wurde durch den spezifischen DNA-Farbstoff DAPI sichtbar gemacht. Die Core-Histone H2B, H3 und H4 verhielten 
sich untereinander ähnlich, ihre Fluoreszenz war eindeutig in den Zellkernen detektierbar. Im Fall von H2A war auch ein großer Fluoreszenzanteil im Zytoplasma erkennbar, die stark gefärbten Nukleoli zeigten aber an, daß ein signifikanter Anteil des Proteins in den Kern transportiert worden war. Dieser unvollständige Kerntransport war bei den Core-Histonen häufig zu beobachten, wobei sich unterschiedliche Präparationen der fluoreszenzmarkierten Produkte in ihrer Importrate unterschieden. Möglicherweise wurden durch die Kopplung des Farbstoffs an Lysine und Arginine der Proteine potentielle Kernlokalisationssignale teilweise maskiert.

Interessanterweise akkumulierten die Core-Histone vorwiegend in den Nukleoli. Erklären läßt sich dieses Phänomen dadurch, daß die Core-Histone im Interphase Chromatin der permeabilisierten HeLa-Zellen nicht ins Chromatin eingebaut werden können, da Nukleosomen nur in der S-Phase gebildet werden. Aus diesem Grund binden sie bevorzugt an ribosomale RNA, die sich im Nukleolus befindet.

Wurde die Transportreaktion in Abwesenheit von exogenem Zytosol durchgeführt, während alle übrigen Bedingungen konstant gehalten wurden, so war zu beobachten, daß alle Substrate außerhalb des Zellkerns im Zytoplasma verblieben. Die Fluoreszenz war dabei allerdings teilweise nur sehr schwach oder gar nicht erkennbar. Dies ist darauf zurückzuführen, daß während der Waschschritte des Importassays das Substrat aus dem extranukleären Bereich ausgewaschen wurde. Dieser Effekt war bereits in anderen Arbeiten für verschiedene Proteine beobachtet worden (Schwamborn et al., 1998, Pollard et al, 1996). Durch die Detektion der Zellkerne mittels DAPI-Färbung war es aber stets möglich, die Position der Zellkerne zu bestimmen. Eine fehlende Fluoreszenz konnte daher einem Ausbleiben des Transports in den Zellkern der permeabilisierten Zellen gleichgesetzt werden. Darüber hinaus sei an dieser Stelle bemerkt, daß die digitale Verwertung der fluoreszenzmikroskopischen Aufnahmen mit einem Verlust an Auflösung der zu dokumentierenden Fluoreszenz verbunden ist, so daß in mehreren Fällen eine Abschwächung gegenüber dem im Mikroskop beobachteten Befund resultierte.

Die Beobachtung, daß die Substrate in Anwesenheit, aber nicht in Abwesenheit von exogenem Zytosol in den Zellkern transportiert wurden, ließ den Schluß zu, daß der Kerntransport sowohl des Kontrollsubstrats als auch der Core-Histone von löslichen zytosolischen Komponenten abhängig ist. Die Funktion dieser Komponenten blieb aber zunächst unbekannt. Es konnte sich hierbei aufgrund der Daten mit dem NLSKontrollsubstrat um Importfaktoren wie Importine handeln. Denkbar war aber auch, daß die zytoplasmatische Retention der Core-Histone in Abwesenheit von exogenem 
Zytosol durch Bindung an Zytoskelettstrukturen zustande kommt, die erst bei Zugabe von Retikulozytenlysat durch Interaktion von Core-Histon bindenden Faktoren (z.B. NAP-1, Ito et al., 1996) gelöst wird. Dagegen sprach aber die Beobachtung, daß die fluoreszierenden Histone in vielen Fällen ausgewaschen wurden.

\subsection{Inbierungsexperimente: Der Kerntransport der Core-Histone ist ein aktiver, rezeptorvermittelter Prozeß}

Die oben gezeigte Abhängigkeit des Core-Histon-Kerntransports von löslichen zytosolischen Komponenten ließ vermuten, daß die Core-Histone nicht durch einen passiven Diffusionsvorgang in den Zellkern gelangen. In den folgenden Experimenten sollten daher weitere Charakteristika des Transports von Core-Histonen in den Zellkern untersucht werden.

Dazu wurde der Einfluß verschiedener inhibitorischer Bedingungen auf den Import betrachtet:

In Abb. 8 sind zunächst die Kontrollexperimente, mit und ohne Retikulozytenlysat als exogene Zytosolquelle gezeigt. Diese Kontrollen wurden bei allen in vitro Importexperimenten parallel durchgeführt, um die Spezifität des Assays zu kontrollieren. Unter Standardbedingungen wurden die Histone und SV40-NLS-Substrat in den Zellkern importiert, ohne Retikulozytenlysat fand kein Transport statt.

Um den Einfluß der Temperatur auf den Kerntransport zu untersuchen, wurde die Transportreaktion nicht bei der Standardtemperatur von $37^{\circ} \mathrm{C}$, sondern bei $4^{\circ} \mathrm{C}$ durchgeführt.

Dabei konnte beobachtet werden, daß die Substrate im Zytoplasma verblieben, der Import also inhibiert wurde. Diese strenge Temperaturabhängigkeit ließ sich nicht allein durch einen passiven Diffusionsvorgang der Histone erklären. Zwar ist Diffusion auch ein temperaturabhängiger Vorgang, aber innerhalb der Inkubationszeit wäre auch bei $4^{\circ} \mathrm{C}$ eine Diffusion des Substrats zu erwarten gewesen.

Im nächsten Experiment wurde untersucht, inwiefern der Kerntransport der CoreHistone direkt energieabhängig ist. Hierfür wurde in der Transportreaktion das ATP- 


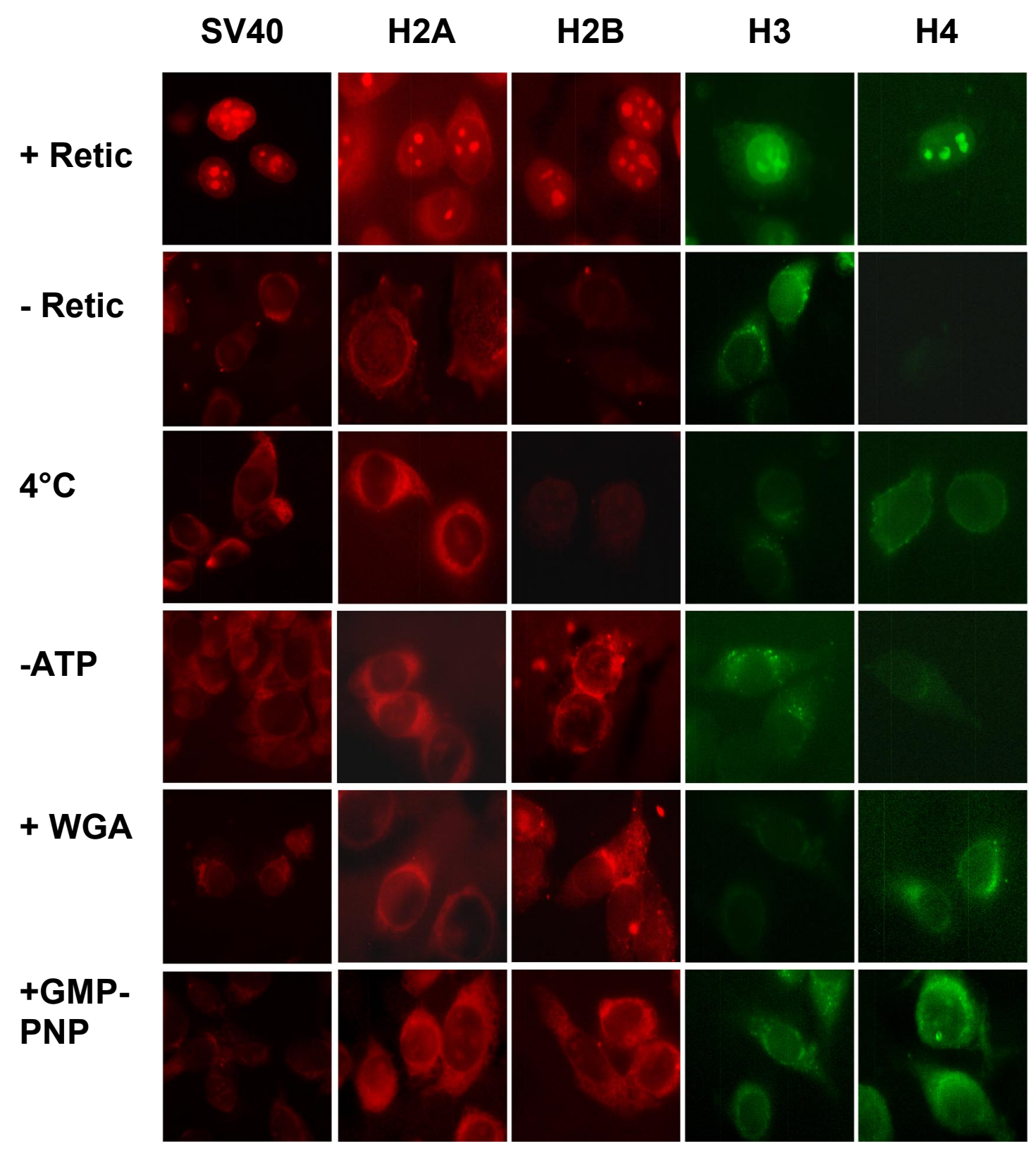

Abb. 8. Zusammenfassung der Inhibierungsexperimente: Der Kerntransport der vier CoreHistone $\mathrm{H} 2 \mathrm{~A}, \mathrm{H} 2 \mathrm{~B}, \mathrm{H} 3$ und $\mathrm{H} 4$ wurde unter verschieden inhibitorischen Bedingungen untersucht. Diginonin-permeabilisierte HeLa-Zellen wurden mit fluoreszenzmarkierten CoreHistonen, Retikulozytenlysat und einem Energieregenerierenden System für $30 \mathrm{~min}$ bei $37^{\circ} \mathrm{C}$ inkubiert (Standardbedingungen, siehe erste Zeile). In der zweiten bis fünften Zeile sind die Resultate der verschiedenen vom Standard veränderten Bedingungen gezeigt: Retikulozytenlysat ersetzt durch Transportpuffer (-Retic), Inkubation bei $4{ }^{\circ} \mathrm{C}$, ATPregenerierenden System ersetzt durch Puffer und Zellen mit Apyrase behandelt (-ATP), Vorinkubation der permeabilisierten Zellen mit WGA, Inkubation in Anwesenheit von GMPPNP. 
regenerierende System durch Puffer ersetzt und endogenes ATP durch Apyrasezusatz hydrolysiert. Auch hier ließ sich keine Fluoreszenzfärbung im Zellkern erkennen. Dies ließ den Schluß zu, daß der Kerntransportprozeß neben der Temperaturabhängigkeit auch eine Energieabhängigkeit besitzt. Anschließend wurde untersucht, ob der Transportweg eine Interaktion mit der Kernpore verlangt. Das Lektin WGA (Wheat Germ Agglutinin) bindet spezifisch an Proteine des Kernporenkomplexes (Davis und Blobel, 1986) und verhindert so die Translokation durch die Kernpore sofern dafür die Interaktion mit Nukleoporinen erforderlich ist. Passive Diffusion wird dabei nicht oder nur geringfügig beeinflußt (Finlay et al., 1987). Wie in Abb. 8 gezeigt, wurde der Import der Core-Histone durch Zugabe von WGA inhibiert, da in keinem der Fälle eine Fluoreszenz im Kern detektierbar war. Dies war ein Hinweis darauf, daß der Kerntransport der Core-Histone über Bindung an Nukleoporine verläuft und kein passiver Diffusionsprozeß ist.

Da bereits bekannt war, daß an vielen Kerntransportprozessen die kleine GTPase Ran beteiligt ist (Moore und Blobel, 1993, Melchior et al., 1993, Moore et al., 1998), wurde im nächsten Experiment untersucht, inwiefern die Hydrolyse von GTP auch für den Kerntransport von Core-Histonen von Bedeutung ist. Hierfür wurden die nicht spaltbaren GTP-Analoga GMP-PNP bzw. GTP $\gamma S$ zu der Transportreaktion hinzugegeben. Diese Analoga werden zwar von einer GTPase gebunden, können aber nur sehr langsam von ihr hydrolysiert werden. Da keine Fluoreszenz im Kern beobachtet werden konnte, ließ sich schlußfolgern, daß der Kerntransport der CoreHistone von GTP-Hydrolyse abhängig war. Zusammenfassend kann durch die in vitro Importexperimente festgestellt werden, daß der Kerntransport der Core-Histone abhängig von löslichen zytosolischen Komponenten, Energie, GTP-Hydrolyse und der Interaktion mit der Kernpore ist. Dies war ein Hinweis darauf, daß der Import der CoreHistone kein passiver Diffusionsvorgang ist sondern ein aktiver, rezeptorvermittelter Prozeß.

\subsection{Identifizierung von Kernlokalisationssignalen (NLS)}

Da die Ergebnisse aus den Inhibierungsexperimenten vermuten ließen, daß die CoreHistone durch einen rezeptorvermittelten Transportweg in den Zellkern gelangen, galt es im folgenden herauszufinden, welche Sequenzabschnitte der einzelnen CoreHistone für die Erkennung des Importrezeptors und damit für die Translokation in den 
Zellkern maßgeblich sind. In der Vergangenheit waren sog. Kernlokalisationssignale (NLS) beschrieben worden, die karyophile Proteine in den Kern dirigieren. Die ersten NLS, die identifiziert worden waren, sind durch eine Anhäufung von basischen Aminosäuren gekennzeichnet und werden als klassische NLS bezeichnet. Man unterscheidet dabei zwischen zwei unterschiedlichen Typen: Das NLS des großen TAntigens des SV40-Virus, mit der Aminosäuresequenz PKKKRKV, wurde als erstes NLS überhaupt identifiziert (Kalderon et al., 1984). Es besteht aus einem Heptapeptid mit fünf aufeinanderfolgenden basischen Aminosäuren, die von Prolin und Valin flankiert sind. Das NLS von Nukleoplasmin ist ein zweigeteiltes (bipartites) Signal mit der Sequenz KRPAATKKAGQAKKKK (Robbins et al., 1991). Es besteht aus zwei basischen Clustern, die durch einen variablen Bereich von zehn Aminosäuren getrennt sind. Aber auch mit weniger basischen Aminosäuren können funktionsfähige NLS gebildet werden, was am NLS des Protooncogens c-Myc mit der Sequenz PAAKRVKLD (Nadler et al., 1997) deutlich wird.

In letzter Zeit sind aber auch NLS beschrieben worden, die sich von dem klassischen Typ deutlich unterscheiden. So enthält die M9-Domäne, die den Kerntransport des Ribonukleoproteins hnRNP A1 vermittelt (Pollard et al.,1996), in ihren 38 Aminosäuren keine basischen Cluster, ist statt dessen reich an Glycin. In verschiedenen ribosomalen Proteinen sind NLSs beschrieben worden, die zwar auch sehr basisch sind, sich aber komplexer gestalten als die klassischen Prototypen (Schaap et al., 1991, Jäkel et al., 1998, Claussen et al., 1999).

Da Histone sehr basische Proteine sind, liegt es nahe, daß NLS identifizierbar sind, die sich aus basischen Aminosäuren zusammensetzen. Vorhersagen über potentielle NLS aus der Sequenz sind allerdings schwierig, da etwa 25-30 \% der Aminosäuren der Core-Histone basisch sind. Jedoch sind anhand der Primärstruktur Bereiche zu erkennen, die erhöhte Konzentrationen von Arginin und Lysin enthalten. So enthalten die aminoterminalen Domänen der vier Core-Histone einen überdurchschnittlich hohen basischen Anteil (28-42 \% basische Aminosäuren), während die globulären Domänen und C-terminalen Endstücke verhältnismäßig geringen basischen Charakter haben (15-20 \% basische Aminosäuren). Einem NLS vom klassischen basischen Typ kam der Bereich der Aminosäuren 26-35 in H2B am nächsten, der fünf basische Aminosäuren in Folge enthält. Aber auch außerhalb dieser Domänen waren Cluster erhöhter Basizität identifizierbar (z.B. H2A AS 70-78, H3 AS 130-136, H4 AS 30-48 und 77-79). Beim Sequenzvergleich mit den klassischen NLS SV40-T-Antigen, Nukleoplasmin oder anderen bereits bekannten NLS-Sequenzen waren jedoch keine Übereinstimmungen aufgefallen. Anreicherungen von Glycin wie in der M9-Domäne 
des Ribonukleoproteins hnRNPA1 (Michael et al, 1995) war ebenfalls in keinem der Core-Histone enthalten.

Um die NLSs in den Core-Histonen zu identifizieren, wurden verschiedene Abschnitte der Core-Histone auf ihre Fähigkeit, den Kerntransport zu vermitteln, untersucht. Die Einteilung in die einzelnen Abschnitte erfolgte einerseits nach basischen Motiven, andererseits wurde aber auch die Domänenstruktur der Histone berücksichtigt:

Diese läßt sich durch eine unstrukturierte, N-terminale Domäne mit zahlreichen basischen Aminosäuren, und eine hydrophobe, globuläre Domäne mit definierter Tertiärstruktur sowie durch ein kurzes carboxyterminales „Endstück“ beschreiben, wobei letzteres in $\mathrm{H} 3$ und $\mathrm{H} 4$ fehlt.

Um die Fähigkeit einzelner Proteinabschnitte der Core-Histone, Kerntransport zu vermitteln, festzustellen, wurden die gesamten Core-Histongene bzw. einzelne Fragmente mit dem Gen für die bakterielle $\beta$-Galaktosidase fusioniert und in einer humanen Zellinie exprimiert. $\beta$-Galaktosidase ist mit einer molekularen Masse von 116 kDa größer als das Ausschlußvolumen der Kernporen, enthält kein NLS und wird deshalb vom Zellkern ausgeschlossen. Es ist darüber hinaus durch Immunfluoreszenz leicht nachweisbar, und war daher ein geeignetes Reporterprotein für die Suche nach Kernlokalisationssignalen.

\subsubsection{Klonierung der $\beta$-Galaktosidase-Fusionskonstrukte}

Als Ausgangvektor für die Klonierungen der $\beta$-Galaktosidase-Fusionskonstrukte diente das Plasmid pKS10 (Schwamborn et al., 1998). Dieses geht auf den pSV $\beta$-Vektor zurück, ein eukaryontischer Expressionsvektor für $\beta$-Galaktosidase, der für weitere Klonierungarbeiten mit den zusätzlichen Restriktionsschnittstellen, Bg/ll, Nhel und Nrul ausgestattet worden war. In pKS10 wurden alle Gene für die vier Core-Histone und deren zu untersuchende Fragmente vor das 5'-Ende des $\beta$-Galaktosidasegens kloniert (Abb. 9). Die codierenden Sequenzen für die Core-Histone erhielt man aus Plasmiden, die das H2A/d- (Acc. No. Z83739), H2B/d- (Acc. No.Z83336), H3/k- (Acc. No. Z83735) bzw. H4/j-Gen (Acc. No. Z80787) enthielten (Albig und Doenecke, 1997). Die Gene wurden durch PCR aus dem entsprechenden Plasmid amplifiziert, wobei Primer verwendet wurden, die am 5'-Ende die Sequenz einer Bglll- und am 3'-Ende die einer Nhel-Restriktionsschnittstelle enthielten. Die PCR-Produkte konnten nach Restriktionsverdauung mit Bg/ll und Nhel für die Ligation in den pKS10-Vektor 
verwendet werden, der entsprechend geschnitten und dephosphoryliert worden war. Für kleine Core-Histonfragmente (pMB8, 9, 22, 29) wurden doppelsträngige Oligonukleotide verwendet. Nach Sequenzüberprüfung wurden die DNAFusionskonstrukte durch Elektroporation transient in HeLa-Zellen transfiziert und die

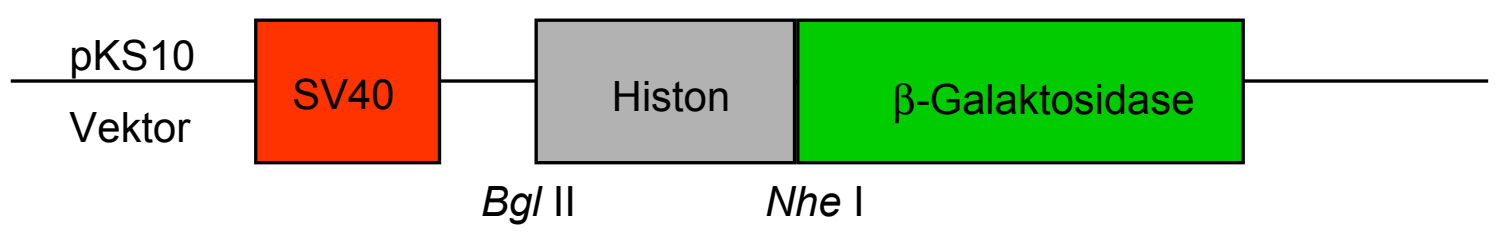

Abb. 9: Herstellung der $\beta$-Galaktosidase Fusionskonstrukte: PCR-amplifizierte Histongene wurden in N-terminaler Richtung vor $\beta$-Galaktosidase in die Bg/ll- und NhelRestriktionsschnittstellen des zu pKS10 modifizierten pSV $\beta$-Vektor kloniert. Die Expression des Genproduktes steht unter der Kontrolle des SV40 Promotors.

intrazelluläre Lokalisation der exprimierten Fusionsproteine durch indirekte Immunfluoreszenz mit einem polyklonalen Antikörper gegen $\beta$-Galaktosidase und einem fluoreszenzmarkierten Zweitantikörper nachgewiesen.

\subsubsection{Transfektion der $\beta$-Galaktosidase Konstrukte in HeLa-Zellen durch Elektroporation}

Um Plasmid-DNA in eine eukaryontische Zelle einzubringen, gibt es verschiedene Transfektionsmethoden, von denen der Einsatz von Lipofectaminen und die Elektroporation zu den bekanntesten gehören. Hier wurde ausschließlich die Elektroporation angewendet, die sich für HeLa-Zellen als gut geeignet erwiesen hatte (Schwamborn et al., 1998). Bei dieser Methode werden die Zellen kurzen elektrischen Spannungen ausgesetzt, die zu einer kurzfristigen Permeabilisierung der Zellmembran führen und diese für Plasmid-DNA passierbar machen.

Für einen Elektroporationsansatz wurden $20 \mu \mathrm{g}$ Plasmid-DNA und $5 \times 10^{5}$ HeLa-Zellen in $500 \mu \mathrm{l}$ Kulturmedium verwendet. Die Detektion des Genproduktes durch Immunfluoreszenz erfolgte etwa $48 \mathrm{~h}$ nach der Elektroporation, so daß die Zellen mindestens einen vollständigen Zellzyklus (für HeLa-Zellen ca. 24 h) durchlaufen konnten, um das entsprechende Fusionsprotein $\mathrm{zu}$ synthetisieren und es gegebenenfalls in den Zellkern zu transportieren. Durch Verwendung von DAPI, einem DNA-Farbstoff, konnten die Zellkerne sichtbar gemacht werden, was für die Auswertung eine gute Orientierungshilfe war. 


\subsubsection{Core-Histone und Core-Histon-Fragmente als Vermittler des Kerntransports in Fusionskonstrukten}

Zunächst wurden die vier Core-Histone als vollständige Proteine analysiert. Abb. 10 zeigt einige repräsentative Immunfluoreszenzbilder dieser Kerntransportexperimente von Fusionskonstrukten.

Dabei war erkennbar, das gesamte Protein mit $\beta$-Galaktosidase fusioniert in den Zellkern importiert wurde (pWA355, pWA352, pWA356, pWA357), da der Kern der HeLa-Zellen eine Fluoreszenzfärbung zeigte, während das zytoplasmatische
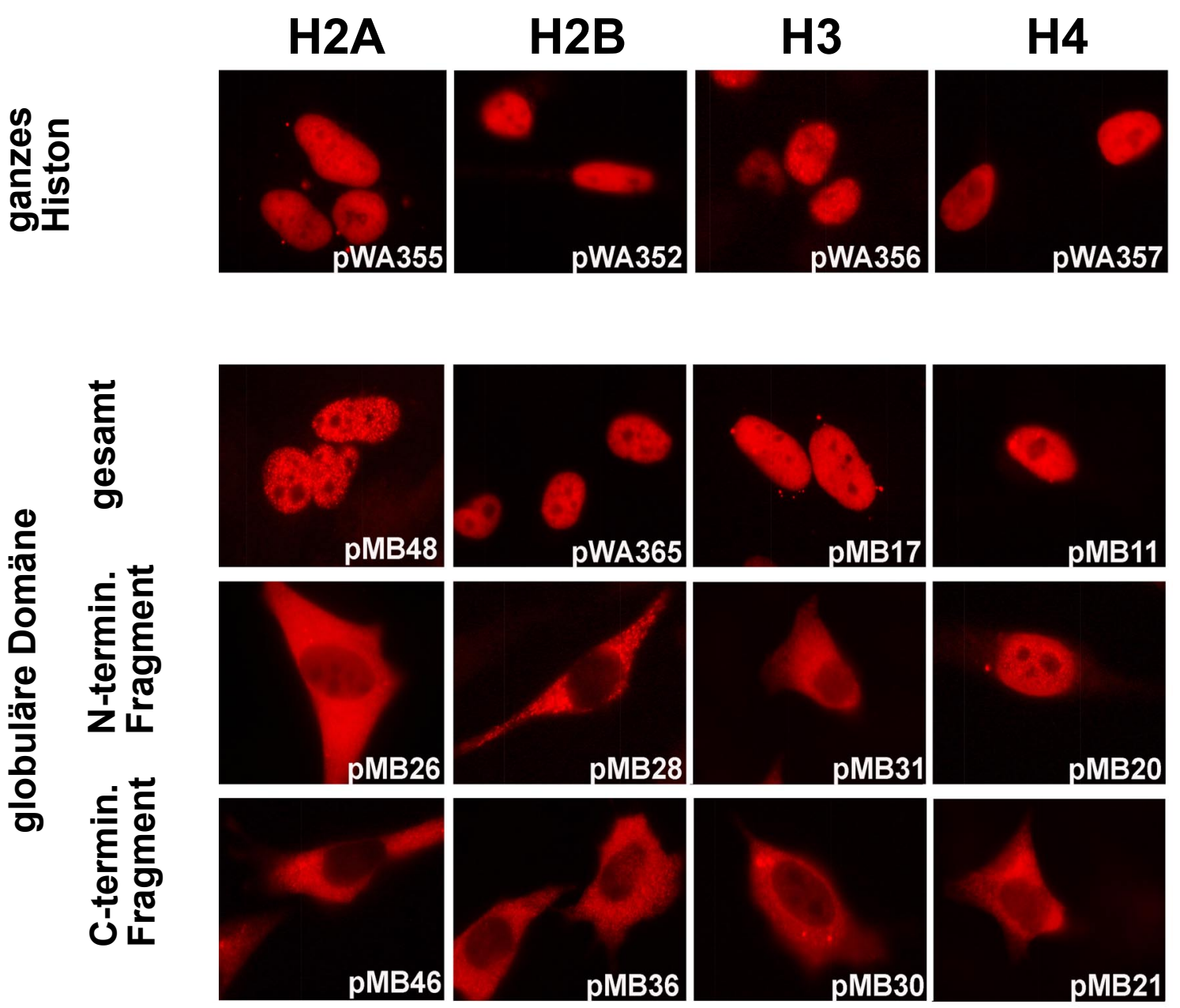

Abb. 10. Intrazelluläre Lokalisation transfizierter $\beta$-Galaktosidase-Fusionskonstrukte in HeLa-Zellen: Dargestellt sind ausgewählte Fusionskonstrukte, die gesamten Core-Histone sowie ihre globuläre Domänen und Teilfragmente davon. HeLa-Zellen wurden durch Elektroporation mit Plasmid-DNA, die die entsprechenden Genbereiche für die gewünschten $\beta$ Galaktosidase-Fusionsproteine enthielten, transfiziert. Nach etwa $48 \mathrm{~h}$ wurden diese durch Immunfluoreszenz nachgewiesen. Als Erstantikörper wurde ein polyklonaler Antikörper gegen $\beta$-Galaktosidase verwendet, als Zweitantikörper ein fluoreszenzmarkierter Anti-MausAntikörper. 
Kompartiment nicht zu erkennen war (Abb. 10).

Anschließend wurden die Histonbereiche eingegrenzt, die die Informationen für die Kernlokalisation der Core-Histone enthalten. Dazu wurden zunächst die einzelnen Domänen der vier Core-Histone auf ihre Transportkompetenz hin untersucht:

\subsubsection{Core-Histon H2A}

In H2A repräsentierte pWA362 die $\mathrm{N}$-terminale Domäne, die reich an basischen Aminosäuren ist. Dieser Anteil von $\mathrm{H} 2 \mathrm{~A}$ als Fusionsprotein mit $\beta$-Galaktosidase wurde effizient in den Kern importiert (pMB10, Abb. 11). Der verbleibende Teil enthielt die globuläre Domäne und das C-terminale Endstück (pMB48). Dieser Histonabschnitt ist verhältnismäßig hydrophob, enthält aber drei basische Bereiche, die sich in den Aminosäuren 29-36, 70-81 sowie am carboxyterminalen Ende in den Aminosäuren 117-129 befinden. Im Transfektionsexperiment konnte gezeigt werden, daß auch dieses Histonfragment (pMB48) transportkompetent war. Die Fluoreszenzfärbung war ausschließlich im Zellkern zu finden (Abb. 10, Abb. 11). Daraus war zunächst zu schließen, daß H2A mindestens zwei Kernlokalisationssignale besitzt: eines befindet sich in der aminoterminalen Domäne, wenigstens ein weiteres mußte in dem übrigen Proteinanteil lokalisiert sein.

Die Aminosäuren 26-36, unter denen vier basische Aminosäuren sind, zeigten keine Transportkompetenz, das entsprechende Fusionsprotein wurde nicht in den Kern importiert (pMB9). Dagegen konnte das verbleibende Histonfragment als $\beta$ Galaktosidase-Fusionsprotein im Kern detektiert werden (pWA363). Wurde dieses nun in zwei Untereinheiten, die die Aminosäuren 93-129 (pMB24) bzw. die Aminosäuren 37-92 (pMB25) enthielten, aufgeteilt, so ging jeweils die Transportkompetenz verloren; beide Fragmente verblieben als Fusionen mit dem Reporterprotein im Zytoplasma. Um auszuschließen, daß an dem Fusionsbereich ein potentielles (z.B. zweigeteiltes) NLS zerstört worden war, wurden Konstrukte hergestellt, die einen überlappenden Bereich enthielten (pMB42, pMB45, pMB46). Auch diese Konstrukte konnten nicht in den Zellkern importiert werden. Dies legte den Schluß nahe, daß im Bereich der globulären und C-terminalen Domäne ein NLS enthalten war, das sich nicht aus einem kurzen Sequenzabschnitt formierte, da wenigstens eines der untersuchten Fragmente als $\beta$ Galaktosidase-Fusion (pMB42, pMB45, pMB46) in den Kern hätte importiert werden müssen. Es ließ sich sogar ein 76 Aminosäuren langes Fragment erzeugen, das voll- 
ständig zytoplasmatisch blieb (pMB47). Interessanterweise gewann es an Transportkompetenz, wenn es in $\mathrm{N}$ - oder C-terminaler Richtung um Bereiche von 9 bzw. 15 Aminosäuren erweitert wurde (pWA363 und pMB39), obwohl diese aber für sich kein NLS darstellten, da verschiedene Fusionskonstrukte mit diesem Proteinbereich zytoplasmatisch lokalisiert waren (pMB9, pMB26, pMB24, pMB46).

\section{H2A}

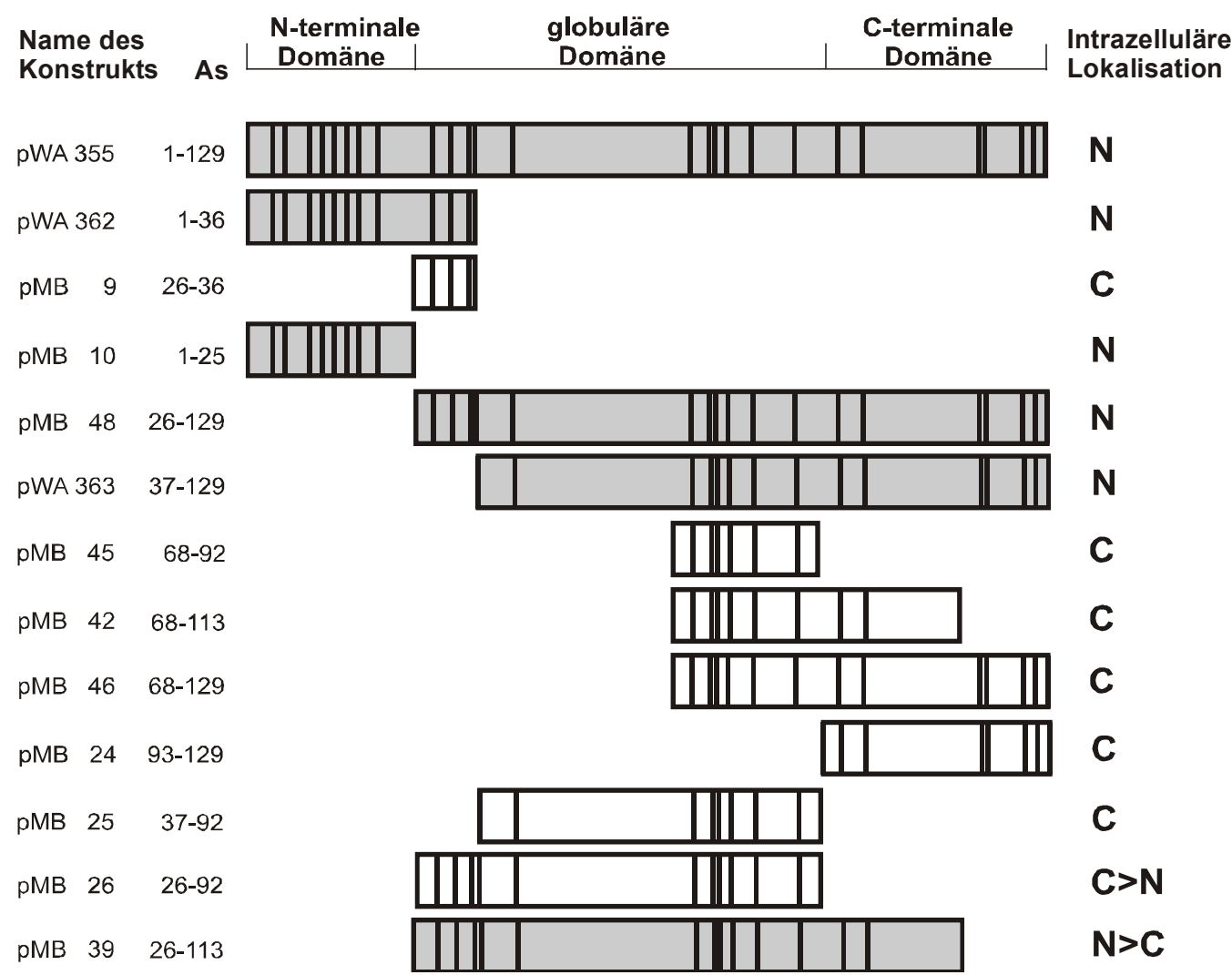

Abb. 11: Zusammenfassung der Transfektionsexperimente für H2A: HeLa-Zellen wurden mit DNA-Fusionskonstrukten transfiziert, die die codierenden Sequenzen für jeweils das gesamte Core-Histon $\mathrm{H} 2 \mathrm{~A}$ oder einzelne Fragmente, jewils fusioniert mit $\beta$-Galaktosidase, enthielten. Die intrazelluläre Lokalisation der Genprodukte wurde anschließend durch Immunfluoreszenz nachgewiesen. Die dargestellten Balken zeigen die entsprechenden CoreHiston-Abschnitte, die mit $\beta$-Galaktosidase fusioniert waren. Die senkrechten Linien geben die basischen Aminosäuren Arginin bzw. Lysin an. Die Fusionsproteine waren entweder im Zellkern (N) oder zytoplasmatisch (C) lokalisiert. In manchen Fällen war in beiden Kompartimenten Fluoreszenz detektierbar. Sie war entweder vorwiegend zytoplasmatisch $(\mathrm{C}>\mathrm{N})$ oder nukleär $(\mathrm{N}<\mathrm{C})$.

In C-terminaler Richtung ist von Aminosäure 26 ausgehend eine Zunahme an NLSFunktion zu erkennen: Während pMB9 noch zu einer rein zytoplasmatischen Lokalisation des Fusionsproteins führte, besaß pMB26 schon partiellen NLS- 
Charakter, da $\beta$-Galaktosidase zumindest teilweise im Kern detektierbar war. PMB39 führte zu einer vorwiegenden und pMB48 zu einer vollständigen nukleären Anreicherung des Reporters im Zellkern. Diese Daten zeigen deutlich, daß das NLS des globulären und carboxyterminalen Histonbereichs wesentlich komplexerer Natur ist, als das bei den klassischen NLS-Motiven der Fall ist. Insgesamt läßt die Tatsache, daß gerade dieser globuläre Proteinteil eine definierte tertiäre Struktur besitzt, den Schluß zu, daß sich sein NLS eben durch diese dreidimensionale Anordnung formiert. Es handelt sich hier also nicht um eine kurze Signalsequenz die als NLS funktioniert, sondern um einen Signalbereich, der sich über ca. 90 Aminosäuren erstreckt.

\subsubsection{Core-Histon H2B}

In H2B war die Situation bezüglich des Importverhaltens der Domänen vergleichbar mit H2A: Die N-terminale Domäne transportierte $\beta$-Galaktosidase ebenso effizient in den Kern (pWA364) wie die globuläre zusammen mit der C-terminalen Domäne (pWA365, Abb. 10). Abb. 12 faßt die Ergebnisse für H2B zusammnen.

Darüber hinaus konnte im N-Terminus ein basischer Bereich von 10 Aminosäuren identifiziert werden, der als NLS funktionieren konnte (pMB8), während der verbleibende Anteil (pMB5) eindeutig im Zytoplasma lokalisiert war. Das importkompetente Peptid enthielt die Aminosäuresequenz " ${ }^{27} \mathrm{GK}^{29} \mathrm{KRKRSRKE"} \mathrm{und}$ zeigte damit starke Ähnlichkeit mit dem NLS des SV40-T-Antigens (PKKKRKV). Um zu überprüfen, ob die Importkompetenz dieses kurzen Histonfragments wie im Fall des klassischen SV40-NLS durch seine basischen Aminosäuren determiniert wird, wurde zunächst Lysin29 durch eine nicht-basische Aminosäure (Threonin) ausgetauscht (pMB22). Das resultierende $\beta$-Galaktosidase-Fusionsprotein zeigte ein verändertes Importverhalten; es war zwar in einigen Zellen kernlokalisiert, in der überwiegenden Anzahl jedoch entweder teilweise oder vollständig im Zytoplasma angereichert. Die Beobachtung, daß sich Zellen im selben Experiment so unterschiedlich bezüglich des Kernimports eines Proteins verhalten, könnte dadurch erklärt werden, daß sich die Zellen zum Zeitpunkt der Transfektion oder der Detektion in einer unterschiedlichen Phase des Zellzyklus befanden. Die Erkennung des künstlich generierten Fusionsproteins war möglicherweise vom Stadium des Zellzyklus abhängig, so daß eine Translokation in den Kern nur zu einer bestimmten Phase des Zellzyklus erfolgen konnte. Der Austausch einer zweiten Aminosäure (Arg34 zu Gly) führte zu einer 
eindeutig zytoplasmatischen Lokalisation des Fusionsproteins (pMB29). Dies zeigte, daß die Funktion als NLS in diesem aus 10 Aminosäuren bestehen Peptid von basischen Aminosäuren abhängig ist. Interessanterweise reduzierten dieselben

\section{H2B}

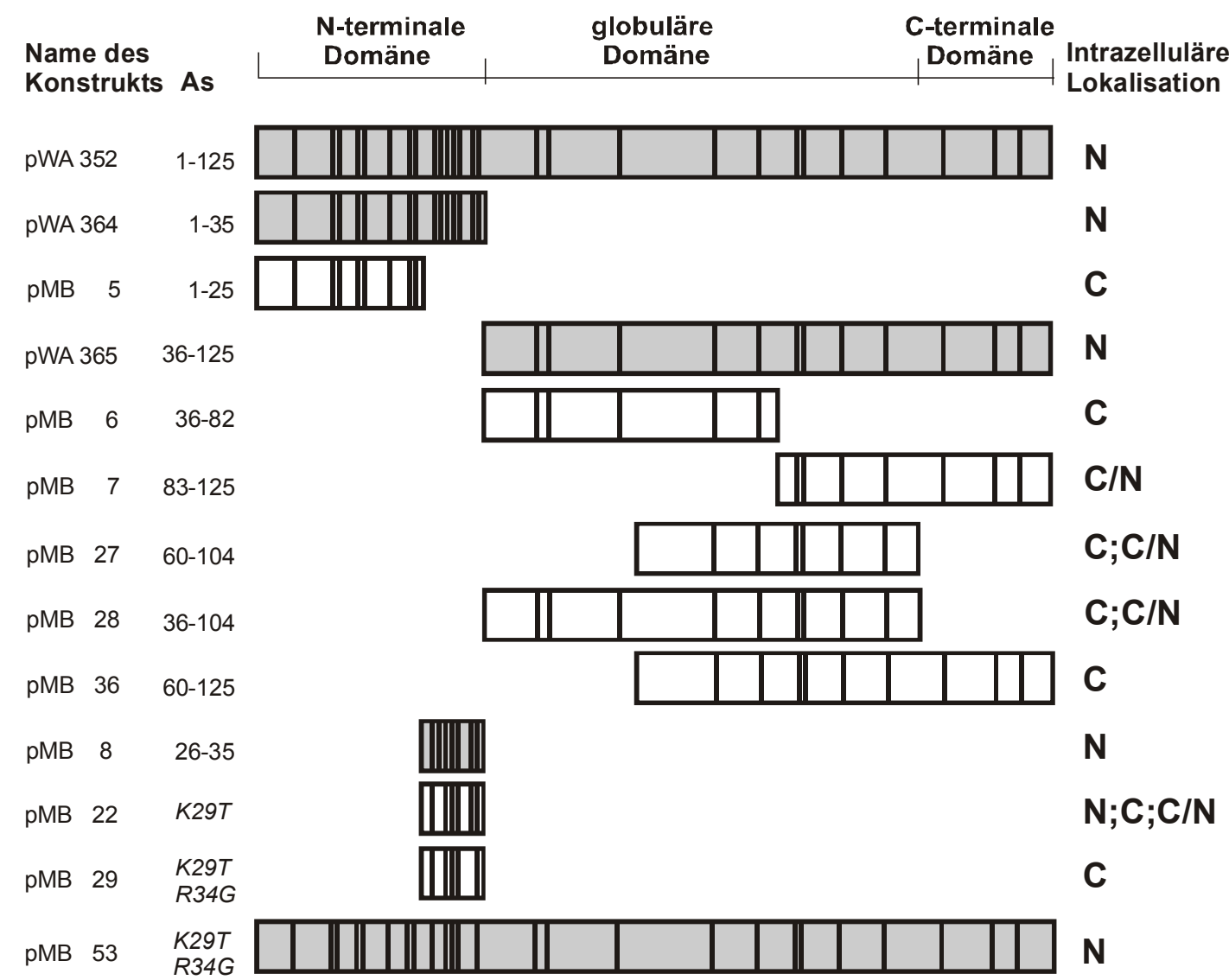

Abb. 12: Zusammenfassung der Transfektionsexperimente für H2B: Darstellung wie in Abb. 11. In einigen Fällen zeigte sich eine gleichmäßige Verteilung zwischen beiden Kompartimenten $(\mathrm{C} / \mathrm{N})$. Im Fall von pMB22 war das Fusionsprotein entweder im Kern, im Zytoplasma oder in beiden Kompartimenten nachweisbar $(\mathrm{N}, \mathrm{C} ; \mathrm{C} / \mathrm{N})$.

Mutationen im gesamten Core-Histon die Transporteffizienz nicht (pMB53). Dies ließt sich nur dadurch erklären, daß im H2B noch mindestens ein weiteres NLS enthalten war. Abb. 13 faßt die Ergebnisse der Mutationsanalyse zusammen.

Die Aminosäuren 36-125 (pWA365) umfassen die globuläre und C-terminale Domäne. Dieser Bereich ist mit nur 12 basischen von ca. 90 Aminosäuren, verhältnismäßig hydrophob. Trotz des Fehlens eines erkennbaren potentiellen NLS konnte das $\beta$ - 
Galaktosidase-Fusionsprodukt in den Zellkern importiert werden. Teilung dieses Fragments in zwei Teilfragmente (pMB6 und pMB7) führte jeweils zu einer Verminderung der Importkompetenz. Der N-terminale Teil war komplett zytoplasmatisch (pMB6), während sich der c-terminale Anteil zu etwa gleichen Anteilen im Zytoplasma wie im Zellkern verteilte (pMB7). Fragmente, denen nur die C-terminale Domäne oder die Aminosäuren 36-59 der globulären Domäne fehlten, waren ebenfalls nicht importkompetent (pMB27, pMB28, pMB36). Dies zeigt, daß die Funktionsfähigkeit als NLS bei diesem H2B-Fragment mit den Aminosäuren 36-125 nicht auf einen klassischen NLS-Typ zurückzuführen ist:

Zum einen fehlt ein klassisches basisches Motiv, zum anderen ist auch hier wie schon im Fall von $\mathrm{H} 2 \mathrm{~A}$ ein umfangreicher Teil des Proteins, der den hochstrukturierten Proteinbereich der globulären Domäne enthält, für den Kernimport des Reporters verantwortlich.

\subsubsection{Core-Histon H3}

Bei der Analyse des Core-Histons H3 fielen in der Primärstruktur der aminoterminalen Domäne Muster von basischen Aminosäuren auf, die eine gewisse Ähnlichkeit mit dem klassischen zweigeteilten NLS-Typ besaßen. Im Experiment zeigte sich, daß diese transportkompetente Domäne (pMB12, Abb. 14) mindestens zwei NLS-Bereiche vom basischen NLS-Typ enthielt (pMB15, pMB16). Der ebenfalls basische C-Terminus wurde dagegen nicht in den Kern transportiert (pMB30). Die globuläre Domäne konnte zwar als NLS funktionieren (pMB17), fehlten ihr aber die ersten 10 Aminosäuren, so verblieb das resultierende $\beta$-Galaktosidase-Fusionsprotein im Zytoplasma (pMB13), obwohl diese Aminosäuren für sich kein NLS bildeten (pMB31). Daraus konnte gefolgert werden, daß sie nur im Kontext mit der gesamten globulären Domäne ein funktionsfähiges Importsignal formieren. Auch im Fall von H3 ist die Integrität der globulären Domäne essentiell für die Funktionsfähigkeit dieses Histonbereichs als NLS. 


\section{H3}

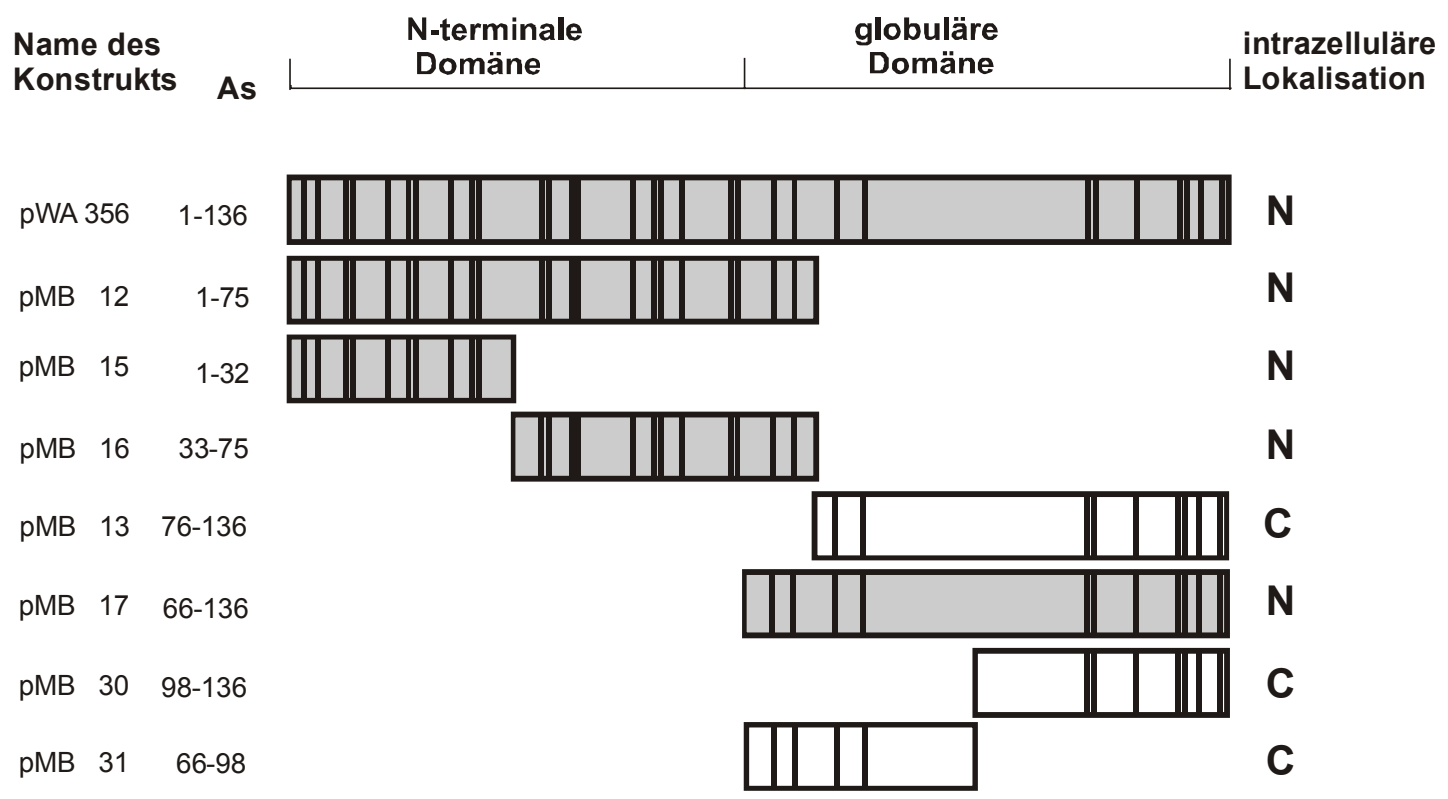

Abb. 14: Schematische Zusammenfassung der Transfektionsexperimente für H4: Darstellung wie in Abb. 11. Die Fusionskonstrukte aus $\mathrm{H} 3$ bzw. einzelner Fragmente und $\beta$ Galaktosidase waren entweder im Kern (N) oder im Zytoplasma $(C)$ detektierbar. $\mathrm{H} 3$ enthält drei importkompetente Proteinbereiche (pMB15, 16, 17).

\subsubsection{Core-Histon H4}

Wie schon bei den besprochenen anderen Core-Histonen konnte im Fall von H4 gezeigt werden, daß auch seine $\mathrm{N}$-terminale Domäne als Fusionsprodukt mit $\beta$ Galaktosidase in den Kern importiert wird (Abb. 15, pMB18). Auch hier lassen sich aufgrund des verhältnismäßig hohen Anteils an basischen Aminosäuren Sequenzmotive erkennen, die einem klassischen NLS ähnlich sind. Außerdem konnte auch im H4 die globuläre Domäne als importkompetent identifiziert werden (pMB51), wobei die Besonderheit auftrat, daß zwei Bereiche identifiziert wurden, die als NLS funktionieren konnten (pMB19, pMB20). Das C-terminale Fragment blieb dagegen zytoplasmatisch (pMB21). Der N-terminale NLS-Bereich der globulären Domäne ist verhältnismäßig basisch und enthält auffällige Paare positiv geladener Aminosäuren. 


\section{H4}

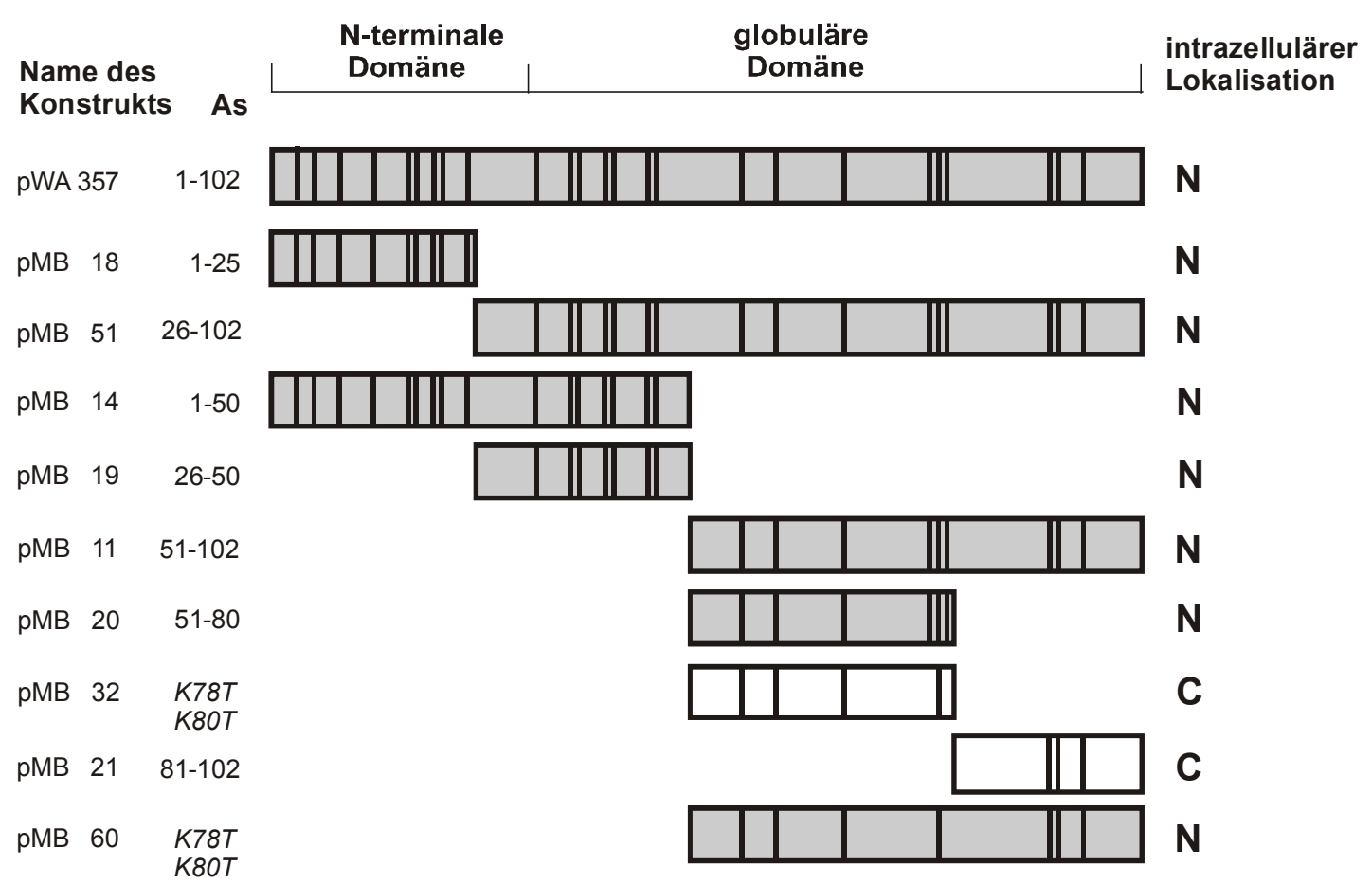

Abb. 15: Zusammenfassung der Transfektionsexperimente für H4: Darstellung wie in Abb. 11. $\mathrm{H} 4$ enthält in der N-terminalen Domäne ein (pMB18) und in der globulären Domäne zwei importkompetente Bereiche (pMB19, 11).

Die Region um die Aminosäuren 51-80 (pMB20) enthielt ein basisches Tripeptid bestehend aus dem Motiv KRK. Mutation der beiden Lysine in Threonine führten zu einer zytoplasmatischen Retention des $\beta$-Galaktosidase-Fusionsproteins (pMB32) und gab damit einen Hinweis auf eine Beteiligung dieser beiden Aminosäuren an der Funktion als NLS. Allerdings konnte dieser Verlust der Importkompetenz durch dieselbe Mutation nicht in pMB11 beobachtet werden, das etwa zwei Drittel der globulären Domäne enthielt: Das resultierende mutierte Fusionsprotein wurde effizient in den Zellkern transportiert (pMB60, Abb. 15 und Abb. 16). Damit erwies sich dieses basische Triplett für die Lokalisation dieses Histonfragments und des gesamten Histons als bedeutungslos. Dieser Widerspruch könnte dadurch erklärt werden, daß im pMB20 durch die Fusion mit $\beta$-Galaktosidase ein artifizielles NLS generiert wurde. In jedem Fall aber kann pMB60 ohne diese beiden Aminosäuren als NLS wirken, während aber seine Teilfragmente (pMB32 und pMB21) keine Transportfunktion haben. 


\subsubsection{Jedes Core-Histon enthält zwei strukturell unterschiedliche NLS-Typen}

Zusammenfassend konnte bei den NLS-Studien gezeigt werden, daß die Core-Histone jeweils in ihrer N-terminalen Domäne NLS besitzen, die aufgrund der Häufung von basischen Aminosäuren in ihrer Primärstruktur Ähnlichkeiten zum klassischen NLSTyp aufweisen. Im Fall von H2B wurde im N-Terminus ein Sequenzelement von 10 Aminosäuren identifiziert, das als NLS funktionierte und eine starke Übereinstimmung mit dem NLS des SV40-T-Antigens zeigte. Darüber hinaus besitzt jedes Core-Histon

globuläre
Domäne

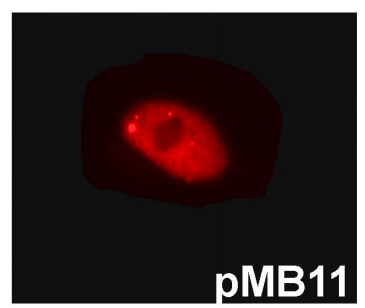

N-terminales

Fragment

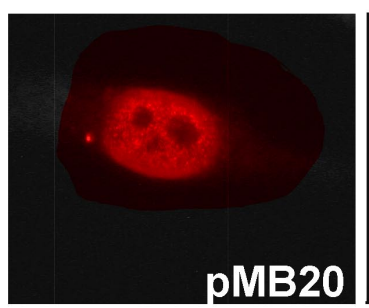

N-terminales

Fragment

K78T, K80T

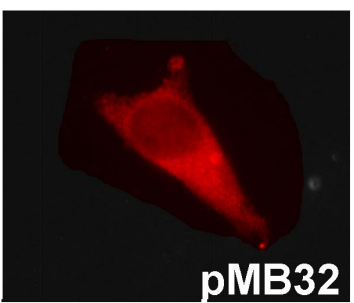

globuläre

Domäne

K78T, K80T

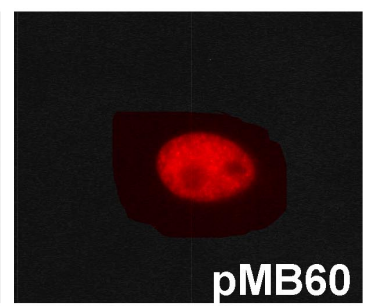

Abb.16: Intrazelluläre Verteilung der Untereinheiten der globulären Domäne von H4: Dargestellt sind die Immunfluoreszenzfärbungen der $\beta$-Galaktosidase-Fusionen der globulären Domäne von $\mathrm{H} 4$ sowie eines Teilbereiches und ihre jeweiligen mutierten Analoga. Die globuläre Domäne (pMB11), wie auch das N-terminale Fragment (pMB20) führen zu einer nukleären Lokalisation des Fusionskonstrukts. Die mutierte Variante des $\mathrm{N}$-terminalen Abschnitts (pMB32) verliert durch den Aminosäureaustausch an Transportkompetenz, während die Mutationen in der gesamten globulären Domäne keinen Einfluß auf den Kerntransport haben (pMB60).

mindestens ein weiteres NLS, das sich aber vom klassischen Typ unterscheidet. Dieses wird durch einen verhältnismäßig hydrophoben Signalbereich von 70-90 Aminosäuren gebildet, an dem jeweils die globuläre Domäne funktionell beteiligt ist. Man kann daher von zwei strukturell unterschiedlichen NLS-Typen in den CoreHistonen ausgehen, die durch die strukturellen Eigenschaften der aminoterminalen bzw. globulären Domänen bestimmt werden.

Offen bleibt dabei allerdings die Frage, welche Importrezeptoren den Kerntransport durch Interaktion mit den NLS der Core-Histone vermitteln und ob die unterschiedlichen NLS-Typen mit unterschiedlichen Rezeptoren interagieren. Proteine die den klassischen basischen NLS-Typ enthalten, werden vom Importin $\alpha /$ Importin $\beta$ - 
Hetrodimer erkannt und in den Kern transportiert. Da die in den N-Termini der CoreHistone identifizierten NLS einen hohen basischen Anteil besitzen, ist es denkbar, daß die Core-Histone durch diese Importrezeptoren in den Kern transportiert werden. Die strukturellen Eigenschaften des zweiten in den Core-Histonen gefundenen NLS-Typs lassen dagegen vermuten, daß alternative Rezeptoren beteiligt sind.

\subsubsection{Untersuchung des Imports von H2A und H2B als Heterodimere}

Da bekannt war, daß H2A mit H2B im Zytoplasma Dimere und H3 mit H4 Tetramere bilden (Kornberg et al., 1974), bestand die Möglichkeit, daß die identifizierten importrelevanten Histonbereiche durch Interaktion mit einem anderen Histon sozusagen als "Huckepack" in den Kern transportiert wurden (Moreland et al., 1987). Die Transfektionsexperimente mit Fusionsproteinen hatten in dieser Hinsicht keine Aussage erlaubt, ob die Core-Histone als Monomere oder als Heterodimere bzw. Heterotetramere importiert werden.

Um einen Hinweis auf die Beteiligung eines $\mathrm{H} 2 \mathrm{~A} / \mathrm{H} 2 \mathrm{~B}$ Heterodimers am Kernimport von $\mathrm{H} 2 \mathrm{~A}$ oder $\mathrm{H} 2 \mathrm{~B}$ zu erhalten, wurde der Import der globulären Domäne von H2B (pWA365) in Abhängigkeit vom Zellzyklus untersucht. Es ist bekannt, daß endogene Core-Histone in der S-Phase synthetisiert und anschließend zur Chromatinbildung in den Kern transportiert werden, daher ist ihre Konzentration im Zytoplasma außerhalb der S-Phase sehr gering. Das Fusionsprotein aus der globulären Domäne von H2B und $\beta$-Galaktosidase wird dagegen zellzyklusunabhängig exprimiert, weil seine Genexpression unter Kontrolle des SV40-Promotors liegt, der unabhängig vom Zellzyklus aktiv ist. Da Zellen, die noch nicht die S-Phase erreicht haben, nur eine minimale zytoplasmatische endogene Histonkonzentration enthalten, war zu erwarten, daß solche Zellen nicht in der Lage sein würden, die globuläre Domäne von H2B wegen des Fehlens des Interaktionspartners H2A in den Kern zu transportieren, sofern die Ausbildung des Dimers für die Translokation essentiell ist.

Die bisher gezeigten Ergebnisse von Transfektionen mit $\beta$-GalaktosidaseFusionsproteinen basierten auf einer etwa 48 stündigen Inkubationszeit zwischen Transfektion des Plasmids und Detektion des Genprodukts, so daß alle Zellen mindestens einmal die S-Phase durchlaufen hatten. Nach kürzeren Zeiten sollte daher ein Teil der Zellen diese Phase noch nicht erreicht haben. Da die Konzentration des konstitutiv exprimierten Transfektionsprodukts dagegen unabhängig von der 
Zellzyklusphase als vergleichsweise hoch anzunehmen ist, kann aufgrund der Stöchiometrie keine quantitative Dimerisierung eines Core-Histons als $\beta$ Galaktosidase-Fusionsprotein erfolgen. Wie in den NLS-Studien gezeigt, wird die globuläre Domäne von H2B (pWA365) in den Kern transportiert (Abb. 10 und Abb. 12). Gerade diese Domäne ist es auch, die durch Interaktion mit H2A zur Ausbildung des Heterodimers führt (Moss et al., 1976). Wird das Konstrukt, welches diese Domäne enthält, transfiziert, sollte der Anteil der Zellpopulation, die noch keine SPhase durchlaufen hat (theoretisch über $50 \%$ ), bereits nach wenigen Stunden ein zytoplasmatisches Fluoreszenzsignal zeigen, wenn die Ausbildung eines Heterodimers von $\mathrm{H} 2 \mathrm{~A}$ und $\mathrm{H} 2 \mathrm{~B}$ für den Transport von $\mathrm{H} 2 \mathrm{~B}$ in den Kern essentiell ist. Umgekehrt würde eine Kernfluoreszenz vor Eintritt in die S-Phase bedeuten, daß die globuläre Domäne von H2B ohne H2A als Interaktionspartner in den Kern importiert werden kann.

Für diese Untersuchung wurden HeLa-Zellen mit dem Plasmid transfiziert, das für das Fusionsprotein aus der globulären Domäne von H2B und $\beta$-Galaktosidase codiert (pWA365). Zu unterschiedlichen Zeitpunkten nach der Transfektion wurde seine intrazelluläre Lokalisation durch Immunfluoreszenz untersucht. Dabei zeigte sich, daß das Fusionsprotein bereits $4 \mathrm{~h}$ nach Transfektion in allen detektierbaren Zellen im Kern zu beobachten war (Daten nicht gezeigt). Vor diesem Zeitpunkt war keine Fluoreszenz nachweisbar; danach zeigten ebenfalls alle detektierbaren Zellen eine eindeutige Kernfluoreszenz. Unter der Annahme, daß einige der detektierten Zellen sich noch vor der S-Phase befunden haben, ist dies ein Hinweis darauf, daß H2A und H2B nicht als Heterodimer, sondern unabhängig voneinander und durch ihre eigenen NLS vermittelt in den Kern transportiert werden.

\subsubsection{NLS-Studien von nicht-Histon-Proteinen, die das "Histone-Fold-Motif" enthalten}

Die globulären Domänen aller vier Core-Histone enthalten in ihrer Sekundärstruktur ein auffallend ähnliches Sequenzmotiv, das als "Histone-Fold-Motif" (HFM) bezeichnet wird (Arents et al., 1991). Dieses besteht aus einem sich wiederholenden HelixSchleifen-Helix-Motiv und umfaßt etwa 65 Aminosäuren. Das HFM besitzt unter den vier Core-Histonen eine ausgeprägte Strukturhomologie, während die Ähnlichkeit der Aminosäuresequenz sehr gering ist. 
In Röntgenstrukturanalysen wurde die räumliche Struktur des Nukleosoms identifiziert, wobei auch die Gestalt der Core-Histone und der in innen enthaltenen HFM beschrieben wurde. Es zeigte sich, daß die HFM der vier Core-Histone in ihrer räumlichen Struktur nahezu identisch sind. Darüber hinaus konnte gezeigt werden, daß diese Proteinanteile für die Interaktionen der Core-Histone untereinander und mit nukleosomaler DNA verantwortlich sind (Arents et al. 1995, Luger et al., 1997).

Durch Sequenzvergleich von Core-Histonen mit einer Proteindatenbank sind eine

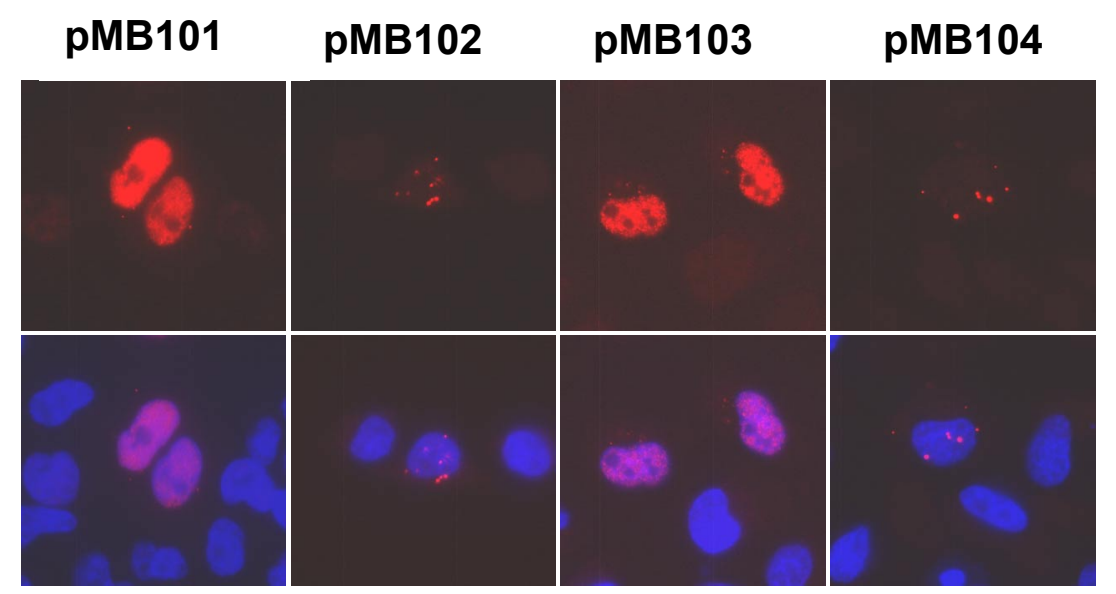

Abb. 17: Fluoreszenzdetektion einiger $\beta$-Galaktosidase-Konstrukte mit NF-YB. Die obere Zeile stellt die Immunfloureszenzfärbung der $\beta$-Galaktosidase-Fusionsproteine dar. In der unteren Zeile ist eine Kombination der DAPI-Färbung der Kern-DNA mit der Färbung der Immunflureszenz aus der oberen Zeile zu erkennen. Fusionsproteine mit enthaltenem HFM waren eindeutig im Zellkern detektierbar (pMB101, pMB103). Enthielt das Fusionsprotein Teilbereiche von NF-YB, denen das HFM fehlte, so war keine spezifische nukleäre Färbung detektierbar (pMB102, pMB104). Siehe auch Abb. 18.

Reihe von DNA-bindenden nicht-Histon-Proteinen aufgefallen, die interessanterweise Strukturmotive mit einer ausgeprägten Strukturhomologie zum HFM der Core-Histone enthalten, während die Aminosäuresequenzen aber sehr unterschiedlich sind (Baxevanis et al., 1995). Es handelte sich dabei um verschiedene Transkriptionsfaktoren, die zur Ausbildung von oligomeren Komplexen neigen und spezifische DNA-Motive erkennen. Für einige von innen konnte auch die räumliche Stukturanalogie ihres HFM zu dem der Core-Histone gezeigt werden (Xie et al., 1996).

Da einerseits für die globuläre Domäne der Core-Histone, die jeweils das HFM enthält, eine Funktion als NLS beobachtet werde konnte (vgl. 3.4) und andererseits die charakteristische Strukturhomologie zu verschiedenen nicht-Histon-Proteinen bestand, 
war es denkbar, das das HFM auch anderer Proteine als Signal für den Transport in den Zellkern dient. Um dies zu prüfen, wurde exemplarisch der Transkriptionsfaktor NF-Y (nuclear factor $Y$ ) untersucht, ein trimerer Komplex, der aus den Untereinheiten NF-YA, NF-YB und NF-YC besteht. Dieser interagiert spezifisch mit dem CCAATMotiv, das in Promotoren höherer Eukaryonten vorkommt (Mantovani, 1999).

\title{
Histone-Fold- Motif
}

\author{
pMB101 1-204 \\ pMB109 1-139 \\ pMB102 1-55 \\ pMB103 56-139 \\ pMB104 140-204 \\ pMB110 56-204
}

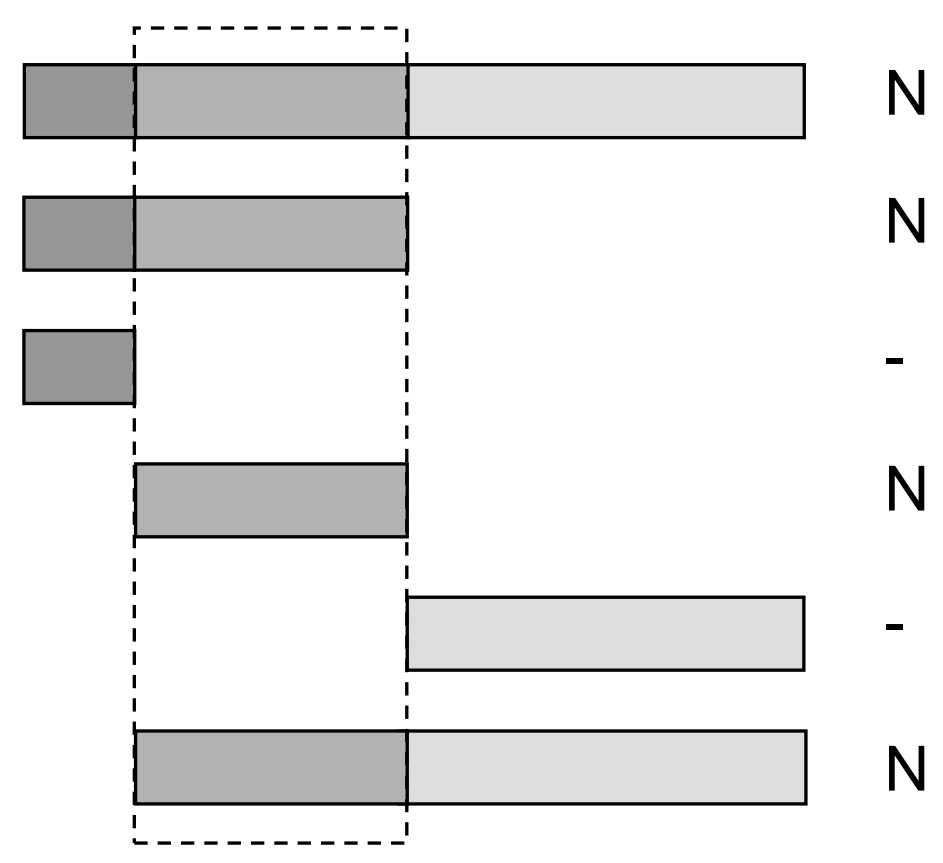

Abb. 18: Zusammenfassung der NLS-Studien an NF-YB. Horizontale Balken stellen das Protein bzw. einzelne Proteinbereiche dar, die als $\beta$-Galaktosidase-Fusionsproteine untersucht wurden. Links ist jeweils der Name, sowie die Aminosäuren bezogen auf das Gesamtprotein angegeben, rechts die intrazelluläre Lokalisation der Fusionsproteine, die entweder nukleär $(\mathrm{N})$, zytoplasmatisch (C) oder nicht eindeutig bestimmbar war (-). Die gestrichelte Linie rahmt den Proteinbereich ein, der das Histone-Fold-Motif enthält.

NF-YB und NF-YC besitzen jeweils ein HFM mit einer hohen Übereinstimmung zu den Core-Histonen H2A bzw. H2B, wobei auch hier die absolute Homologie der Aminosäuresequenzen sehr gering ist. Mutationsanalysen ergaben, daß die Integrität des HFM für die Formierung des trimeren Komplexes sowie für die DNABindungsaffinität essentiell ist (Maity und de Crombrugghe, 1998). Die transkriptionsaktivierenden Funktionen werden in der N-terminalen Domäne von NFYA und in der C-terminalen von NF-YC vermutet (Li et al., 1992, Coustry et al., 1996). 
$\mathrm{Da}$ in der Primärstruktur der NF-Y-Untereinheiten keine basischen Aminosäurecluster erkennbar waren, konnte angenommen werden, daß der Kerntransport von NF-Y bzw. seiner Untereinheiten nicht durch ein dem klassischen Signal ähnliches sondern durch ein alternatives Signal vermittelt wird.Um herauszufinden, ob das NLS von NF-YB und NF-YC im HFM lokalisiert ist, wurden beide im Transfektionsassay auf potentielle Importsignale hin untersucht. Die Untereinheit NF-YA enthält dieses Motiv nicht und wurde daher nicht mit einbezogen. Für die NLS-Untersuchungen konnten dieselben Methoden verwendet werden, wie für die Core-Histone (vgl. 3.4). Die codierenden Gene für NF-YB und NF-YC wurden als cDNA in Bluescript-Vektoren freundlicherweise von Dr. Roberto Mantovani (Mailand, Italien) zur Verfügung gestellt. Die Gene für die vollständigen Proteine sowie für Teilfragmente von innen wurden für die Expression als $\beta$-Galaktosidase-Fusionsproteine in den modifizierten pSV $\beta$-Vektor (pKS10) kloniert (vgl. 3.4.1., Abb. 9). Transfektion und Immunfluoreszenzdetektion wurden entsprechend wie bei den Core-Histonen durchgeführt.

Wie in Abb. 17 zu erkennen, wurde das vollständige NF-YB als $\beta$-GalaktosidaseFusionsprotein in den Zellkern importiert (pMB101). Fusionskonstrukte, die das

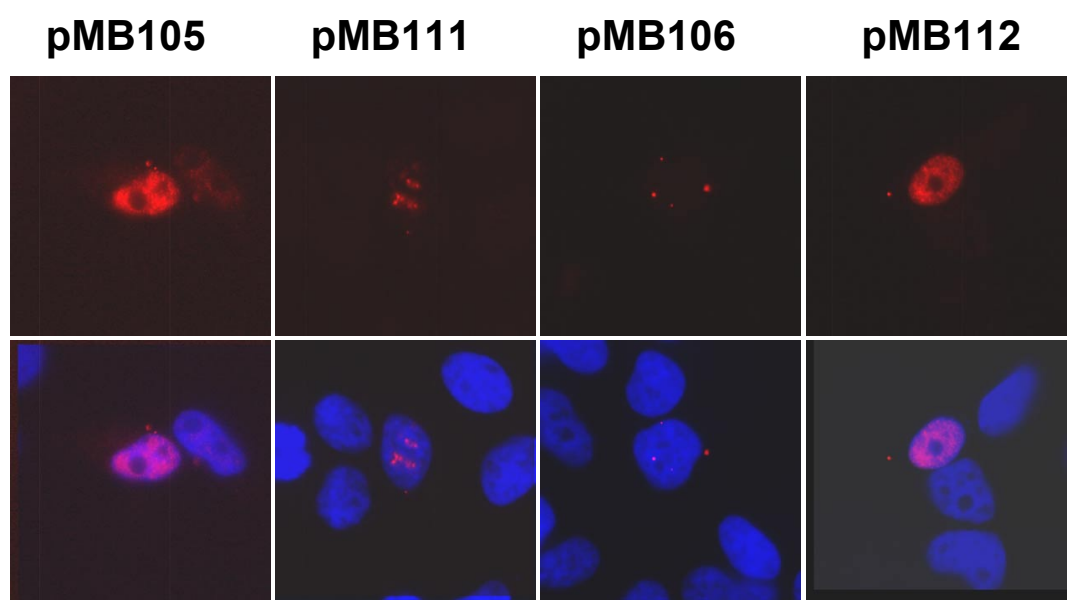

Abb. 19: Fluoreszenzdetektion einiger $\beta$-Galaktosidase-Konstrukte mit NF-YC. Darstellung wie in Abb. 17. Fusionsproteine mit enthaltenem HFM sind eindeutig im Zellkern detektierbar (pMB105, pMB112). Im pMB ist die Fluoreszenz spezifisch in den Nukleoli detektierbar. Enthielt das Fusionsprotein Teilbereiche von NF-YB, denen das HFM fehlte, so ist keine spezifische nukleäre Färbung detektierbar (pMB106). Siehe auch Zusammenfassung in Abb. 20.

"Histone-Fold-Motif" enthalten, konnten ebenfalls im Zellkern identifiziert werden (pMB103, pMB109, pMB110, Abb. 18). Die Kernlokalisation blieb aber aus, wenn dieses Motiv fehlte (pMB102, pMB104). In diesen Fällen war allerdings die 
intrazelluläre Lokalisation schwer zu identifizieren, da das Fusionsprotein nicht eindeutig im zytoplasmatischen Kompartiment zu erkennen war, sondern fluoreszierende Punkte zeigte, die eher unspezifisch in der Zelle verteilt waren. Möglicherweise handelte es sich hierbei um Aggregate der Fusionsproteine oder ihrer proteolytischen Abbauprodukte. Im Rahmen dieser Arbeit konnte dieses Phänomen nicht näher untersucht werden. Die eindeutige nukleäre Lokalisation der Fusionsproteine mit enthaltenem HFM aber deuteten aber darauf hin, daß in diesem Motiv die Information für die Kernlokalisation enthalten war.

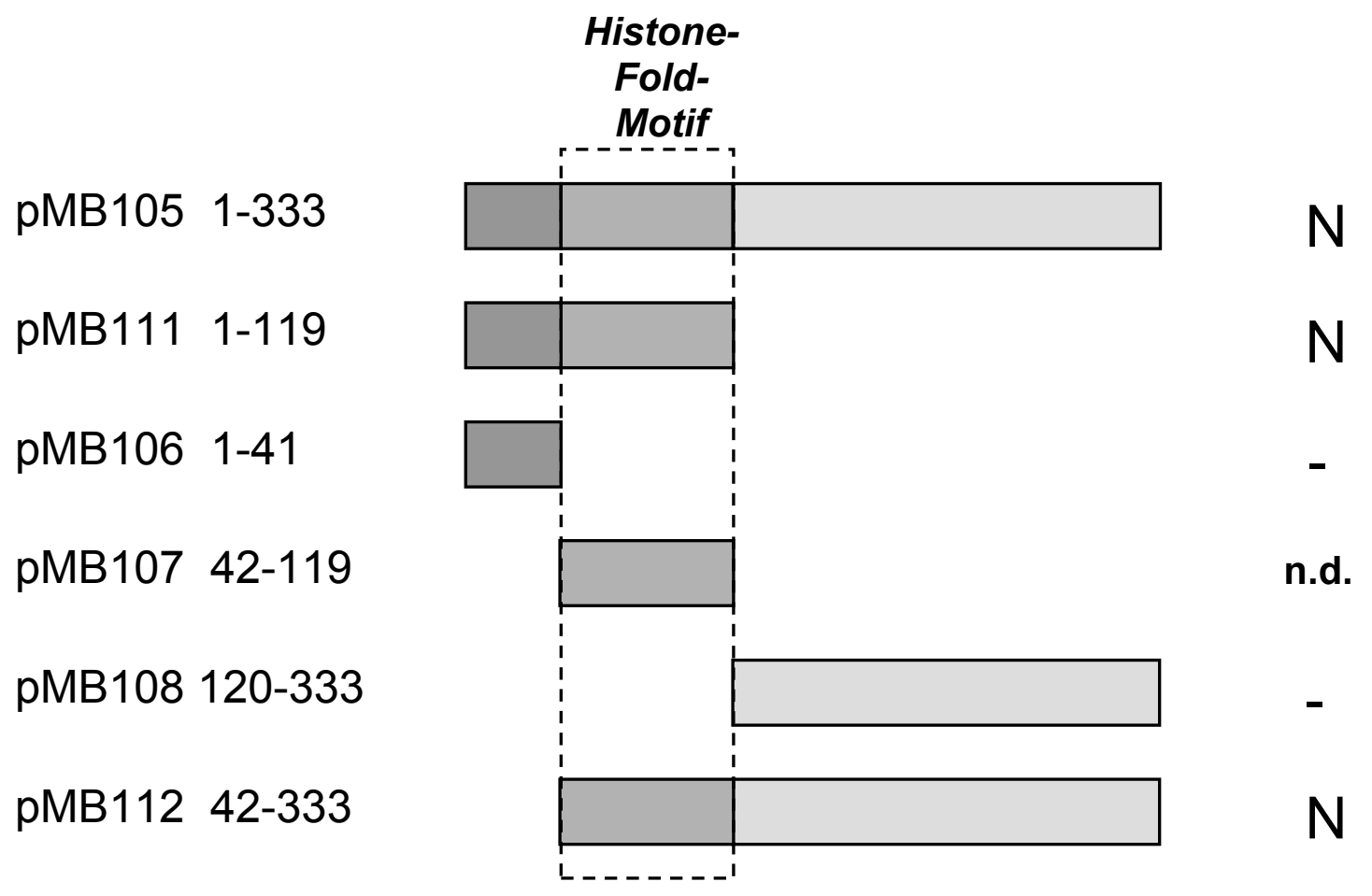

Abb. 20: Zusammenfassung der NLS-Studien an NF-YC. Wie in Abb. 18, dargestellt sind die Ergebnisse für NF-YC. Die Lokalisation der $\beta$-Galaktosidase-Fusionskonstrukte war entweder nukleär $(\mathrm{N})$, nicht eindeutig zuzuordnen, aber nicht nukleär (-) oder nicht detektierbar (n.d.).

In NF-YC gestaltete sich die Situation ähnlich: Auch hier schien das HFM am Kerntransport beteiligt zu sein, da nur diejenigen Fusionskonstrukte, die dieses Motiv enthielten, im Zellkern detektierbar waren (pMB105, pMB111, pMB112, Abb. 19). Eine Ausnahme stellte hier allerdings das Konstrukt pMB107 dar, das nicht detektierbar war und seine intrazelluläre Lokalisation daher nicht bestimmt werden konnte. Im Fall von pMB111 wurde eine inhomogene Fluoreszenz beobachtet, die einerseits Aggregatbildung andeutete, sich aber spezifisch in den Nukleoli anreicherte und daher 
als erfolgreicher Kernimport des Fusionsproteins gewertet wurde. Die C-terminale Domäne (pMB108) war nicht in der Lage, $\beta$-Galaktosidase in den Kern zu dirigieren, was an der eindeutig zytoplasmatischen Fluoreszenz erkennbar war. Die Lokalisation des Fusionsprotein aus N-terminale Domäne (pMB106) und Reporterprotein war ähnlich wie in einigen Fällen von NF-YB (pMB102, pMB104) nicht eindeutig bestimmbar, zeigte aber, daß kein Kernimport stattgefunden hatte.

In beiden untersuchten Proteinen konnte damit gezeigt werden, daß ihr NLS im HFM lokalisiert ist. Das Fehlen von bekannten NLS-Motiven in ihrer Aminosäuresequenz bei ausgeprägter Strukturhomologie der HFM von NF-Y und der Core-Histone läßt vermuten, daß das Strukturmotiv des HFM als solches ein Kernlokalisationssignal darstellt.

Analog zu den Core-Histonen besteht aber auch bei dieser Proteinklasse die Möglichkeit, daß die Formierung der drei Untereinheiten zum trimeren Komplex für den Import in den Kern Voraussetzung ist, wobei das NLS möglicherweise in nur einer Untereinheit vorhanden ist.

\subsection{Identifizierung beteiligter Faktoren beim Kernimport der Core-Histone}

\subsubsection{Kompetitionsexperimente: Import der Core-Histone wird nicht durch klassische NLS oder Linker-Histone kompetiert}

Die folgenden Experimente zielten darauf ab, die Rezeptoren zu identifizieren, die an dem Kerntransportprozeß der Core-Histone beteiligt sind. Kernproteine mit klassischem NLS wie SV40-NLS oder Nukleoplasmin werden über den sog. klassischen Importinweg in den Kern importiert, der unter Beteiligung von Importin $\alpha$ und Importin $\beta$ verläuft. Dabei bindet das klassische NLS an den heterodimeren Komplex aus Importin $\alpha$ und Importin $\beta$. Die Bindung erfolgt spezifisch über Importin $\alpha$, das seinerseits über seine IBB-Domäne (Importin-beta-binding-Domain) an Importin $\beta$ bindet (Görlich et al., 1996). Importin $\alpha$ fungiert dabei als Adaptermolekül, das die Bindung an Importin $\beta$ vermittelt, da klassische NLS selbst keine Bindungsaffinität zu Importin $\beta$ besitzt. Importin $\beta$ dagegen ist der eigentliche Transporter, der das Substrat, 
hier im Komplex mit Importin $\alpha$, über die Interaktion mit der Kernpore in den Zellkern dirigiert.

Da zu dem Zeitpunkt dieser Experimente noch keine rekombinanten Importrezeptoren für eine Rekonstitution des Transports der Core-Histone vorlagen, wurde zunächst indirekt versucht, Informationen über den Transportweg bzw. über seine beteiligten Importrezeptoren durch Kompetitionsexperimente zu erhalten. Dabei wurden als Kompetitoren Transportsubstrate verwendet, deren Importweg und daran beteiligte Importfaktoren bereits gut charakterisiert waren. Mit Hilfe des in vitro Importassays ließ sich mit diesen Experimenten herausfinden, ob das zu untersuchende Substrat und

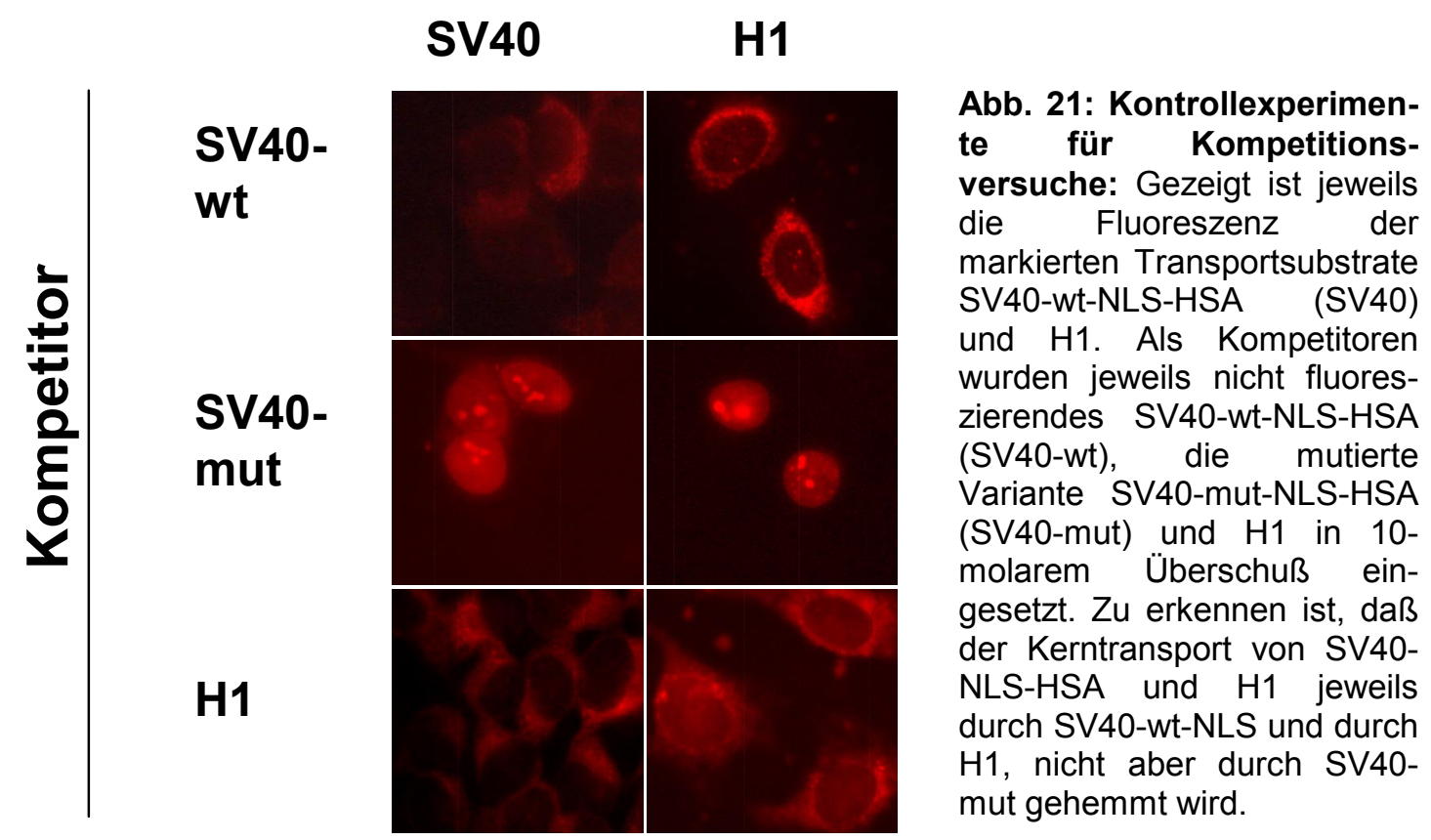

Kompetitor gleiche Transportfaktoren für den Transport von Zytoplasma in den Zellkern verwenden. Die Kompetitoren waren nicht fluoreszenzmarkiert und wurden dabei im Überschuß zu dem Transportansatz hinzugegeben, der wie unter Standardbedingungen Retikulozytenlysat, ein Energie-regenerierendes System sowie das zu untersuchende fluoreszenzmarkierte Substrat enthielt. Durch den molaren Überschuß an Kompetitor kommt es zu einer Absättigung derjenigen Importfaktoren, die am Import des Kompetitors beteiligt sind. Diese stehen damit einem Import des fluoreszenzmarkierten Substrats nicht mehr zur Verfügung und das Substrat kann nicht importiert werden, sofern es die gleichen Transportfaktoren für seine Translokation in den Kern benötigt wie der Kompetitor. Verbleibt das eigentliche 
Importsubstrat im Zytoplasma (zytoplasmatisches Fluoreszenzsignal), so kann gefolgert werden, daß es mit dem Kompetitor wenigstens einen Rezeptor für den Transport in den Zellkern gemeinsam hat.

Abb. 22: Core-Histone als Kompetitoren des klassischen Importinwegs und des H1-Imports:

Dargestellt sind die Fluoreszenzaufnahmen der fluoreszierenden Substrate SV40NLS-HSA (SV40) und H1. Die Kerntransportreaktion wurde in Anwesenheit jeweils des 10-molaren Überschusses an H2A, H2B, H3 bzw. H4 durchgeführt. Die zytoplasmatische Fluoreszenz zeigt, daß der Kerntransport von SV40-NLS$\mathrm{HSA}$ und $\mathrm{H} 1$ jeweils deutlich gehemmt wurde.

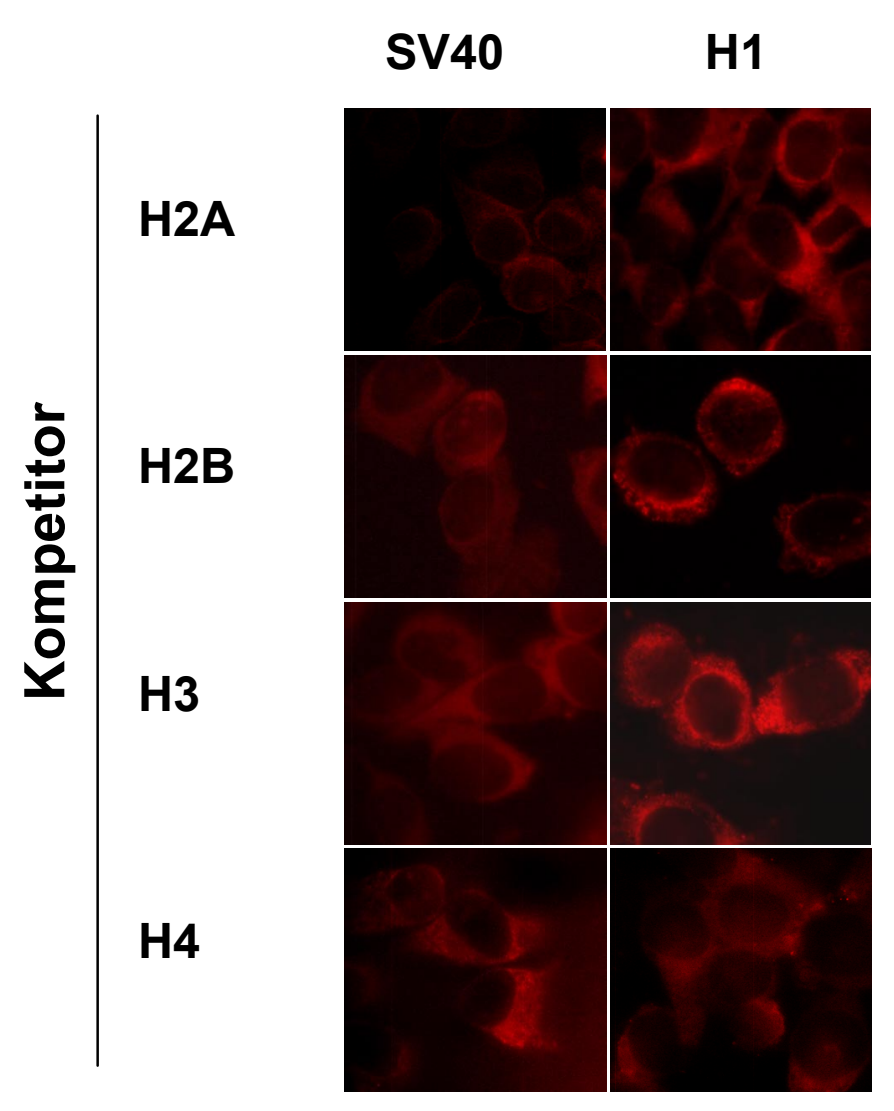

Zunächst wurde der Transport des fluoreszenzmarkierten SV40-NLS-HSA (NLS des SV40-T-Antigens an HSA gekoppelt) in Gegenwart von verschiedenen Kompetitoren untersucht. Wie in Abb. 21 zu sehen ist, wurde der Import von fluoreszenzmarkiertem SV40-NLS-HSA in Anwesenheit eines Überschusses an nicht-markiertem SV40-NLSHSA effektiv kompetiert, da das Substrat vollständig im Zytoplasma verblieb. Wurde dagegen das mutierte NLS verwendet, so zeigte sich eine eindeutig nukleäre Fluoreszenz: die Substrate wurden in den Kern importiert. Diese Experimente dienten zur Kontrolle der Spezifität der Kompetitionsexperimente. Das mutierte NLS sollte keinen Importrezeptor binden, und daher erwartungsgemäß keinen Einfluß auf den Transport des Substrats haben. Das NLS des Wild-Typs dagegen sättigte durch seinen Überschuß vermutlich vorhandenes Importin $\alpha$ und Importin $\beta$ ab, wodurch das markierte Substrat keine Importrezeptoren mehr vorfand und daher im Zytoplasma verblieb. 
Der Kerntransport des SV40-NLS-HSA wurde auch durch die Linker-Histone erfolgreich kompetiert, was an der fehlenden Kernfluoreszenz zu erkennen war. Die Kompetition durch $\mathrm{H} 1$ läßt sich wie folgt erklären: Wie bereits erwähnt, werden die H1Histone durch einen Heterodimer aus Importin $\beta$ und Importin7 in den Kern transportiert (Jäkel et al., 1999). Daraus war zu schließen, daß die Zugabe von nicht-markiertem H1 im Überschuß dem Transportansatz Importin $\beta$ durch Bindung an $\mathrm{H} 1$ zusammen mit Importin7 entzogen hatte. Dadurch war die Ausbildung eines Importin $\alpha /$ Importin $\beta$ SV40-NLS Importkomplexes nicht mehr möglich, so daß das SV40-NLS-Substrat im Zytoplasma zurückgehalten wurde. Dieses Experiment konnte umgekehrt werden: Wie in Abb. 21 an der zytoplasmatischen Fluoreszenz erkennbar, wurde der Kernimport von fluoreszierendem $\mathrm{H} 1$ effizient durch SV40-NLS als Kompetitor gehemmt. Dies kann analog erklärt dadurch werden, daß SV40 durch die Bildung des Importin $\alpha /$ Importin $\beta / S V 40-N L S-I m p o r t k o m p l e x e s$ seinerseits dem Transportansatz Importin $\beta$ entzieht, das für die Bildung des Importin $\beta /$ Importin7 Heterodimers nicht mehr zur Verfügung steht, so daß H1 nicht importiert werden konnte.

In Abb. 22 ist zu erkennen, daß der Einsatz von Core-Histonen als Kompetitoren des

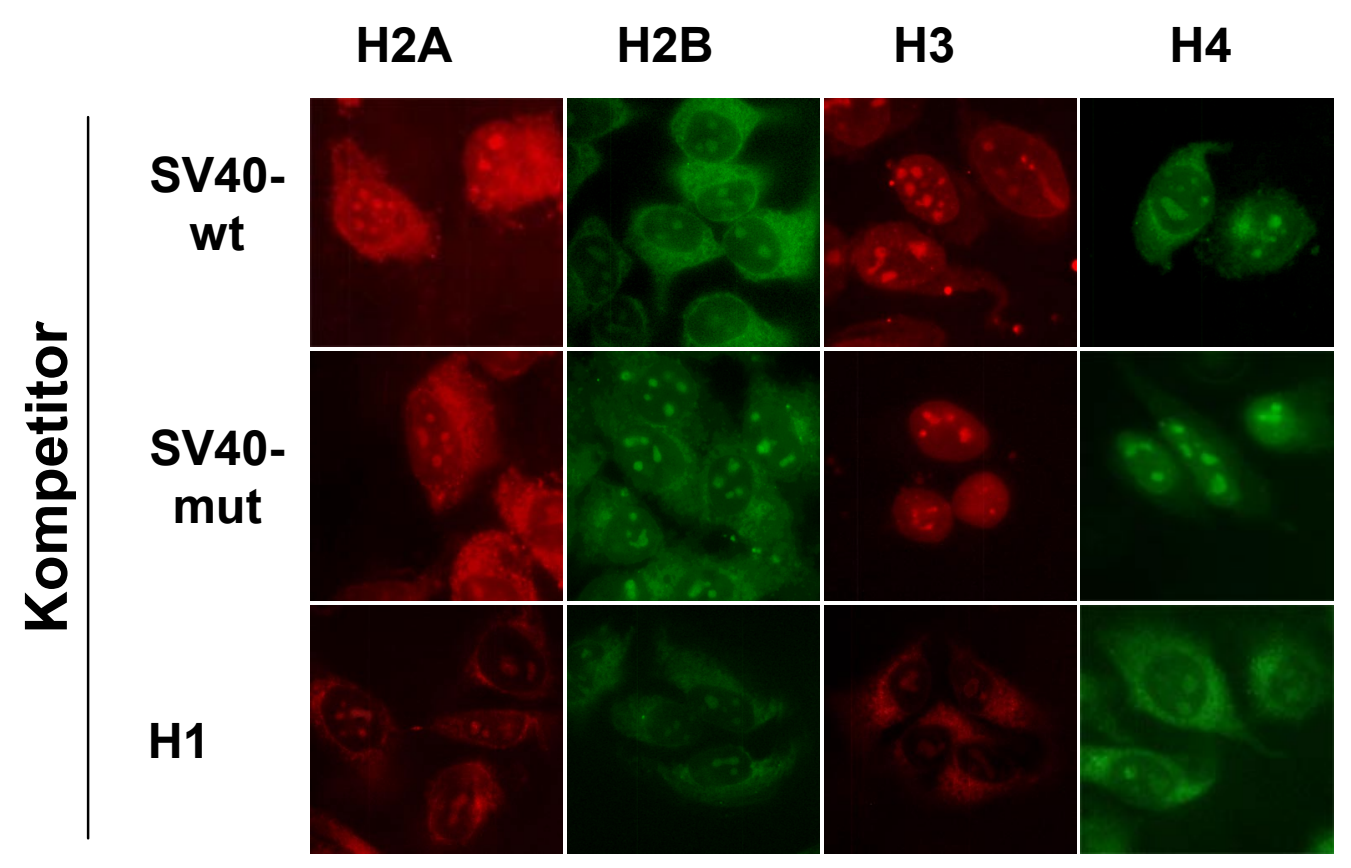

Abb. 23: Der Kerntransport der Core-Histone wird weder durch Substrate des klassischen Importinwegs noch durch H1-Histone kompetiert. Dargestellt sind die Fluoreszenzen der Transportreaktionen der Core-Histone H2A, H2B, H3 und H4 in Anwesenheit eines 20-molaren (SV40-wt-NLS, SV40-mut-NLS) bzw. eines 10-molaren Überschusses $(\mathrm{H} 1)$ des entsprechenden Kompetitors. Die erkennbare Fluoreszenz in den Nukleoli zeigte, daß erhebliche Anteile der Core-Histone trotz Anwesenheit des SV40-wt-NLS-HSA-Konjugats oder der H1-Histone in die Zellkerne der permeabilisierten Zellen transportiert wurden. 
SV40-NLS- und H1-Imports zum Ausbleiben eines nukleären Fluoreszenzsignals

führte. Daher inhibierten alle vier Core-Histone den Import sowohl von SV40-NLS als auch von H1. Für die Core-Histone war bislang noch kein Importrezeptor identifiziert worden. Die Ergebnisse dieser Kompetitionsexperimente ließen aber vermuten, daß Importin $\beta$ am Kerntransport beteiligt ist, da die Transportwege für SV40-NLS und H1 jeweils Importin $\beta$ erfordern.

In den Experimenten mit fluoreszenzmarkierten Core-Histonen als Substrate zeigte

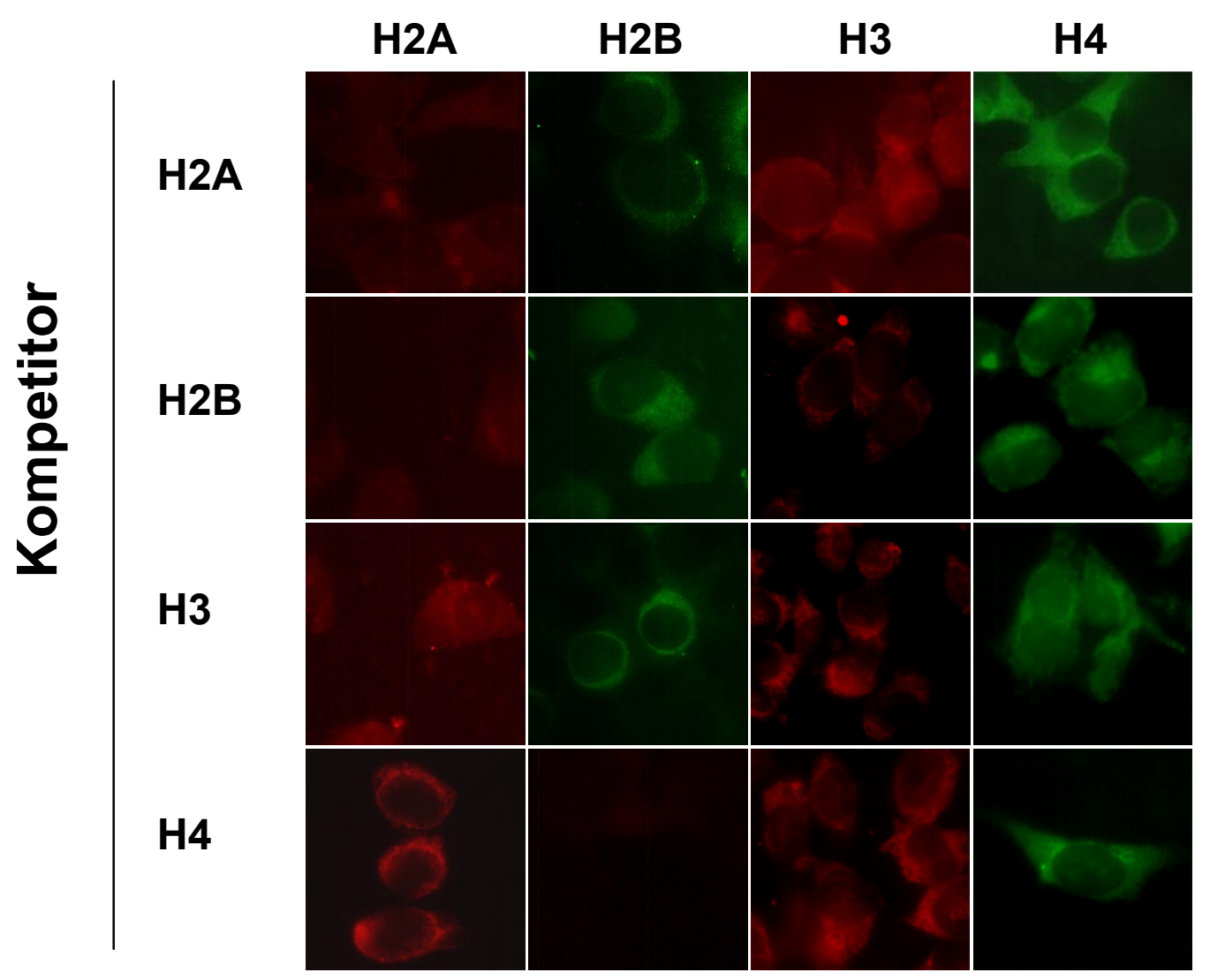

Abb. 24: Der Kerntransport jedes Core-Histons ist mit einem anderen kompetierbar. Dargestellt sind die Fluoreszenzen der Transportreaktionen der Core-Histone H2A, H2B, H3 und $\mathrm{H} 4$ jeweils in Anwesenheit eines 10-Molaren Überschusses eines der vier Core-Histone. In keinem der Experimente konnte das Transportsubstrat in den Zellkern importiert werden.

sich, daß inr Transport in den Zellkern anders als im Falle der $\mathrm{H} 1$-Histone und Proteine mit klassischem NLS nicht effizient von SV40-NLS kompetiert wurde (Abb. 23). Zwar blieb ein großer Anteil der Substrate im Zytoplasma, aber ein signifikanter Teil war auch im Zellkern, vor allem, in den Nukleoli, detektierbar. Daraus ließ sich 
zunächst schlußfolgern, daß sich die Core-Histone unter gleichen Bedingungen anders verhielten als die Linker-Histone und als Proteine, die dem klassischen Importinweg folgen.

Eine Erklärung für diese Beobachtungen war, daß der Kerntransport der Core-Histone nicht auf einen Importrezeptor beschränkt ist, sondern verschiedene Rezeptoren in gleicher Weise Core-Histone in den Kern dirigieren können, vergleichbar dem Import von ribosomalen Proteinen (Jäkel und Görlich, 1998).

Wurde $\mathrm{H} 1$ als Kompetitor eingesetzt, so war neben der vorwiegend zytoplasmatischen Fluoreszenz ebenfalls eine schwache Färbung der Nukleoli erkennbar. Dies ließ vermuten, daß $\mathrm{H} 1$ den Import der Core-Histone zwar stark einschränkte, aber ähnlich wie SV40-NLS nicht alle Importrezeptoren absättigte, so daß andere funktionelle Transporter als Importin $\beta$ und Importin7 für die Core-Histone in Frage kamen.

Darüber hinaus war den Kompetitionsexperimenten zu entnehmen, daß sich die CoreHistone untereinander gegenseitig beim Transport kompetierten. In allen Fällen fehlte jede nukleäre Fluoreszenz (Abb. 24). Sie konkurrierten damit offenbar um dieselben Importrezeptoren.

Die Kompetitionsexperimente geben nur einen Hinweis auf beteiligte Importrezeptoren, da die Auswirkung des zugeführten Proteinüberschusses auf Bestandteile des Zytoskeletts oder rezeptorunspezifische Komponenten, wie das Ran-System, unberücksichtigt bleiben. Zudem war die Auswertung der erhaltenen Fluoreszenzbilder häufig erschwert, da es, vermutlich bedingt durch die Zugabe großer Proteinmengen, zu Präzipitationen kam, die auch die fluoreszierenden Substrate betraf. Dadurch war in manchen Fällen die eindeutige Determinierung der intrazellulären Lokalisation beeinträchtigt.

Ingesamt geben die Ergebnisse aus den Kompetitionsexperimenten den Hinweis, daß die Core-Histone über einen Importweg in den Zellkern gelangen, der für alle CoreHistone der gleiche ist, sich aber vom klassischen Importinweg und vom Importweg der Linker-Histone unterscheidet, wobei die Beteiligung von Importin $\beta$ wahrscheinlich ist.

Näheren Aufschluß über die beteiligten Transportrezeptoren des Core-Histone Imports sollten Rekonstitutionsexperimente mit aufgereinigten rekombinanten Transportfaktoren geben. 


\subsubsection{Rekonstitutionsexperimente: Importin $\beta$, Importin7, Importin5 und Transportin sind funktionelle Importrezeptoren für Core-Histone}

Wie die Kompetitionsexperimente zeigten, war zu vermuten, daß die Core-Histone anders als das SV40-T-Antigen-NLS und H1, aber unter Beteiligung von Importin $\beta$ in den Zellkern importiert werden, eventuell vergleichbar mit dem Transport ribosomaler Proteine. Mit aufgereinigten rekombinanten Importfaktoren Importin $\alpha$, Importin $\beta$, Importin5, Importin7 und Transportin sowie den Bestandteilen des Ran-Systems RanGDP und NTF2 wurde versucht, den Kerntransport der Core-Histone im in vitro Importassay zu rekonstituieren.

Dafür mußten neben den Importfaktoren auch die zugehörigen Kontrollsubstrate zur Bestimmung der Funktionalität der eingesetzten Faktoren präpariert werden.

SV40-NLS-HSA wurde für Importin $\alpha /$ Importinß, die IBB-Domäne (Importin beta binding Domain) für Importin $\beta$ (Görlich et al., 1996), H1 für den Heterodimer aus Importinß/Importin7 (Jäkel et al., 1999) und die M9-Domäne, das NLS des Ribonukleoproteins hnRNPA1, für Transportin (Pollard et al., 1996) verwendet. Das ribosomale Protein L23a war als Importsubstrat für alle Importrezeptoren mit Ausnahme von Importin $\alpha$ beschrieben worden (Jäkel und Görlich, 1998). In Tab. 1 (vgl. 1.2) sind verwendete Importrezeptoren sowie in der Literatur beschriebene Substrate zusammengestellt.

\subsubsection{Präparation der Transportrezeptoren und Kontrollsubstrate}

SV40-NLS-HSA-TRITC und H1-TRITC waren wie bereits beschrieben (vgl. 3.2) hergestellt worden. Die IBB-Domäne wurde als aufgereinigtes, fluoreszenzmarkiertes Protein von Dr. Görlich (Heidelberg) zur Verfügung gestellt. L23a, sowie Ran und NTF2 wurden in unserer Arbeitsgruppe präpariert (Marc Bäuerle, Diss. in Präp.).

Die Importfaktoren und die M9-Domäne wurden in E. coli exprimiert und aufgereinigt. Die für Importin $\alpha$, Importin $\beta$, Importin5, Importin7, und Transportin codierenden Expressionsvektoren wurden von Dr. Görlich (Heidelberg) zur Verfügung gestellt. Die codierenden Sequenzen waren jeweils in pQE-Vektoren kloniert worden, die am 3'Ende des codierenden Bereichs die Sequenz für eine Polyhistidindomäne enthalten. Diese führt $\mathrm{zu}$ einemFusionsprotein mit sechs Histidinen am C-Terminus und 
ermöglicht dadurch die affinitätschromatische Aufreinigung des Proteins. Die Vektoren enthalten in ihrer Kontrollregion die Promotorregion des T5-Phagen sowie zwei lac-

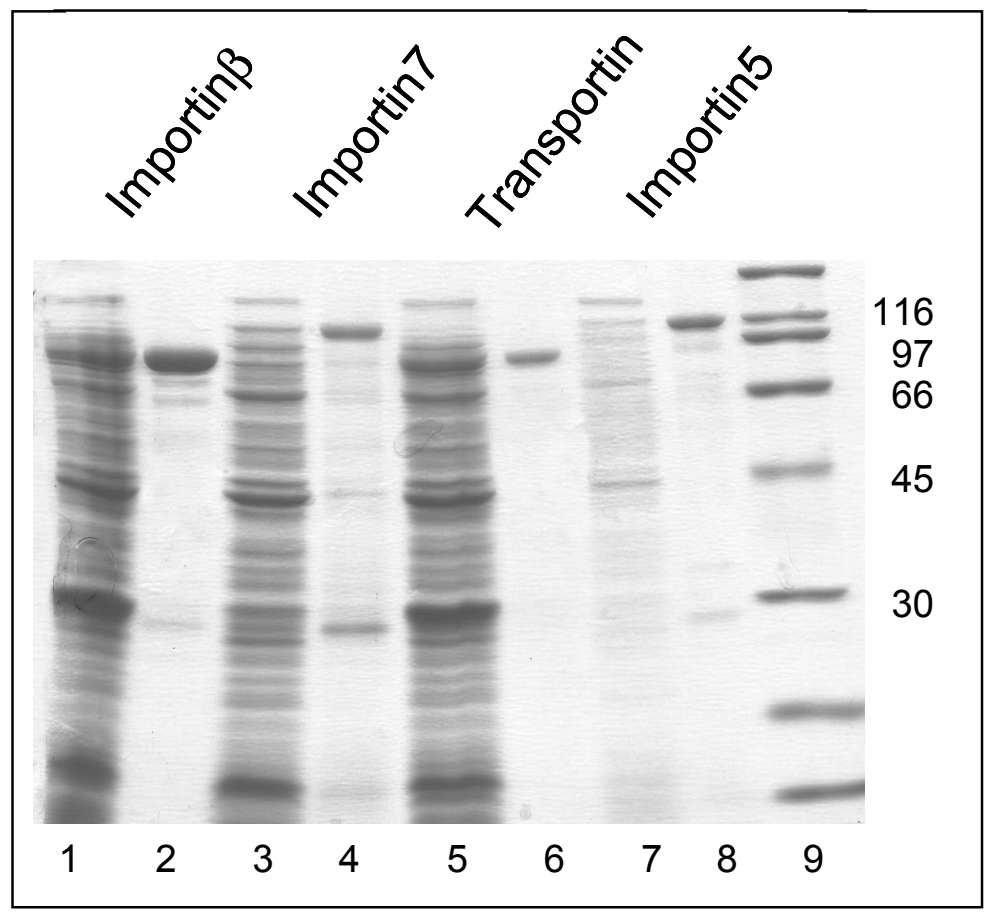

Abb. 25: Analyse der affinitätschromatographisch aufgereinigten Importfaktoren. Dargestellt ist die Coomassie-Färbung eines Polyacryamid-Gels (12,5\%). Abwechselnd sind jeweils Bakterienlysat und daraus aufgreinigtes Protein aufgetragen. Spur 1 und 2: Importin $\beta ; 3$ und 4: Importin7; 5 und 6: Transportin, 7 und 8: Importin5, 9: Proteinmarker.

Operator-Elemente. Die Genexpression wird durch lac-Repressormoleküle zunächst verhindert, durch Zugabe von IPTG, das den Repressor deaktiviert, wird die Genexpression induziert. Die Aufreinigung erfolgte durch Affinitätschromatographie über Ni-NTA-Agarose. Diese bindet durch freie Bindungsstellen im $\mathrm{Ni}^{2+}$-lon sehr spezifisch an Polyhistidinregionen von Proteinen. Da natürlich vorkommende Proteine in der Regel nicht über mehrere aneinandergereihte Histidine verfügen, gelingt es, rekombinante Proteine mit Polyhistidin-"Tag" von endogenen bakteriellen Proteinen zu trennen, indem sie zunächst an die Ni-NTA-Agarosematrix gebunden und nach Inkubation mit Imidazol eluiert werden. Imidazol konkurriert dabei mit dem Protein um die Bindungsstellen des $\mathrm{Ni}^{2+}$ und verdrängt es schließlich bei hohen Konzentrationen. Die gelelektrophoretische Analyse einiger aufgereinigter Transportfaktoren ist in Abb. 25 dargestellt. Tab. 4 zeigt die verwendeten Importfaktoren und die Ausbeuten ihrer Proteinpräparationen. 
Von Dr. Dreyfuss (Philadelphia, USA) wurde ein Expressionsvektor zur Verfügung gestellt, der für ein Fusionsprotein aus der M9-Domäne und Glutathion-S-Transferase (GST) codiert. GST bindet spezifisch an Glutathion und ermöglicht so die affinitätschromatographische Aufreinigung über eine Glutathion-Sepharosematrix. Die Elution erfolgt dabei durch Glutathion in einer Konzentration von $10 \mathrm{mM}$, das mit dem matrixgebundenen Glutathion (GT) um die Bindung mit dem GST-Anteil im Fusionsprotein konkurriert.

\begin{tabular}{|c|c|c|c|c|c|}
\hline & Importin $\alpha$ & Importin $\beta$ & Importin5 & Importin7 & Transp. \\
\hline Referenz & $\begin{array}{l}\text { Görlich et } \\
\text { al., } 1994\end{array}$ & $\begin{array}{l}\text { Görlich et } \\
\text { al., } 1996\end{array}$ & $\begin{array}{l}\text { Jäkel et al., } \\
1998\end{array}$ & $\begin{array}{l}\text { Görlich et } \\
\text { al.,1997 }\end{array}$ & $\begin{array}{l}\text { Pollard et } \\
\text { al, } 1996\end{array}$ \\
\hline Organismus & Xenopus I. & Mensch & Mensch & Xenopus I. & Mensch \\
\hline Vektor & pQE70 & pQE30 & pQE30 & pQE9 & pQE32 \\
\hline $\begin{array}{l}\text { Ausbeute } \\
{[\mu \mathrm{g} / \mathrm{ml}]}\end{array}$ & 0,5 & 0,2 & 0,3 & 0,1 & 0,5 \\
\hline
\end{tabular}

Tab. 4: Übersicht über verwendete Importfaktoren. Die Proteine wurden bakteriell exprimiert und aufgereinigt. Die Gene sind in PQE-Vektoren enthalten, die eine Aufreinigung des exprimierten Proteins über Ni-NTA durch einen Hexahistidinanteil ermöglichen. Die Ausbeute der Proteinpräparation ergibt sich aus der Menge an präpariertem Protein in $\mu \mathrm{g}$ im Verhältnis zum Volumen der verwendeten Bakterienkultur in ml. Abk.: Transp.: Transportin; Xenop. I.: Xenopus laevis

Die M9-Domäne wurde in E. coli (XI1-blue) exprimiert und über GT-Sepharosematrix aufgereinigt. Dabei wurden etwa 2,0 $\mu \mathrm{g}$ Protein / ml Kulturmedium erhalten. Das M9GST-Fusionsprotein wurde nicht fluoreszenzmarkiert, sondern nach der Transportreaktion im in vitro Importassay durch Immunfluoreszenz mit einem Primärantikörper gegen GST und einem fluoreszenzmarkierten Zweitantikörper nachgewiesen.

\subsubsection{In vitro Import der Core-Histone mit aufgereinigten Importfaktoren}

Alle Reaktionsansätze enthielten Ran, NTF2, einen Energiemix sowie unterschiedliche Kombinationen von Importfaktoren und das zu untersuchende fluoreszierende Transportsubstrat. Abb. 26 zeigt die intrazelluläre Lokalisation einiger in der Literatur beschriebener Kontrollsubstrate in Abhängigkeit von verschieden Importrezeptoren. 
Zum Vergleich sind die Experimente unter Standardbedingungen (Retic) sowie in Abwesenheit von Zytosol und Transportfaktoren (Puffer) gezeigt. Die Kontrollsubstrate konnten unter

Standardbedingungen effektiv in den Kern importiert werden, wobei im Fall des L23a eine extrem starke nukleoläre Fluoreszenz beobachtet wurde. Diese war für das ribosomale Protein L23a zu erwarten, da die Assemblierung der Ribosomen in den Nukleoli stattfindet.

SV40-NLS wurde als Substrat des klassischen Importinwegs nur durch Importin $/ /$ Importin $\beta$ in den Zellkern importiert. Dies war an der deutlichen Kernfluoreszenz erkennbar, während Importin $\beta$, ebensowenig wie Importin7, Importinß/Importin7, Transportin oder Importin5 nicht hinreichend waren, da in diesen Fällen jeweils keine Lokalisation des Substrats im Kern zu beobachten war.

Die IBB-Domäne wurde effektiv nur durch Importin $\beta$ in den Kern transportiert. War neben Importin $\beta$ auch Importin $\alpha$ vorhanden, so war der Import vermutlich durch den kompetitiven Effekt von Importin $\alpha$ gehemmt. Die M9-Domäne fand nur in Anwesenheit von Transportin den Weg in den Kern. Die Linker-Histone konnten nur im Kern detektiert werden, wenn sowohl Importin $\beta$ als auch Importin7 vorhanden waren.

Das Importverhalten von L23a konnte ebenfalls reproduziert werden: das Protein konnte in Anwesenheit jedes einzelnen Importrezeptors im Importassay mit Ausnahme von Importin $\alpha$ im Kern detektiert werden. Die Core-Histone verhielten sich in diesen Experimenten anders als SV40-NLS und die Linker-Histone: Sie ließen sich nicht mit Imp $\alpha /$ Imp $\beta$ importieren; dies war an der fehlenden Kernfluoreszenz erkennbar (Abb. 27). War allerdings Importin $\alpha$ abwesend und nur Importin $\beta$ vorhanden, zeigte sich bei allen vier Core-Histonen eine deutliche nukleäre Fluoreszenz. Die Core-Histone wurden also allein durch Importin $\beta$ in den Kern transportiert. Importin $\alpha$ hatte dabei offensichtlich einen Inhibitorischen Effekt. Eine Bindung von Importin $\alpha$ an Importin $\beta$ verhindert möglicherweise eine Interaktion von Importin $\beta$ mit dem Core-Histon und damit die Ausbildung eines Importin $\beta /$ Substrat-Komplexes. Dieses Phänomen wurde auch bei IBB und bei den ribosomalen Proteinen in weniger ausgeprägter Form beobachtet (Jäkel und Görlich, 1998). Interessanterweise stellt Importin $\beta$ nicht den einzigen funktionellen Importrezeptor für die Core-Histone dar, da auch Importin7 in der Lage war, diese in den Zellkern zu 


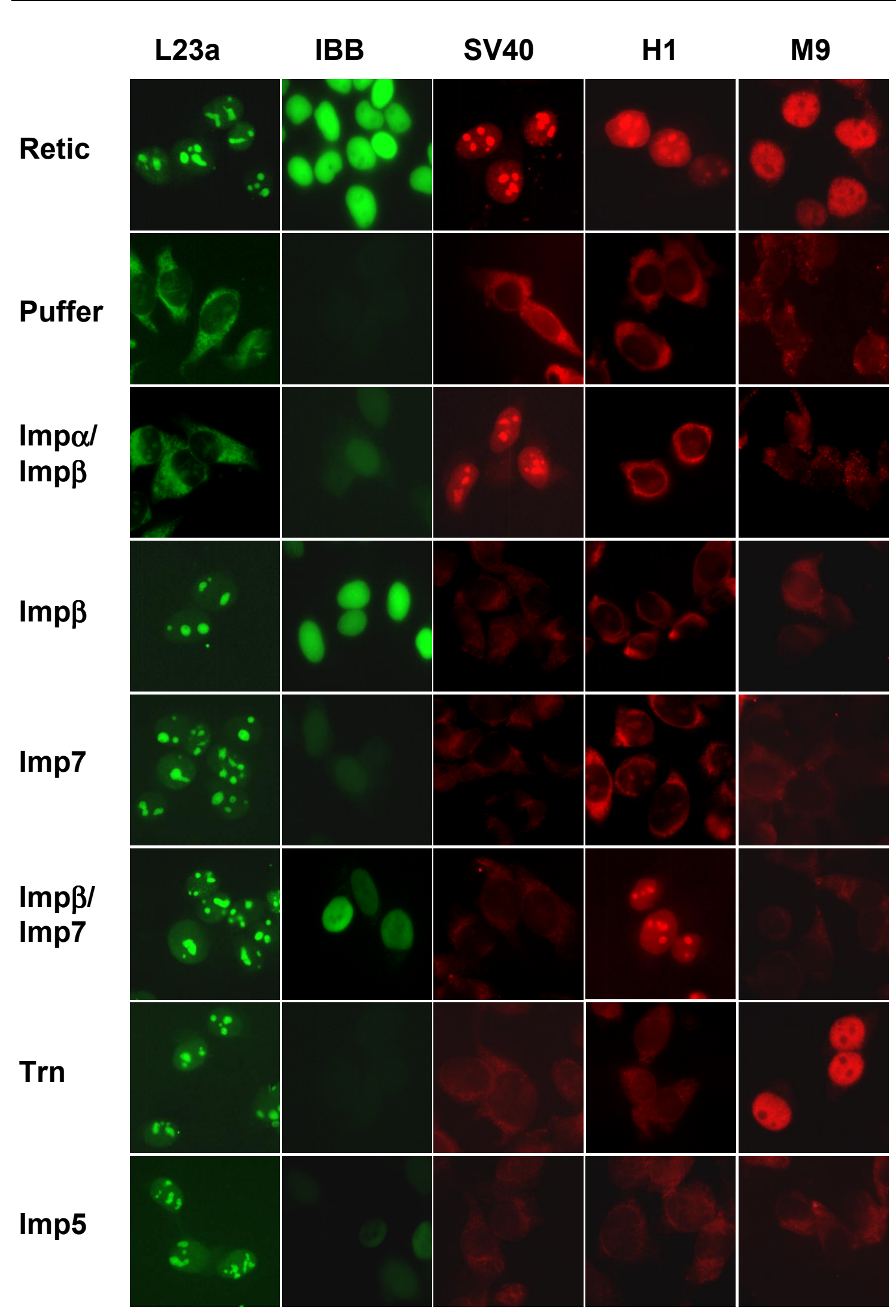

Abb. 26: In vitro Rekonstitutionsexperimente mit Kontrollsubstraten und aufgereinigten Importfaktoren: Gezeigt ist die Fluoreszenzdetektion der Importexperimente unter Standardbedingungen mit verschiedenen Kontrollsubstraten (obere Zeile) in Gegenwart von exogenem Zytosol (Retic), Transportpuffer (Puffer) oder Lösungen von Importfaktoren (wie angegeben). Wie anhand der Fluoreszenzen erkennbar, wurde SV40-NLS-HSA ausschließlich durch Importin $\alpha / \operatorname{Importin} \beta(\operatorname{Imp} \alpha / \operatorname{Imp} \beta)$, IBB durch $\operatorname{Importin} \beta(\operatorname{Imp} \beta)$, H1 durch Importin $\beta$ und Importin7 ( $\operatorname{Imp} \beta / \mathrm{Imp} 7)$, M9 durch Transportin (Trn) in den Kern importiert. Für L23a waren alternativ Importin $\beta$, Importin7, Transportin und Importin5 (Imp5) funktionell. 


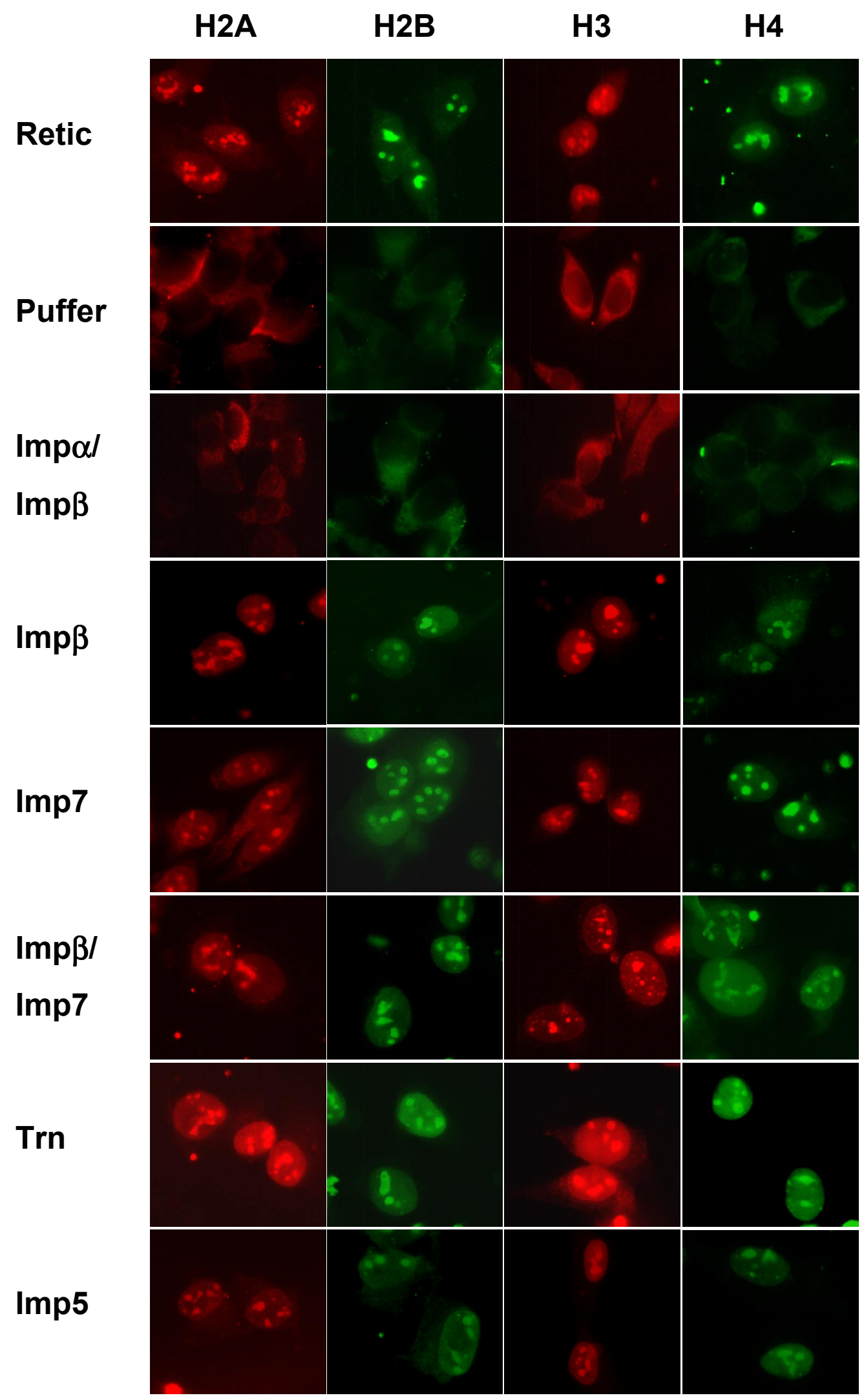

Abb. 27: In vitro Rekonstitutionsexperimente mit fluoreszenzmarkierten Core-Histonen und aufgereinigten Importfaktoren: Die Experimente wurden wie in Abb. 26 durchgeführt. Kernfluoreszenz der permeabilisierten Zellen zeigte einen erfolgreichen Kerntransport der Core-Histone an. Dies war der Fall in Anwesenheit von exogenem Zytosol, Importin $\beta$, Importin7, Transportin, oder Importin5. Enthielt der Reaktionszusatz aber nur Transportpuffer oder neben Importin $\beta$ auch Importin $\alpha$, so wurden die Core-Histone nicht in den Zellkern importiert. 
dirigieren.

Waren sowohl Importin $\beta$ als auch Importin7 vorhanden, so konnte ebenfalls ein Kerntransport beobachtet werden. Die nukleären Fluoreszenzen waren vergleichbar intensiv, so daß geschlossen werden konnte, daß das Vorliegen beider Faktoren weder einen inhibitorischen noch einen kooperativen Effekt auf den Kerntransport der Core-Histone hatte. Anders als die Linker-Histone werden also die Core-Histone ohne Ausbildung eines Importin $\beta /$ Importin7-Dimers in den Kern importiert.

Wie an den fluoreszierenden Kernen in der siebten Zeile von Abb. 27 erkennbar, wurden alle vier Core-Histone auch durch Transportin in den Kern importiert. Hier zeigte sich die stärkste Fluoreszenz, was den Schluß zuließ, daß Transportin möglicherweise den effektivsten Importrezeptor für die Core-Histone darstellte.

Importin5 war bislang nur beim Import der ribosomalen Proteine als Importrezeptor beschrieben worden. Aber auch die Core-Histone wurden durch Importin5 in den Kern importiert, wie an der nukleären Fluoreszenz erkennbar ist. Damit konnte auch Importin5 als funktioneller Importrezeptor für die Core-Histone identifiziert werden.

Zusammenfassend kann aus den in vitro Rekonstitutionsexperimenten geschlossen werden, daß Importin $\beta$, Importin5, Importin7 und Transportin funktionelle Importrezeptoren für die vier Core-Histone darstellen. Dabei wirken sie autonom, ohne einen Adapter oder einen weiteren Partner zur Ausbildung eines funktionellen Importerkomplexes zu benötigen. Daraus ist zu schließen, daß die Core-Histone anders als die Linker-Histone auf mindestens vier verschiedenen Wegen alternativ in den Kern transportiert werden, unabhängig von der Ausbildung eines Importin $\beta /$ Importin7-Heterodimers. Der Importweg der Core-Histone stimmt damit dem der ribosomalen Proteine L23a und L5 überein, deren funktionelle Importrezeptoren dieselben sind (Jäkel und Görlich, 1998). 


\subsubsection{H2B enthält ein klassisches NLS, das im Kontext des gesamten Proteins nicht funktionell ist}

In H2B war in den NLS-Studien ein basischer Bereich von 10 Aminosäuren gefunden worden, der als NLS identifiziert wurde (H2B-NLS1), da er $\beta$-Galaktosidase in den Zellkern dirigierte (pMB8, Abb. 12, Abb. 13). Darüber hinaus zeigte seine Aminosäuresequenz (GKKRKRSRK) eine hohe Übereinstimmung mit dem SV40-TAntigen-NLS (PKKKRKV); beide enthielten fünf aufeinanderfolgende basische Aminosäuren.

Man konnte daher annehmen, daß es sich hierbei um ein typisches klassisches NLS handelte. Dies bedeutete wiederum, daß dieses Peptid auch den Kernimport über den klassischen Importweg also mit Importin $\alpha /$ Importin $\beta$ vermittelt. In den Rekonstitutionsexperimenten konnte allerdings keine Kernfluoreszenz von H2B als ganzes Protein mit Importin $\alpha$ und Importin $\beta$ beobachtet werden, obwohl es dieses Peptid enthielt (Abb. 27).

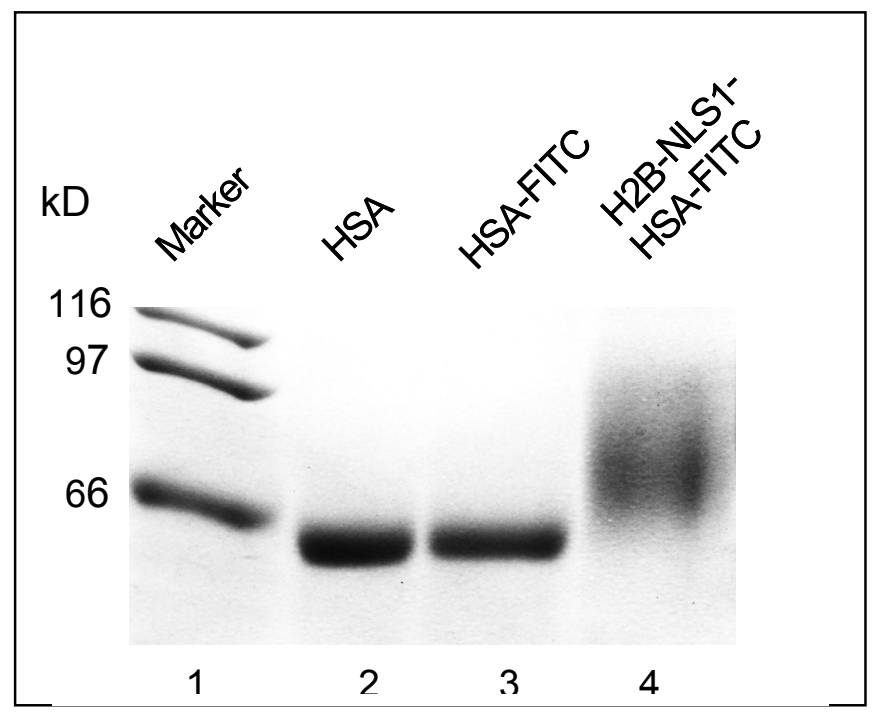

Abb. 28: Gelelektrophoretische Analyse des H2B-NLS1-HSAFITC-Konjugats:

Dargestellt ist ein Coomassie-gefärbtes SDS-Polyacrylamid-Gel $(10 \%)$. Je Spur sind ca. 2-3 $\mu$ g aufgetragen. Spur 1: Proteinmarker; 2: HSA (nicht modifiziert); 3: HSA-FITC; 4: H2BNLS1-HSA-FITC. 
Um diesen Widerspruch erklären zu können, wurde ein synthetisches Peptid, das die entsprechende Aminosäures equenz enthielt, analog zu dem bereits erwähnten SV40T-Antigen-NLS-Peptid (vgl. 3.2.1) chemisch an fluoreszenzmarkiertes HSA gekoppelt. Abb. 28 zeigt die gelelektrophoretische Analyse des Reaktionsprodukts. Die Bande zeigt analog zu dem SV40-HSA-Konjugat (vgl. Abb. 5) einen breiten Verlauf, befindet

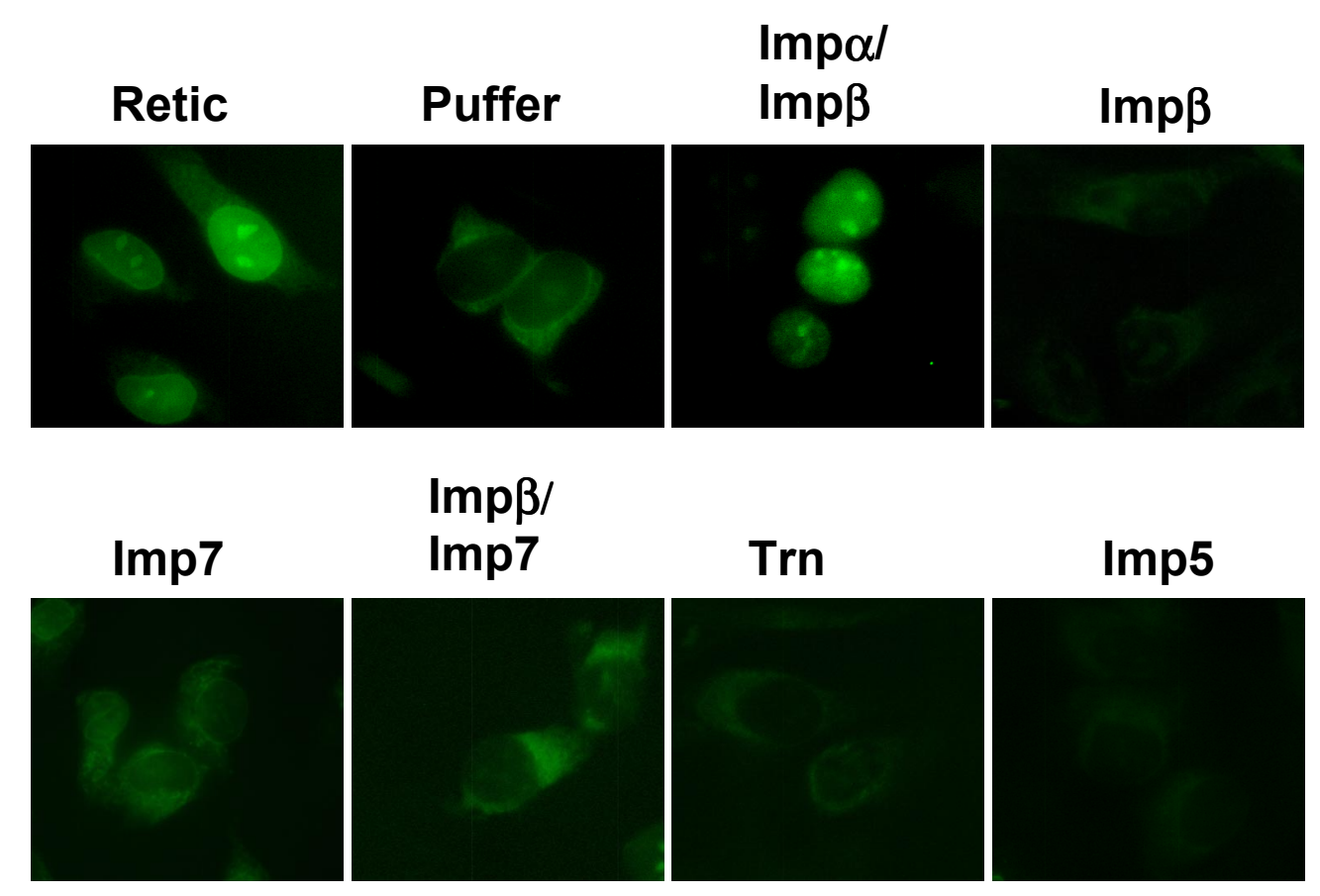

Abb. 29: Rekonstitutionsexperimente zur Identifizierung des Importrezeptors des H2BNLS1: Der Kernimport von fluoreszenzmarkiertem H2B-NLS1-HSA wurde im in vitro Importassay mit unterschiedlichen Zusätzen wie angegeben untersucht. Die Transportreaktion wurde entweder in Gegenwart von exogenem Zytosol (Retic), Transportpuffer (Puffer), Importin $\alpha$ und Importin $\beta(\operatorname{Imp} \alpha / \operatorname{Imp} \beta)$, Importin $\beta$ (Imp $\beta)$, Importin7 (Imp7), Importin $\beta$ und Importin7, Transportin (Trn) oder Importin5 (Imp5) durchgeführt. Alle Ansätze enthielten ein Energie-regenerierendes System, die Lösungen aufgereinigter Importfaktoren außerdem noch RanGDP und NTF2. Kernimport des Transportsubstrats wurde nur in Anwesenheit von exogenem Zytosol oder mit Importin $\alpha$ und Importin $\beta(\operatorname{Imp} \alpha / \operatorname{Imp} \beta)$ beobachtet.

sich aber bei geringeren molekularen Massen. Das Konjugat enthält schätzungsweise 5-15 gekoppelte Peptide pro HSA-Molekül.

Das wie beschrieben modifizierte HSA wurde nach Reinigung in einer Konzentration von etwa $300 \mathrm{nM}$ im Importassay eingesetzt. In den Kontrollansätzen zeigte sich, daß sich das Substrat unter Standardbedingungen im Zellkern, in Abwesenheit von exogenem Zytosol im Zytoplasma anreicherte (Abb. 29). Daher war davon 
auszugehen, daß der Kerntransport des H2B-NLS1-Peptids von Zytosolischen Komponenten abhängig ist.

Weiterhin wurde beobachtet, daß das H2B-NLS1-HSA-Hybrid-Substrat in Anwesenheit von Importin $\alpha$ und Importin $\beta$ in den Kern transportiert wurde, was durch die eindeutige Fluoreszenz des Zellkerns der permeabilisierten HeLa-Zellen zu erkennen war. Weder durch Importin $\beta$, Importin7 oder Importin $\beta /$ Importin7, noch durch Transportin oder Importin5 konnte das Substrat in den Kern importiert werden; denn in keinem dieser Fälle war nukleäre Fluoreszenz zu erkennen (Abb. 29). Diese Resultate zeigen, daß das H2B-NLS1 einem typischen klassischen NLS entspricht: Einerseits besteht es aus einem kurzen, sehr basischen Peptid, das in seiner Aminosäuresequenz zwar keine vollständige Übereinstimmung, aber zumindest eine sehr starke Ähnlichkeit zum Prototyp des klassischen NLS-Typs aus dem SV40-T-Antigen aufweist. Andererseits wird es durch den klassischen Importinweg, mit Importin $\alpha$ und Importin $\beta$, in den Zellkern importiert. Es handelt sich damit sowohl strukturell als auch funktionell um einen klassischen NLS-Typ. Um so erstaunlicher ist, daß das gesamte H2B-Protein, obwohl es das Peptid in sich trägt, nicht über diesen Importweg transportiert werden konnte. Dies könnte so erklärt werden, daß im Kontext des Gesamtproteins die Zugänglichkeit des NLS-Peptids durch die Wechselwirkung mit benachbarten Proteineinheiten derart beeinflußt wird, daß Importin $\alpha$ nicht mehr effektiv binden kann. 


\section{DISKUSSION}

Für eine funktionierende eukaryontische Zelle ist es notwendig, daß ein ständiger molekularer Austausch zwischen Zellkern und Zytoplasma gewährleiset ist. Dabei muß die Kernmembran überwunden werden, die das nukleäre Kompartiment abgrenzt. Der Austausch von Nukeinsäuen und Proteinen zwischen beiden Zellkompartimenten geschieht durch den Kernporenkomplex NPC, einen makromolekularen Proteinkomplex, der in die Kernmenbran eingebettet ist. Proteintransportprozesse durch den NPC erfordern spezifische Kernlokalisationsignale in der Proteinstruktur sowie daran bindende Transportrezeptoren, die durch Interaktion mit dem NPC den Transport in den Kern vermitteln.

Transportprozesse zwischen Zellkern und Zytoplasma stellen einen Teil der in einer Zelle ablaufenden Translokationsvorgänge dar und sind daher Gegenstand zahlreicher Forschungsprojekte mit dem Ziel, das molekulare Verständnis intrazellulärer Transportprozesse zu erweitern.

\subsection{Kerntransport von Histonen}

Histone werden in einer großen Anzahl während der S-Phase des Zellzyklus benötigt, um die replizierte DNA in kondensierte Chromatinstrukturen zu verpacken. Sie müssen daher nach ihrer Synthese im Zytoplasma in den Kern transportiert werden, damit sie dort ihre Funktion bei der Chromatinbildung erfüllen können. Mit einer Größe unterhalb des Ausschlußvolumens des NPC von 40-60 kDa (Bonner, 1978) sollte es aber Histonen möglich sein, durch den Kanal des NPC hindurch zu diffundieren. Verschiedene Arbeiten an $\mathrm{H} 1$-Histonen ergaben aber, daß der Transport in den Kern ein aktiver, rezeptorvermittelter Prozeß ist (Breeuwer und Goldfarb, 1990, Imamoto et al, 1995, Kurz, et al., 1995, Schwamborn et al., 1998), wobei die beteiligten Importrezeptoren bereits identifiziert werden konnten (Jäkel et al., 1999).

Der Kerntransport der Core-Histone ist dagegen noch nicht gut untersucht, die Resultate aus den Studien an $\mathrm{H} 1$ ließen aber die Arbeitshypothese zu, daß auch im Fall der Core-Histone der Kernimport rezeptorvermittelt abläuft. Diese Vermutung 
wurde durch Untersuchungen am Core-Histon H2B aus Saccharomyces cerevisiae unterstützt, in denen Proteinbereiche mit einer potentiellen Funktion als NLS (Kernlokalisationssignal) identifiziert wurden (Moreland et al., 1987).

In der vorliegenden Arbeit wurde der Transport der vier Core-Histone H2A, H2B, H3 und H4 von Zytoplasma in den Zellkern untersucht. Dabei zielten die Experimente zunächst darauf $a b$, zu zeigen, ob der Transport durch Diffusion zustande kommt, oder aber rezeptorvermittelt abläuft. Anschließend wurden die NLS in den CoreHistonen und die für den Transport erforderlichen Importrezeptoren identifiziert.

\subsection{In vitro Kernimportstudien von Core-Histonen}

Experimente, die in vitro durchgeführt werden, haben gegenüber in vivo Systemen den entscheidenden Vorteil, daß es möglich ist, gezielt einzelne definierte Parameter zu variieren, während alle anderen Bedingungen identisch gehalten werden können. Dies ermöglicht die Analyse der Aufgabe einzelner Komponenten an verhältnismäßig komplexen Vorgängen. Da aber nur Teilaspekte untersucht werden können, ist es häufig nur unter starken Einschränkungen möglich, Ergebnisse aus in vitro Experimenten auf in vivo Situationen zu übertragen.

Der in vitro Kernimportassay mit permeabilisierten Zellen (Adam et al., 1990) ist ein wichtiges Instrument in der Untersuchung von Kerntransportprozessen und den daran beteiligten Komponenten. Durch eine selektive Permeabilisierung der Plasmamembran mit Digitonin kommt es dabei zu einem Verlust an endogenem Zytosol, während die Kernmembran, funktionell intakt bleibt. An diesen Zytosol-"depletierten", semiintakten Zellen kann durch Zugabe von exogenem Zytosol der Kerntransport eines detektierbaren Testsubstrats rekonstituiert und untersucht werden (Adam et al., 1991). Darüber hinaus ermöglicht diese Methode die Untersuchung des Einflusses verschiedener äußerer Bedingungen, sowie der Auswirkung bestimmter Faktoren oder zytosolischer Fraktionen auf den Kerntransport des Testsubstrats. Der Einsatz des in vitro Importassays hat maßgeblich zur Identifizierung wesentlicher Bestandteile des Kerntransportsystems und damit zum Verständnis von Kerntransportprozessen beigetragen. So wurden die Importrezeptoren der Proteinfamilie der Importin $\beta$ ähnlichen Transportrezeptoren und des Ran-Systems (Übersichten: Görlich und Kutay, 1999; Nakielny und Dreyfuss, 1999, Jans, 2000) mit Hilfe dieser Methode identifiziert. 
Der in vitro Importassay wurde in dieser Arbeit für Untersuchungen am Kerntransport der Core-Histone verwendet. Diese Untersuchungen zielten zunächst darauf ab, herauszufinden, ob der Transport durch Diffusion oder aktiv und rezeptorvermittelt zustande kommt. Gegebenenfalls waren dann im nächsten Schritt die beteiligten Importfaktoren zu identifizieren.

Zur Kontrolle der Funktionalität und Spezifität des in vitro Systems wurde ein Kontrollsubstrat präpariert. Dazu wurde ein synthetisches Peptid, das die Aminosäuresäuresequenz des NLS des SV40-T-Antigens enthielt, an fluoreszenzmarkiertes HSA gekoppelt. Unter Einsatz von Retikulozytenlysat als exogenes Zytosol und damit als Quelle für alle am Transportprozeß beteiligten Komponenten wurde das Kontrollsubstrat in die Zellkerne der permeabilisierten Zellen transportiert. Bei Ersatz des Retikulozytenlysats durch Puffer blieb ein erkennbarer Kernimport aus. Diese Abhängigkeit des Kernimports von löslichen zytosolischen Komponenten entsprach den Erwartungen, da in verschieden Arbeiten bereits gezeigt werden konnte, daß der Kerntransport von Proteinen, die das SV40-NLS enthalten, rezeptorvermittelt verläuft und damit also auch abhängig von zytosolischen Faktoren ist (Moore und Blobel, 1992, Adam und Adam, 1994).

Für die Verwendung als detektierbare Transportsubstrate wurden die Kalbsthymushistone $\mathrm{H} 2 \mathrm{~A}, \mathrm{H} 2 \mathrm{~B}, \mathrm{H} 3$ und $\mathrm{H} 4$ fluoreszenzmarkiert. Im in vitro Importassay verhielten sie sich wie das SV40-NLS-Kontrollsubstrat und zeigten ebenso eine Abhängigkeit des Kernimports von zugegeben Zytosol. Damit war ein erster Hinweis auf einen rezeptorvermittelten Transport erbracht, da die Core-Histone bei einem passiven Diffusionsvorgang auch in Abwesenheit von zytosolischen Komponenten zumindest teilweise im Zellkern hätten detektierbar sein müssen.

Die Abhängigkeit des Kerntransports von der Gegenwart zytosolischer Komponenten muß aber nicht zwangsläufig die Beteiligung von Rezeptoren am Importprozeß bedeuten. Die zytoplasmatische Retention des Substrats in Abwesenheit von zytosolischen Interaktionspartnern kann auch durch eine Wechselwirkung z.B. mit Zytoskelettstrukturen oder durch eine Oligomerisierung, die zu Aggregaten mit Größen oberhalb der Ausschlußgrenze der Kernpore führt, bedingt sein. Dies muß gerade im Fall der extrem basischen Histone, die zur Ausbildung von Hetero-Dimeren bzw. Tetrameren bereits im Zytoplasma neigen (Kornberg und Thomas, 1974), berücksichtigt werden. Zytosolische Interaktionspartner verhindern möglicherweise diese zytoplasmatischen Bindungen und Aggregatbildungen der Core-Histone und ermöglichen so den ungehinderten Zugang zur bzw. durch die Kernpore. Denkbar ist 
außerdem, daß bestimmte zytosolische Faktoren durch Interaktion eine Konformationsänderung der Core-Histone hervorrufen, wodurch diese erst importierbar werden. Verschiedene Core-Histon-Interaktionspartner sind bereits beschrieben worden, denen eine dieser Aufgaben zukommen könnte. Viele von innen sind als Untereinheiten sogenannter Chromatin Assembly Faktoren (CAF) an der Bildung des Chromatins beteiligt und werden mit einer Funktion als Chaperon für Core-Histone in Verbindung gebracht (Rodriguez et al., 2000).

Weitere Charakteristika des Kerntransports der Core-Histone wurden in Inhibierungsexperimenten untersucht. Unter Verwendung des in vitro Importassays wurde mit dem SV40-NLS-Kontrollsubstrat, aber auch mit den vier Core-Histonen in Gegenwart von Zytosol, eine Hemmung des Kerntransports durch Kühlung beobachtet. Diese strenge Temperaturabhängigkeit des Kernimports war eher durch einen rezeptorvermittelten Prozeß als durch einen auf passive Diffusion basierenden Vorgang erklärbar. Die beobachtete Inhibierung des Kerntransports in Abwesenheit eines energieregenerierenden Systems ließ den Schluß zu, daß der Kerntransport der Core-Histone Energie benötigt. Diese Beobachtungen stimmten weitgehend mit den Daten verschiedener Arbeiten überein, in denen durch Kühlung mikroinjizierter Zellen oder durch Entfernung endogenen ATPs bzw. durch Hemmung der ATP-Synthese eine Energieabhängigkeit von NLS-vermittelten Kerntransportprozessen demonstriert worden war (Newmeyer et al., 1986, Richardson et al., 1988). Durch ähnliche Experimente an Substraten mit synthetisch gekoppelten Peptiden konnte darüber hinaus gezeigt werden, daß die Energieabhängigkeit des Kerntransports eines Proteins direkt mit einem vorhandenen NLS zusammenhängt (Breeuwer und Goldfarb, 1990; Dingwall et al., 1991).

Um zu untersuchen, ob die Interaktion mit dem NPC am Kerntransport der CoreHistone beteiligt ist, wurde die Wirkung von WGA (wheat germ agglutinin) auf den Kernimport untersucht. Es war bekannt, daß Nukleoporine N-Acetylglukosamine enthalten (Davis und Blobel, 1986), an die das Lektin WGA spezifisch bindet. Dadurch wird die Interaktion mit dem NPC für andere Moleküle wie Importrezeptoren verhindert, so daß der Import durch den NPC spezifisch blockiert wird (Finlay, 1987; Görlich et al., 1997). Im Experiment mit Core-Histonen wurde beobachtet, daß Zugabe von WGA einen hemmenden Einfluß auf den Transport in den Zellkern hatte. Daher konnte angenommen werden, daß der Kerntransport der Core-Histone über eine Interaktion mit der Kernpore verläuft. 
Kerntransportstudien haben ergeben, daß neben den eigentlichen Importrezeptoren die GTPase Ran (Moore und Blobel, 1993) für einen effektiven Transport notwendig ist. Sie ist an der Freisetzung des Importsubstrats sowie am Recycling der Importrezeptoren beteiligt und bestimmt die Richtung der Transportprozesse durch den NPC (Izaurralde et al., 1997). Zugabe nicht hydrolysierbarer GTP-Analoga führte zur Inhibition des Imports der Core-Histone, was den Schluß zuließ, daß der Kerntransport der Core-Histone von GTP-Hydrolyse abhängig ist und dabei möglicherweise die Beteiligung von Ran erfordert. Dieses Verhalten ist ebenfalls in der Literatur an etablierten Substraten beschrieben worden (Moore und Blobel, 1993, Melchior et al., 1993, Moore, 1998).

Insgesamt konnte aus den Ergebnissen der in vitro Inhibierungsexperimente geschlossen werden, daß die vier Core-Histone $\mathrm{H} 2 \mathrm{~A}, \mathrm{H} 2 \mathrm{~B}, \mathrm{H} 3$ und $\mathrm{H} 4$ nicht durch passive Diffusion in den Kern gelangen, sondern durch einen Importweg in den Kern transportiert werden, der von löslichen zytosolischen Komponenten sowie Energie abhängig ist und sowohl die Interaktion mit dem NPC als auch die Hydrolyse von GTP erfordert. Der Core-Histon-Import erfüllt damit essentielle Kriterien eines aktiven, rezeptorvermittelten Transports. Dies ist keineswegs als trivial zu betrachten, da für verschiedene, allerdings zytoplasmatische Proteine vergleichbarer Größe gezeigt worden war, daß sie durchaus durch Diffusion vom Zytoplasma in den Kern gelangen und sich dort durch unspezifische Interaktionen anreichern, ohne NLS zu besitzen (Breeuwer und Goldfarb, 1990). Im Gegensatz dazu zeigten aber andere kleine Proteine wie die $\mathrm{H} 1$-Histone dieses Verhalten nicht, sondern ließen einen rezeptorvermittelten Importweg in den Zellkern erkennen (Breeuwer und Goldfarb, 1990, Imamoto et al., 1995, Kurz et al., 1997; Schwamborn et al., 1998.)

Für einige wenige karyophile Proteine, die kleiner als das Ausschlußvolumen des NPC sind, sind tatsächlich Abweichungen vom typischen Verhalten beobachtet worden. So gibt es Hinweise, daß Calmodulin und eine katalytische Untereinheit der CAMPabhängigen Proteinkinase (PKA) durch Diffusion in den Kern gelangen, da sie in ähnlichen Inhibierungsexperimenten keine Transporthemmung zeigten (Harootunian et al., 1993, Liao et al., 1999). $\beta$-Catenin gelangt vermutlich durch direkte Interaktion mit der Kernpore in den Kern, eine Eigenschaft, die sonst für Importrezeptoren typisch ist (Fagotto et al., 1998, Yokoya et al., 1999, Wiechens und Fagotto, 2001). Die KNSDomäne (K nuclear shuttling domain) des Ribonukleoproteins hnRNP K wurde als ein Signal identifiziert, das den Kerntransport sowohl unabhängig von Energie als auch von zytosolischen Komponenten vermittelt (Michael et al., 1997). 
Durch die in vitro Inhibierungsexperimente ist für die Core-Histone allerdings nicht gezeigt, daß der Transport auch tatsächlich von Importrezeptoren abhängt, da eine direkte Interaktion der Histone mit der Kernpore und damit eine „erleichterte Diffusion“ in diesem Experiment nicht grundsätzlich ausgeschlossen werden kann. Diese könnte die Beteiligung von Importrezeptoren entbehrlich machen, aber möglicherweise die Interaktion mit anderen zytosolischen Komponenten erfordern, ohne den experimentellen Ergebnissen unmittelbar zu widersprechen.

Da während der DNA-Replikation in der S-Phase des Zellzyklus ein großer Bedarf an Histonen im Zellkern besteht, ist aber zu erwarten, daß ein spezifischer und effizienter Transportmechanismus existiert, der gewährleistet, daß zum entsprechenden Zeitpunkt eine ausreichende Menge an Histonen im Zellkern zur Verfügung steht. Ein passiver Diffusionsvorgang würde diese Aufgabe nicht erfüllen können. Nur ein rezeptorvermittelter Prozeß ermöglicht eine quantitative wie zeitliche Regulation des Imports.

\subsection{Identifizierung von Kernlokalisationssignalen (NLS)}

Rezeptorvermittelte Kerntransportprozesse hängen von Kernlokalisationssignalen (NLS) in der Primärstruktur ab, die die Bindung zu den entsprechen Importrezeptoren herstellen. Die ersten identifizierten NLS bestehen aus Motiven basischer Aminosäuren, wie im T-Antigen des SV40-Virus und in Nukleoplasmin, die beide als klassische NLS bezeichnet werden. Während das SV40-T-Antigen-NLS aus einem Heptapeptid mit fünf aneinandergereihten basischen Aminosäuren (Lysin oder Arginin) besteht, enthält das Nukleoplasmin-NLS ein zweigeteiltes Signal, bei dem zwei basische Motive durch einen variablen Sequenzbereich von zehn Aminosäuren getrennt sind. Beide vermitteln den Kerntransport über einen Importweg, der die Interaktion mit Importin $\alpha$ erfordert und als klassischer Importinweg bezeichnet wird. Importin $\alpha$ funktioniert dabei als Adapter, der die Interaktion mit Importin $\beta$, dem eigentlichen Transporter, herstellt. Inzwischen ist eine große Zahl von karyophilen Proteinen gefunden worden, die ähnlich zusammengesetzte Signale besitzen und durch den klassischen Importinweg in den Kern gelangen (zusammengefaßt in Jans, 2000). 
Da Histone reich an basischen Aminosäuren sind, war zu erwarten, daß sich in ihrer Primärstruktur NLS identifizieren lassen, die dem klassischen Typ entsprechen. Diese Erwartung wurde unterstützt durch Arbeiten von Moreland et al., die beschrieben, daß H2B aus der Hefe Saccharomyces cerevisiae im N-Terminus eine dem SV40-NLS sehr ähnliche Sequenz enthält, die NLS-Aktivität besitzt (Moreland et al., 1987).

Entgegen der Annahme, daß sich alle Kernlokalisationssignale aus basischen Motiven zusammensetzen (Dingwall, 1991, Chelsky, 1989, Michaud und Goldfarb, 1993), wurden in letzter Zeit verschiedene NLS-Typen identifiziert, die sich sowohl strukturell eindeutig vom klassischen Typ unterscheiden als auch einen anderen Importweg in den Kern determinieren. Zu diesen gehört die M9-Domäne aus dem Ribonukleoprotein hnRNPA1 (Michael et al., 1995), die aus 38 Aminosäuren besteht, aber kein basisches Motiv enthält. Sie stellt die Bindungsstelle für den Importrezeptor Transportin dar (Pollard et al., 1996). Auch basische NLS-Motive unterscheiden sich häufig in ihrer Zusammensetzung, so daß es nicht möglich ist, aus der Aminosäuresequenz direkt auf NLS-aktive Proteinabschnitte zu schließen. Daher ist es notwendig, detaillierte funktionelle Analysen zu betreiben, um Aussagen über existierende NLS in einem Protein machen zu können.

Die NLS-Studien wurden, angelehnt an die Methode von Moreland et al. (1987) und Schwamborn et al. (1998), in vivo durch Transfektion von Plasmiden durchgeführt, die für Fusionsproteine mit einem Histon- und einem $\beta$-Galaktosidaseanteil codierten. $\beta$ Galaktosidase diente dabei als Reporterprotein, das einerseits durch seine Größe unspezifische Diffusion durch die Kernpore verhinderte (Hall et al., 1984) und andererseits eine Detektion durch Immunfluoreszenz ermöglichte.

In diesen Experimenten wurde gefunden, daß die Core-Histone jeweils wenigstens zwei NLS besitzen. In H3 und H4 waren sogar drei Sequenzbereiche detektierbar, die Importkompetenz aufwiesen. Das Vorhandensein von NLS in den Core-Histonen unterstützte zunächst das Ergebnis aus den Inhibierungsexperimenten, daß die Histone nicht durch freie Diffusion in den Kern gelangen, sondern unter Beteiligung von Erkennungssignalen rezeptorvermittelt importiert werden.

Die Beobachtung, daß in einem Protein mehrere Signale den Transport in den Zellkern vermitteln können, wurde schon bei anderen Proteinen gemacht. Im Linker Histon $\mathrm{H} 1^{\circ}$ wurden mehrere Elemente gefunden, die als NLS funktionieren (Schwamborn et al., 1998). Andere Beispiele sind bei Landford und Butel (1984) bzw. Mears et al., (1995) beschrieben worden. In weiteren Arbeiten wurde berichtet, daß die Existenz von mehreren NLS in demselben Protein seine Transporteffizienz steigern kann (Dworetzki 
et al., 1988; Cserpan und Udvardy, 1995). Übertragen auf die Histone würde dies Sinn machen, da sie zu den Proteinen gehören, deren Konzentration in den Zellkernen eukaryontischer Zellen am höchsten ist, und daher einen effizienten Transportmechanismus erfordern.

Darüber hinaus wird angenommen, daß Importrezeptoren neben ihrer Aufgabe als Vermittler der Translokation in den Zellkern eine weitere Funktion haben, die darin besteht, durch ihre Bindung an das Substrat reaktive Proteindomänen vor unerwünschten Interaktionen zu schützen. Dies könnte für basische Proteine wie die Core-Histone von Bedeutung sein, die eine hohe Tendenz besitzen, unter physiologischen Salzkonzentrationen zu präzipitieren oder Aggregate zu bilden. Ein Importrezeptor sollte daher einen möglichst großen Bereich des Proteins schützen, was die Existenz mehrerer NLS, die sich über den gesamten Proteinbereich erstrecken, erklären könnte.

Bei allen vier Core-Histonen fällt auf, daß der N-Terminus wie auch der verbleibende Teil, der eine vollständige globuläre Domäne enthält, als NLS funktionieren. Diese beiden importkompetenten Domänen sind strukturell sehr unterschiedlich: Die aminoterminale Domäne ist sehr basisch und in ihrer Tertiärstruktur völlig unstrukturiert. Die globuläre Domäne dagegen ist verhältnismäßig hydrophob und arm an basischen Aminosäuren, zeigt aber eine definierte Tertiärstruktur.

Die Beobachtung, daß die aminoterminalen Domänen als NLS funktionieren können, war aufgrund der hohen Basizität und der Ergebnisse von Moreland et al. für das H2B aus der Hefe Saccharomyces cerevisiae nicht unerwartet. Obwohl aber gerade diese Histonbereiche am wenigsten konserviert sind, konnte im humanen $\mathrm{H} 2 \mathrm{~B}$ im $\mathrm{N}-$ Terminus eine importkompetente Sequenz (H2B-NLS1) identifiziert werden. Beim Sequenzvergleich unter den beiden Spezies (Hefe und Mensch) fällt eine gewisse Übereinstimmung auf, wobei die Sequenz des humanen Histons dem klassischen NLS-Typ aus SV40-T-Antigen (vgl. Tab. 5) sogar noch näher zu kommen scheint (jeweils fünf aufeinanderfolgende basische Aminosäuren) als das Gegenstück aus der Hefe. In Mutationsanalysen wurde außerdem die Beteiligung von basischen Aminosäuren an der Funktionalität dieses Peptid gezeigt.

Da die Erkennungssequenzen für den klassischen Importinweg durchaus variieren (Hodel et al., 2001; Jans et al., 2000), war anzunehmen, daß dieses NLS-Peptid in die Konsensussequenz für den Import über den klassischen Importinweg paßt und den Import von H2B durch Importin $\alpha /$ Importin $\beta$ vermittelt. Dies kann jedoch in Transfektionsexperimenten nicht untersucht werden. 


\begin{tabular}{llcl} 
basisches Motiv & Sequenz & Kernimport & Referenz \\
\hline H2B (human)-NLS1: & GKKRKRSRK & ja & - \\
H2B (Hefe)-NLS: & GKKRSKA & ja & Moreland, 1987 \\
H2B (Xenop. I) & PKKGSKKA & nein & Breeuwer et al., 1990 \\
SV40-NLS: & PKKKRKV & ja & Moore, Blobel, 1992 \\
C-Myc-NLS: & PAAKRVKLD & ja & Nadler et al., 1997
\end{tabular}

Tab. 5: Zusammenstellung basischer Motive in der Aminosäuresequenz der N-terminalen Domäne von H2B unterschiedlicher Spezies im Vergleich mit etablierten klassischen NLS.

Die Amino-Termini der übrigen Core-Histone $\mathrm{H} 2 \mathrm{~A}, \mathrm{H} 3$ und $\mathrm{H} 4$ zeigen ein solches Motiv nicht, obwohl sie sehr reich an basischen Aminosäuren sind und auch als NLS funktionieren können. Die Variabilität der erforderlichen Aminosäuresequenz für die Funktionalität als NLS schließt aber nicht aus, daß die Aminotermini NLS vom klassischen Typ enthalten. So unterscheidet sich das NLS von c-Myc (Nadler et al., 1997) doch stark vom SV40-NLS, wird aber dennoch durch Importin $\alpha /$ Importin $\beta$ importiert (vgl. Tab 5).

Die NLS der anderen Core-Histonbereiche, die jeweils die globuläre Domäne enthalten, haben keine Ähnlichkeit mit dem klassischen NLS-Typ. Eine Analogie zur M9-Domäne in hnRNP A1 ist auch nicht feststellbar.

Die Transfektionsexperimente demonstrierten eine Abhängigkeit von der Integrität der globulären Domäne für die Funktion als NLS. Untersuchungen von einzelnen Teilen der globulären Domäne zeigten, daß diese keine Transportfunktion besaßen. In der globulären Domäne ist keine erhöhte Konzentration von basischen Aminosäuren erkennbar, sie stellt jeweils vielmehr den hydrophoben Teil der Core-Histone dar. Es ist also eher davon auszugehen, daß die Funktion als NLS anders als in den Nterminalen Domänen oder im Fall des klassischen NLS-Typs weniger durch kurze Abschnitte von basischen Aminosäuren gebildet wird, sondern daß der gesamte Proteinbereich von etwa 70-90 Aminosäuren als Erkennungssignal dient.

NLS, die einen weiten Proteinbereich umspannen, sind auch in anderen Proteinen gefunden worden. Die BIB-Domäne (beta-like import-receptor-binding-domain), die für den Import des rpL23a verantwortlich ist, besteht aus 41 Aminosäuren (Jäkel und Görlich, 1998) und die oben bereits erwähnte M9-Domäne enthält 38 Aminosäuren (Pollard et al., 1996). 
Für das Histon $\mathrm{H}^{\circ}$, eine $\mathrm{H} 1$-Replacementvariante, konnte gezeigt werden, daß es viele Sequenzbereiche enthält, die als NLS funktionieren können. Dabei enthielt der NTerminus einen hohen Anteil basischer Aminosäuren, war aber nicht als NLS aktiv. Die ebenso sehr basische, aber in $\mathrm{H} 1$-Histonen wesentlich größere C-terminale Domäne enthält viele Sequenzbereiche mit NLS-Funktionalität. Ähnlich wie in den CoreHistonen erwies sich die relativ hydrophobe globuläre Domäne des $\mathrm{H}^{\circ}$ als NLS-aktiv, wobei auch hier die Integrität des 75 Aminosäuren umspannenden Proteinteils Bedingung für die Funktionalität war (Schwamborn et al., 1998).

Eine besondere Eigenschaft der globulären Domänen der Core-Histone ist, daß sie bei einer geringen Sequenzähnlichkeit trotzdem eine hohe Strukturhomologie besitzen. Ihre strukturelle Funktion in den Nukleosomen war durch Röntgenstrukturanalysen analysiert worden (Arents et al., 1993, Luger et al., 1997). Dabei zeigte sich, daß die globulären Domänen, seither als "Histone-Fold-Motif" (HFM) bezeichnet (Arents er al., 1991), einerseits für Histon-DNA-Interaktionen wie auch für die Wechselwirkungen der Core-Histone untereinander verantwortlich sind, die sich in der Bildung von $\mathrm{H} 2 \mathrm{~A} / \mathrm{H} 2 \mathrm{~B}-$ Dimeren sowie $(\mathrm{H} 3 / \mathrm{H} 4)_{2}$-Tetrameren und dem daraus bestehenden Histonoktamer des Nukleosomenkernes manifestieren (Arents et al., 1995; Luger et al., 1997).

Das Strukturmotiv des HFM findet man nicht nur bei den Core-Histonen, es ist darüber hinaus auch in einigen DNA-bindenden nicht-Histon-Proteinen vorhanden, obwohl die Sequenzähnlichkeit verhältnismäßig gering ist (Baxevanis et al. 1995). H1-Histone enthalten dieses Motiv aber nicht.

Diese besonderen strukturellen Eigenschaften der globulären Domäne der vier CoreHistone sowie das Fehlen eines primären Strukturelements in diesem Bereich läßt vermuten, daß die Konformation des Gesamtbereichs der globulären Domäne und dadurch das HFM die Funktion als NLS bestimmt. Der unmittelbare Nachweis für diesen Zusammenhang wäre allerdings nur dann wirklich erbracht, wenn durch eine gezielte Veränderung der räumlichen Struktur ein Verlust an Importaktivität der globulären Domäne demonstriert würde. Experimente hierzu sind mit dem Problem verbunden, daß Veränderungen der Tertiärstruktur, z.B. durch Mutationen, nicht mit einfachen Mitteln nachweisbar sind, so daß nicht unmittelbar gezeigt werden kann, daß ein verändertes Importverhalten eher mit einer modifizierten räumlichen Struktur als mit der ausgetauschten Aminosäure als bestimmendes Element bei der Interaktion mit einem Rezeptor zusammenhängt.

Durch die NLS-Studien der Core-Histone konnte allerdings nicht ausgeschlossen werden, daß die Importkompetenz der globulären Domänen der Core-Histone sowie der ganzen Histone mit der die Beteiligung von Histonoligomeren zusammenhängt. Da 
die Bildung von $\mathrm{H} 2 \mathrm{~A} / \mathrm{H} 2 \mathrm{~B}$-Dimeren sowie $(\mathrm{H} 3 / \mathrm{H} 4)_{2}$-Tetrameren durch die Interaktion der HFM-Motive der globulären Domänen zustande kommt (Arents et al, 1995, Luger et al., 1997), ist es denkbar, daß im Transfektionsexperiment die globulären Domänen mit endogenen, neusynthetisierten Histonen unter Ausbildung von Oligomeren interagieren und, vermittelt durch deren N-terminales NLS, sozusagen "Huckepack" in den Kern transportiert werden (Moreland et al., 1987). Diese Möglichkeit wird durch Untersuchungen von Kolodrubetz et al. (1982) und Schuster et al. (1986) unterstützt, die an Hefemutanten die Auswirkungen von Deletionen im Proteincode von H2A und H2B auf die Überlebensfähigkeit untersucht haben. Dabei wurde gefunden, daß die Deletion des $\mathrm{N}$-Terminus in einem der beiden Histone keinen Einfluß auf das Zellwachstum hatte. Des weiteren waren die N-Termini beider Histone gegeneinander austauschbar, ohne daß die Lebensfähigkeit der Hefezellen wesentlich beeinflußt wurde. Als letal wirkte sich lediglich die gleichzeitige Deletion beider $\mathrm{N}$-Termini aus. Der N-Terminus des einen Proteins konnte daher die Funktion des anderen komplementieren. Eine der Interpretationen der Ergebnisse war, daß die N-Termini der Core-Histone am Kerntransport von H2A/H2B-Dimeren beteiligt sind, während die globulären Domänen die Interaktion der Histone untereinander bestimmen.

Eigene Untersuchungen ergaben aber, daß schon vier Stunden nach Transfektion eines H2B-Konstrukuts dessen Genprodukt im Kern angereichert war. Unter der Annahme, daß zu diesem Zeitpunkt die Mehrzahl der transfizierten Zellen noch keine S-Phase durchlaufen hatten, also noch kein neusynthetisiertes, endogenes $\mathrm{H} 2 \mathrm{~A}$ als Dimerisierungspartner zur Verfügung stehen konnte, spricht dieser frühe Transport bei fehlender zytoplasmatischer Retention für einen Transport ohne Dimerisierung.

Gegen einen Transport der Core-Histone als Oligomere spricht außerdem, daß in den in vitro Rekonstitutionsexperimenten jedes Core-Histon unabhängig von einem anderen Histon importiert werden konnte.

Die Schlußfolgerungen von Moreland et al. (1987) und Schuster et al. (1986) sind aber möglicherweise von der zu jener Zeit verbreiteten Annahme geprägt, daß alle Kernlokalisationssignale aus basischen Motiven gebildet werden. Wie erwähnt, befinden sich solche Motive nur in den N-Termini, nicht aber in den globuläre Domänen der Core-Histone. Nicht-basische NLS wurden erstmals 1995 für die M9Domäne in hnRNP A1 beschrieben (Michael et al., 1995).

Berücksichtigt werden muß auch die Möglichkeit, daß eine Interaktion der globulären Domänen mit anderen NLS-tragenden Proteinen den Transport in den Kern vermitteln könnten. Einige Core-Histon-bindende Proteine sind als Histon-Chaperone beschrieben worden, die meist am Zusammenbau der Chromatinstrukturen im Zellkern 
beteiligt sind. Zu innen gehören N1/N2 (Laskey et al., 1993), die H3 und H4 binden, während Nukleoplasmin (Earnshaw et al., 1980,) und die Mitglieder der NAP-Familie bereits im Zytoplasma bevorzugt H2A und H2B binden (Ito et al., 1996). Interessanterweise enthalten sie klassische NLS des bipartit-Typs (Dingwall und Laskey 1991, Hu und Jans, 1999), was zu der Annahme führte, daß sie als Transportvehikel für Histone den Übergang vom Zytoplasma in den Zellkern dienen und sie dort ins Chromatin einbauen ( Ito et al., 1996, Rodriguez et al., 2000). Da aber in allen Core-Histonen mehrere NLS identifiziert wurden und im Rekonstitutionsexperiment keine weiteren Faktoren nötig waren, bleibt diese Theorie allerdings vorerst spekulativ.

Die globuläre Domäne von $\mathrm{H} 4$ verhielt sich in den Experimenten mit $\beta$-GalaktosidaseFusionen einzelner Fragmente etwas anders als die der übrigen Core-Histone. Hier zeigte sich, daß neben der N-terminalen Domäne zwei Bereiche der globuläre Domäne unabhängig voneinander Importkompetenz aufwiesen (pMB19, pMB11). Damit ist für den Transport die Integrität der gesamten globulären Domäne nicht zwingend erforderlich (pMB11). Der C-terminale NLS-Teil ließ sich sogar noch weiter verkürzen, ohne daß die Transportkompetenz eingebüßt wurde (pMB20). Die zwanzig abgetrennten Aminosäuren waren demnach für die Funktionalität des NLS nicht von Bedeutung. Interessanterweise ist dieser Teil auch für den Einbau von $\mathrm{H} 4$ ins Histonoktamer für die Nukleosomen entbehrlich (Freeman et al., 1996), obwohl er für die Überlebensfähigkeit in Hefemutanten notwendig ist (Kayne et al., 1988).

Der resultierende globuläre Teil enthielt 30 Aminosäuren, wobei ein Motiv von drei aufeinanderfolgenden basischen Aminosäuren auffällig war. Austausch zweier dieser Aminosäuren in neutrale führte im Fusionskonstrukt dieses Abschnitts mit $\beta$ Galaktosidase zu einem Verlust der Fähigkeit, als NLS zu funktionieren und ließ vermuten, daß dieses basische Motiv an der Formation des NLS beteiligt ist. Andererseits hatten dieselben Mutationen in dem längeren globulären Konstrukt keinen Einfluß (pMB60). Dieser Widerspruch ist nur schwer aufzulösen, möglicherweise verursacht die Verkürzung des Fragments pMB11 zu pMB20 eine Veränderung der Konformation dieses globulären Anteils, die zufällig durch die Fusion mit $\beta$-Galaktosidase zu einer Bindungsstelle eines Importrezeptors wird. Hierbei würde es sich um ein Artefakt des Fusionsprodukts handeln und möglicherweise die Beteiligung der Aminosäuren 81-102 an der Funktionalität als NLS wiederum erforderlich machen. 
Zusammenfassend kann hier festgestellt werden, daß die Core-Histone wenigstens zwei NLS besitzen. Diese gehören zu zwei unterschiedlichen strukturellen Typen, von denen einer in der unstrukturierten aminoterminalen Domäne lokalisiert ist und durch eine kurze Aminosäuresequenz gebildet wird, an der basisch Aminosäuren beteiligt sind. Der andere NLS-Typ zeichnet sich durch einen weitgestreckten Proteinbereich aus, der seine Funktionalität vermutlich durch die Konformation der verhältnismäßig hydrophoben globulären Domäne erhält. Welche Importfaktoren am Kerntransport beteiligt sind und ob beide NLS-Typen unabhängig voneinander im ganzen Protein wirken, muß noch gezeigt werden.

\subsection{Untersuchung des "Histone-Fold-Motifs" als NLS in nicht- Histonproteinen}

Das "Histone-Fold-Motif" (HFM; Arents et al., 1991), das die globuläre Domäne umfaßt, besteht aus einem charakteristischen Strukturmotiv mit einem sich wiederholenden Helix-Schleifen-Helix Motiv in der Sekundärstruktur. Dieses Motiv zeigt unter den Histonen eine geringe absolute Sequenzidentität (14-18\%), während die Strukturhomologie dagegen stark ausgeprägt ist (Arents und Moundrianakis, 1995). NF-YB und NF-YC gehören zu einer Reihe von DNA-bindenden Proteinen, die interessanterweise das gleiche Strukturmotiv enthalten (Baxevanis et al., 1995). Ähnlich wie in den Core-Histonen ist das HFM auch in diesen Proteinen an der Bildung von Heterodimeren beteiligt. NF-YB und NF-YC bilden mit einer dritten Einheit (NFYA), die aber kein HFM enthält, einen transkriptionsaktiven trimeren Komplex. Über Kernlokalisationssignale oder Kerntransportwege dieser Proteine ist bisher nichts bekannt. Da aber das HFM der Core-Histone als NLS-aktives Element aufgefallen war, sollte untersucht werden, ob dieses Strukturmotiv auch in nicht Histonproteinen Importkompetenz besitzt.

Mit der bereits bei den Core-Histonen angewendeten Methode wurde für NF-YB und NF-YC gefunden, daß die amino- und carboxy-terminalen Domänen nicht transportaktiv waren, während alle untersuchten Proteinteile, die ein vollständiges HFM enthielten, als NLS funktionierten. Daher war davon auszugehen, daß das HFM auch in diesen Proteinen am Kernimport beteiligt ist. In der Aminosäuresequenz sind nur sehr wenige basische Aminosäuren enthalten, wobei auch kein typisches basisches Motiv erkennbar war, das Ähnlichkeiten zum klassischen NLS-Typ aufwies. Es war daher anzunehmen, daß sich die NLS-Aktivität hier wie im Fall der Core- 
Histone auch in der räumlichen Struktur des HFM begründet, wenngleich nicht ausgeschlossen ist, daß ein kurzes primäres Strukturelement die NLS-Funktionalität bestimmen könnte. Für den Fall, daß das HFM als dreidimensionales Strukturelement die Interaktion mit Importrezeptoren determiniert, ist es wahrscheinlich, daß CoreHistone, NF-Y und möglicherweise auch andere Proteine, die das HFM enthalten, über denselben Transportweg in den Kern importiert werden.

\subsection{Identifizierung des Importwegs der Core-Histone}

Nachdem gezeigt worden war, daß die Core-Histone einerseits durch einen rezeptorvermittelten Importweg in den Zellkern gelangen und andererseits Kernlokalisationssignale identifiziert werden konnten, zielten weiterführende Experimente darauf $a b$, herauszufinden, über welchen Importweg die Core-Histone in den Kern transportiert werden. In der Vergangenheit waren unterschiedliche Wege beschrieben worden, die jeweils die Beteiligung verschiedener Importrezeptoren erfordern. Die Importrezeptoren gehören zu einer gemeinsamen Proteinfamilie der Importin $\beta$-ähnlichen Transportrezeptoren. Neben dem klassischen Importinweg, mit dessen Hilfe Importin $\alpha$ und Importin $\beta$ Proteine mit klassischem NLS in den Kern transportieren, ist der Transportinweg beschrieben, der mit Transportin als funktionellen Importrezeptor das Ribonukleoprotein hnRNPA1 in den Kern dirigiert. Die $\mathrm{H} 1$-Histone werden über einen eigenen Weg in den Kern transportiert, der von einem Heterodimer, bestehend aus Importin $\beta$ und Importin 7 abhängt.

Zunächst wurde versucht, Informationen über am Kerntransport der Core-Histone beteiligte Importfaktoren durch in vitro Kompetitionsstudien mit Substraten und Kompetitoren zu erhalten, deren Importweg gut beschrieben ist. Dabei wurde der in vitro Importassay verwendet und einem fluoreszierenden Substrat ein Kompetitor im Überschuß zugegeben. Als Substrate dienten fluoreszenzmarkiertes SV40-NLS-HSA, H1, sowie die vier Core-Histone. Die nicht-fluoreszierenden Analoga sowie die importdefiziente, mutierte SV40-NLS-Variante zur Kontrolle der Spezifität des Experiments wurden als Kompetitoren verwendet. Da die mutierte Variante nicht importiert wird und mit keinem Importweg interferiert, sollte sie keinen Einfluß auf den Transport der untersuchten Substrate haben (Moore und Blobel, 1992, Goldfarb et al., 1986). Dies konnte im Experiment beobachtet werden, wodurch die Spezifität der 
Experimente demonstriert war. Durch die Wildtyp-Variante des SV40-NLS, wie auch durch $\mathrm{H} 1$ und jedes einzelne Core-Histon waren der Kernimport des SV40-NLS und des $\mathrm{H} 1$-Histons kompetierbar. Das SV40-NLS und $\mathrm{H} 1$ sollten, da sie jeweils Importin $\beta$ für ihren Kerntransport benötigen, sich erwartungsgemäß jeweils gegenseitig kompetieren.

Die Beobachtung, daß auch die Core-Histone einen kompetitiven Effekt auf den Import sowohl von SV40-NLS als auch der H1-Histone hatten, ließ sich am naheliegendsten durch die Beteiligung von Importin $\beta$ am Core-Histon-Import erklären.

Umgekehrt allerdings konnten die Core-Histone als Substrate weder durch das SV40NLS, noch durch $\mathrm{H} 1$ vollständig kompetiert werden. Dies konnte dadurch erklärt werden, daß die Core-Histone auf einen alternativen Importweg zurückgreifen können. Die Core-Histone kompetierten sich auch gegenseitig, jedes führte zur Hemmung des Imports jedes einzelnen Core-Histons. Daher war anzunehmen, daß die vier CoreHistone dieselben Importrezeptoren für den Transport in den Kern benötigen.

Kompetitionsstudien stellen aber nur bedingt ein aussagekräftiges Testsystem dar, da die hohen Proteinüberschüsse zu unbekannten Interferenzen und Effekten führen können. Außerdem geben diese Studien keine eindeutige Aussage über beteiligte Importrezeptoren. Für die genaue Beschreibung des Importwegs war es daher notwendig, den Kerntransport der Core-Histone mit aufgereinigten Importfaktoren zu rekonstituieren.

\subsubsection{Der Kernimport der Core-Histone kann alternativ durch Importin $\beta$, Importin5, Importin7 und Transportin rekonstituiert werden}

Für die Rekonstitutionsexperimete wurde der Einfluß bakteriell exprimierter und aufgereinigter Importrezeptoren im in vitro Importassay auf den Kerntransport der Core-Histone untersucht. Dabei waren jeweils ein Energie-regenerierendes System sowie die zytoplasmatischen Komponenten des Ran-Systems, RanGDP und NTF2, anwesend. In Kontrollexperimenten mit Substraten, deren Importrezeptoren für die Translokation bekannt waren, wurde das Testsystem eingestellt und die Funktionalität der präparierten Importfaktoren überprüft. SV40-NLS als Substrat des klassischen Importinwegs wurde dabei ausschließlich mit Importin $\alpha /$ Importin $\beta$ (Görlich et al., 1994), die IBB-Domäne als Importin $\beta$-bindende Domäne von Importin $\alpha$ mit Importin $\beta$ (Görlich 
et al., 1996, Weis et al., 1996), die M9-Domäne als NLS des Ribonukleoproteins hnRNPA1, mit Transportin (Pollard et al., 1996), H1 mit Importin $\beta /$ Importin7 (Jäkel et al., 1999) und L23a mit Importinß, Importin7, Importin5 oder Transportin (Jäkel und Görlich, 1998) in die Zellkerne der permeabilisierten Zellen importiert. Damit war die Spezifität des Testsystems und die Funktionalität der präparierten Importfaktoren demonstriert.

Die Experimente mit Core-Histonen zeigten zunächst, daß diese nicht durch Importin $\alpha$ und Importin $\beta$ importiert werden. Dies war nicht unbedingt zu erwarten, da alle vier Core-Histone in den NLS-Studien im N-Terminus NLS-kompetente Bereiche zeigten, die starken basischen Charakter aufwiesen und die Beteiligung des klassischen Importinwegs suggerierten. Besonders im Fall von H2B war das identifizierte basische NLS mit einer starken Ähnlichkeit zum SV40-NLS ein Hinweis auf die Beteiligung von Importin $\alpha /$ Importin $\beta$ gewesen.

Interessanterweise ließ sich der Kernimport aber mit Importin $\beta$ in Abwesenheit von Importin $\alpha$ rekonstituieren. Vermutlich hat Importin $\alpha$ einen inhibitorischen Effekt auf die Interaktion von Importin $\beta$ und Core-Histon. Da Importin $\beta$ vermutlich direkt an die CoreHistone bindet, konkurriert Importin $\alpha$ mit den Histonen um die Bindungsstelle in Importin $\beta$, während es selbst aber nicht an das NLS im Histon binden kann. Die Affinität von IBB (Importin $\beta$-Bindungs-Domäne) in Importin $\alpha$ für Importin $\beta$ scheint hier im Vergleich mit den Core-Histonen stärker zu sein. Ähnlich gestalteten sich die Resultate von Johnson-Saliba et al. (2000), die in Bindungsstudien von Importfaktoren mit DNA-bindenden Proteinen gefunden hatten, daß immobilisierte Core-Histone zwar den Importin $\alpha /$ Importin $\beta$-Heterodimer binden, daß Importin $\beta$ aber in Abwesenheit von Importin $\alpha$ eine höhere Affinität zu den Substraten besaß. Demgegenüber konnten in Overlay-Assays nur schwache Interaktionen von $\mathrm{H} 2 \mathrm{~A}$ und $\mathrm{H} 2 \mathrm{~B}$ mit Importin $\beta$ beobachtet werden (Langer, 2000).

Inhibitorische Effekte von Importin $\alpha$ auf die Substrat-Importin $\beta$-Interaktion waren bereits für andere Importin $\beta$-Substrate beschrieben worden (Lam et al., 1999; Chan et al., 1998; Jäkel und Görlich, 1998).

Importin7 offenbarte sich ebenfalls als ein funktioneller Importrezeptor für die CoreHistone. Daraus war schlußzufolgern, daß sie anders als die Linker H1-Histone unabhängig durch Importin $\beta$ oder Importin7 transportiert werden, ohne daß die Bildung eines Heterodimers von Importin $\beta$ und Importin7 erforderlich wäre (Jäkel et al., 1999). Interessanterweise konnten obendrein sowohl Transportin als auch Importin5 die 
Core-Histone in den Kern importieren. Dies bedeutete, daß neben Importin $\beta$ und Importin7 sowohl Transportin als auch Importin5 unabhängige funktionelle Importrezeptoren für den Kerntransport der Core-Histone darstellen, die nicht auf Adapter für die Substraterkennung angewiesen sind (siehe Abb. 30). Dabei zeigte sich, daß Transportin den effektivsten von allen verwendeten Importfaktoren darstellte, während Importin5 verhältnismäßig geringe Aktivität besaß.

Importin $\beta$ wurde als funktioneller Importrezeptor zuerst für ein artifizielles Substrat, die

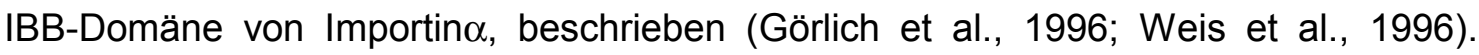
Später wurde es aber auch als Importrezeptor für verschiedene andere Proteine nachgewiesen, wie das Rev Protein des HIV (Henderson und Percipalle, 1997, Truant und Cullen, 1999). Transportin ist bisher nur für den Import der M9-Domäne in hnRNP A1 (Pollard et al., 1996) und der BIB-Domäne des ribosomalen Proteins L23a (Jäkel und Görlich, 1998) in Erscheinung getreten. Importin7 und Importin5 konnten als autonome Importrezeptoren bisher nur bei den ribosomalen Proteinen beobachtet werden, die darüber hinaus auch mit Importin $\beta$ und Transportin importiert werden können (Jäkel und Görlich, 1998).

Diese Ergebnisse sind in mehrfacher Hinsicht aufschlußreich: Zum einen zeigen sie, daß sich die Core-Histone in der Rekonstitutionsanalyse genauso wie die ribosomalen Proteine verhalten, sich aber eindeutig von den $\mathrm{H} 1$-linker-Histonen, die ein Heterodimer aus Importin $\beta$ und Importin7 benötigen, unterscheiden. Sie folgen auch nicht dem klassischen Importinweg, obwohl zumindest für H2B ein NLS identifiziert worden war, das aufgrund seiner strukturellen Analogie zum SV40-NLS die Beteiligung von Importin $\alpha$ erwarten ließ.

Darüber hinaus stimmen diese Resultate gut mit den Kompetitionsstudien überein, die darauf hindeuteten, daß die Core-Histone weder dem klassischen noch dem Importweg der H1-Histone in den Zellkern folgen. Die Möglichkeit der Core-Histone, mit Transportin oder Importin5 in den Kern importiert zu werden, erklärt das Ausbleiben einer vollständigen Kompetition des Core-Histonimports bei Zugabe von SV40-NLS-HSA oder H1.

Da die Proteinfamilie der Importin $\beta$-ähnlichen Transportrezeptoren etwa 21 Mitglieder umfaßt (Görlich und Kutay, 1999), ist denkbar, daß es noch weitere Importrezeptoren gibt, die am Kerntransport der Core-Histone beteiligt sind. 

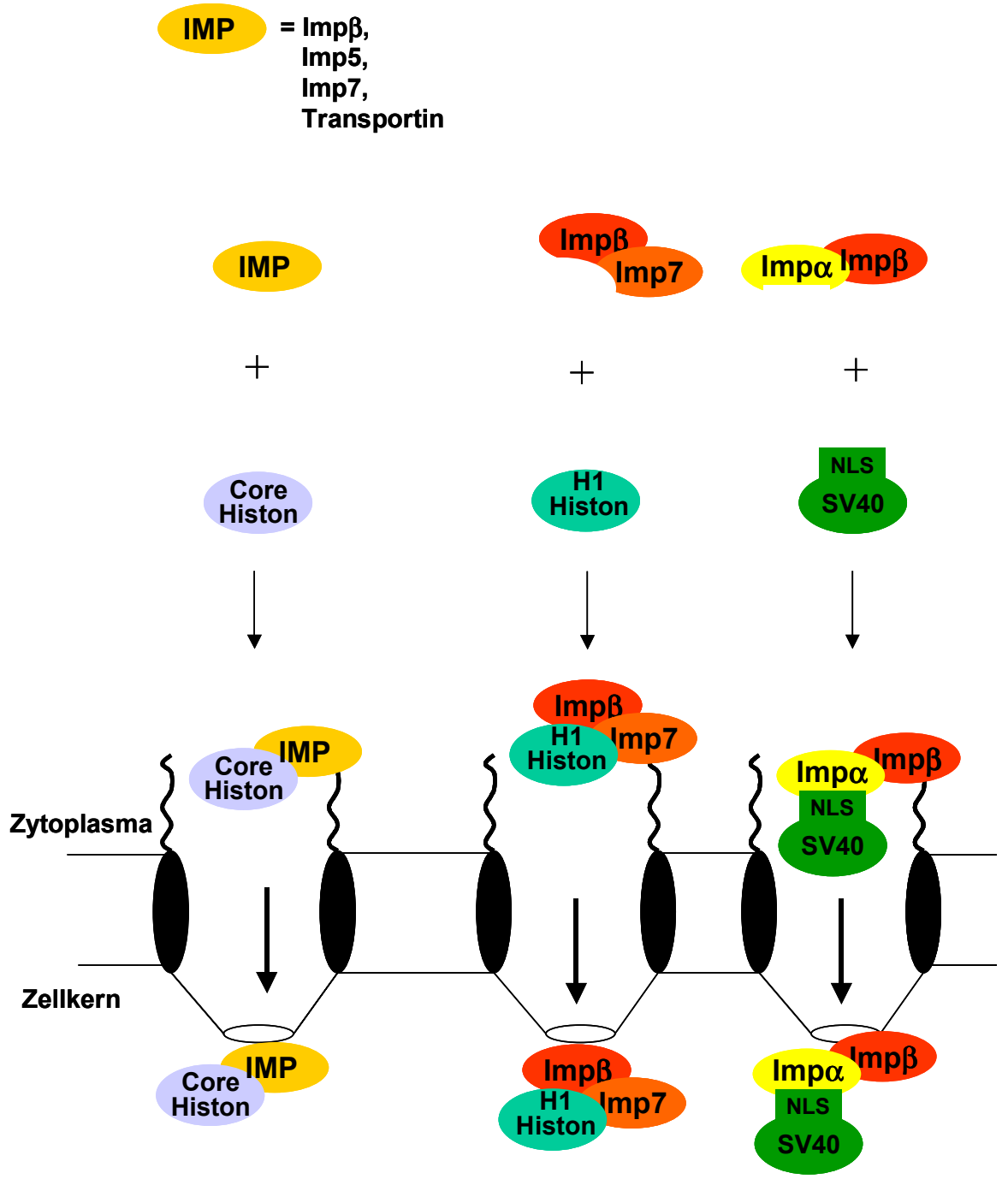

Abb. 30: Modell für den Kernimport der Core-Histone im Vergleich mit dem klassischen Importinweg und dem Importweg der H1-Histone. Dargestellt sind die für einen erfolgreichen Kernimport erforderlichen Importrezeptoren verschiedener Importsubstrate und die resultierenden Importkomplexe während ihres Importwegs durch den Kernporenkomplex. Substrate des klassischen Importinwegs, z.B. SV40-NLS, benötigen einen Tranportrezeptor $(\operatorname{Imp} \beta)$ und einen Adapter $(\operatorname{Imp} \alpha)$, die H1-Histone zwei Rezeptoren (Imp $\beta$ und Imp7) für den Transport. Dagegen kommen die Core-Histone mit einem von vier alternativen Transportern aus (Imp $\beta$, Imp5, Imp7 oder Transportin). Abkürzungen: IMP: Importin $\beta$-ähnlicher Imprtrezeptor; SV40: T-Antigen des Simian Virus 40; NLS: Kernlokalisationssignal; Imp $\beta$ : Importin $\beta$; Imp5: Importin5; Imp7: Importin7, Impo: Importin $\alpha$

Das in den NLS-Studien von H2B identifizierte basische NLS-Peptid (H2B-NLS1) war Ziel weiterer Rekonstitutionsexperimente. Dabei wurde das synthetische Peptid gekoppelt an fluoreszierendes HSA im in vitro Importassay untersucht. Es zeigte sich, daß dieses Peptid den Kernimport nur in Gegenwart von Importin $\alpha$ und Importin $\beta$ 
vermittelte. Alle übrigen verwendeten Rezeptoren bzw. Kombinationen führten zu keinem effektiven Kernimport.

Dies bestätigte einerseits die Annahme, daß es sich bei diesem Peptid um ein klassisches NLS handelte, wirft aber andererseits die Frage auf, warum dann das gesamte H2B-Protein nicht auf diesem Weg in den Kern transportiert werden konnte, obwohl es ja dieses Peptid enthält.

Offensichtlich ist das NLS-Peptid im Kontext des gesamten H2B-Proteins nicht aktiv. Vermutlich ist die Ausbildung eines stabilen Importin $\beta$-Importin $\alpha-H 2 B-K o m p l e x e s$ gehemmt, weil Importin $\alpha$ nicht effektiv an das NLS binden kann. Dies kann darauf zurückzuführen sein, das diese Bindungsstelle nicht exponiert ist, sondern möglicherweise durch Anordnungen der Sekundärstruktur oder Abschirmungseffekte durch die benachbarte globuläre Domäne in ihrer Zugänglichkeit behindert ist.

In verschiedenen Arbeiten sind Beobachtungen beschrieben worden, die darauf schließen lassen, daß das Vorhandensein eines NLS in einem Protein nicht zwangsläufig auch mit einer Lokalisation des Proteins im Kern einhergehen muß (Garcia-Bustos, 1991, Roberts, 1989). Ein Faktor, der dabei eine Rolle zu spielen scheint, ist die Position des NLS im Protein, der Proteinkontext (Roberts, 1989). Dies entspricht dem allgemeinen Konsensus, daß ein funktionelles NLS an der Oberfläche des Proteins exponiert und für die Erkennung eines Rezeptors zugänglich sein muß (Moreland et al., 1985, Roberts et al., 1987).

Erklärbar ist dieses Phänomen durch intramolekulare Maskierungseffekte, wie sie z.B. in NF-kB (Nuclear Factor KB) beobachtet worden sind (Henkel et al., 1992).

Denkbar ist auch, daß das NLS durch Modifikationen wie Methylierung, Acetylierung, oder Phosphorylierung maskiert ist. Über eventuelle Modifikationen des verwendeten Kalbsthymushistons $\mathrm{H} 2 \mathrm{~B}$ ist allerdings wenig bekannt, das synthetisch hergestellte Peptid ist aber frei von Modifikationen. In der Literatur ist der Einfluß von Phosphorylierungen auf die NLS-Funktionalität meist bei Proteinen beschrieben, deren Kernimport und -Export differentiell reguliert werden müssen. Dabei können Phosphorylierungen sowohl den Import stimulieren als auch inhibieren. Für Histone ist eine solche Regulierung bisher zwar nicht beschrieben, aus der Literatur ist aber bekannt, daß Phosphorylierungen in der unmittelbaren Nähe von NLS zur Inhibition der NLS-Funktion führen können (Jans, 1995), wie dies bei SV40-T-Antigen (TPPKKKRKV; Jans et al., 1991), Lamin B2 (SSRGKRRRIE, Hennekes et al., 1993) und v-jun (SRKRKL, Tagawa et al., 1995) der Fall ist. Da das humane H2B-NLS ein Serin enthält (GKKRKRSRK), ist es denkbar, daß eine Phosphorylierung an dieser 
Position die Funktion des NLS hemmt und den Kernimport durch Importin $\alpha$ und Importin $\beta$ inhibiert, so daß die globuläre Domäne ausschlaggebend für den Transport in den Kern wird. Möglicherweise hat dies eine regulierende Funktion, die mit dem Zellzyklus koordiniert ist.

Nicht auszuschließen ist allerdings auch, daß die Zugänglichkeit des NLS durch die Kopplung mit dem Fluoreszenzfarbstoff, der spezifisch an Aminogruppen bindet, blockiert wurde. Eine solche Abhängigkeit ist jedoch noch für kein markiertes Substrat beobachtet worden.

Der $\mathrm{N}$-Terminus von $\mathrm{H} 2 \mathrm{~B}$ ist der am wenigsten konservierte Teil der Core-Histone. Wie bereits erwähnt, ist er in Hefe sogar deletierbar, ohne daß die Überlebensfähigkeit der Hefezellen wesentlich beeinträchtigt ist (Schuster et al., 1986). Auch ein Austausch der N-Termini zwischen $\mathrm{H} 2 \mathrm{~B}$ und $\mathrm{H} 2 \mathrm{~A}$ war für die Zellen nicht letal. Die geringe Konservierung betrifft auch das in humanem H2B identifizierte NLS1. In Hefe ist diese Sequenz anders zusammengesetzt, aber als NLS noch funktionell (Moreland et al., 1987), ebenso in im N-Terminus von H2B aus Trypanosoma brucei, allerdings analog zum Nukleoplasmin-Prototyp in Gestalt eines zweigeteilten Signals (Marchett, 2000). Der analoge Bereich in Xenopus laevis (Tab. 5) zeigt aber interessanterweise keine Importkompetenz (Goldfarb et al., 1986). Der Kerntransport des H2B aus Xenopus laevis sollte daher erwartungsgemäß über die konservierte globuläre Domäne als Interaktionspartner mit einem Rezeptormolekül verlaufen.

Die mutmaßliche fehlende Aktivität des H2B-NLS1 läßt schlußfolgern, daß auch hier der Import von humanem H2B über die globuläre Domäne verläuft. Damit wäre indirekt ein Hinweis darauf gegeben, daß die globuläre Domäne des H2B und möglicherweise auch der anderen Core-Histone das aktive Erkennungssignal für die identifizierten funktionellen Importrezeptoren Importin $\beta$, Importin5, Importin7 und Transportin enthält. Dies wiederum unterstützt die Beobachtung, daß das in der globulären Domäne enthaltene "Histone-Fold-Motif" auch in nicht-Histon-Proteinen an der Signalerkennung für den Kerntransport beteiligt ist.

Die Beobachtung, daß die Core-Histone wie die ribosomalen Proteine und auch verschiedene andere Proteine an dieselben Importrezeptoren wie z.B. Importin $\beta$ und Transportin binden können, ist durchaus bemerkenswert, da sich aus der Aminosäuresequenz keine Motive ableiten lassen, die eine Konsensussequenz für die Interaktion mit bestimmten Rezeptoren erklären könnten. Weiterhin besitzen die CoreHistone in der globulären Domäne eine definierte Sekundärstruktur (HFM-Motiv), die 
sich von allen anderen bisher identifizierten Substraten für spezifische Rezeptorbindungen unterscheiden dürfte. Da für Importin $\beta$ und Transportin beschrieben wurde, daß sie verschiedene Substrate an unterschiedlichen Bindungsstellen binden können (Jäkel et al., 1999), ist es aber denkbar, daß ein Importrezeptor durchaus für eine große Zahl an spezifischen Kernlokalisationssignalen zugänglich ist.

Bei Betrachtung der karyophilen Proteine, die über den klassischen Importweg mit Importin $\alpha$ und Importin $\beta$ in den Zellkern transportiert werden, fällt auf, daß es sich hierbei meist um Proteine handelt, die an Prozessen der Genexpression beteiligt sind (z.B. Johnson-Saliba et al., 2000, Jans, 2000), während es sich bei den Substraten, die auf alternativen Wegen importiert werden, häufig um Kernstrukturproteine handelt (Histone, ribosomale Proteine, Jäkel und Görlich, 1998, Jäkel et al., 1999). Diese werden außerdem in verhältnismäßig großen Mengen in den Kern transportiert und werden nicht wieder exportiert. Transkriptionsfaktoren kommen dagegen im Kern nur in geringer Konzentration vor, werden auch nur zu bestimmten Zeitpunkten in den Kern importiert und nach Ausübung der Funktion meist wieder exportiert. Ihr Im- und Export erfordert eine sehr differentielle Regulation, die häufig durch Phosphorylierung bestimmt wird (Jans, 1995). Dabei stehen die Phosphorylierungsstellen im engen Kontext zum NLS, und können je nach relativer Position zum NLS importstimulierende oder importinhibierende Funktionen haben. Dieser Regulationsmechanismus ist möglicherweise vorteilhaft bei klassisch-strukturierten NLS, da es sich um relativ kurze Proteinbereiche handelt, deren Funktion als NLS durch einzelne Phosphatgruppen in der unmittelbaren Umgebung leichter beeinflußt werden kann, als dies bei Erkennungssignalen der Fall ist, die sich über 40 oder mehr Aminosäuren erstrecken.

Die Tatsache, daß sich der Kerntransport der Core-Histone stark von dem der H1Linker-Histone unterscheidet, ist zunächst überraschend, da es sich um eine Proteingruppe mit ähnlichen biochemischen Eigenschaften und Funktionen handelt. Demgegenüber müssen die H1-Histone aber als Sonderfall höherer Eukaryonten angesehen werden, da z.B. die Hefe Saccharomyces cerevisiae kein H1 enthält. Dies ist übereinstimmend mit den Beobachtungen, daß in der Hefe kein Importinß/Importin7-Hetrodimer identifizierbar war (Jäkel et al., 1999) und daß humanes $\mathrm{H} 1^{\circ}$, das in Hefe exprimiert wurde, nicht in den Zellkernen akkumulierte, sondern im Zytoplasma Aggregate bildete (Albig et al., 1998, Schwamborn, Diss., 1998). Für die Core-Histone waren Probleme der Expression in Hefe nicht beschrieben 
worden (Moreland et al., 1987). Darüber hinaus enthält H1 kein "Histone-Fold-Motif". Die globuläre Domänen der Core-Histone, die das HFM enthalten, und der H1-Histone zeigen deutlich unterschiedliche räumliche Strukturen (Arents et al., 1991). Da vermutlich die globulären Domänen entscheidenden Anteil an der Formierung des aktiven NLS der Histone haben, ist es verständlich, daß sich der Kerntransport der Core-Histone von dem $\mathrm{H} 1$-Histone unterscheidet.

Warum Core-Histone mit einem einzigen Rezeptor für den Transport in den Zellkern auskommen, und dabei auch noch die Wahl zwischen vier verschiedenen haben, während die H1-Histone einen Dimer aus zwei Rezeptoren benötigen, bleibt aber schwer erklärbar. Sicherlich spielt die Tatsache eine Rolle, daß Core-Histone gegenüber $\mathrm{H} 1$ in achtfacher Stöchiometrie (pro Nukleosom insgesamt acht CoreHistone, aber nur ein Linker H1-Histon) in den Kern importiert werden müssen und dafür einen leistungsfähigen Importmechanismus erfordern. Eine andere Erklärung ist, daß H1 aufgrund seiner Größe im Vergleich zu den Core-Histonen einen größeren Bereich vor unerwünschten Interaktionen schützen muß, die durch die basischen Eigenschaften der Histone bedingt sind. Für diesen Schutz mag H1 zwei Interaktionspartner benötigen (Jäkel et al., 1999), während für die kleineren Core-Histone ein einziger Interaktionspartner ausreichend ist.

\subsection{Ausblick}

Trotz der umfangreichen Untersuchungen zum Kerntranport der Core-Histone bleiben noch einige Fragen offen, die im Rahmen dieser Arbeit nicht geklärt werden konnten. So ist denkbar, daß es über die untersuchten Rezeptoren hinaus noch weitere aus der Proteinfamilie der Importin $\beta$-ähnlichen Importrezeptoren gibt, die für den Kerntransport der Core-Histone funktionell sind.

Die Interaktion der Core-Histone, besonders der einzelnen charakterisierten NLS mit den Importrezeptoren muß noch genauer untersucht werden, um Aussagen darüber machen zu können, welches NLS tatsächlich im Protein aktiv ist. Dabei ist Bedeutung der räumlichen Struktur der globuläre Domäne für die Funktion als NLS noch zu klären. Interessant ist auch die Frage, ob die untersuchten Untereinheiten des Transkriptionsfaktors NF-Y mit denselben Importfaktoren in den Kern importiert werden, oder ob andere beteiligt sind. Die Funktion des "Histone-Fold-Motifs" als NLS 
sollte in diesem Zusammenhang ein wichtiger Gegenstand weiterer Untersuchungen sein.

Noch zu klären bleibt außerdem, ob die Core-Histone in vivo als Monomere oder als Dimere bzw. Tetramere in den Zellkern importiert werden, da dies durch die Transfektionsexperimente nicht ausgeschlossen werden konnte. 


\section{ZUSAMMENFASSUNG}

In dieser Arbeit wurde der Transport der vier Core-Histone H2A, H2B, H3 und H4 vom Zytoplasma in den Zellkern untersucht.

In in vitro Untersuchungen mit permeabilisierten HeLa-Zellen konnte gezeigt werden, daß die vier Core-Histone nicht durch freie Diffusion in den Zellkern gelangen, sondern durch einen aktiven, rezeptorvermittelten Prozeß transportiert werden.

Die für die Erkennung der Transportrezeptoren erforderlichen Kernlokalisationssignale (NLS) wurden in in vivo Transfektionsstudien mit HeLa Zellen identifiziert. Dabei zeigte sich, daß die vier Core-Histone jeweils zwei bzw. drei Sequenzbereiche enthalten, die als NLS funktionieren können. Jedes Histon enthält dabei zwei strukturell unterschiedliche NLS-Typen: Einer ist reich an basischen Aminosäuren und in der unstrukturierten aminoterminalen Domäne der Core-Histone lokalisiert. Der andere ist relativ hydrophob und enthält jeweils die hochstrukturierte globuläre Domäne. Darüber hinaus erwies sich ein in der gobulären Domäne enthaltenes charakteristisches Sekundärstrukturmotiv auch in zwei nicht-Histonproteinen als importvermittelnd.

In Kompetitionsstudien wurde gezeigt, daß sich der Kerntransport der Core-Histone sowohl von dem der $\mathrm{H} 1$-Histone als auch von dem klassischen Importinweg unterscheidet.

Die für den Kerntransport der Core-Histone verantwortlichen Transportrezeptoren konnten in weitern in vitro Studien identifiziert werden. Es zeigte sich dabei, daß der Kerntransport jedes Core-Histons sowohl durch Importin $\beta$ als auch Importin7 sowie Importin5 und Transportin rekonstituiert werden konnte. Damit folgen die Core-Histone jeweils dem gleichen Transportweg vom Zytoplasma in den Zellkern wie das ribosomale Protein L23a, aber einem anderen Weg als dem klassischen Importinweg oder dem der H1-Histone.

In den in vivo NLS-Studien konnte in H2B ein Peptid identifiziert werden, das NLSFunktion besaß und eine starke Übereinstimmung zu dem klassischen NLS-Typ aufweist. Im in vitro Experiment wurde beobachtet, daß dieses H2B-NLS den Kerntransport über den klassischen Importinweg mit Importin $\alpha$ und Importin $\beta$ 
vermittelte und damit ein klassisches NLS repräsentierte. Da das gesamte $H 2 B$ aber die Beteiligung anderer Importrezeptoren erforderte, war davon auszugehen, daß das H2B-NLS-Peptid im vollständigen Protein nicht funktionell war. 


\section{LITERATURVERZEICHNIS}

Adam E.J.H., Adam S.A. (1994)

Identification of cytosolic factors required for nuclear location sequence-mediated binding to the nuclear envelope.

J. Cell Biol.; 125: 547-555

Adam S.A., Sterne-Marr R., Gerace L. (1990)

Nuclear protein import in permeabilized mammalian cells requires soluble cytoplasmic factors.

J. Cell Biol.; 111: 807-816

Adam S.A., Sterne-Marr R., Gerace L. (1991)

In vitro protein import using permeabilized mammalian cells.

Methods Cell Biol.; 35: 469-482

Albig W, Doenecke D. (1997)

The human histone gene cluster at the D6S105 locus.

Hum. Genet.; 101: 284-294

Albig W., Runge D.M., Kratzmeier M., Doenecke D. (1998)

Heterologous expression of human $\mathrm{H} 1$ histones in yeast.

FEBS Lett., 435(2-3): 245-250

Akey C.W., Radermacher M. (1993)

Architecture of the Xenopus nuclear pore complex revealed by three-dimensional cryoelectron microscopy.

J. Cell Biol.; 122: 1-19 
Arents G., Burlingame R.W., Wang B.C., Love W.E., Moudrianakis E.N. (1991)

The nucleosomal core histone octamer at 3.1 A resolution: a tripartite protein assembly and a left-handed superhelix.

Proc. Natl. Acad. Sci. USA ;88(22): 10148-10152

Arents G., Moudrianakis E.N. (1993)

Topography of the histone octamer surface: repeating structural motifs utilized in the docking of nucleosomal DNA.

Proc. Natl. Acad. Sci. USA; 90(22): 10489-10493

Arents G., Moudrianakis E.N. (1995)

The histone fold: a ubiquitous architectural motif utilized in DNA compaction and protein dimerization.

Proc. Natl. Acad. Sci. USA; 92(24): 11170-11174

Arts G.J., Kuersten S., Romby P., Ehresmann B., Mattaj I.W. (1998)

The role of exportin-t in selective nuclear export of mature tRNAs.

EMBO J.; 17(24):7430-7441

Baxevanis A.D., Arents G., Moudrianakis E.N, Landsman D. (1995)

A variety of DNA-binding and multimeric proteins contain the histone fold motif. Nucleic Acids Res.; 23(14): 2685-2691.

Bischoff F.R., Görlich D. (1997)

RanBP1 is crucial for the release of RanGTP from importin ß-related nuclear transport factors.

FEBS Lett.; 419: 249-254

Bischoff F.R., Klebe C., Kretschmer J., Wittinghofer A., Ponstingl H. (1994)

RanGAP1 induces GTPase activity of nuclear ras related Ran.

Proc. Natl. Acad. Sci. USA; 91: 2587-2591

Bischoff F.R., Ponstingl H. (1991)

Catalysis of guanine nucleotide exchange on Ran by the mitotic regulator RCC1.

Nature; 354: 80-82

Blobel G. (1980) 
Intracellular protein topogenesis.

Proc. Natl. Acad. Sci. USA; 77: 1496-1500

Bogerd H.P., Benson R.E., Truant R., Herold A., Phingbodhipakkiya M., Cullen B.R. (1999)

Definition of a consensus transportin-specific nucleocytoplasmic transport signal.

J. Biol. Chem.; 274(14): 9771-9777

\section{Bonner W.M. (1978)}

Proximity and accessibility studies of histones in nuclei and free nucleosomes.

Nucleic Acids Res., 5(1): 71-85

\section{Boulikas T. (1994)}

Putative nuclear localization signals (NLS) in protein transcription factors.

J. Cell Biochem.; 55(1): 32-58

\section{Breeuwer M., Goldfarb D.S. (1990)}

Facilated nuclear transport of histone $\mathrm{H} 1$ and small nucleophilic proteins.

Cell; 60: 99-1008

Chan C.K., Hübner S., Hu W., Jans D.A. (1998)

Mutual exclusivity of DNA binding and nuclear localisation signal recognition by the yeast transcription factor GAL4: implications for ninviral DNA delivery.

Gene Therapy; 5: 1204-1212

Chelsky D., Ralph R., Jonak G. (1989)

Sequence requirements for synthetic peptide-mediated translocation to the nucleus. Mol. Cell Biol.; 9(6): 2487-2492

Claussen M., Rudt F., Pieler T. (1999)

Functional modules in ribosomal protein $L 5$ for ribonucleoprotein complex formation and nucleocytoplasmic transport.

J. Biol. Chem.; 274(48): 33951-33958

Coustry F, Maity S.N, Sinha S, de Crombrugghe B. (1996) 
The transcriptional activity of the CCAAT-binding factor CBF is mediated by two distinct activation domains, one in the CBF-B subunit and the other in the CBF-C subunit.

J. Biol. Chem.; 271(24): 14485-14491

\section{Cserpan I., Udvardy A. (1995)}

The mechanism of nuclear transport of natural or artificial transport substrates in digitonin-permeabilized Cells.

J. Cell Sci.; 108: 1849-1861

Dang C.V., Lee W.M.F. (1988)

Identification of the human c-myc protein nuclear translocation signal.

Mol. Cell Biol.; 8: 4048-4054

Davis L.I., Blobel G. (1986)

Identification and characterization of a nuclear pore complex protein.

Cell; 45(5): 699-709.

Dingwall C. (1991)

Transport across the nuclear envelope: enigmas and explanations.

Bioessays; 13(5):213-218

Dingwall C., Laskey R.A. (1991)

Nuclear targeting sequence - a consensus?

Trends Biochem. Sci.; 16: 478-481

Dingwall C., Sharnick S.U., Laskey R.A. (1982)

A polypeptide domain that specifies migration of nucleoplasmin into the nucleus.

Cell; 30: 449-458

Dworetzky S.I., Lanford R.E., Feldherr C.M. (1988)

The effects of variations in the number and sequence of targeting signals in nuclear uptake.

J. Cell Biol.; 107: 1279-1287

Earnshaw W.C., Honda B.M., Laskey R.A., Thomas J.O. (1980) 
Assembly of nucleosomes: the reaction involving $X$. laevis nucleoplasmin.

Cell; 21(2): 373-383

Fagotto F., Gluck U., Gumbiner B.M. (1998)

Nuclear localization signal-independent and importin/karyopherin-independent nuclear import of beta-catenin.

Curr. Biol.; 8(4): 181-190

Feldherr C.M., Kallenbach E., Schultz N. (1984)

Movement of a karyophilic protein through the nuclear pores of oocytes.

J. Cell Biol.; 99: 2216-2222

Finlay D.R., Newmeyer D.D., Price T.M., Forbes D.J. (1987)

Inhibition of in vitro nuclear transport by a lectin that binds to nuclear pores.

J. Cell Biol.; 104(2): 189-200

Freeman L., Kurumizaka H., Wolffe A.P. (1996)

Functional domains for assembly of histones $\mathrm{H} 3$ and $\mathrm{H} 4$ into the chromatin of Xenopus embryos.

Proc. Natl. Acad. Sci. USA; 93(23): 12780-127855

Garcia-Bustos J., Heitmann J., Hall M.N. (1991)

Nuclear protein localization.

Biochim. Biophys. Acta; 1071: 83-101

Goldberg M.W., Allen T.D. (1996)

The nuclear pore complex and lamina: three-dimensional structure and interactions determined by field emmission in-lens scanning electron microscopy.

J. Mol. Biol.; 257: 848-865

Goldfarb D.S., Gariepy J., Schoolnik G., Kornberg R.D. (1986)

Synthetic peptides as nuclear localization signals.

Nature; 322(6080): 641-444

Görlich D., Dabrowski M., Bischoff F.R., Kutay U., Bork P., Hartmann E., Prehn S., Izaurralde E. (1997) 
A novel class of RanGTP binding protein.

J. Cell Biol.; 138: 65-80

Görlich D., Henklein P., Laskey R.A., Hartmann E. (1996)

A 41 amino acid motif in importin alpha confers binding to importin beta and hence transit into the nucleus.

EMBO J.; 15: 1810-1817

Görlich D. und Kutay U. (1999)

Transport between the cell nucleus and the cytoplasm.

Annu. Rev. Cell Dev. Biol.; 15: 607-660

Görlich D., Prehn S., Laskey R.A., Hartmann E. (1994)

Isolation of a protein that is essential for the first step of nuclear protein import.

Cell; 79: 767-778

Görlich D., Vogel F., Mills A.D., Hartmann E., Laskey R.A. (1995)

Distinct functions for the two importin subunits in nuclear protein import.

Nature; 377: 246-248

Hall M.N., Hereford L.M., Herskowitz I, (1984).

Targeting of E. coli $\beta$-gal to the nucleus in yeast.

Cell; 36: 1057-1065

Harootunian A.T., Adams S.R., Wen W., Meinkoth J.L., Taylor S.S., Tsien R.Y. (1993)

Movement of the free catalytic subunit of cAMP-dependent protein kinase into and out of the nucleus can be explained by diffusion.

Mol. Biol. Cell; 4(10): 993-1002 
Helling R.B., Goodman H.M., Boyer H.W. (1974)

Analysis of the endonuclease Eco RI fragments of the DNA from lambdoid bacteriophages and other viruses by agarose gel electrophoresis.

J. Virol.; 14: 1235-1244

Henderson B.R., Percipalle P. (1997)

Interactions between HIV Rev and nuclear import and export factors: the Rev nuclear localisation signal mediates specific binding to human importin-beta.

J. Mol. Biol.; 274(5): 693-707

Hennekes H., Peter M., Weber K., Nigg E.A. (1993)

Phosphorylation of protein kinase $\mathrm{C}$ sites inhibits nuclear import of lamin B2.

J. Cell Biol.; 120: 1293-1304

Henkel T., Zabel U., van Zee K., Muller J.M., Fanning E., Baeuerle P.A. (1992)

Intramolecular masking of the nuclear location signal and dimerization domain in the precursor for the p50 NF-kappa B subunit.

Cell; 68(6): 1121-1133

Herold A., Truant R., Wiegand H., Cullen B.R. (1998)

Determination of the functional domain organization of the importin alpha nuclear import factor.

J. Cell Biol.; 143(2): 309-318

Hetzer M., Mattaj I.W. (2000)

An ATP-dependent, Ran-independent mechanism for nuclear import of the U1A and U2B" spliceosome proteins.

J. Cell Biol.; 148(2): 293-303

Hodel M.R., Corbett A.H., Hodel A.E. (2001)

Dissection of a Nuclear Localization Signal.

J. Biol. Chem.; 276(2): 1317-1325 
Hood J.K. und Siver P.A. (1999)

In or out? Regulating nuclear transport.

Curr. Opin. Cell Biol.; 11: 241-247

Ho S.N., Hunt H.D., Horton R.M., Pullen J.K., Pease L.R. (1989)

Site-directed mutagenesis by overlap extension using the polymerase chain reaction.

Gene; 77: 51-59

Huber J., Cronshagen U., Kadokura M., Marshallsay C., Wada T., Sekine M., Luhrmann R. (1998)

Snurportin1, an m3G-cap-specific nuclear import receptor with a novel domain structure.

EMBO J.; 17(14): 4114-4126

Hu W. und Jans D.A., (1999)

Efficiency of importin alpha/beta-mediated nuclear localization sequence recognition and nuclear import. Differential role of NTF2.

J. Biol. Chem.; 274(22): 15820-15827

Imamoto N., Matsuoka Y., Kurihara T., Kohno K., Miyagi M., Sakiyama F., Okada Y., Tsunasawa S., Yoneda Y. (1992)

Antibodies against 70-kD heat shock cognate protein inhibit mediated nuclear import of karyophilic proteins.

J. Cell Biol.; 119(5): 1047-1061

Imamoto N., Tachibana T., Matsubae M., Yoneda Y. (1995)

A karyophilic protein forms a stable complex with cytoplasmic components prior to nuclear pore binding.

J. Biol. Chem.; 270: 8559-8565

lovine M.K., Watkins J.L., Wente S.R. (1995)

The GLFG repetitive region of the nucleoporin Nup116p interacts with Kap95p, an essential yeast nuclear import factor.

J.Cell Biol.; 131: 1699-1713

Ito T., Bulger M., Kobayashi R., Kadonga J.K. (1996) 
Drosophila NAP-1 is a Core Histone Chaperone that funktions an ATP-facilitated assembly of regulatory spaced nucleosomal arrays.

Mol. Cell Biol.; 16: 3112-3124

\section{Izaurralde E., Kutay U., von Kobbe C., Mattaj I.W., Gorlich D. (1997)}

The asymmetric distribution of the constituents of the Ran system is essential for transport into and out of the nucleus.

EMBO J.; 16(21): 6535-6547

Jäkel S., Albig W., Kutay U., Bischoff F.R., Schwamborn K., Doenecke D., Görlich D. (1999)

The importin $\beta /$ importin 7 heterodimer is a functional nuclear importreceptor for histone $\mathrm{H} 1$.

EMBO J.; 18: 2411-2423

Jäkel S. und Görlich D. (1998)

Importin $\beta$, transportin, RanBP5 and RanBP7 mediate nuclear import of ribosomal proteins in mammalian cells.

EMBO J.; 17: 4491-4502

Jans A.D. (1995)

The regulation of protein transport to the nucleus by phosphorylation.

Biochem. J.; 311: 705-716

Jans D.A., Ackermann M., Bischoff J.R., Beach D.H., Peters R. (1991)

p34cdc2-mediated phosphorylation at T124 inhibits nuclear import of SV-40 T antigen proteins.

J. Cell Biol.; 115(5): 1203-1212

Jans D.A., Xiao C.Y., Lam M.H. (2000)

Nuclear targeting signal recognition: a key control point in nuclear transport?

Bioessays; 22(6): 532-544. 
Jeoung D.I., Chen S., Windsor J., Pollack R.E. (1991)

Human major HSP70 protein complements the localization and functional defects of cytoplasmic mutant SV40 T antigen in Swiss 3T3 mouse fibroblast cells.

Genes Dev.; 5(12A): 2235-2244

Johnson-Saliba M., Siddon N.A., Clarkson M.J., Tremethick D.J., Jans D.A. (2000)

Distinct importin recognition properties of histones and chromatin assembly factors. FEBS Lett.; 467(2-3): 169-174

Jullien D., Görlich D., Laemmli U.K., Adachi Y. (1999)

Nuclear import of RPA in Xenopus egg extracts requires a novel protein XRIP $\alpha$ but not importin $\alpha$.

EMBO J.; 18: 4348-4358

Kalderon D., Richardson W.D., Markham A.F., Smith A.E. (1984)

Sequence requirements for nuclear location of simian virus 40 large-T antigen.

Nature; 311: 33-38

Kambach C., Mattaj I.W. (1994)

Nuclear Transport of the U2 snRNP-specific U2B protein is mediated by both direct and indirect signalling mechanism.

J. Cell Sci.; 107: 1807-1816

Katahira J., Strasser K., Podtelejnikov A., Mann M., Jung J.U., Hurt E. (1999)

The Mex67p-mediated nuclear mRNA export pathway is conserved from yeast to human.

EMBO J.; 18(9): 2593-2609

Kayne P.S., Kim U.J., Han M., Mullen J.R., Yoshizaki F., Grunstein M. (1988)

Extremely conserved histone $\mathrm{H} 4 \mathrm{~N}$ terminus is dispensable for growth but essential for repressing the silent mating loci in yeast.

Cell; 55(1): 27-39 
Knippers R. (1995)

Molekulare Genetik

Thieme-Verlag (Stuttgart-New-York); 6. Auflage, 143

Kolodrubetz D., Rykowski M.C., Grunstein M. (1982)

Histone $\mathrm{H} 2 \mathrm{~A}$ subtypes associate interchangeably in vivo with histone $\mathrm{H} 2 \mathrm{~B}$ subtypes.

Proc. Natl. Acad. Sci. USA; 79(24): 7814-7818

Kornberg R.D. und Lorch Y. (1999)

Twenty-five years of the nucleosome, fundamental particle of the eukaryote chromosome.

Cell; 98: 285-94

Kornberg R.D., Thomas J.O. (1974)

Chromatin structure; oligomers of the histones.

Science; 184: 865-868

Kurz M., Doenecke D., Albig W. (1997)

Nuclear transport of $\mathrm{H} 1$ histones meets the criteria of a nuclear localization signalmediated process.

J. Cell. Biochem.; 64: 573-578

Kutay U., Bischoff F.R., Kostka S., Kraft R., Görlich D. (1997)

Export of importin $\alpha$ from the nucleus is mediated by a specific nuclear transport factor.

Cell; 90: 1061-1071

Kutay U., Lipowsky G., Izaurralde E., Bischoff F.R., Schwarzmaier P. (1998) Identification of a tRNA-specific nuclear export receptor.

Mol. Cell; 1: 359-369

Laemmli U.K. (1970)

Cleavage of structural proteins during the assembly of the head of bacteriophage T4. Nature; 227: 680-685 
Lam M.H.C., Briggs L.J., Hu W., Martin T.J., Gillespie M.T., Jans D.A. (1999)

Importin $\beta$ recognizes parathyroid hormone-related protein (PTHrP) with high affinity and mediates its nuclear import in the absence of importin $\alpha$.

J. Biol. Chem.; 274: 7391-7398

Lanford R.E., Butel J.S. (1984)

Construction and characterization of an SV40 mutant defective in nuclear transport of T antigen.

Cell; 37: 801-813

\section{Langer T. (2000)}

Nuclear transport of histone $2 \mathrm{~b}$ in mammalian cells is signal- and energy-dependent and different from the importin alpha/beta-mediated process.

Histochem. Cell Biol.; 113(6): 455-465

Laskey R.A., Dingwall C. (1993)

Nuclear shuttling: the default pathway for nuclear proteins?

Cell; 74: 585-586

Liao B., Paschal B.M., Luby-Phelps K. (1999)

Mechanism of $\mathrm{Ca}^{2+}$-dependent nuclear accumulation of calmodulin.

Proc. Natl. Acad. Sci. USA; 96(11): 6217-6222

Li X.Y., Mantovani R., Hooft van Huijsduijnen R., Andre I., Benoist C., Mathis D. (1992)

Evolutionary variation of the CCAAT-binding transcription factor NF-Y.

Nucleic Acids Res.; 20: 1087-1091

Luger K., Mader A.W., Richmond R.K., Sargent D., Richmond T.J. (1997)

Crystal structure of the nucleosome core particle at $2.8 \mathrm{~A}$ resolution.

Nature; 389(6648): 251-260 
Maity S.N., de Crombrugghe B. (1998)

Role of the CCAAT-binding protein CBF/NF-Y in transcription.

Trends Biochem. Sci.;23(5): 174-178

Mandel M., Higa A. (1970)

Calcium dependent bacteriophage DNA infection.

J. Mol. Biol.; 53: 154-162

Maniatis T., Frisch F., Sambrook J. (1989)

Molecular cloning.

2. Edition Cold Spring Harbor, New York

Mantovani R. (1999)

The molecular biology of the CCAAT-binding factor NF-Y.

Gene; 239: 15-27

Markkerh P.S., Dingwall C., Laskey R.A. (1996)

Comparative mutagenesis of nuclear localization signals reveals the importance of neutral and acidic amino acids.

Curr. Biol.; 6: 1025-1027

Marchetti M.A., Tschudi C., Kwon H., Wolin S., Ullu E. (2000)

Import of proteins into the trypanosome nucleus and their distribution at karyokinesis.

J. Cell Sci.; 113: 899-906

Mears W.E., Lam V., Rice S.A. (1995)

Identification of nuclear and nucleolar localization signals in the Herpes Simplex Virus regulatory protein ICP27.

J. Virol.; 69: 935-947

Melchior F., Gerace L. (1998)

Two-way trafficking with Ran.

Trends Cell Biol.; 8(5): 175-179

Melchior F., Paschal B., Evans E., Gerace L. (1993) 
Inhibition of nuclear protein import by nonhydrolyzable analogs of GTP and identification of the small GTPase Ran/TC4 as an essential transport factor.

J. Cell Biol.; 123: 1649-1659

Michael W.M., Choi M., Dreyfuss G. (1995)

A nuclear export signal in hnRNP A1: a signal-mediated, temperature-dependent nuclear protein export pathway.

Cell; 83: 415-422

\section{Michael W.M., Eder P.S., Dreyfuss G. (1997)}

The $\mathrm{K}$ nuclear shuttling domain: a novel signal for nuclear import and nuclear export in the hnRNP K protein.

EMBO J.; 16(12):3587-3598

\section{Michaud N., Goldfarb D.S. (1993)}

Most nuclear proteins are imported by a single pathway.

Exp. Cell Res.; 208(1): 128-136

Moore M.S. (1998)

Ran and nuclear transport.

J. Biol. Chem.; 273(36): 22857-22860

\section{Moore M.S. (1999)}

Ran and nuclear transport.

J. Biol. Chem.; 273: 22857-22860

Moore M.S., Blobel G. (1992)

The two steps of nuclear import, targeting to the nuclear envelope and translocation through the nuclear pore, require different cytosolic factors.

Cell; 69: 939-950

Moore M.S., Blobel G. (1993)

The GTP-binding protein Ran/TC4 is required for protein import into the nucleus. Nature; 365: 661-663

Moore M.S., Blobel G. (1994) 
Purification of a Ran-interacting protein that is required for protein import into the nucleus.

Proc. Natl. Acad. Sci. USA; 91: 10212-10216

Moreland R.B., Langevin G.L., Singer R.H., Garcea R.L., Hereford L.M. (1987)

Amino acid sequences that determine the nuclear localization of yeast histone 2B.

Mol. Cell Biol.; 7: 4048-4057

Moreland R.B., Nam H.G., Hereford L.M., Fried H.M. (1985)

Identification of a nuclear localization signal of a yeast ribosomal protein.

Proc. Natl. Acad. Sci. USA; 82(19): 6561-6565

Moss T., Cary P.D., Abercrombie B.D., Crane-Robinson C., Bradbury E.M. (1976)

A pH-dependent interaction between histones $\mathrm{H} 2 \mathrm{~A}$ and $\mathrm{H} 2 \mathrm{~B}$ involving secondary and tertiary folding.

Eur. J. Biochem.; 71(2): 337-350

Mullis K.B. und Faloona F.A. (1987)

Specific Synthesis of DNA in vitro via a polymerase-catalyzed chain reaction.

Methods Enzymol.; 155: 335-350

Nadler S.G., Tritschler D., Haffar O.K., Blake J., Bruce A.G., Cleaveland J.S. (1997)

Differential Expression and sequence-specific interactions of karyopherin $\alpha$ with nuclear localization sequences.

J. Biol. Chem.; 272: 4310-4315

Nakielny S., Dreyfuss G. (1999)

Transport of proteins and RNAs in and out of the nucleus.

Cell; 99(7): 677-690

Newmeyer D.D., Lucocq J.M., Burglin T.R., DeRobertis E.M. (1986) 
Assembly in vitro of nuclei active in nuclear protein transport: ATP is required for nucleoplasmin accumulation.

EMBO J.; 5: 501-510

Ohno M., Fornerod M., Mattaj I.W. (1998)

Nucleocytoplasmic transport: The last 200 nanometers.

Cell; 92: 327-336

\section{Ohtsubo M., Okazaki H., Nishimoto T. (1989)}

The RCC1 protein, a regulator for the onset of chromosome condensation locates in the nucleus and binds to DNA.

J. Cell Biol.; 109: 1389-1397

Paine P.L. (1993)

Nuclear protein accumulation by facilitated transport and intranuclear binding.

Trends Cell Biol.; 3: 325-329

Palmeri D., Malim M.H. (1999)

Importin beta can mediate the nuclear import of an arginine-rich nuclear localization signal in the absence of importin alpha.

Mol. Cell Biol.; 19(2):1218-1225

Panté N., Aebi U. (1994)

Towards understanding the three-dimensional structure of the the nuclear pore complex at the molecular level.

Curr. Opin. Struct. Biol.; 4:187-196

Paschal B.M., Gerace L. (1995)

Identification of NTF2, a cytosolic factor for nuclear import that interacts with nuclear pore protein $\mathrm{p} 62$.

J. Cell Biol.; 129: 925-937

Pollard V.M., Michael W.M., Nakielny S., Siomi M.C., Wang F., Dreyfuss G. (1996) A novel receptor-mediated nuclear protein import pathway. 
Cell; 86: 985-994

Radu A., Moore M.S., Blobel G. (1995)

The peptide repeat domain of nucleoporin Nup98 functions as a docking site in transport across the nuclear pore complex.

Cell; 81: 215-222

Reichelt R., Holzenburg A., Buhle E.L., Jarnik M., Engel A., Aebi U. (1990)

Correlation between structure and mass distribution of the nuclear pore complex and of distinct pore complex components.

J. Cell Biol.; 110(4):883-894

Ribbeck K., Lipowsky G., Kent H.M., Stewart M., Gorlich D. (1998)

NTF2 mediates nuclear import of Ran.

EMBO J.; 17(22):6587-6598

Richardson W.D., Mills A.D., Dilworth S.M., Laskey R.A., Dingwall C. (1988)

Nuclear protein migration involves two steps: rapid binding at the nuclear envelope followed by slower trnaslocation through nuclear pores.

Cell; 52: 655-664

Robbins J., Dilworth S.W., Laskey R.A., Dingwall C. (1991)

Two interdependent basic domains in nucleoplasmin nuclear targeting sequence: identification of a class of bipartite nuclear targeting sequence.

Cell; 64: 615-623

Roberts B. (1989)

Nuclear location signal-mediated protein transport.

Biochim. Biophys. Acta; 1008(3): 263-280 
Roberts B.L., Richardson W.D., Smith A.E. (1987)

The effect of protein context on nuclear location signal function.

Cell; 50: 465-475

Rodriguez P., Pelletier J., Price G., Zannis-Hadjopopoulos M. (2000)

NAP-2: Histone chaperone function and phosphorylation state through the cell cycleJ. Mol. Biol.; 298:225-238

Rout M.P., Aitchison J.D., Suprapto A., Hjertaas K., Zhao Y., Chait B.T. (2000) The yeast nuclear pore complex: composition, architecture, and transport mechanism. J. Cell Biol.; 21;148(4): 635-651

Rout M.P., Blobel G., Aitchison J.D. (1997)

A distinct nuclear import pathway used by ribosomal Proteins.

Cell; 89: 715-725

Sanger F., Nicklen S., Coulson A. (1977)

DNA sequencing with chain-termination inhibitors.

Proc. Natl. Acad. Sci. USA; 74: 5463-5467

Schaap P.J., van't Riet J., Woldringh C.L., Raue H.A. (1991)

Identification and analysis of the nuclear localisation signal of ribosomal protein L25 from Saccharomyces cerevisiae.

J. Mol. Biol.; 221: 225-237

Schmolke S., Drescher P., Jahn G., Plachter B. (1995)

Nuclear targeting of the tegument protein pp65 (UL83) of human Cytomegalovirus: an unusual bipartite nuclear localization signal functions with other portions of the protein to mediate its efficient nuclear transport.

J. Virol.; 69: 1071-1078

Schuster T., Han M., Grunstein M. (1986)

Yeast histone $\mathrm{H} 2 \mathrm{~A}$ and $\mathrm{H} 2 \mathrm{~B}$ amino termini have interchangeable functions.

Cell; 45: 445-451

Schwamborn K. (1998) 
Der Transport des Histons $\mathrm{H}^{\circ}$ vom Cytoplasma in den Zellkern.

Dissertation, Universität Göttingen

Schwamborn K., Albig W., Doenecke D. (1998)

The histone $\mathrm{H} 1^{\circ}$ contains multiple sequence elements for nuclear targeting.

Exp. Cell Res.; 244: 206-217

Showe M.K., Williams D.L., Showe L.S. (1992)

Quantitation of transient Gene expression after electroporation.

Nucleic Acids Res.; 20: 3153-5157

Tagawa T., Kuroki T., Vogt P.K., Chida K. (1995)

The cell cycle-dependent nuclear import of v-Jun is regulated by phosphorylation of a serine adjacent to the nuclear localization signal.

J. Cell Biol.; 130(2):255-263

Truant R., Cullen B.R. (1999)

The arginine-rich domains present in human immunodeficiency virus type 1 Tat and Rev function as direct importin beta-dependent nuclear localization signals.

Mol. Cell Biol.; 19(2): 1210-1217.

Underwood M.R., Fried H. (1990)

Characterization of nuclear localizing sequences derived from yeast ribosomal protein L29.

EMBO J.; 9: $91-100$

Weis K., Ryder U., Lamond A.I. (1996)

The conserved amino-terminal domain of hSRP1 alpha is essential for nuclear protein import.

EMBO J.; 15(8):1818-1825.

Wiechens N., Fagotto F. (2001)

CRM1- and Ran-independent nuclear export of beta-catenin.

Curr. Biol.; 11(1): 18-27.

Wolffe A.P. (1998)

Chromatin. Structure and Function. 


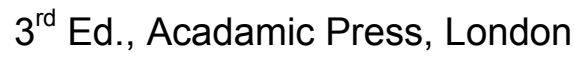

Xie X., Kokubo T., Cohen S.L, Mirza U.A., Hoffmann A., Chait B.T., Roeder R.G., Nakatani Y., Burley S.K. (1996)

Structural similarity between TAFs and the heterotetrameric core of the histone octamer.

Nature; 380(6572):316-322

Yokoya F., Imamoto N., Tachibana T., Yoneda Y. (1999)

beta-catenin can be transported into the nucleus in a Ran-unassisted manner. Mol. Biol. Cell; 10(4): 1119-11131. 


\section{Lebenslauf}

Name:

Baake

Vorname:

Matthias

Geburtsdatum:

27. Juli 1970

Geburtsort:

Rehren

Staatsangehörigkeit:

deutsch

Ausbildung:

$1976-1980$

Grundschule in Hessisch Oldendorf

$1980-1982$

Orientierungsstufe Hessisch Oldendorf

$1982-1990$

Schiller-Gymnasium Hameln

1990

Abitur

1990-1991

Zivildienst

April 1992

Beginn des Studiums der Chemie an der GeorgAugust-Universität zu Göttingen

April 1995

Vordiplom in den Fächern Organische Chemie, Anorganische Chemie, Physikalische Chemie und Physik

Juni 1996

Diplomarbeit mit dem Titel „Sreening nach Wirkstoffen aus marinen Streptomyceten Isolierung und Strukturaufklärung eines neues Pyrazinderivats am Institut für Organische Chemie in der Abteilung von Prof. Dr. H. Laatsch

Juni 1997

Hauptdiplomprüfung in den Fächern Organische Chemie, Anorganische Chemie und Physikalische Chemie

Oktober 1997 - April 2001

Anfertigung der hier vorliegenden Dissertation mit dem Titel „Faktoren des Kerntransports von CoreHistonen: Strukturelle und funktionelle Analyse“ am Institut für Biochemie und molekulare Zellbiologie der Georg-August Universität Göttingen in der Abteilung von Herrn Prof. Dr. D. Doenecke 


\section{Danksagung}

Mein besonderer Dank gilt Herrn Prof. Dr. D. Doenecke für die Überlassung des Dissertationsthemas und für die gewährte experimentelle Freiheit sowie für die darüber hinausgehende Unterstützung beim Erstellen dieser Arbeit.

Herrn P.D. Dr. W. Albig danke ich für die ausgezeichnete Betreuung und gute Zusammenarbeit sowie für die stete Bereitschaft zur wissenschaftlichen Diskussion.

Angesichts des nicht unerheblichen Arbeitsaufwandes, den die Betreuung einer externen Dissertation mit sich bringt, möchte ich mich besonders bei Herrn Prof. Dr. A. Zeeck für seine spontane Bereitschaft bedanken, die Vertretung dieser Arbeit an der Georg-August-Universität Göttingen in der Chemischen Fakultät zu übernehmen.

Bei Herrn Prof. Dr. L.F. Tietze möchte ich mich für die sofortige Bereitschaft, das Korreferat zu übernehmen, bedanken.

Weiterhin danke ich mich bei allen Mitarbeitern der Abteilung Molekularbiologie für die gute Zusammenarbeit und für das angenehme Arbeitsklima. Besonderer Dank gilt hierbei Marcimarc für die Unterstützung bei der Proteinaufreinigung. Seqman Andreas Nolte danke ich für die Sequenzierungen, und den Mitarbeitern der Abteilung Entwicklungsbiologie für die gute Kooperation.

Für die vielen Freuden außerhalb des wissenschaftlichen Lebens danke allen meinen Freunden - und natürlich den Simpsons.

Ein besonderer Dank gilt meinen lieben Eltern, die mir dieses Studium ermöglicht haben. 